\title{
DEVELOPMENT OF ALTERNATIVE FUELS FROM COAL-DERIVED SYNGAS
}

Quarterly Status Report No. 6

DE93 011629

For The Period 1 January - 31 March 1992

19 May 1992

Contractor

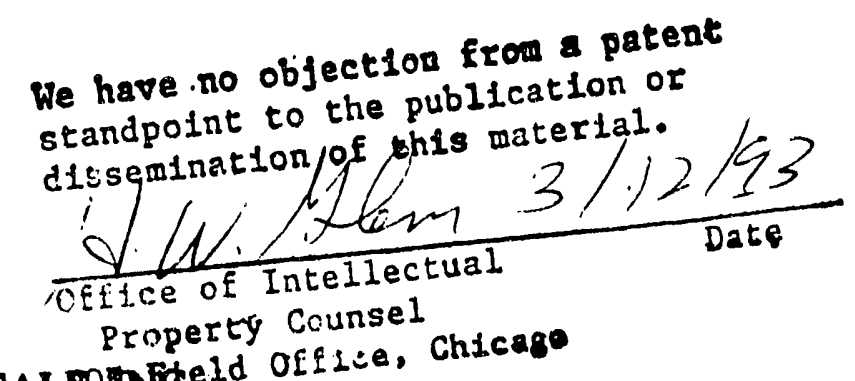

AIR PRODUCTS AND CHEMICALEP INE

7201 Hamilton Blvd.

Allentown, PA 18195-1501

Prepared for the United States Department of Energy

Under Contract No. DE-AC22-91 PC90018

Contract Period 1 October 1990 - 1 July 1994

\section{NOTICE}

This repgt contains jhformation which is poténtially patentable. U.S. patent applications covering these cohcepts wily be filed with the U.S. Patent Office shortly. As per instructions from the Office of Patent Counse1, U.S. Department of Exergy, Argonne, Illinois, the following notice is in effect:

\section{PATENT HOLD}

This document copy, since it is transmitted in advance of patent clearance, is made available in confidence solely for use in performance of work under contracts witb the U.S. Department of Energy. This document is not to be published no - its contents otherynse disseminated or used for purposes other than specified above before parent approval forsuch release or use has been secured, upon refijest,from the Chief, Office of Parent Counsel, W.S. Department of Energy, 9800 South Cass Avenue, Argonne, Illinois 60439. 


\title{
DEVELOPMENT OF ALTERNATIVE FUELS FROM COAL-DERIVED SYNGAS
}

\author{
Quarterly Status Report No. 6
}

For The Period 1 January - 31 March 1992

19 May 1992

Contractor

AIR PRODUCTS AND CHEMICALS, INC. 7201 Hamilion Blvd.

Allentown, PA 18195-1501

Prepared for the United States Department of Energy

Under Contract No. DE-AC22-91PC90018

Contract Period 1 October 1990 - 1 July 1994

\section{NOTICE}

This report contains information which is potentially patentable. U.S. patent applications covering these concepts will be filed with the U.S. Patent Office shortly. As per instructions from the Office of Patent Counsel, U.S. Department of Energy, Argonne, Illinois, the following notice is in effect:

\section{PATENT HOLD}

This document copy, since it is transmitted in advance of patent clearance, is made available in confidence solely for use in performance of work under contracts with the U.S. Department of Energy. This document is not to be published nor its contents otherwise disseminated or used for purposes other than specified above before patent approval for such release or use has been secured. upon request, from the Chief, Office of Patent Counsel, U.S. Department of Energy, 9800 South Cass Avenue, Argonne, Illinois 60439. 


\section{DISTRIBUTION LIST}

Alternative Fuels I

Quarterly Technical Progress Report

(Final Version)

Mr. Gary Stiegel (2 copies)

Project Manager

U.S. DOE/PETC

P.O. Box 10940, MS 922-H

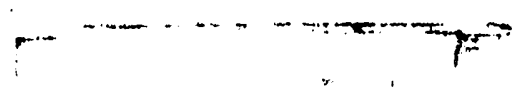

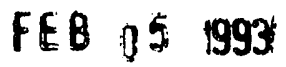

Pittsburgh, PA 15236

Ms. Dona G. Sheehan

Contract Specialist

U.S. DOE/PETC

P.O. Box 10940, MS 921-165

Pittsburgh, PA 15236

Mr. Robert Hamilton

FE-25, E-155 GTN

U.S. Department of Energy

Washington, DC 20545

Office of Patent Counsel

Chicago Operations Office

U.S. Department of Energy

9800 South Cass Ave.

Argonne, II 60439

U.S. Department of Energy

Office of Technology Transfer

Pittsburgh Energy Technology Center

P.O. Box 10940, MS 58-217

Pittsburgh, PA 15236

Ms. Joanne Wastek

U.S. Department of Energy

Pittsburgh Energy Technology Center

P.O. Box 10940

Pittsburgh, PA 15236

Mr. Norm Stewart

Electric Power Research Institute

P.O. Box 10412

Palo Alto, CA 94303 


\section{Mr. Gary J. Stiegel}

Project Manager

U.S. Department of Energy/PETC

P.O. Box 10940, MS 922-H

Pittsburgh, PA 15236

Subject: Contract No. DE-AC22-91PC90018

"Development of Alternative Fuels from

Coal-Derived Syngas"

Quarterly Status Report No. 6

\section{Dear Gary:}

Pursuant to Item 4.F of the Reporting Requirements Checklist (Attachment B) of the subject Contract, enclosed please find two (2) copies of the quarterly status report for 1 January -31 March 1992. This report contains information that is potentially patentable, and is subject to the notice appearing on the title page. If you have any questions, please feel free to contact me.

Sincerely,

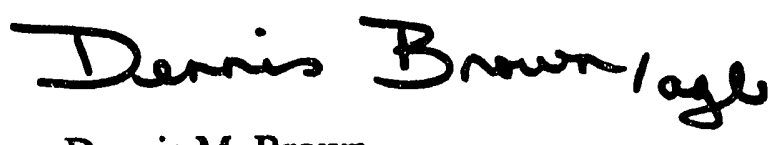

Dennis M. Brown

Program Manager

cc: DOE (See Attached Distribution)

Air Products:

D. W. Tyndall 


\section{DISCLAIMER}

This work was prepared as an account of work sponsored by the United States Government. Neither the United States nor the United States Department of Energy, nor any of their employees, makes any warranty, express or implied, or assumes any legal liability for the accuracy, completeness, or usefulness of any information, apparatus, product, or process disclosed, or represents that its use would not infringe privately owned rights. Reference herein to any specific commercial product, process, or service by trade name, mark, manufacturer, or otherwise, does not necessarily constitute or imply its endorsement, recommendation, or favoring by the United States Government or any agency thereof. The views and opinions of authors expressed herein do not necessarily state or reflect those of the United States Government or any agency thereof. 


\title{
DEVELOPMENT OF ALTERNATIVE FUELS FROM COAL-DERIVED SYNGAS
}

\author{
Quarterly Technical Progress Report \\ 1 January - 31 March 1992
}

\section{Contract Objectives}

The overall objectives of this program are to investigate potential technologies for the conversion of coal-derived synthesis gas to oxygenated fuels, hydrocarbon fuels, fuel intermediates, and octane enhancers; and to demonstrate the most promising technologies at DOE's LaPorte, Texas, Slurry Phase Alternative Fuels Development Unit (AFDU). The program will initially involve a continuation of the work performed under the Liquid Phase Methanol Program but will later draw upon information and technologies generated in current and future DOE-funded contracts, as well as test commercially available catalysts.

\section{Summary of Activity}

- BASF continues to have difficulties in scaling-up the new isobutanol synthesis catalyst developed in Air Products' laboratories. Investigations are proceeding, but the proposed operation at LaPorte in April is now postponed. DOE has accepted a proposal to demonstrate Liquid Phase Shift (LPS) chemistry at LaPorte as an alternative to isobutanol. There are two principal reasons for carrying out this run. First, following the extensive modifications at the site, operation on a relatively "benign" system is needed before we start on Fischer-Tropsch technology in July. Second, use of shift catalyst in a slurry reactor will enable DOE's program on coal-based Fischer-Tropsch to encompass commercially available cobalt catalysts - up to now they have been limited to iron-based catalysts which have varying degrees of shift activity. In addition, DOE is supportive of continued fuel testing of LaPorte methanol-tests of M100 at Detroit Diesel have been going particularly well. LPS offers the opportunity to produce methanol as the catalyst, in the absence of steam, is active for methanol synthesis.

- Final preparations are underway for the LPS demonstration at LaPorte. The Design Verification Review (DVR) and Operational Readiness Inspection (ORI) were completed and the run plan issued. The NEXTGEN Data Acquisition System was commissioned, and the new analytical lab became operational with the link between lab HP computer and the VAX/NEXTGEN established. The process team is now on-site and catalyst slurry preparation is underway.

- A meeting was held in Pittsburgh during March for the prospective Fischer-Tropsch partners. Exxon, Statoil, and UOP attended with DOE and Air Products. Shell, whose agreement is pending, did not attend. The criteria of a successful run were established; stable reactor operation over a large number of days with at least $50 \% \mathrm{CO}$ conversion; correlation between lab and 
LaPorte reactor performance is important, as is some measure of column hydrodynamics. Efficient catalyst-wax separation was not viewed as critical and a decision was made to investigate a low alpha $\left(\mathrm{C}_{8}-\mathrm{C}_{20}\right)$ catalyst option with the manufacturer. This is probably a wise move as recent filter tests showed some problems in efficient separation of catalyst particles from the F-T wax.

- The mystery deepens over BASF's inability to scale-up the cesium doped S3-86 catalyst for isobutanol synthesis. PSG personnel successfully prepared catalysts using the exact same precursors used by BASF. Subtle differences in preparation technique are suspected, and closer cooperation with BASF Ludwigshafen will be needed. Meanwhile, Haldor-Topsoe's MK101 methanol catalyst was tried as a substrate rather than S3-86. The resulting catalyst performed less well than the cesium promoted BASF S3-86.

- Alcohol injection experiments were conducted in the \#1300 ml autoclave to study the effect of lower alcohol recycle on the synthesis of isobutanol. A simulation of total recycle of methanol, ethanol, and propanol showed a $60 \%$ enhancement in isobutanol production rate.

- The reaction chemistry responsible for the conversion of DME to isobutanol over an oxide catalyst appears to be unique. Presently the gas phase oxidation of DME and isobutanol to CO and $\mathrm{CO}_{2}$ are responsible for the low yields.

- A literature search has pointed out several catalyst candidates for the dehydration of isobutanol to isobutylene, although nothing seems to have been practiced commercially. Initial lab tests with a Catapal gamma (8)-alumina dispersed in Drakeol-10 mineral oil show high conversions $(>90 \%)$ and high selectivities to isobutylene ( $>80 \mathrm{~mol} \%$ ). A group of metal phosphate catalysts identified in the literature have also been evaluated in Air Products' gas phase reactor and are demonstrating similar high conversions with almost $100 \%$ selectivity to butylenes.

\section{Future Plans}

- Initiate operations at the LaPorte AFDU to demonstrate Liquid Phase Shift (LPS). Commission and debug new control and data acquisition systems, and the new analytical laboratory. Produce 20,000 gallons of crude methanol for further fuel tests over the next two years. Demonstrate ability to tailor $\mathrm{H}_{2} / \mathrm{CO}$ within the LPS reactor for use with oxygenates or F-T catalysts, for a variety of feed gases.

- Finalize membership of the Fischer-Tropsch consortium. Implement necessary steps when the AFDU is ready for operation in July: obtain catalyst from UCI, mineral oil for start-up, analytical services, mechanical modifications.

- Solve the scale-up issue of the cesium doped S3-86 and continue to optimize the cesium catalyst for maximum $\mathrm{iC}_{4} \mathrm{OH}$ yield. 
- Assess status of $\mathrm{DME} / \mathrm{O}_{2}$ coupling technology. Decide on respective level of effort for this and for promoting secondary alcohol formation in the methanol to isobutanol reaction sequence.

\section{RESULTS AND DISCUSSION}

\section{Task 1: Engineering and Modifications}

\section{Control Room and Lab Room Relocation and Upgrade}

This project was finished during the second quarter. The five major items completed were:

1. Relocate the control room to the new shelter and convert the existing control system to a Bailey distributed control system (DCS).

2. Physically relocate the GC lab, wet lab, and sample hot box to the new shelter.

3. Purchase, configure, and install three new GCs in the new lab.

4. Replace the old AIM data acquisition system with NEXTGEN.

5. Link the various computer systems through communication wiring.

\section{Convert Control System to Bailey DCS}

The signal terminations, tie-ins, and rewiring construction work was completed. Both above-ground and underground wiring between the field, the DCS building (formerly the GC Lab Building), the plant interface panel (located in the old control room), and the new control room are now in place. The Miscellaneous Cabinet (which contains hard-wired safety switches and the reactor's nuclear density gauge controls/readout) was also installed in the new control room. The DCS operator terminals were installed in the control room and commissioned. This commissioning work included a complete check-out of the new and existing controls and instruments.

\section{Relocate Laboratory Facilities}

The construction and furmishing of the wet lab was completed. Wet lab commissioning will be completed when required. The commissioning of the GC lab was also completed. The installation of the cabinets, hood, and the HVAC (heating, ventilation, and air conditioning) was finished in January. The air exhaust rates were balanced in February. In February, the drawings for the sampleline layout were received and construction began. This was followed by the construction and arrival of a new flow control box which was subsequently mounted and tied into the sample lines. 


\section{Purchase, Configure And Install New GCs}

The GC laboratory setup was completed by connecting two of the new GCs, one of the older GCs, and one liquid GC to the newly installed flow control box. These analytical devices were then commissioned and calibrated. Each of the GCs are connected to, and driven by, an HP computer. The reconfiguration of this computer was also completed as part of the general laboratory commissioning work.

\section{Upgrade the Data Acquisition System (DAS)}

The data acquisition system (DAS) has been completely revamped. New hardware from Digital Equipment Corporation (DEC) was purchased and delivered to Air Products' Trexlertown campus. While on campus, the computer was outfitted with a new DAS software named NEXTGEN. The database definition was also completed and installed. Finally, communication software (which allowed the HP computer to send GC data to the DEC computer) was written and debugged. Once the initial DAS setup was completed, the HP and DEC computers and peripherals were shipped down to the AFDU where the final setup and staging was completed.

\section{Link Computer Systems}

With all the computer hardware in place, the final step was to complete the communication links. Ethernet cable was run from the GC lab to the control room for HP-to-DEC communications. The ethernet link was also extended from the DEC computer to selected offices for DEC-to-PC communications. The HP-to-DEC and DEC-to-PC communication protocol (using a Local Area Network, LAN) was then installed and tested. Finally, the Bailey DCS-to-DEC link (handled via modem communications) was connected.

\section{Summary}

The relocation and upgrade of the process control and data acquisition systems has been completed. The major, on-site equipment are itemized below: 
TABLE 1.1.1

Major On-Site Equipment

\begin{tabular}{|c|c|c|}
\hline Item & No. & Function \\
\hline $\begin{array}{l}\text { Bailey Multifunction Controller } \\
\text { Cabinet }\end{array}$ & 2 & $\begin{array}{l}\text { Interface between field instrumentation/controls and the } \\
\text { control room displays. }\end{array}$ \\
\hline Bailey Operator Terminal & 2 & $\begin{array}{l}\text { Used by operators to view and control operation of the } \\
\text { plant. }\end{array}$ \\
\hline Bailey Printer & 2 & Generate hard copy of alarms and reports. \\
\hline HP 5890 GC (Series II) & 2 & $\begin{array}{l}\text { Analyze gas samples ( } 6 \text { samples per GC, continuous } \\
\text { analysis) }\end{array}$ \\
\hline Carle GC & 2 & $\begin{array}{l}\text { Analyze reactor feed gas (only one is fully functional, } \\
\text { the other is used as a spare) }\end{array}$ \\
\hline HP Liquid GC & 1 & $\begin{array}{l}\text { Analyze liquid products (batch). This is also fitted with } \\
\text { an electron capture device (ECD) for gas-phase } \\
\text { carbonyl analysis. }\end{array}$ \\
\hline HP Computer/Terminal/Storage & 1 & $\begin{array}{l}\text { Receives data from the various GCs, directs integration/ } \\
\text { normalization, transfers results to DEC computer. }\end{array}$ \\
\hline HP Integrator & 4 & $\begin{array}{l}\text { Connected to each GC. Controls valve switching/timing } \\
\text { and prints "raw" hard copy. }\end{array}$ \\
\hline HP Printer & 1 & Prints normalized hard copy reports for all the GCs. \\
\hline DEC Computer/Terminal/Storage & 1 & $\begin{array}{l}\text { Main data acquisition machine. Communicates with the } \\
\text { Bailey, the HP, and PCs. Displays current plant and } \\
\text { analytical data as well as historical data. Computer is } \\
\text { also used to perform data analysis and produce reports. }\end{array}$ \\
\hline DEC Printer & 1 & Hard copy device for DEC computer. \\
\hline
\end{tabular}


TABLE 1.1.1 (cont'd)

Major On-Site Equipment

\begin{tabular}{||c|c|c||}
\hline Item & No. & \multicolumn{1}{|c|}{ Function } \\
\hline Bailey Workstation & 1 & $\begin{array}{l}\text { An Intel brand PC which is connected to both the } \\
\text { Bailey and DEC computers. When in Bailey-mode, this } \\
\text { machine is used to configure controllers off-line. When } \\
\text { in DEC-mode, this machine is used to download data } \\
\text { from the DEC and, in the near future, will be able to } \\
\text { "emulate" a DEC terminal. When in PC-mode, this } \\
\text { machine is used to work-up plant data and to write } \\
\text { daily reports. }\end{array}$ \\
\hline
\end{tabular}

In addition to the analytical equipment on site, an FID (flame ionization detector) was purchased and configured, but not installed.

Future work includes:

1. Reconfigure and stage the analytical equipment for the Fischer-Tropsch demonstration.

2. Complete the software installation to allow PCs to emulate DEC workstations. This will allow engineers and other staff to view the "live" plant data without physically being in the control room.

3. Write and stage computer software to allow the DEC computer to send data to the Bailey. This feature would make it possible for the Bailey to receive molecular weight data from the DEC and use that data to correct the displayed flow. (Currently, flow as displayed by the Bailey is only corrected for pressure and temperature while that on the DEC is corrected for molecular weight as well.)

All three of these items are scheduled to be completed prior to the Fischer-Tropsch demonstration.

\section{Engineering, Design, and Modifications for the Spring Isobutanol Demonstration}

By early January, the bulk of the detailed engineering and design work was completed. Most of our efforts were devoted to making the necessary site modifications and completing the final hazards review.

By the end of January, the installation of new equipment items was finished and fabrication of new field piping/insulation was $90 \%$ complete. Reactivation of existing equipment also commenced in January. The overhaul of the $01.10 / 01.20$ compressor was undertaken. Motors for all pumps, fans, and agitators were set in place. Twenty of the safety relief valves were removed and sent out for inspection and any necessary repair. In February, pressure testing and $x$-ray testing (where required) were performed on the new equipment and piping. 
In February, it was decided that the spring demonstration of isobutanol production would be postponed and replaced with the demonstration of liquid-phase-shift (LPS). Nevertheless, we did complete the final hazards review (Design Verification Review) for IBOH (see Appendix 1).

\section{Engineering, Design, and Modifications for the Spring Liquid-Phase Shift Demonstration}

As of February, the run plan called for the demonstration of the water-gas shift reaction in the liquid phase (LPS). The switch form IBOH to LPS was brought about by the supplier's inability to prepare the isobutanol catalyst which met our performance targets. The LPS demonstration requires much of the same equipment as would have been required to carry-out isobutanol. A commercial shift catalyst, which has been thoroughly tested in our labs previously, would be used.

All required engineering, design, and modification work was coinpleted. Highlights are summarized below.

\section{Technology}

The shift reaction is described as follows:

$$
\mathrm{H}_{2} \mathrm{O}+\mathrm{CO}=\mathrm{H}_{2}+\mathrm{CO}_{2}
$$

Most state-of the art gasifiers produce a syngas with a $\mathrm{H}_{2}: \mathrm{CO}$ ratio between $0.5: 1$ and $1: 1$. In contrast, the stoichiometry of oxygenate synthesis and Fischer-Tropsch synthesis requires $\mathrm{H}_{2}: \mathrm{CO}$ ratios of 1:1 to 2:1. As a result, coal derived syngas cannot be completely converted to these fuels without the use of a shift step to upgrade the hydrogen content. Therefore, shift is viewed as an integral unit operation in the overall syngas-to-fuels process. Gas-phase shift has been commercially practiced for years; liquid-phase shift has been previously demonstrated in the labs but, to our knowledge, has yet to be demonstrated in a bubble column.

\section{Demonstration Plan}

At the AFDU, LPS will be carried-out by injecting 500 psi steam into the feed gas prior to introduction to the reactor. The steam will react with the $\mathrm{CO}$ to form $\mathrm{H}_{2}$ and $\mathrm{CO}_{2}$; the reaction will be carried-out at $250^{\circ} \mathrm{C}$ and 400 to 450 psig. The objective of this demonstration is to prove feasibility. Thus, the focus will be to study different feed gas types and produce products with a $\mathrm{H}_{2}$ :CO ratio between $1: 1$ and $2: 1$ (or more). Process variables such as pressure and temperatr e are not to be considered here but could easily be studied in the laboratory autoclave reactors.

The shift catalyst we intend to use is made by BASF (K3-110). This catalyst is one of the commercial "low temperature" shift catalysts and is composed of $\mathrm{CuO}, \mathrm{ZnO}$, and alumina. Since these components are the same as those found in many methanol catalysts it is also possible to use the catalyst to produce methanol. Methanol production at the AFDU as part of the Spring 1992 demonstration is advantageous for two reasons: 
1. It provides a means to shakedown and calibrate the DCS and DAS systems under real operating conditions. The altemative is to shakedown without catalyst (fill the reactor and vessels with oil and circulate syngas).

2. It provides a means of replenishing our dwindling supply of liquid phase methanol product for engine tests. Recent tests by Detroit Diesel have been extremely successful and we are anticipating demand for "LaPorte Methanol" to exceed our existing stock. The altemative would be to restart the AFDU at some later date for the sole purpose of making methanol.

After consultation with PETC, a run plan was adopted which included the demonstration of both LPM and LPS technologies. The run plan is reproduced in Table 1.1.

TABLE 1.1

Run Plan for Spring 1992 L.PS Demonstration

\begin{tabular}{|c|c|c|}
\hline Run \# & Operation & Duration \\
\hline \multicolumn{2}{|c|}{ CITALYST ACTIVATION } & 2.0 days \\
\hline \multicolumn{2}{|c|}{ LPM DEMONSTRATION } & \multirow[b]{2}{*}{$\begin{array}{l}6.5 \\
0.5\end{array}$} \\
\hline AF-R4 & $\begin{array}{l}\text { Methanol synthesis w/K3-110 } \\
\text { Drain reactor to } 275 \# \text { of catalyst (oxide basis) }\end{array}$ & \\
\hline \multicolumn{2}{|c|}{ LPS DEMONSTRATION } & \multirow{6}{*}{$\begin{array}{l}2.0 \\
1.0 \\
1.0 \\
1.0 \\
0.5\end{array}$} \\
\hline AF-R5 .1 & Texaco Gas, $S V=10000, \mathrm{H}_{2}: \mathrm{CO}=1: 1$ & \\
\hline .2 & Texaco Gas, $\mathrm{SV}=10000, \mathrm{H}_{2}: \mathrm{CO}=2: 1$ & \\
\hline .3 & Texaco Gas, $\mathrm{SV}=6000, \mathrm{H}_{2}^{2}: \mathrm{CO}=2: 1$ & \\
\hline .4 & Texaco Gas, $\mathrm{SV}=6000, \mathrm{H}_{2}^{2}: \mathrm{CO}=1: 1$ & \\
\hline & Change-out methanol in $\mathrm{CO}_{2}$ removal section & \\
\hline AF-R5 .5 & Shell Gas, $S V=7000, H_{2}: C O=2: 1$ & \multirow{5}{*}{$\begin{array}{l}1.0 \\
1.0 \\
1.0 \\
1.0 \\
0.5\end{array}$} \\
\hline .6 & Shell Gas, $\mathrm{SV}=7000, \mathrm{H}_{2}^{2} \mathrm{CO}=1: 1$ & \\
\hline .7 & Shell Gas, $S V=4000, \mathrm{H}_{2}: C O=1: 1$ & \\
\hline .8 & Shell Gas, $\mathrm{SV}=4000, \mathrm{H}_{2}^{2}: \mathrm{CO}=2: 1$ & \\
\hline & Prepare for once-through operation & \\
\hline \multirow{3}{*}{\multicolumn{2}{|c|}{ 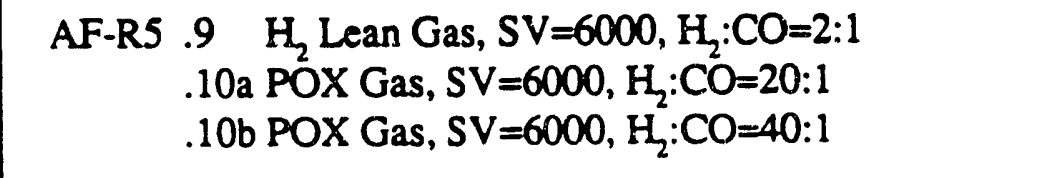 }} & \multirow{3}{*}{$\begin{array}{l}1.0 \\
1.0 \\
1.0\end{array}$} \\
\hline & & \\
\hline & & \\
\hline & TOTAL & 22.0 \\
\hline
\end{tabular}


SV is space velocity expressed as sL/kg-hr. Runs R5.6, R5.7, and R5.iOb are optional and will be carried-out if the schedule can be maintained. The feed gas compositions to be used are presented in Table 1.2.

TABLE 1.2

Feed Gas Compositions for Spring 1992 LPS Demonstration

\begin{tabular}{|l|r|r|r|r|}
\hline Component: & \multicolumn{1}{|c|}{$\mathrm{H}_{2}$} & $\mathrm{CO}$ & $\mathrm{CO}_{2}$ & \multicolumn{1}{|c|}{$\mathrm{N}_{2}$} \\
\hline Shell Gas & 31.0 & 65.0 & 3.0 & 1.0 \\
Texaco Gas & 35.0 & 51.0 & 13.0 & 1.0 \\
$\mathrm{H}_{2}$ Lean Gas & 1.5 & 72.0 & 13.4 & 13.1 \\
POX Gas & 60.7 & 37.7 & 1.6 & 0.0 \\
\hline
\end{tabular}

\section{Process Development}

From the viewpoint of the AFDU, operation of LPS is similar to IBOH with some exceptions. The operation is similar in the sense that some level of $\mathrm{CO}_{2}$ removal is required to allow unreacted syngas to be recycled. However, some modifications to the plant are necessary: new tie-in of HP steam to the process feed, installation of a throttling valve downstream of the 01.10 feed compressor (to allow for low pressure operation of the reactor), new tie-ins to the flare, and repiping around the 10.85 pump.

\section{Process Description (see Figure 1.1-Flowsheet)}

Hydrogen, carbon monoxide, and carbon dioxide are blended and compressed, then mixed with recycle gas to form the desired syngas composition and flow. This reactor feed is preheated (in the 21.10) then combined with high pressure steam. The mixed feed is directed to the 02.61 where it is further heated by condensing HP steam, and then finally introduced to the bottom of the 27.10 slurry reactor.

The syngas flows upward through the slurry (catalyst-mix plus mineral oil) where water and $\mathrm{CO}$ react to form $\mathrm{H}_{2}$ and $\mathrm{H}_{2} \mathrm{O}$; some methanol may also be formed as a by-product. The heat of reaction is absorbed by the oil and then rejected to an internal heat exchanger. The gross reactor effluent is passed through the 27.11 cyclone to remove catalyst fines, then cooled in the 21.10 to condense traces of slurry oil. The resultant vapor is considered to be the net reactor effluent. This stream is subsequently chilled against cooling water (in the 21.30), and introduced to a 22.10 separator where virtually all the unreacted water (and any methanol) are recovered as liquid.

The vapor from the 22.10 is cooled in the 21.38 exchanger and combined with a circulating $\mathrm{MeOH}$ fluid. This combined stream is then chilled to $0^{\circ} \mathrm{F}$ in the 21.80 kettle evaporator. Simultaneously, $\mathrm{CO}_{2}$ is absorbed into the liquid $\mathrm{MeOH}$. This stream enters the 22.14 where approximately $50 \%$ of 


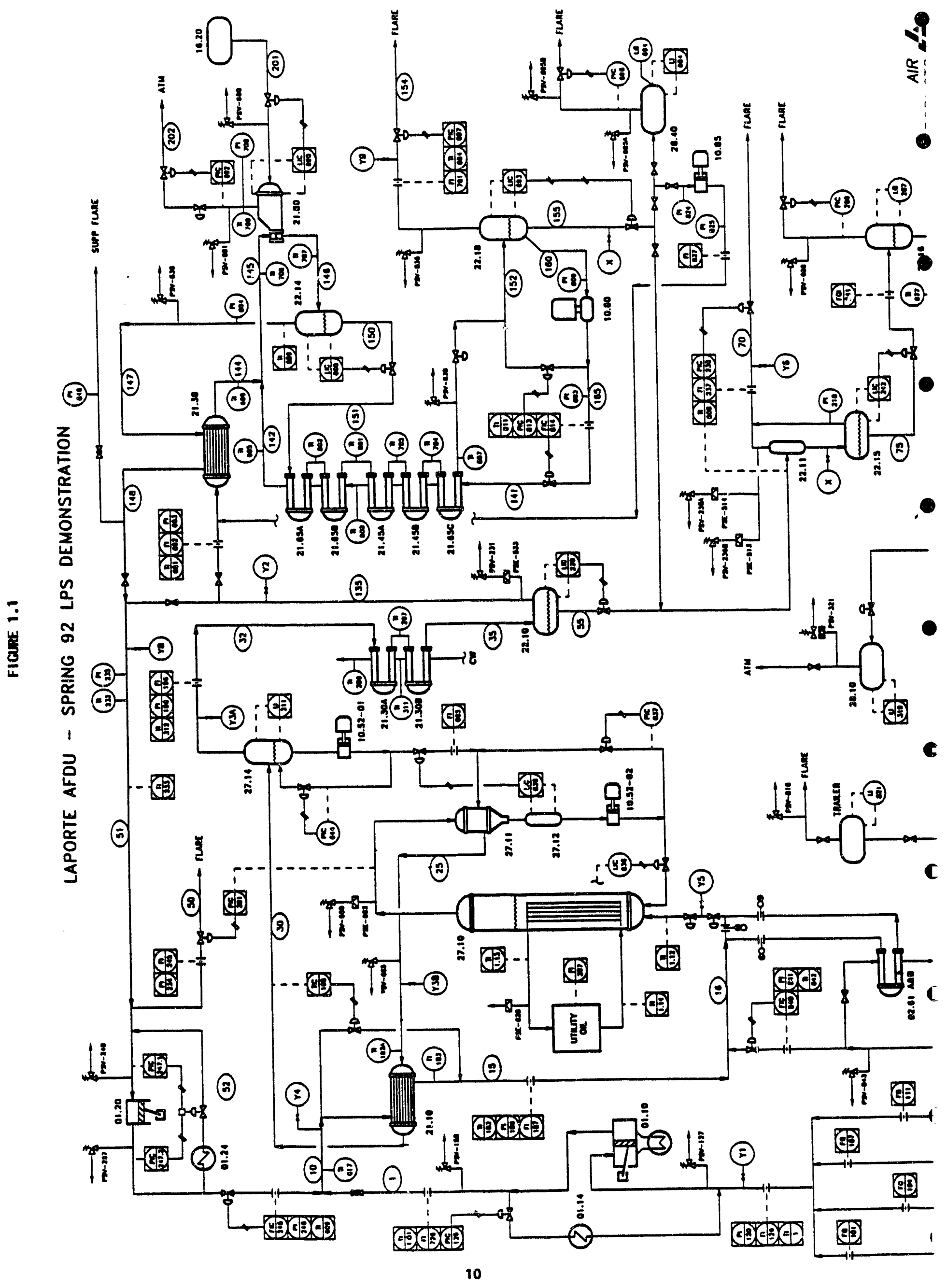


the contained $\mathrm{CO}_{2}$ is recovered in the liquic. The remaining $\mathrm{CO}_{2}$ and syngas is rewarmed by cross exchange in 21.38. A portion of this vapor is sent to flare and the remainder recycled to the frontend.

The liquid from the 22.14 is let down in pressure, then warmed to ambient in the 21.45 and 21.65 hairpin exchangers. The MeOH-rich stream is then degassed in the 22.18. The off-gas, which contains the previously absorbed $\mathrm{CO}_{2}$, is sent to flare. The liquid from the 22.18 is pumped in the 10.80 and then chilled in the 21.65 and 21.45 prior to being combined with the 22.10 vapor take-off.

A small amount of the methanol and water is carried over from the 22.10. To maintain a constant volume in the cold end, a bleed line is required. The bleed will empty into the 22.11 . (Throughout the run, the cold end will operate in an unsteady state as the composition in the cold end changes. The change in composition will affect the level of $\mathrm{CO}_{2}$ removal. Consequently, the liquid inventory is periodically dumped and then recharged.)

The vapor off the 22.10 is saturated with water. This water would normally condense and potentially freeze on the tubes of the 21.38. To keep this from happening, a small methanol flow will be drawn from the 22.18, pumped in the 10.85 and injected into the gas steam prior to its introduction to the 21.38.

\section{Engineering and Design}

First, preliminary heat and material balances were developed. A revised P\&ID and associated FCNs (flowsheet change notices) were drafted, issued for review, and approved. These were used to design/size valves, instruments and lines. Specifications were released to Design Engineering, where the detailed specifications were drawn up and issued for purchase. The preliminary Hazards Review was conducted which identified action items for further review. Calculations in support of the Design Hazards Review were then completed and discussed with the review team. In March, the final review, Design Verification Review, was completed (see Appendix 2).

\section{Site Modifications}

Required piping modifications and instrument installations were completed in March. At the same time, shakedown activities continued: controller function check-out was conducted with nitrogen and oil. Finally, syngas was introduced to the plant during the last week of March. Regular operations will be ready to begin 1 April.

\section{Engineering and Design for the Summer Fischer-Tropsch Demonstration}

P\&ID development work was completed for the Summer 1992 Fischer-Tropsch demonstration run. New control valves as well as new safety valves were specified and approved for purchase. The 21.85 double pipe heat exchanger was also ordered. Piping design work was completed and construction packages were released. Reactor heat load calculations were performed for various F-T 
process conditions. The calculations indicate significantly higher heat load for $\mathrm{F}-\mathrm{T}$ at highest space velocity ( $6000 \mathrm{~s} / \mathrm{hr}-\mathrm{kg} \mathrm{Fe}$ ) compared to LPM. Even though the space velocities are lower for F-T, $\mathrm{CO}$ conversions are much higher and heat of reaction is somewhat higher. The heat load on the reactor heat exchanger at $6000 \mathrm{GHSV}, 600$ psig and 0.95 alpha, was calculated to be about $1.1 \mathrm{MM}$ Btu/hr compared to the maximum LaPorte capacity of about $0.9 \mathrm{MM} \mathrm{Btu} / \mathrm{hr}$. The fin fan on the utility oil is the limiting equipment. As a result of the heat transfer limitations in the reactor, the highest space velocity was decreased from 6000 to $5000 \mathrm{~s} / \mathrm{hr}-\mathrm{kg}$-Fe. Also, in order to obtain a minimum of $0.14 \mathrm{ft} / \mathrm{sec}$ inlet gas velocity, the lowest space velocity was increased from 2000 to $2500 \mathrm{sl} / \mathrm{hr}-\mathrm{kg}$. Heat and mass balances were developed for the new conditions.

A filter test was conducted at Mott Metallurgical to check the cross-flow filter design for catalystwax separation. Drakeol-10 oil was used as a slurry medium with UCI Fe catalyst for the test. The test was conducted at about $150^{\circ} \mathrm{F}$ to simulate viscosity of wax at $250^{\circ} \mathrm{F}$. Initial results indicated excellent filter performance with 1 micron grade filter element at 20 wt\% slurry concentration. After four hours of operation, the filtrate flow stabilized at $0.17-0.18 \mathrm{gpm} / \mathrm{ft}^{2}$ for next 4 hours. This was about $35 \%$ above the design flux of $0.13 \mathrm{gpm} / \mathrm{ft}^{2}$. Also, no backflush was necessary throughout the day. The slumy was maintained at $150^{\circ} \mathrm{F}$ overnight with the filter shut off. On the second day, the slurry was concentrated to $25 \mathrm{wt} \%$. The filter now needed a backflush every 20 minutes to maintain the design flux. Overnight on the second day, the slurry got overheated to $250^{\circ} \mathrm{F}$. On the third day, the filter plugged right away when a test with $20 \mathrm{wt} \%$ slurry was attempted. Even when the filter element was replaced with a new element, only 5 minute cycles were achieved. It appeared that the slurry properties had changed. Particle size measurements indicated reduction in particle size from a median (by particle number) of 12 microns to 6 microns in 16 hours of operation. Mott did not believe that particle size was the cause since they have had better performance with finer catalysts in the past. Also, the step changes in performance after overnight shutdowns at temperature indicated possible change in the chemical nature of the slurry. One possibility was that water came off the catalyst and leached potassium oxide from the catalyst forming potassium hydroxide. Hydroxides are known to inhibit filter performance because they make the particles slippery and allow finer particles to penetrate the filter, thus plugging up the filter. Several analytical tests were conducted to investigate the cause of filter plugging problems. Fresh, intermediate, and spent slurry samples were analyzed. Titrations of the oil samples indicated no alkalinity (hydroxides) or acidity in any of the samples. Atomic adsorption of the oil samples did not detect the presence of any metals ( $\mathrm{Fe}, \mathrm{Cu}, \mathrm{K}$ or $\mathrm{Si}$ ). The brown tint in the spent oil was attributable to very fine Fe particles. These particles would not settle or centrifuge and were only removed by filtration using a fine membrane. Infrared analysis of the oil samples did not show any evidence of breakdown or oxidation of the oil. XRD on the catalyst samples indicated that crystallite of $\mathrm{Fe}_{2} \mathrm{O}_{3}$ represented only 7.7 to $9.6 \%$ of the defraction pattern with no difference in crystallite size between samples. So, it appears that there was no change in the chemical nature of the slurry. Perhaps the physical grinding of the catalyst at high concentrations through the $1 / 4$ " test filter element was the cause of the plugging problems.

As a result of filter plugging problems, the catalyst-wax separation design was changed. It was decided to attempt some settling prior to filtration. This would reduce concentration of the slurry going to the filter. The connections to the slurry holding vessel (27.13) were changed such that the 
connections to and from the reactor will be at the bottom while the connections to and from the filter will be near the liquid level ( $3 \mathrm{ft}$ ). The settling is expected to be substantial at the base condition; however, it will only be partial at the high production condition.

CAER, Kentucky completed activity tests with the UCI catalyst to compare Drakeol-10 with Ethylflow-164 as a starting slurry medium. Both the tests showed poor catalyst activities (see Figures 1.2 and 1.3). This is in contrast to acceptable and comparable activities observed at both UOP and Texas A\&M. It appears that the catalyst samples at CAER went through a slow activation and were never fully activated. CAER also had filter plugging problems in both the tests. Even though attempts were made at CAER to duplicate UOP activation procedures, two differences emerged as a result of detailed discussions with both the parties. UOP switches from $\mathrm{N}_{2}$ to syngas at $280^{\circ} \mathrm{C}$ while CAER heated up the slurry from $25^{\circ} \mathrm{C}$ to $280^{\circ} \mathrm{C}$ in 2.2 hours under syngas flow. Also, the CAER stirring rate appears to be low-750 rpm compared to $1100-1200 \mathrm{rpm}$ typically used by UOP and Air Products in the autoclaves. CAER plans to conduct another test.

Following completion of a partnership agreement between Air Products and Exxon, we visited Exxon on 25 February to discuss plans for the F-T run. Exxon has abandoned catalyst systems with $\mathrm{SiO}_{2}$. They have observed catalyst instability when the catalyst was supported on $\mathrm{SiO}_{2}$. Also, they find these catalysts hard to activate reproducibly. Instead, they are prefer unsupported catalysts with $\mathrm{Fe}, \mathrm{Cu}$ and $\mathrm{K}$. Exxon is concentrating on low alpha operations (about 0.75 ), producing low molecular weight $\mathrm{HC}$ liquids. This reduces wax cracking and catalyst-wax separation requirements.

A meeting was held on $19-20$ March in Pittsburgh with DOE and industrial partners to discuss catalyst selection, run plan and analytical assistance. Our partners to date include Exxon, UOP and Statoil; an agreement with Shell is pending. At the partners' meeting, it was decided to pursue a lower alpha catalyst, which would minimize heavy wax $\left(\mathrm{C}_{26}{ }^{+}\right)$production and increase lower molecular weight hydrocarbon liquid products $\left(C_{8}-C_{20}\right)$. It was generally felt that, in view of filtering difficulties experienced by Air Products at Mott and by Rentech in Colorado, it was worth minimizing the load on the catalyst-wax separation system and focusing on reactor performance. which is the main goal of this first run. After the meeting, follow-up discussions were held by Air Products and Exxon with UCI regarding the catalyst preparation. UCI has agreed to prepare two different low alpha catalysts on a small scale by end of April. One batch will made with about 1\% $\mathrm{K}_{2} \mathrm{O}$ and $1.6 \% \mathrm{SiO}_{2}$, starting with potassium silicate. This requires a minimum change from the current method of producing high alpha catalyst which also uses potassium silicate as staring material $\left(5.9 \% \mathrm{~K}_{2} \mathrm{O}\right.$ and $\left.9.7 \% \mathrm{SiO}_{2}\right)$. The $\mathrm{K}_{2} \mathrm{O}$ to $\mathrm{SiO}_{2}$ ratio will remain the same. The second batch will involve adding extra $\mathrm{SiO}_{2}$ from another source making up to $5 \% \mathrm{SiO}_{2}$. The second batch will be a back-up catalyst, in case the first batch has less than acceptable physical properties due to lower silica content. Both the samples will be tested by UCI for physical properties such as attrition resistance. UOP will then activity-test the catalyst selected from the two in early May. By mid-May, a decision will be made on whether to proceed with a high or a low alpha catalyst. UCI has blocked out pilot plant time to prepare $2000 \mathrm{lbs}$ of the selected catalyst between mid-May and mid-June. Thus, the catalyst will be prepared in time for the July run as scheduled. 


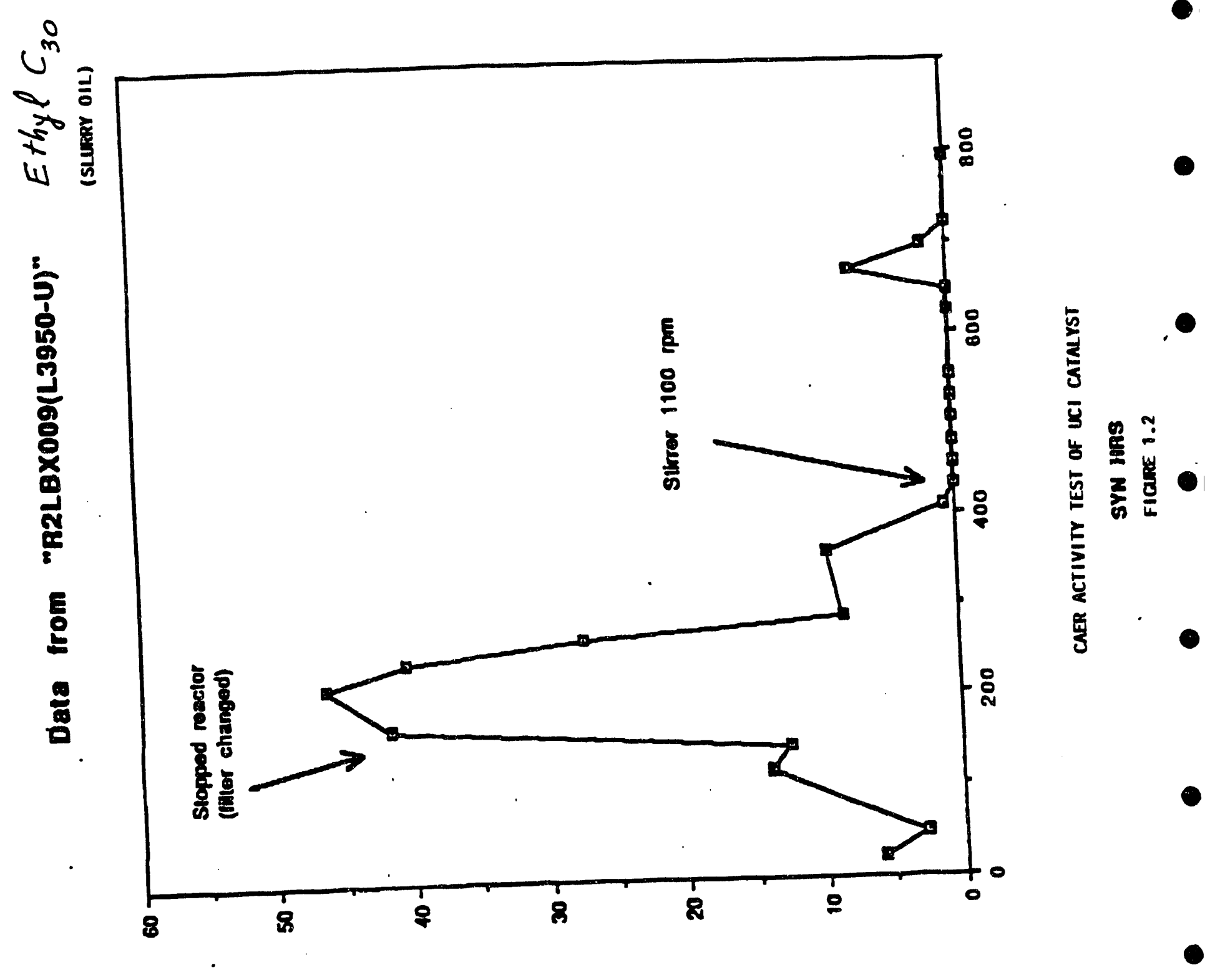

ANOO 00 


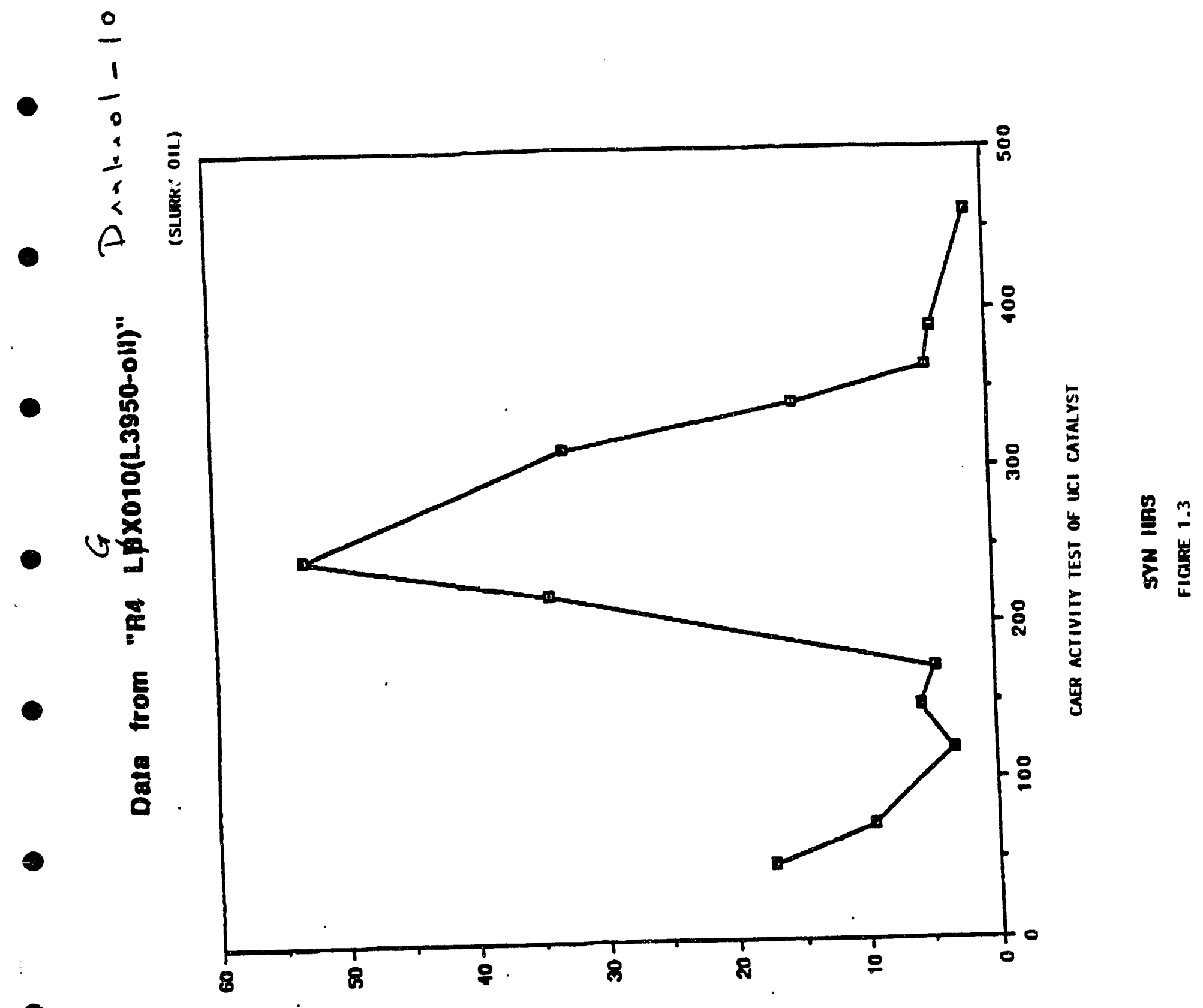

ANOS OO 
During the meeting, Exxon offered the use of their process wax as a starting slurry medium to eliminate the time needed to displace Drakeol-10 with product wax. Follow-up discussions were held between Air Products and Exxon regarding the supply of the starting wax. For Exxon to supply process wax, they would need to restrict access to their wax and would require those with access to sign a non-disclosure agreement. However, since starting wax will end up with the product wax, it will be very difficult to limit the access to the starting wax. Also, with the run coming up in about three months, there is not enough time to get legal agreements in place. Exxon offered Isopar, which is a $C_{20}-C_{30}$ saturated isoparaffin liquid. Hcwever, in the absence of available wax, it was decided to use Drakeol-10, since it has been extensively and successfully used at LaPorte for LPM and LPDME. Drakeol-10 is a $\mathrm{C}_{16}-\mathrm{C}_{38}$ saturated hydrocarbon liquid which includes straight chain and branched paraffins as well as naphthenic compounds. The catalyst performance would be independent of starting medium so long as it does not contain any contaminants. Drakeol-10 will be used by UOP in future tests after a catalyst decision has been made.

The run plan proposed at the meeting (see Table 1.1) was accepted by the partners. About 780 lbs of catalyst and 210 gallons of Drakeol-10 will be loaded in the reactor to make about 35 wt\% slurry. The catalyst will be activated using $0.7 \mathrm{H} / \mathrm{CO}$ syngas at $2000 \mathrm{sl} / \mathrm{hr}-\mathrm{kg} \mathrm{Fe}, 150 \mathrm{psig}$, and $280^{\circ} \mathrm{C}$ for about $12-16$ hours. About $1 \% \mathrm{~N}_{2}$ will be added to the syngas as an internal standard. The inlet gas velocity of about $0.23 \mathrm{ft} / \mathrm{sec}$ will be sufficient for adequate mixing. Expanded slumy height of $20 \mathrm{ft}$, which is maximum, will be maintained throughout the run. The decline in $\mathrm{CO}_{2}$ and rise in $\mathrm{CH}_{4}$ content of the product gas will be monitored; when they level off the operating conditions will be changed to run conditions. The baseline run (Run No. 1) will be conducted with $0.7 \mathrm{H}_{2} / \mathrm{CO}$ syngas $\left(1 \% \mathrm{~N}_{2}\right)$ at $2500 \mathrm{sl} / \mathrm{hr}-\mathrm{kg} \mathrm{Fe}, 200 \mathrm{psig}$, and $265^{\circ} \mathrm{C}$. It is estimated that the reactor will contain about 490-500 lbs of catalyst during the run; the remaining catalyst will be in the slurry holding tank and the cross-flow filter system. The slurry concentration in the reactor will be about $26 \mathrm{wt} \%$. The inlet gas velocity will be about $0.14 \mathrm{ft} / \mathrm{sec}$, which is the minimum velocity required for adequate mixing. The run at these conditions will be continued for ten days to check for stabilization of the catalyst performance. These conditions will be repeated for four days at the end of the run to check for any catalyst deactivation. Two other conditions will be studied for three days each during the run. The space velocity will be doubled to $5000 \mathrm{~s} / \mathrm{hr}-\mathrm{kg}$ Fe at $200 \mathrm{psig}$ and $265^{\circ} \mathrm{C}$ to study the effect of space velocity (Run No. 2). The inlet gas velocity will be about $0.27 \mathrm{ft} / \mathrm{sec}$. The reactor pressure will then be doubled to $400 \mathrm{psig}$ at $5000 \mathrm{sl} / \mathrm{hr}-\mathrm{kg} \mathrm{Fe}$ and $265^{\circ} \mathrm{C}$ to study the effect of reactor pressure (Run No. 3). The inlet gas velocity will be back to about $0.14 \mathrm{ft} / \mathrm{sec}$.

Discussions were held with DOE at the meeting for analytical assistance. It was decided that Air Products will ship HC liquid and solid wax samples to DOE's Pittsburgh Energy Technology Center (PETC) daily during the run for analysis. PETC is already set up for these analyses and has promised a $1-2$ day turn-around time. Gas analysis will be conducted on-line at LaPone using PETC's analytical methods. Two GCs will be set up to analyze up to $\mathrm{C}_{\mathbf{8}}$ in the gaseous product. 


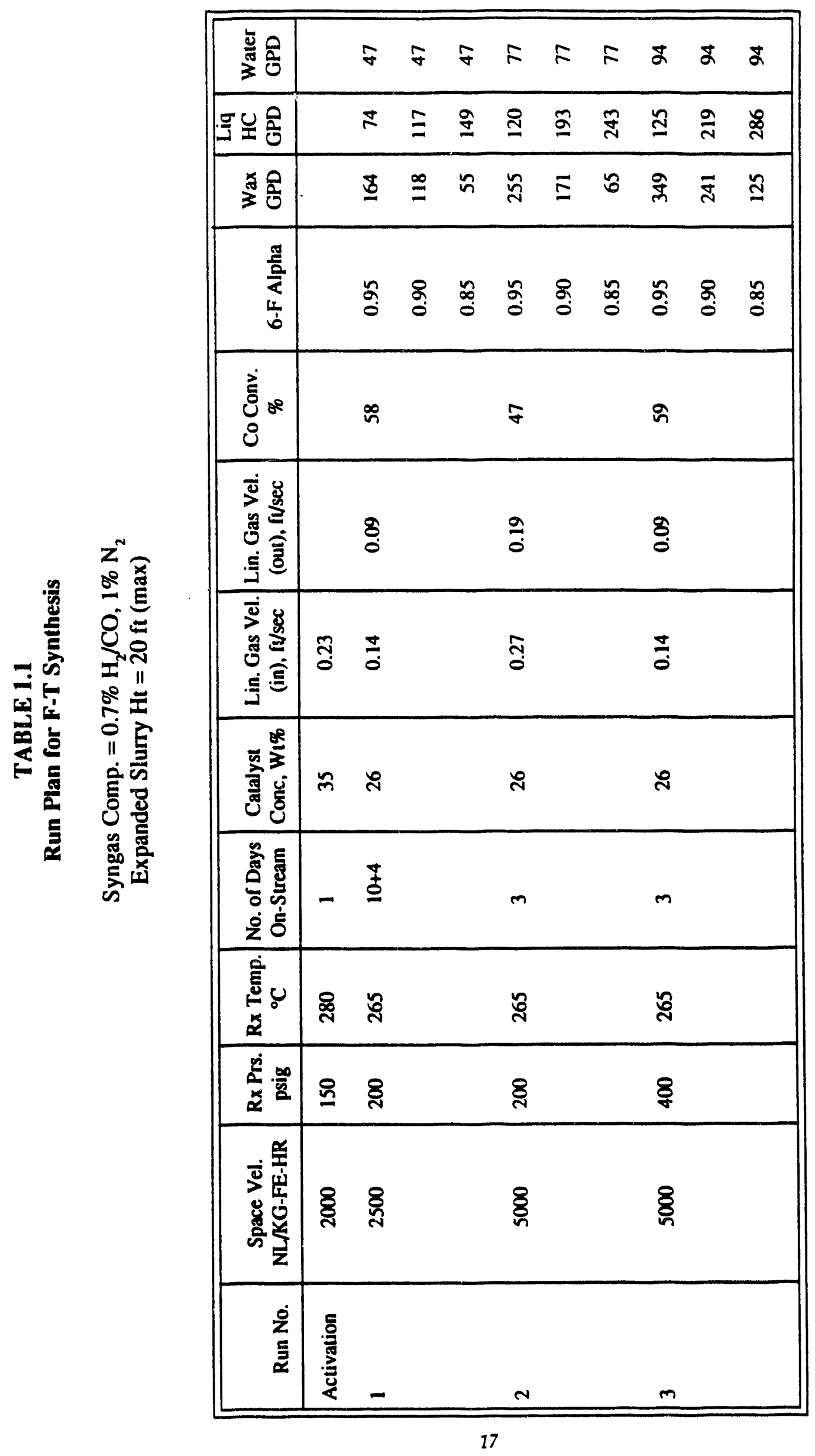




\section{Task 3: Research Program}

\section{Task 3.1: New Fuels From Syngas}

\section{a. Isobutanol/Higher Alcohols:}

Process Variable Scans on Cs-Cu/ZnOIAl, O3 (BASF S3-86)

\section{Model Predictions:}

Process variable studies were done (last Quarterly Report) on Cs-promoted $\mathrm{Cu} / \mathrm{ZnO} / \mathrm{Al}_{2} \mathrm{O}_{3}(1.1$ wt\% Cs) to quantify the effect of various process variables on the performance of the catalyst. The influence of four variables was investigated: 1) temperature, 2) pressure, 3) gas-hourly-spacevelocity (GHSV), and 4) the feed $\mathrm{CO}_{2}$ concentration in a Shell gas matrix. A Box-Behnken statistical experimental design, with three levels of each of the above four variables, was used; a total of 30 experimental observations at 25 different conditions. The levels used for each variable were: temperature $\left(285,300\right.$, and $\left.315^{\circ} \mathrm{C}\right)$, pressure $(500,750$, and $1,000 \mathrm{psig}), \operatorname{GHSV}(2,000,5,000$, and $8,000 \mathrm{std}$. lit./kg-hr), and feed $\mathrm{CO}_{2}$ concentration $(0,1.5$, and $3.0 \mathrm{~mol} \%)$. Response variables, such as rates and selectivities for the individual products, were regressed and fit to $2^{\text {nd }}$-order equations. The experimental results and discussion of the goodness of fit were presented in the last quarterly report (October-December 1991). More detailed model results are presented here.

Regression parameters were determined for a total of 25 key response variables. These parameters were used in the $2^{\text {nd }}$-order equation to predict the response variable as a function of the four independent variables. As an indication of the quality of fit, parity plots for the methanol rate, isobutanol rate, $\Sigma \mathrm{C}_{2}-\mathrm{C}_{6}$ alcohols rate are shown in Figure 3.1.1. Figure 3.1.1 shows, for each measured rate, a corresponding predicted rate as obtained by the $2^{\text {nd }}$-order model. The $2^{\text {nd }}$-order fit is quite good for these three products. The average absolute prediction error per observation is $3.4 \%$, $6.3 \%$, and $5.3 \%$ for methanol, isobutanol, and $\Sigma \mathrm{C}_{2}-\mathrm{C}_{6}$ alcohols, respectively. The equation for methanol rate required 10 parameters, while the isobutanol and $\Sigma C_{2}-C_{6}$ alcohols rate equations required 11 and 12 parameters, respectively.

Previously obtained data, which were not part of the Box-Behnken experimental matrix, on the effect of GHSV at $300^{\circ} \mathrm{C}$ and 850 psig using Shell gas with $3 \% \mathrm{CO}_{2}$ is compared to model predictions in Figure 3.1.2. As shown, the model does an excellent job of predicting the individual product rates, as well as the $\Sigma \mathrm{C}_{2}-\mathrm{C}_{6}$ alcohols rate. Noteworthy is the fact that the $9,000 \mathrm{GHSV}$ condition is slightly outside the range of GHSV used to generate the models, but the fit is still quite good. However, extreme caution should be taken in extrapolating the data to any combination of reaction conditions which is outside the range. The models developed are purely empirical and have no basis in physical or chemical phenomena.

Model predictions of the major product rates and selectivities as a function of temperature, pressure, GHSV, and feed $\mathrm{CO}_{2}$ concentration were generated. These rate and selectivity correlations are presented as functions of GHSV at three levels of another variable (temperature, pressure, or feed $\mathrm{CO}_{2}$ concentration) while holding the remaining two variables constant. These model predictions are shown in Figures 3.1.3-3.1.8. 

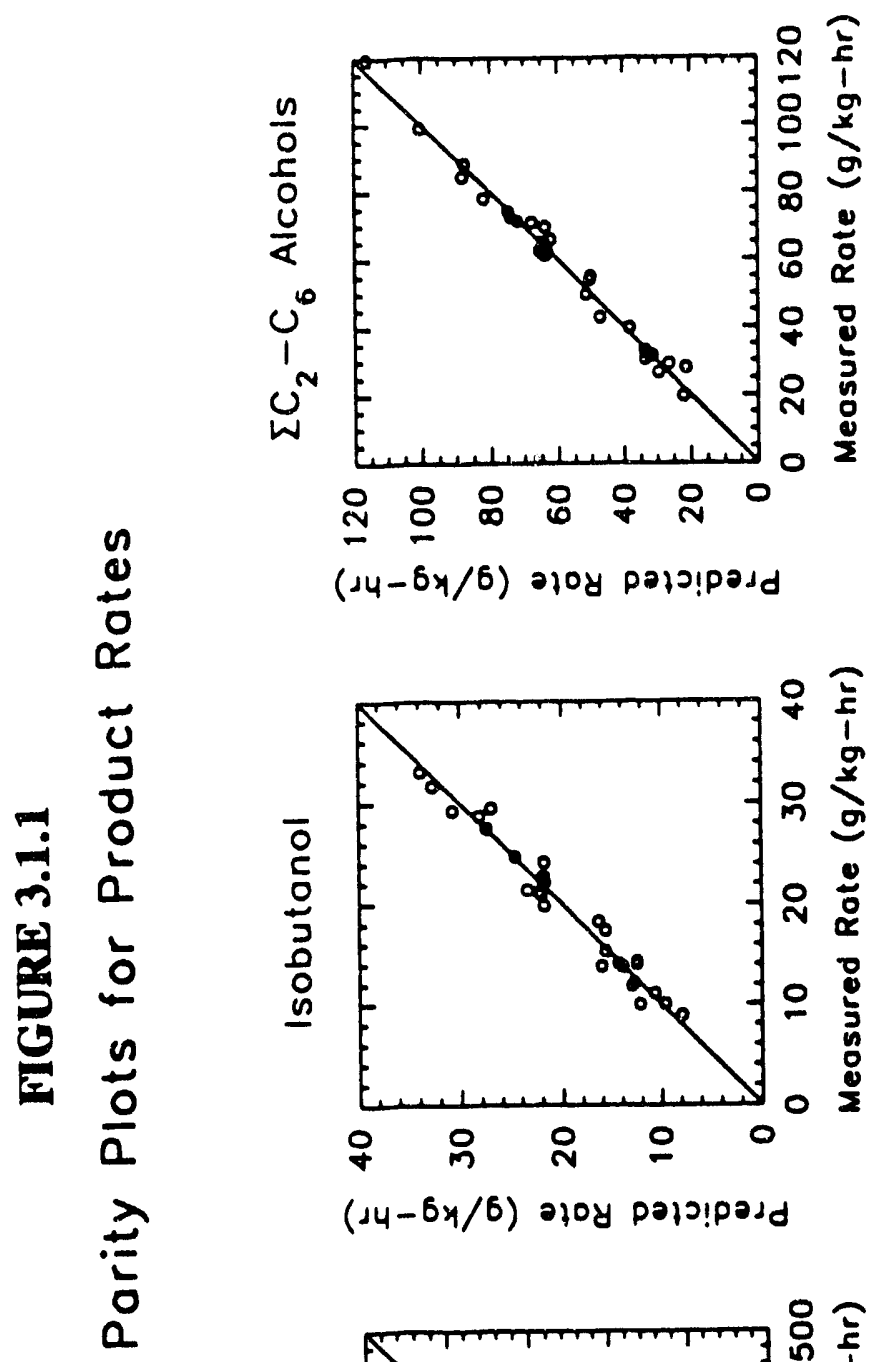

(14-6x/6) oloy poljpodd

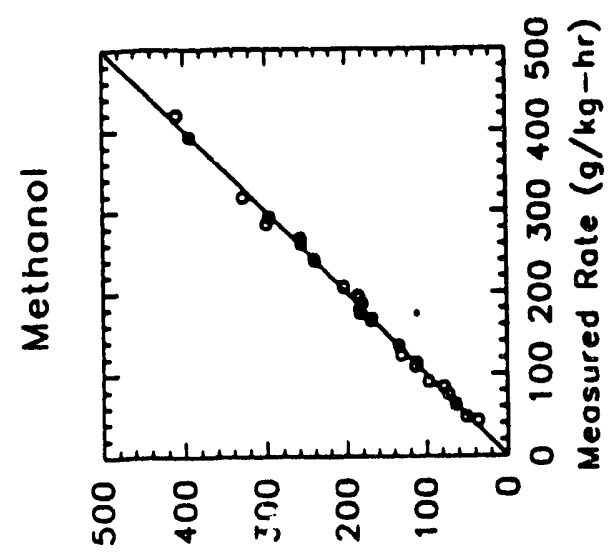

$(14-6 x / 6)$ aloy polo!posd 


\section{FIGURE 3.1.2}

Measured vs Predicted Rates

$$
\mathrm{Cs}-\mathrm{Cu} / \mathrm{ZnO} / \mathrm{Al}_{2} \mathrm{O}_{3}
$$

Shell Gos, $300^{\circ} \mathrm{C}, 850$ psig

Lines ore model prediction

Symbols denote meosured dato
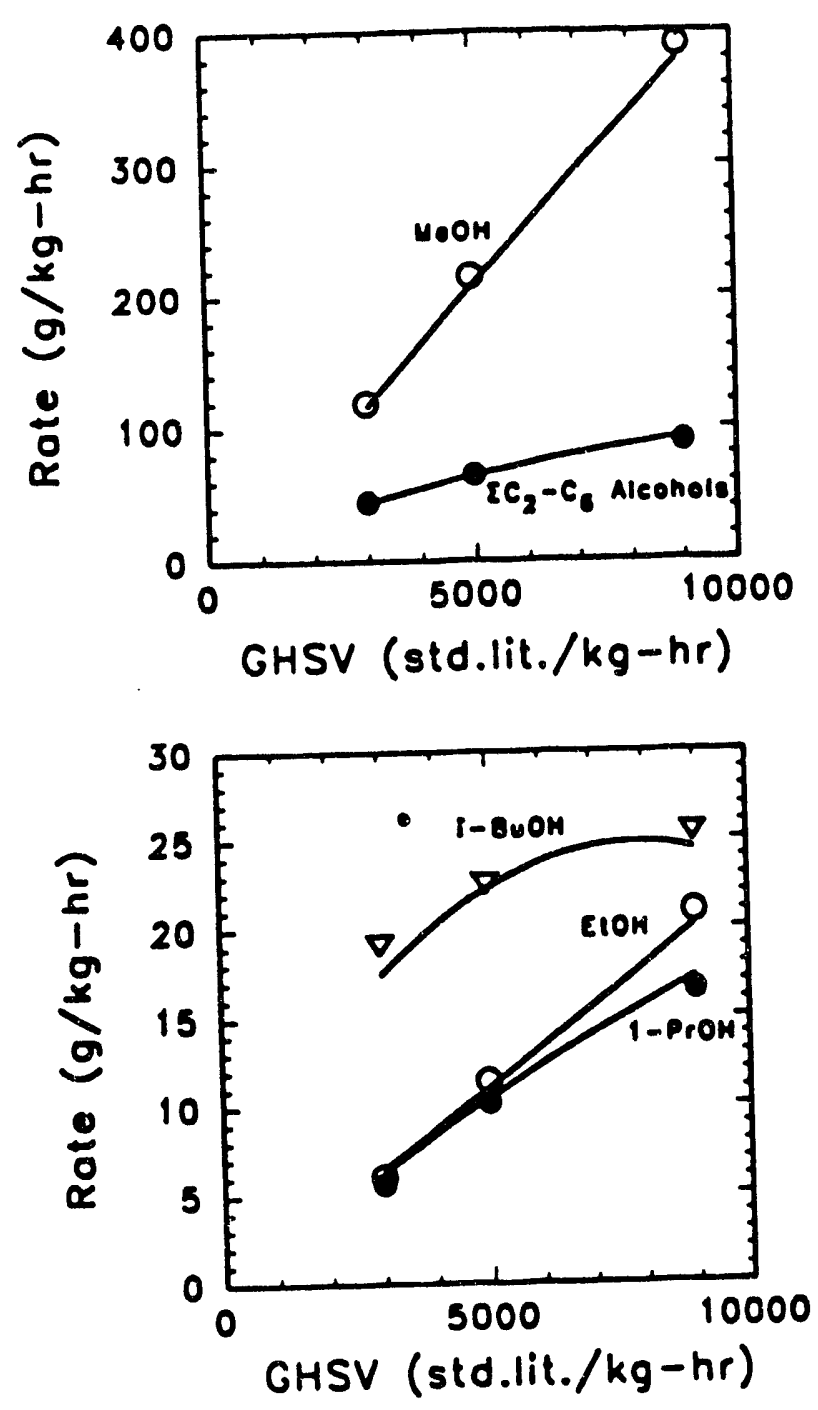

c

C

$\tau$

prepre1.8p9 
The effect of temperature on product rate and selectivity for Shell gas with $3 \% \mathrm{CO}_{2}$ at $750 \mathrm{psig}$, is shown in Figures 3.1.3 and 3.1.4. The rates of synthesis of methanol, ethanol, and 1-propanol decrease monotonically with increasing temperature, while the isobutanol rate increases monotonically. The influence of temperature on the $\Sigma \mathrm{C}_{2}-\mathrm{C}_{6}$ alcohols rate is affected by the particular GHSV, as shown in Figure 3.1.3. Increasing temperature also increases the rate of synthesis of $C_{1}-C_{6}$ hydrocarbons. The effect of GHSV on isobutanol rate at the various temperatures is interesting. At $285^{\circ} \mathrm{C}$, the isobutanol rate goes through a maximum with increasing GHSV, while, at $315^{\circ} \mathrm{C}$, the rate increases continuously with GHSV. Another interesting observation is that the $C_{1}-C_{6}$ hydrocarbons rate decreases monotonically with GHSV at $285^{\circ} \mathrm{C}$ and $300^{\circ} \mathrm{C}$, but is barely influenced by $\mathrm{GHSV}$ at $315^{\circ} \mathrm{C}$. The selectivity results in Figure 3.1 .4 clearly show that methanol selectivity decreases with increasing temperature, while the isobutanol, $\Sigma \mathrm{C}_{1}-\mathrm{C}_{6}$ hydrocarbons, and $\Sigma \mathrm{C}_{2}-\mathrm{C}_{6}$ alcohols rates all increase with temperature. Also shown is the fact that the selectivity to $\Sigma \mathrm{C}_{1}-\mathrm{C}_{6}$ hydrocarbons decreases dramatically with increasing GHSV, at each temperature.

Figures 3.1.5 and 3.1.6 show the effect of pressure on product rate and selectivity for Shell gas with $3 \% \mathrm{CO}_{2}$ and a reaction temperature of $300^{\circ} \mathrm{C}$. Figure 3.1 .5 shows that a substantial increase in the rate of synthesis of all products with increasing pressure is quite evident. As shown in Figure 3.1.6, the selectivity to methanol and isobutanol is not a strong function of pressure. However, selectivities to ethanol and 1-propanol increase with increasing pressure, while selectivity to $\Sigma C_{1}-C_{6}$ hydrocarbons decreases with increasing pressure. Pressure has little effect on the selectivity to total higher alcohols $\left(\Sigma \mathrm{C}_{2}-\mathrm{C}_{6}\right.$ alcohols $)$.

The effect of feed $\mathrm{CO}_{2}$ concentration on product rate and selectivity for Shell gas at 750 psig and $300^{\circ} \mathrm{C}$, is shown in Figures 3.1.7 and 3.1.8, respectively. Methanol rate is not affected by varying $\mathrm{CO}_{2}$ concentration, while the rate of synthesis of all other products increases with decreasing feed $\mathrm{CO}_{2}$ concentration. Figure 3.1 .8 shows that selectivities to higher alcohols increase with decreasing feed $\mathrm{CO}_{2}$ level.

Another response variable correlated was the reactor exit $\mathrm{H}_{2} \mathrm{O}$ concentration. This quantity is important because it determines how much $\mathrm{H}_{2} \mathrm{O}$ may be present in the product alcohols, and also may influence catalyst life by determining the rate of hydrothermal sintering. The catalyst, in particular the copper phase, is expected to sinter faster in the presence of high partial pressure of $\mathrm{H}_{2} \mathrm{O}$. The reactor exit $\mathrm{H}_{2} \mathrm{O}$ concentration was experimentally determined using the on-line KarlFischer titrator. Figure 3.1.9 shows the effece of pressure, temperature, and feed $\mathrm{CO}_{2}$ concentration on the reactor exit $\mathrm{H}_{2} \mathrm{O}$ concentration. The results indicate that exit $\mathrm{H}_{2} \mathrm{O}$ concentration increases dramatically with decreasing GHSV. This correlation suggests that the use of low GHSV may be disadvantageous from the standpoint of product quality and catalyst life. 


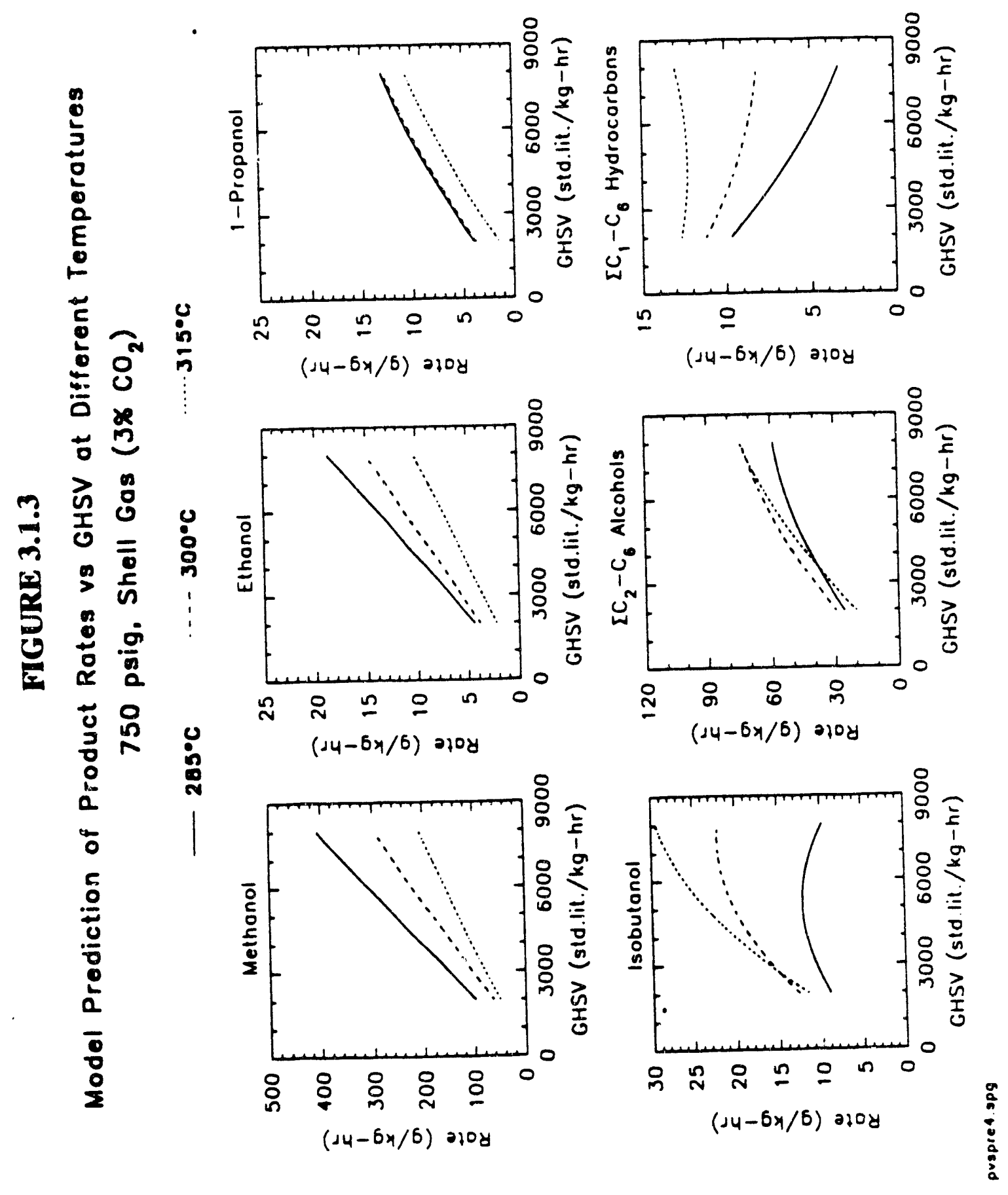




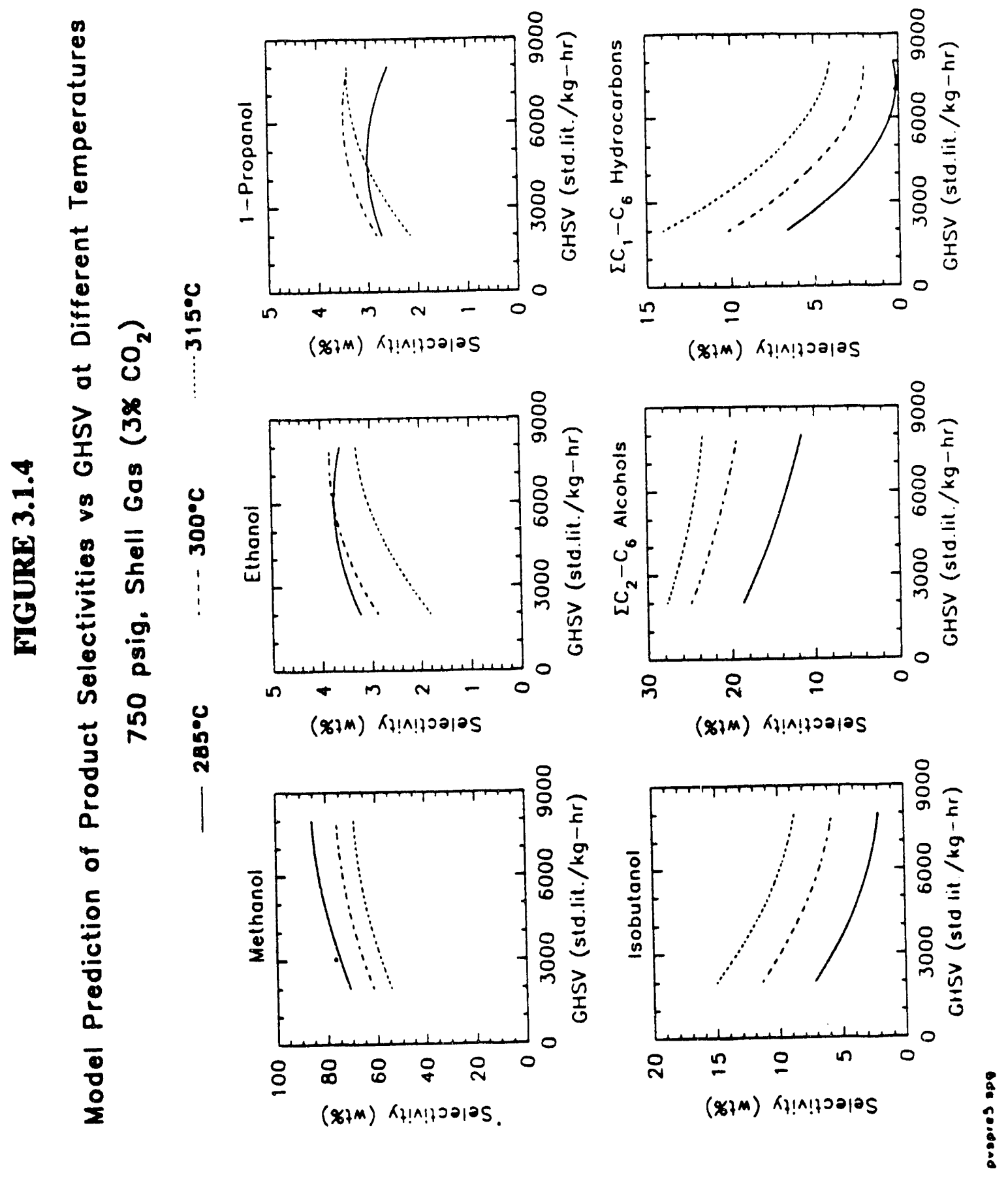




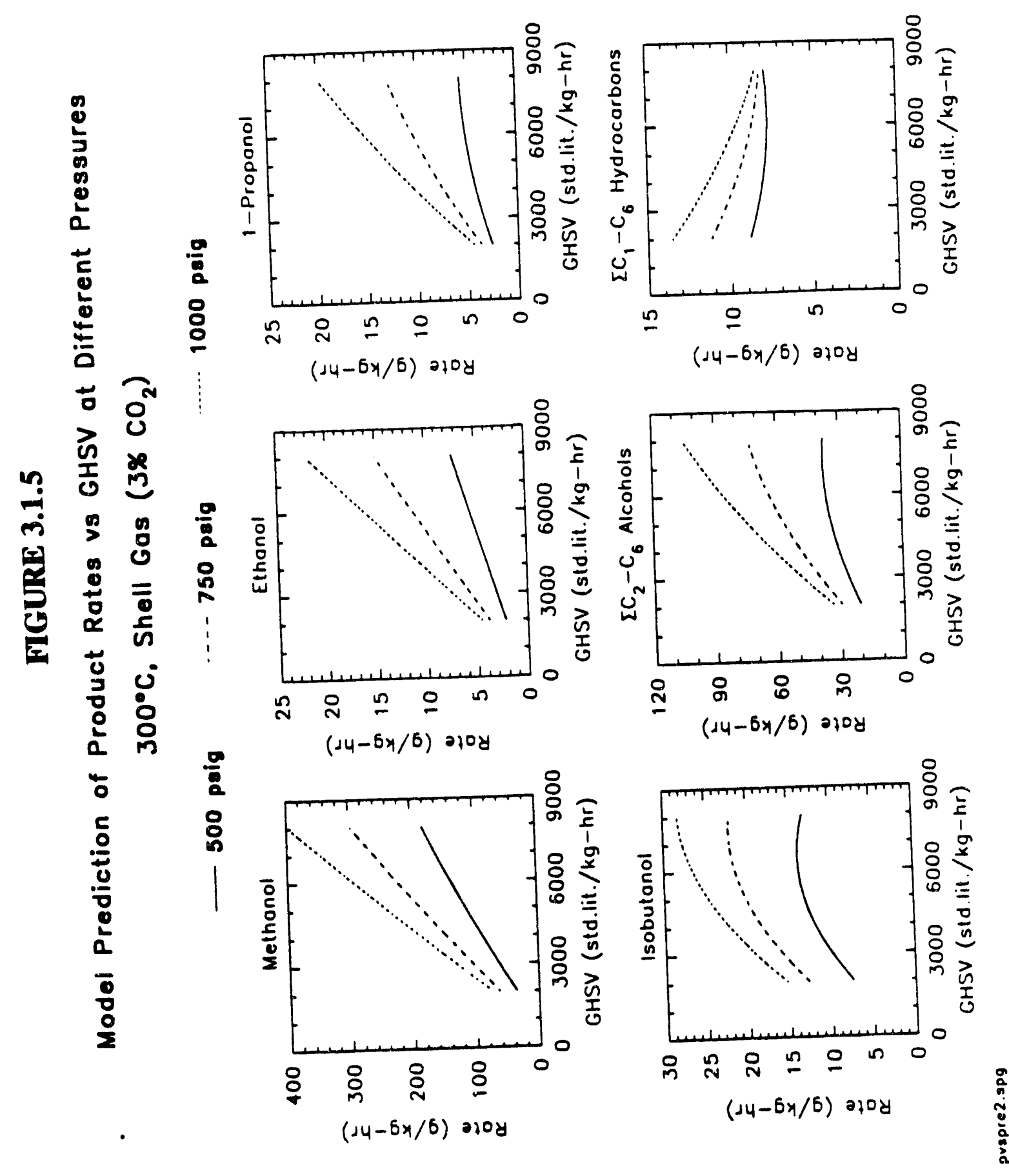




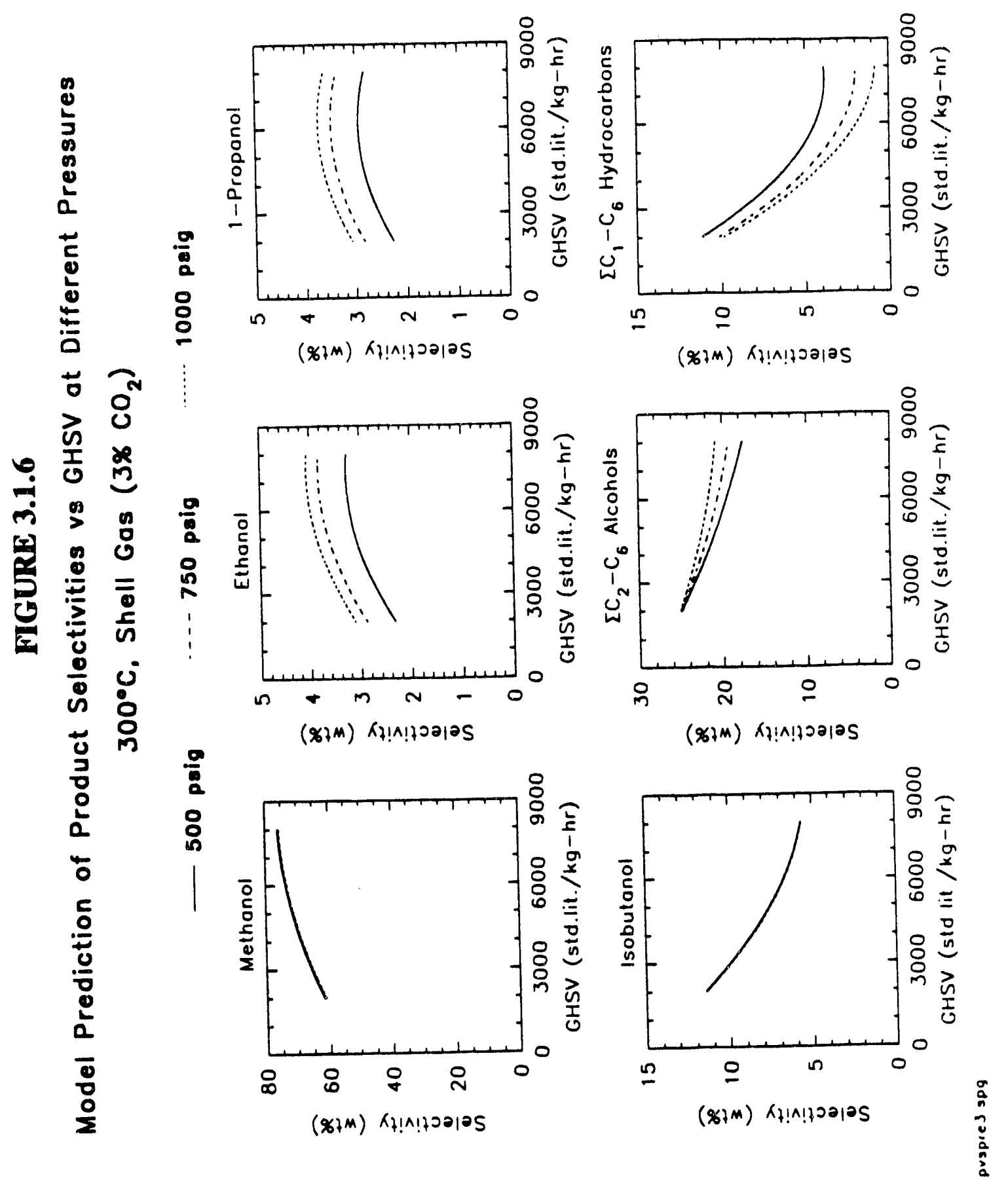




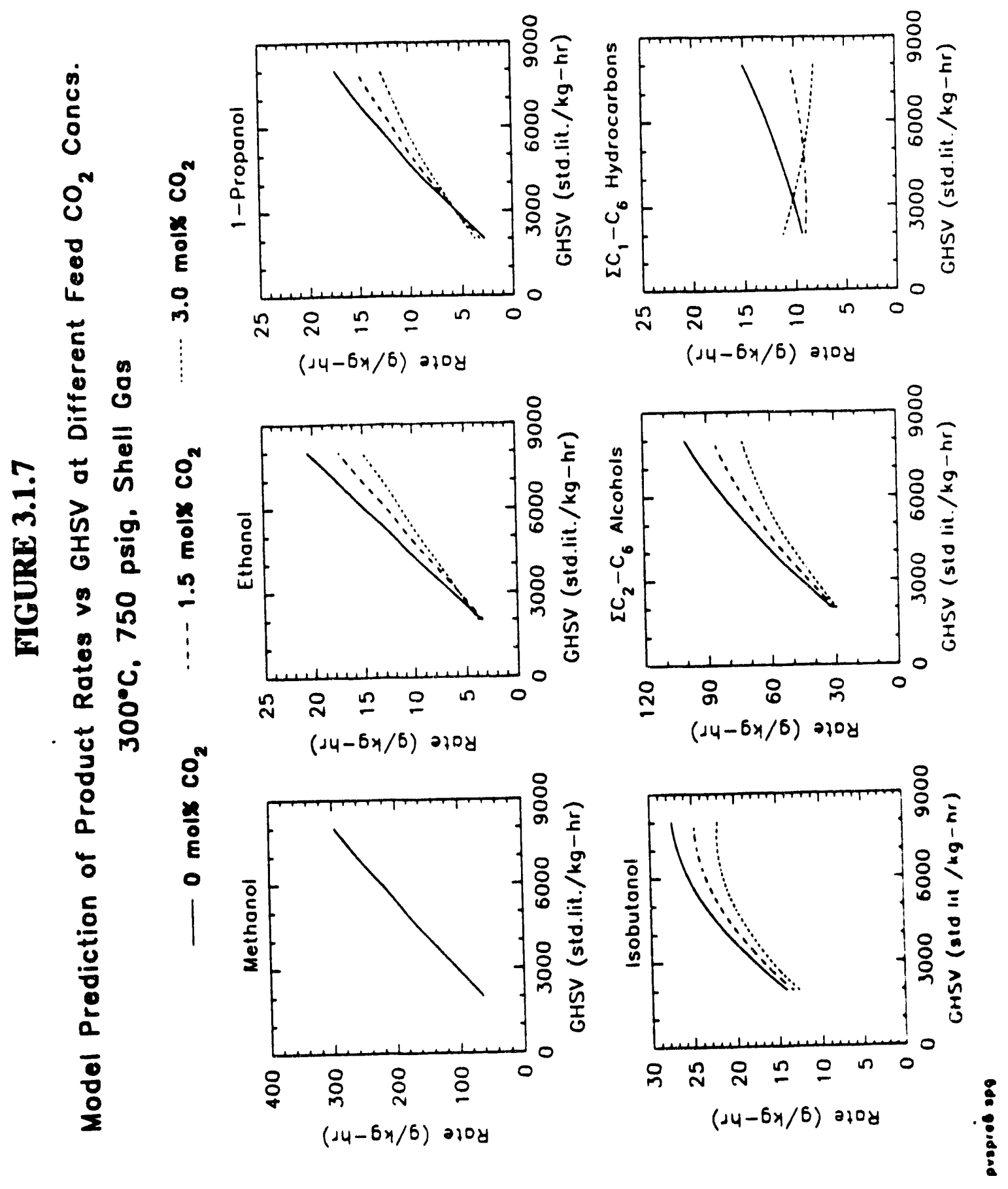




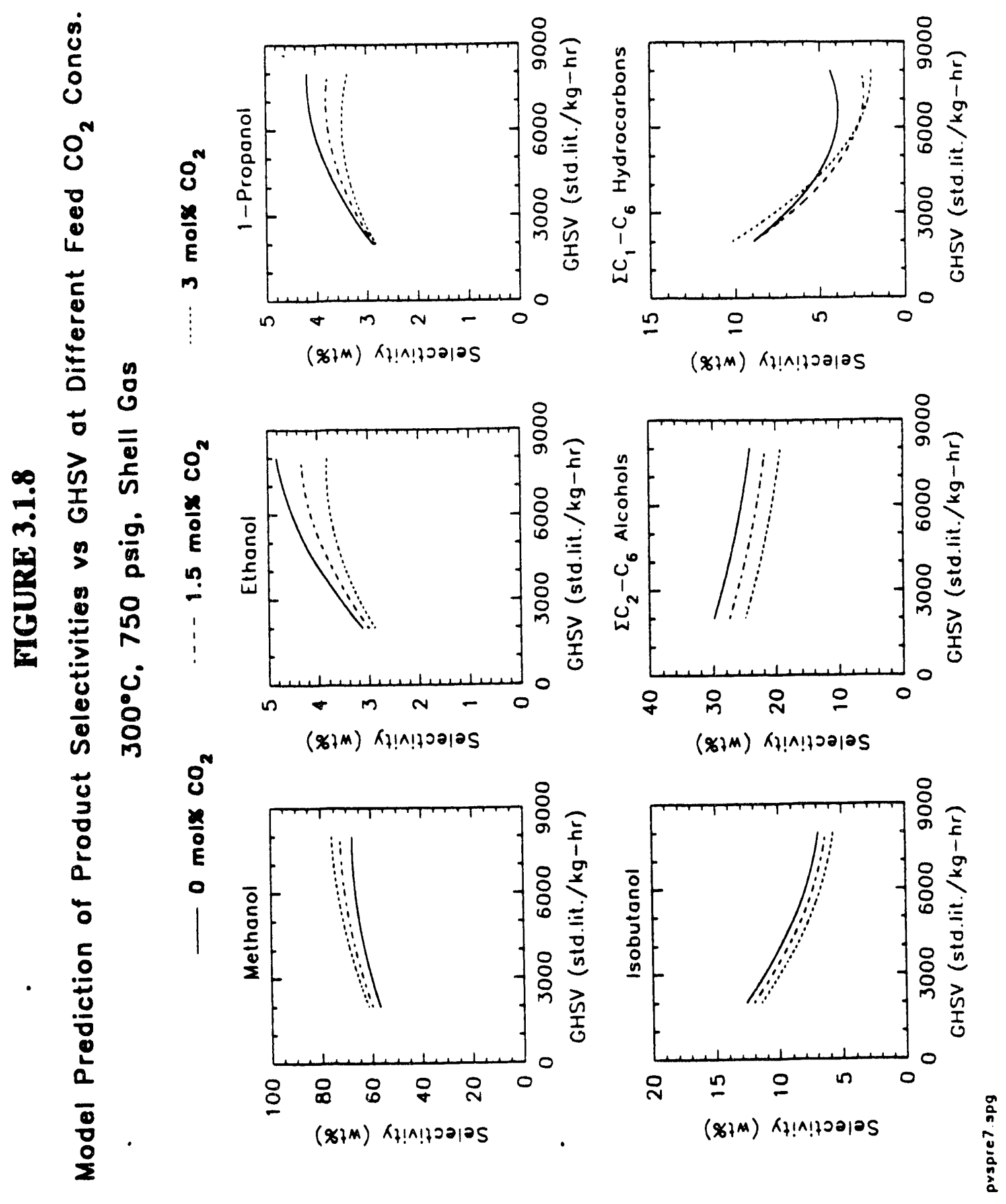




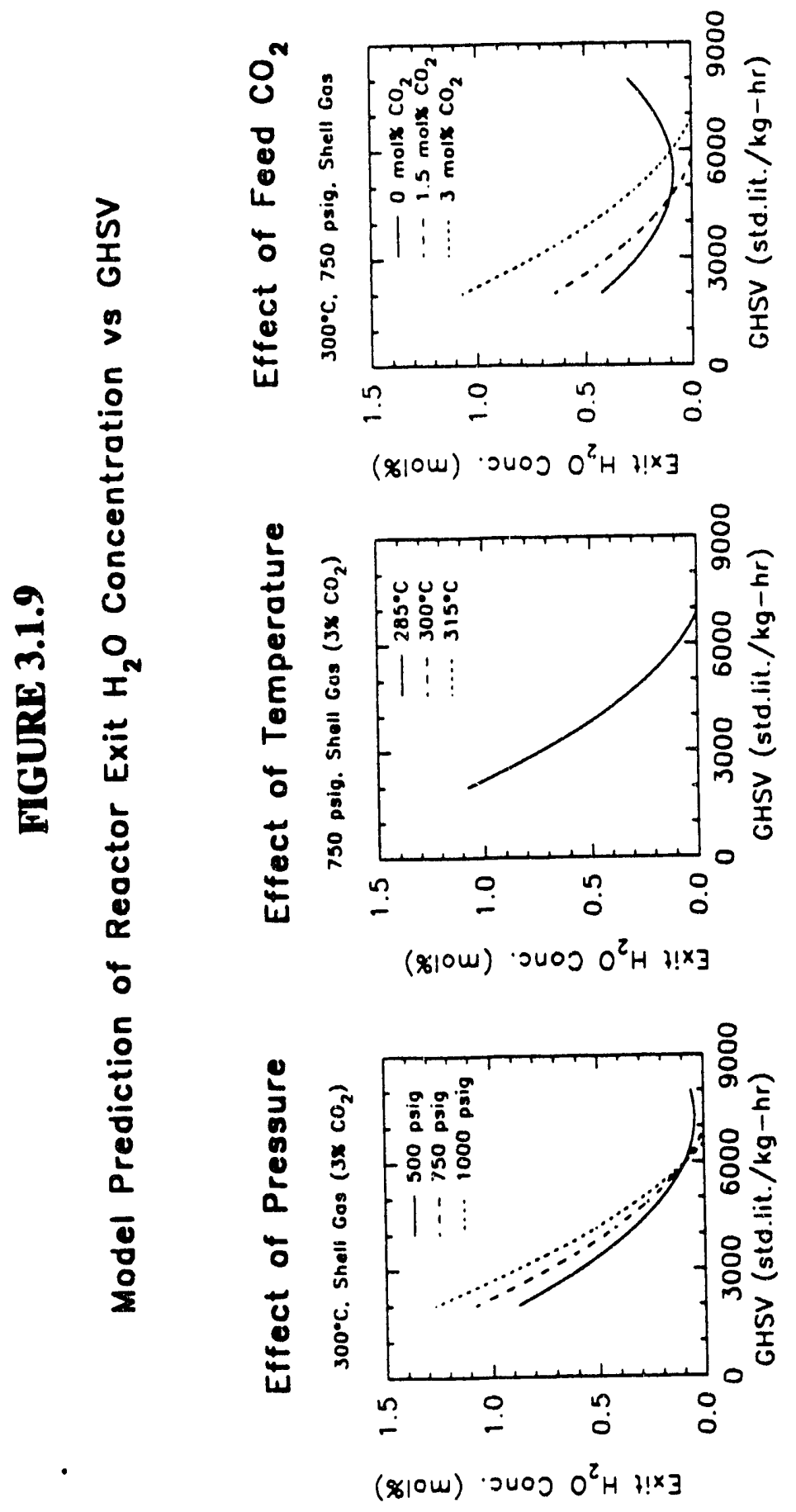




\section{Oprimization:}

Within the ranges of process variables explored, certain of the important response variables were optimized. For these optimizations, temperature, pressure, GHSV, and feed $\mathrm{CO}_{2}$ concentration were constrained to be within the ranges for the Box-Behnken experiments $\left(285-315^{\circ} \mathrm{C}, 500-1000\right.$ psig, 2000-8000 std. lit. $/ \mathrm{kg}-\mathrm{hr}$, and 0-3 mol\% $\mathrm{CO}_{2}$ ). Conditions were determined where each variable (isobutanol rate, isobutanol selectivity, $\Sigma \mathrm{C}_{2}-\mathrm{C}_{6}$ alcohols rate, $\Sigma \mathrm{C}_{2}-\mathrm{C}_{6}$ alcohols selectivity, and $\Sigma \mathrm{C}_{1}-\mathrm{C}_{6}$ alcohols rate) was maximized. Table 3.1.1 shows the results for these determinations.

As shown in Table 3.1.1, isobutanol rate and $\Sigma \mathrm{C}_{2}-\mathrm{C}_{6}$ alcohols rate are maximized at the maximum temperature, pressure, and GHSV, and the minimum feed $\mathrm{CO}_{2}$ content. Selectivity to isobutanol is maximized at maximum temperature and pressure, but minimum GHSV and $\mathrm{CO}_{2}$ content. Low GHSV favors high selectivity to isobutanol, while high GHSV favors high productivity. Interestingly, the maximum selectivity to $\Sigma \mathrm{C}_{2}-\mathrm{C}_{6}$ alcohols occurs at an intermediate temperature and the lowest pressure, GHSV, and $\mathrm{CO}_{2}$ content. Finally, the $\Sigma \mathrm{C}_{1}-\mathrm{C}_{6}$ alcohols rate (total alcohol productivity) is maximized at the lowest temperature (largely because that is where methanol rate is maximized) and feed $\mathrm{CO}_{2}$ content and the highest GHSV and pressure.

TABLE 3.1.1

\section{Optimum Conditions* for Selected Response Variables}

\begin{tabular}{|c|c|c|c|c|c|}
\hline \multirow[b]{2}{*}{$\begin{array}{l}\text { Response } \\
\text { Variable }\end{array}$} & \multirow[b]{2}{*}{$\begin{array}{c}\text { Maximized } \\
\text { Result }\end{array}$} & \multicolumn{4}{|c|}{ Optimum Conditions in Range } \\
\hline & & $\begin{array}{l}\text { Temp. } \\
\left({ }^{\circ} \mathrm{C}\right)\end{array}$ & $\begin{array}{l}\text { Press. } \\
\text { (psig) }\end{array}$ & $\begin{array}{l}\text { GHSV } \\
\text { (std. lit./ } \\
\text { kg-hr) }\end{array}$ & $\begin{array}{l}\text { Feed } \\
\mathrm{CO}_{2} \\
(\mathrm{~mol} \%)\end{array}$ \\
\hline Isobutanol Rate (g/kg-hr) & 45.1 & 315 & 1000 & 8000 & 0 \\
\hline Isobutanol Selectivity (wt\%) & 16.6 & 315 & 1000 & 2000 & 0 \\
\hline$\Sigma \mathrm{C}_{2}-\mathrm{C}_{6}$ Alcohols Rate $(\mathrm{g} / \mathrm{kg}-\mathrm{hr})$ & 136.5 & 315 & 1000 & 8000 & 0 \\
\hline$\Sigma C_{2}-C_{6}^{0}$ Alcohols Sensitivity (wt\%) & 33.21 & 310 & 500 & 2000 & 0 \\
\hline$\Sigma C_{1}-C_{6}$ Alcohols Rate $(g / k g-h r)$ & 628.0 & 285 & 1000 & 8000 & 0 \\
\hline
\end{tabular}

*Allowed ranges of process variables correspond to their ranges in the Box-Behnken experimental design:

Temp. (285-315 $\left.{ }^{\circ} \mathrm{C}\right)$, Press. (500-1000 psig), GHSV (2000-8000 std. lit./kg-hr) Feed $\mathrm{CO}_{2}(0-3 \mathrm{~mol} \%)$

Optimization of the same response variables was done for Shell gas of $3 \mathrm{~mol} \% \mathrm{CO}_{2}$ (i.e., Shell gas without $\mathrm{CO}_{2}$ removal) to obtain more information on the relative importance of $\mathrm{CO}_{2}$ removal. The results are shown in Table 3.1.2. In agreement with the results obtained when $\mathrm{CO}_{2}$ content was allowed to vary (see Table 3.1.1), the isobutanol and $\Sigma \mathrm{C}_{2}-\mathrm{C}_{6}$ alcohols rates are maximized at the maximum temperature, pressure, and GHSV. Also, the isobutanol selectivity is maximized at the highest temperature and pressure but lowest GHSV, in agreement with the results in Table 3.1.1. Finally, also in agreement with Table 3.1 .1 , the $\Sigma C_{1}-C_{6}$ alcohols rate is maximized at the lowest temperature but highest pressure and GHSV. The results in Tables 3.1.1 and 3.1.2 suggest that, to maximize isobutanol rate and selectivity, high temperature and pressure is essential. 
TABLE 3.1.2

Optimum Conditions* for Selected Response Variables

for Shell Gas with $3 \mathrm{~mol} \% \mathrm{CO}_{2}$

\begin{tabular}{|c|c|c|c|c|}
\hline $\begin{array}{l}\text { Response } \\
\text { Variable } \\
\end{array}$ & $\begin{array}{c}\text { Maximized } \\
\text { Result }\end{array}$ & $\begin{array}{l}\text { Temp. } \\
\left({ }^{\circ} \mathrm{C}\right)\end{array}$ & $\begin{array}{l}\text { Press. } \\
\text { (psig) }\end{array}$ & $\begin{array}{l}\text { GHSV } \\
\text { (std. lit./ } \\
\text { kg-hr) }\end{array}$ \\
\hline Isobutanol Rate $(\mathrm{g} / \mathrm{kg}-\mathrm{hr})$ & 39.7 & 315 & 1000 & 8000 \\
\hline Isobutanol Selectivity (wt\%) & 15.8 & 315 & 1000 & 2000 \\
\hline$\Sigma \mathrm{C}_{2}-\mathrm{C}_{6}$ Alcohols Rate $(\mathrm{g} / \mathrm{kg}-\mathrm{hr})$ & 111.7 & 315 & 1000 & 8000 \\
\hline$\Sigma C_{2}-C_{6}$ Alcohols Sensitivity (wt\%) & 29.7 & 315 & 1000 & 2000 \\
\hline$\Sigma C_{1}-C_{6}$ Alcohols Rate $(\mathrm{g} / \mathrm{kg}-\mathrm{hr})$ & 605.7 & 285 & 1000 & 8000 \\
\hline
\end{tabular}

*Allowed ranges of process variables correspond to their ranges in the Box-Behnken design:

Temp. (285-315 $\left.{ }^{\circ} \mathrm{C}\right)$, Press. (500-1000 psig), GHSV (2000-8000 std. lit./kg-hr)

At the end of the process variable experiments, the reactor was run at aggressive conditions to obtain high rate and selectivity to isobutanol, using the results of the process variable scans as a guide. It should be noted that these results were obtained on a catalyst sample which had been in use during the process variable experiments for almost 200 hours on stream. The maximum temperature and pressure were set by practical considerations, i.e., the maximum achievable by the unit. The feed gas used was Shell gas with $3 \mathrm{~mol} \% \mathrm{CO}_{2}$, that is, no $\mathrm{CO}_{2}$ removal. The pressure was 1400 psig and the temperature was $315^{\circ} \mathrm{C}$; space velocities of 2000 and $8000 \mathrm{std}$. lit/kg-hr were used. The results obtained are shown in Table 3.1.3. These experiments produced the highest rate of isobutanol synthesis $(49.4 \mathrm{~g} / \mathrm{kg}-\mathrm{hr}$ at $8000 \mathrm{GHSV})$ ever recorded in our labs.

TABLE 3.1.3

Measured Performance of Catalyst at $315^{\circ} \mathrm{C}$ and 1400 psig

Feed: Shell gas with $3 \mathrm{~mol} \% \mathrm{CO}_{2}$

\begin{tabular}{|c|c|c|c|c|c|c|}
\hline \multirow[b]{2}{*}{ GHSV } & \multicolumn{3}{|c|}{ Rate (g/kg-hr) } & \multicolumn{3}{|c|}{ Selectivity (wt\%) } \\
\hline & Methanol & Isobutanol & $\begin{array}{l}\Sigma C_{2}-C_{6} \\
\text { alcohols }\end{array}$ & Methanol & Isobutanol & $\begin{array}{l}\Sigma \mathrm{C}_{2}-\mathrm{C}_{6} \\
\text { alcohols }\end{array}$ \\
\hline 2000 & 77.5 & 19.5 & 37.7 & 58.1 & 14.6 & 28.3 \\
\hline 8000 & 420 & 49.4 & 140 & 70.1 & 8.2 & 23.3 \\
\hline
\end{tabular}


Scale-up of Cs-Cu/ZnO/Al $\mathrm{O}_{3}$ for LaPorte Isobutanol Run:

Work continued on scaling up the preparation of Cs-promoted $\mathrm{Cu} / \mathrm{ZnO} / \mathrm{Al}_{2} \mathrm{O}_{3}$ for the LaPorte AFDU isobutanol run. In the last quarterly report (October-December 1991), results were presented for some advance samples of Cs-promoted $\mathrm{Cu} / \mathrm{ZnO} / \mathrm{Al}_{2} \mathrm{O}_{3}$ received from the catalyst vendor. These samples ranged in Cs loading from 1.1 to $1.4 \mathrm{wt} \%$, loadings in the optimum range as determined in sample preparations done at Air Products. Recall that none of these samples had an acceptable performance level, in terms of productivity for higher alcohols or isobutanol, and there was no clear trend with cesium loading in the data. The vendor prepared these samples using a cesium precursor consisting of cesium hydroxide plus formic acid at $\mathrm{pH}=7.0$, instead of "straight" cesium formate, which was the precursor used in preparations at Air Products and has a different $\mathrm{pH}$. Since the $\mathrm{pH}$ of the impregnating solution used in the preparation of the catalyst may have a profound effect on the final catalyst performance, the low performance of these samples may be due to the $\mathrm{pH}$ or precursor used.

Additional samples, now prepared using cesium formate as the cesium precursor, were received from the vendor and tested in our microclaves. Results for testing of these samples are presented in Table 3.1.4. Additionally, shown in Table 3.1.5 are results for samples prepared at Air Products.

Before discussing the results presented in Tables 3.1.4 and 3.1.5, some explanation regarding the notation used in the tables is in order. Cesium precursor denotes the cesium compound used to promote the $\mathrm{Cu} / \mathrm{ZnO} / \mathrm{Al}_{2} \mathrm{O}_{3}$ substrate. "Formate (1)" denotes Alfa Products cesium formate, which was used in preparation of most of the samples at Air Products. "Formate (2)" is the cesium formate used by the vendor to prepare samples; this cesium formate was chemically the same as that used by Air Products, but from a different supplier. "Hydroxide" denotes cesium hydroxide, which was used to prepare some samples at Air Products. In addition, three different $\mathrm{Cu} / \mathrm{ZnO} / \mathrm{Al}_{2} \mathrm{O}_{3}$ substrates are indicated in Tables 3.1.4 and 3.1.5. All three are the same methanol synthesis catalyst, but different production lots. Two cesium deposition methods are also indicated in the tables: incipient wetness impregnation (abbr. "incip. wetness") and a spray deposition technique (abbr. "spray"). In the incipient wetness procedure, an aqueous solution of the cesium precursor was added dropwise to the $\mathrm{Cu} / \mathrm{ZnO} / \mathrm{Al}_{2} \mathrm{O}_{3}$ powder substrate with manual stirring until the point of incipient wetness (paste formation) was reached. The spray technique, which is more conducive to scale-up, was the only technique used by the vendor to prepare samples, and was also used at Air Products. This technique involves spraying the cesium precursor solution onto the $\mathrm{Cu} / \mathrm{ZnO} / \mathrm{Al}_{2} \mathrm{O}_{3}$ powder substrate which is being mechanically mixed by tumbling in a vessel. A quantity of more concentrated solution equal to approximately $1 / 2$ of that required in the incipient wetness technique, is employed to ensure that the powder remains free flowing and non-clumping. Finally, two methods of drying were employed. The method designated "impregnator", where drying of the powder was done by heating the same tumbling vessel that was used for the spray deposicion technique, was used only by the vendor. For the drying method labeled "oven", the wetred powder, after deposition of the cesium precursor solution, was transferred to dishes and dried in a standard laboratory convection oven. After either method of drying, all samples, whether prepared by the vendor or Air Products, were calcined in a laboratory convection furnace. 


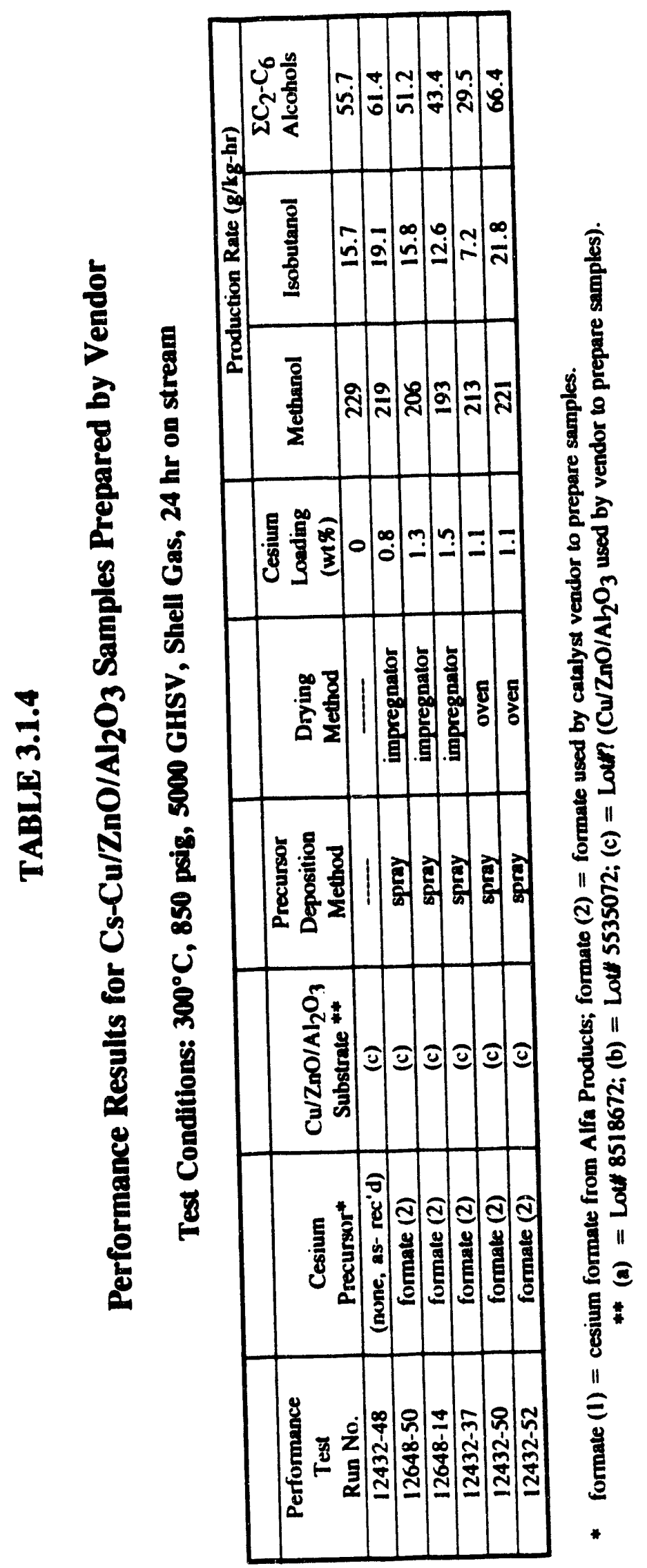




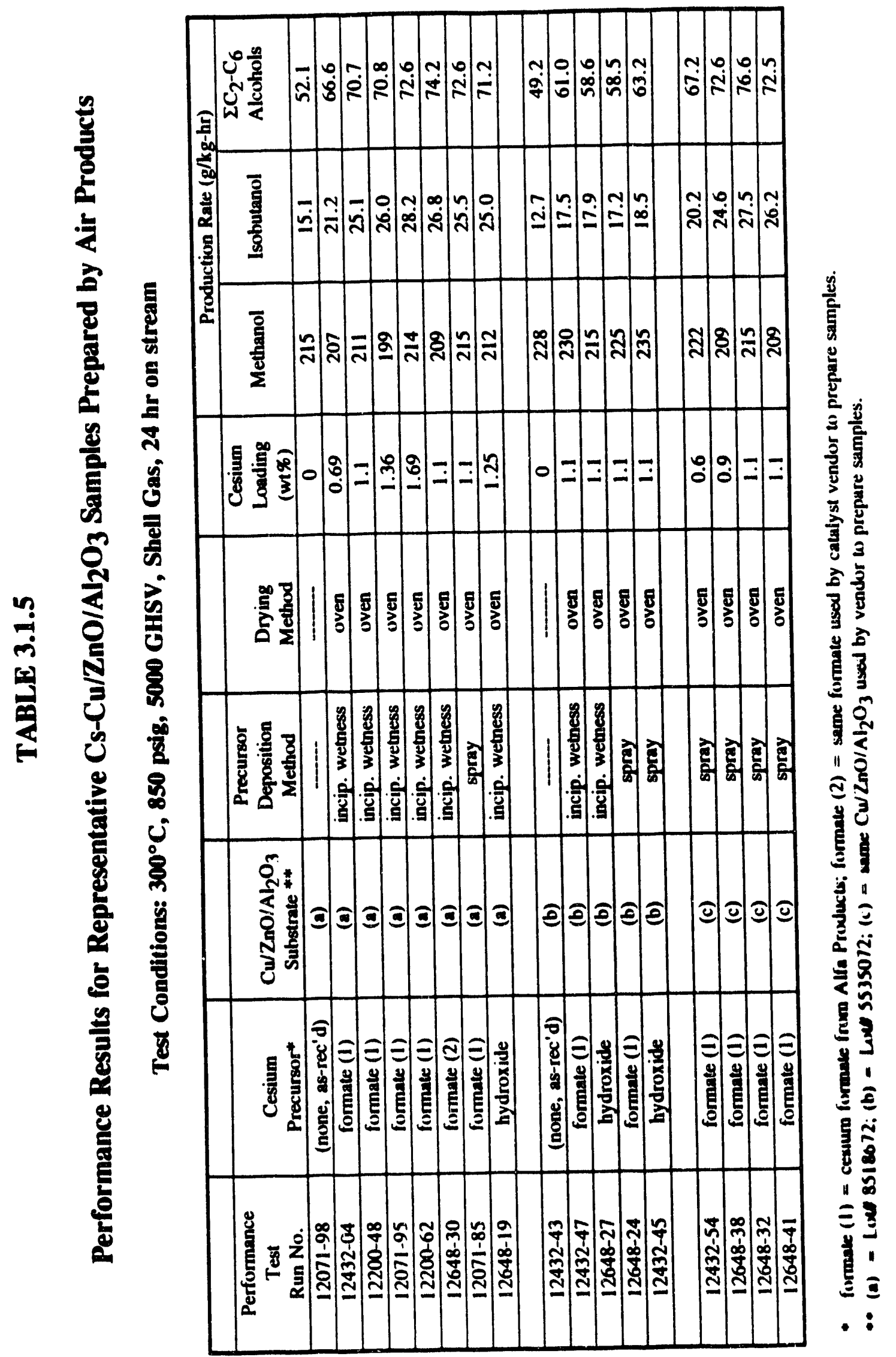


The $\mathrm{Cs}-\mathrm{Cu} / \mathrm{ZnO} / \mathrm{Al}_{2} \mathrm{O}_{3}$ samples prepared by the vendor range in $\mathrm{Cs}$ loading from 0.8 wt\% to 1.5 wt\% (see Table 3.1.4). These samples were prepared using the two different drying methods: in an impregnator and in an oven. The first issue worth noting about the performance results in Table 3.1 .4 is the large degree of inconsistency in the results, particularly in the isobutanol and $\Sigma C_{2}-C_{6}$ alcohols rates. For example, the isobutanol rate ranges from 7.2 to $21.8 \mathrm{~g} / \mathrm{kg}$-hr for these $\mathrm{Cs}-\mathrm{Cu} /$ $\mathrm{ZnO} / \mathrm{Al}_{2} \mathrm{O}_{3}$ samples. A second issue is that the performance of all of these samples is significantly below that which was expected based on results of samples prepared at Air Products. Based on results obtained with Air Products-prepared samples, an isobutanol rate of at least $25 \mathrm{~g} / \mathrm{kg}$-hr and a $\Sigma \mathrm{C}_{2}-\mathrm{C}_{6}$ alcohols rate of at least $70 \mathrm{~g} / \mathrm{kg}-\mathrm{hr}$ at the indicated "standard" reaction conditions are considered to be the performance criteria.

Samples prepared at Air Products were produced using all three lots of $\mathrm{Cu} / \mathrm{ZnO} / \mathrm{Al}_{2} \mathrm{O}_{3}$ catalyst substrate and three different cesium precursors. A large portion of the samples shown in Table 3.1.5 were prepared in an attempt to identify why the vendor-prepared samples had low and inconsistent performance. The results in Table 3.1.5 are presented in three groups, each group corresponding to a different $\mathrm{Cu} / \mathrm{ZnO} / \mathrm{Al}_{2} \mathrm{O}_{3}$ substrate production lot. The early results obtained at Air Products, which prompted interest in this particular catalyst for isobutanol and mixed alcohols synthesis, were obtained on samples prepared using $\mathrm{Cu} / \mathrm{ZnO} / \mathrm{Al}_{2} \mathrm{O}_{3}$ substrate of lot\# 8518672, designated (a) in Table 3.1.5. As can be seen, consistent results were obtained, which established the aforementioned performance criteria for this catalyst. In addition, it is noteworthy that a sample prepared using cesium hydroxide precursor (\#12648-19) showed similar performance to those prepared using formate. Also, a sample prepared (\#12648-30) using the same cesium formate that the vendor used showed high performance consistent with the other lab samples. This result strongly suggests that the cesium precursor (i.e., supplier) is not responsible for the low performance results obtained for the vendor-prepared samples.

Table 3.1.5 also shows results obtained for samples prepared at $\mathrm{Air}$ Products using $\mathrm{Cu} / \mathrm{ZnO} / \mathrm{Al}_{2} \mathrm{O}_{3}$ substrate from production lot\# 5535072. These samples were prepared at $1.1 \mathrm{wt} \% \mathrm{Cs}$ using the two different cesium deposition techniques with formate or hydroxide as the cesium precursor. As shown in Table 3.1.5, the performance results are consistent, but the level of performance is below that which was expected based on the samples prepared using $\mathrm{Cu} / \mathrm{ZnO} / \mathrm{Al}_{2} \mathrm{O}_{3}$ substrate designated (a). These results indicate that the particular lot of $\mathrm{Cu} / \mathrm{ZnO} / \mathrm{Al}_{2} \mathrm{O}_{3}$ substrate used has an impact on the final result. One possible reason is that the surface properties, perhaps the surface acidity, of the $\mathrm{Cu} / \mathrm{ZnO} / \mathrm{Al}_{2} \mathrm{O}_{3}$ substrate may differ from lot to lot, raising the possibility that the optimum cesium loading may be different depending on the particular lot. Surface acidity can vary with variation of the $\mathrm{Al}_{2} \mathrm{O}_{3}$ content of the substrate. Indeed, examination of the product distribution for the samples prepared using $\mathrm{Cu} / \mathrm{ZnO} / \mathrm{Al}_{2} \mathrm{O}_{3}$ substrate $(\mathrm{b})$ indicates that the cesium loading is too low for these samples.

The results described above for samples prepared using $\mathrm{Cu} / \mathrm{ZnO} / \mathrm{Al}_{2} \mathrm{O}_{3}$ substrate (b) indicate that a possible reason why the vendor prepared samples had low performance was because of differences in the $\mathrm{Cu} / \mathrm{ZnO} / \mathrm{Al}_{2} \mathrm{O}_{3}$ substrate used. However, the results shown in Table 3.1.5 for samples prepared at Air Products using substrate (c), the same substrate used by the vendor, indicate that the 
$\mathrm{Cu} / \mathrm{ZnO} / \mathrm{Al}_{2} \mathrm{O}_{3}$ substrate is not the culprit. The four samples prepared at Air Products using substrate (c) showed consistently high performance, very much in line with the results for samples prepared at Air Products using substrate (a). Note that the $0.6 \mathrm{wt} \%$ Cs sample exhibits slightly lower performance, but has a cesium loading outside the optimum range (considered to be $1-1.5 \mathrm{wt} \% \mathrm{Cs}$ ).

The collective results in Tables 3.1.4 and 3.1.5 do not give a clear indication as to why samples prepared by the vendor gave inconsistent and lower than acceptable performance. At this point it appears that the reason lies in some subtle difference in preparation technique, an issue that can most likely be resolved by direct interaction with the catalyst vendor's technical staff. This will take place early in the next quarter. Thus, scale-up of the preparation of this catalyst was not ready in time to proceed with the scheduled isobutanol AFDU run in April 1992. The isobutanol run will be rescheduled for a later date.

\section{Lower Alcohols Recycle on Cs-Promoted Cu/ZnOIAl $\mathrm{O}_{3}$ Catalyst:}

Recycle of $\mathrm{C}_{1}-\mathrm{C}_{3}$ product alcohols during isobutanol synthesis on $\mathrm{Cs}$-promoted $\mathrm{Cu} / \mathrm{ZnO} / \mathrm{Al}_{2} \mathrm{O}_{3}$ was experimentally investigated by injecting alcohols into the autoclave reactor syngas feed. The addition of methanol alone, a mixture of methanol, ethanol and 1-propanol, and a mixture of ethanol and 1-propanol was done and the product rates were compared to the case of syngas only feed. All experiments were done using Shell syngas at $300^{\circ} \mathrm{C}, 850 \mathrm{psig}$, and $5000 \mathrm{GHSV}$.

The $300 \mathrm{cc} \# 1$ autoclave reactor system was used for this investigation. Since this system is not equipped with downstream separation equipment or recycle equipment, recycle of alcohols was simulated by addition of alcohols to the feed syngas. Alcohol addition was done by feeding pure liquid alcohol, or a mixture of alcohols, by a high pressure syringe pump to a heated feed vaporizer. In the feed vaporizer the liquid alcohol stream was vaporized into the feed syngas stream. Some attempts were made to simulate total recycle of particular alcohol products. Determination of the pump rate and composition of the liquid stream is obviously an iterative process, since, for the total recycle situation, the rate of addition must equal the rate of production of that alcohol or alcohols at the reactor exit. The match is fairly close for some of the experiments reported here.

The catalyst used was 1.25 wt\% $\mathrm{Cs}$ on $\mathrm{Cu} / \mathrm{ZnO} / \mathrm{Al}_{2} \mathrm{O}_{3}$ prepared by the incipient wetness technique. The sample was reduced in situ using dilute syngas in $\mathrm{N}_{2}$. The reaction conditions used were: Shell syngas feed, $300^{\circ} \mathrm{C}, 850 \mathrm{psig}$, and a GHSV (based on syngas) of $5000 \mathrm{std}$. lie/kg-hr. The reactor was run at the above conditions throughout the experiments. Periodically, the product rates were determined for the case of no alcohol addition to gather information on catalyst stability and also to provide a basis for comparison for runs involving alcohol addition.

Figure 3.1.10 shows the major product rates as a function of on-stream time for the periodic runs for no alcohol addition. The catalyst deactivated at a slightly higher rate than that observed for samples run in the microclave reactors. A couple of possible reasons are that alcohol addition may increase the deactivation rate or that the new vaporizer used was not fully passivated for carbonyl production 


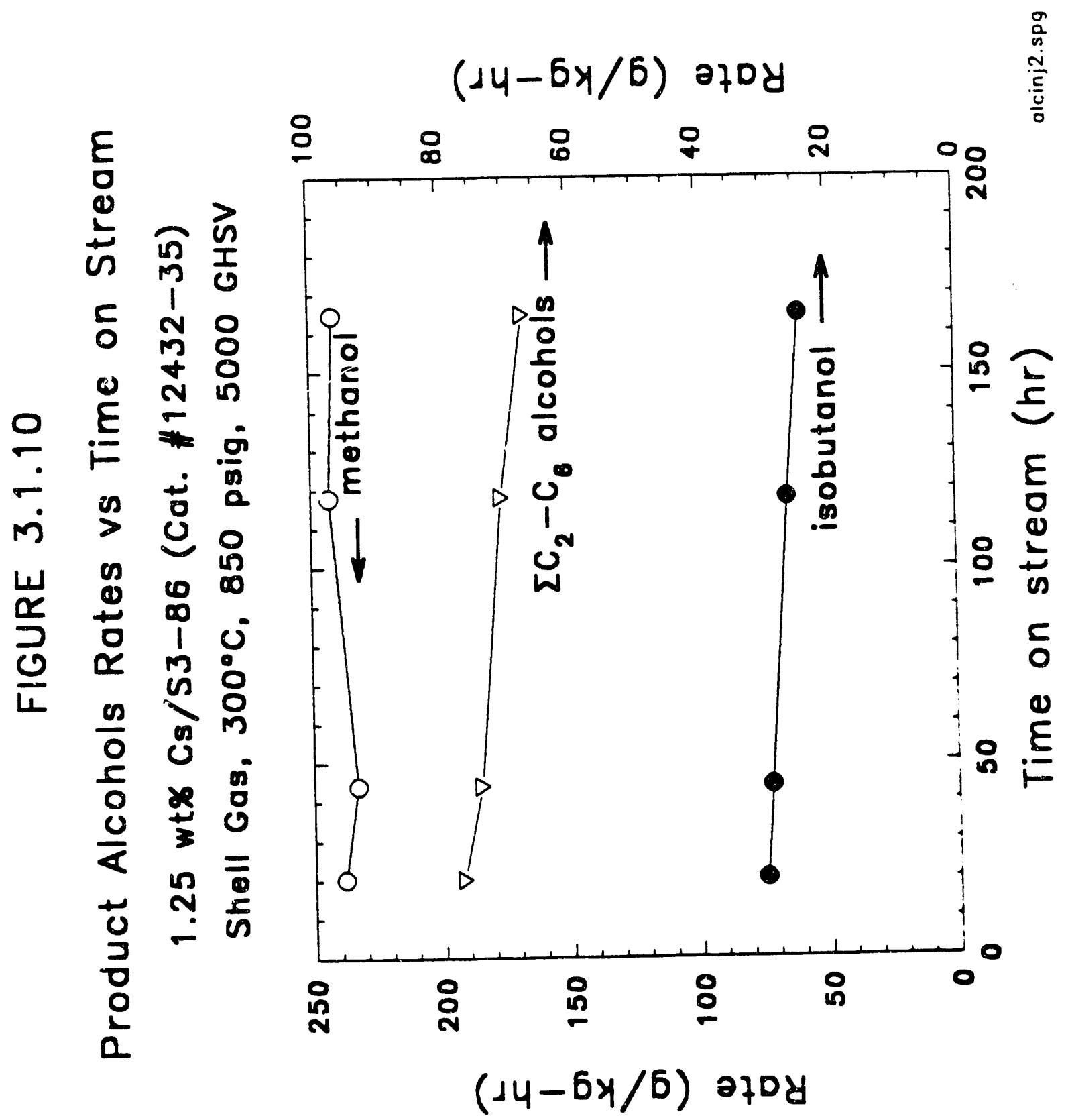


during the runs. In a previous attempt at an experiment, the catalyst sample deactivated extremely rapidly upon heat-up of the feed vaporizer, indicating that it was not passivated. After this previous run, an attempt was made to passivate the vaporizer by heating in flowing syngas for several hours. Whether the vaporizer was sufficiently passivated is not known at this time. In any case, the deactivation rate was low enough to render the results useful.

The other point to make regarding Figure 3.1.10 is that the alcohols rates observed are higher than those observed in the microclave reactors. For example, after 20 hours on stream, the isobutanol rate observed in this study was $30 \mathrm{~g} / \mathrm{kg}$ - hr, compared to $26 \mathrm{~g} / \mathrm{kg}$-hr measure in the microclave. This is probably a result of the mixing or gas-liquid contacting deficiency which is characteristic of the microclaves, a deficiency observed in the past.

Methanol addition to the feed was investigated. The results for this experiment, along with a run done without methanol addition (for comparison), are shown in Table 3.1.6. The rate of methanol addition for this experiment was less than that corresponding to total methanol recycle, actually corresponding to the production rate without methancl addition. As can be seen, the addition of methanol substantially increased the rate of production of ethanol and 1-propanol, while resulting in only a modest increase in isobutanol rate. The ethanol plus 1-propanol rate increased by $38 \%$ upon methanol addition, but the isobutanol rate increased by only $10 \%$. The rate of production of all $\mathrm{C}_{2}-\mathrm{C}_{6}$ alcohols increased by $22 \%$ upon methanol addition.

TABLE 3.1.6

Addition of Methanol to Feed

Reaction Conditions: Shell gas, $300^{\circ} \mathrm{C}, 850 \mathrm{psig}, 5000 \mathrm{GHSV}$

\begin{tabular}{|l|c|c|c|c|c|c||}
\hline & \multirow{2}{*}{} & \multicolumn{5}{|c|}{ Rate (g/kg-hr) } \\
\cline { 3 - 7 } & Time on & & & & & $\mathrm{C}_{2}-\mathrm{C}_{6}$ \\
& Stream (hr) & $\mathrm{MeOH}$ & $\mathrm{EtOH}$ & $1-\mathrm{PrOH}$ & $\mathrm{i}-\mathrm{BuOH}$ & alcohols \\
\hline No alcohol addition & 44 & 233 & 12.6 & 14.2 & 28.9 & 74 \\
Alcohol addition & 47 & 324 & 17.7 & 19.2 & 31.7 & 90 \\
(Alcohol addition rate) & & 233 & 0 & 0 & -- & 0 \\
\hline
\end{tabular}

If the synthesis of higher alcohols occurs by a sequential homologation mechanism, as the literature suggests, then the fact that methanol addition has the largest impact on the ethanol rate is quite reasonable. Perhaps greater incorporation of methanol into products higher than ethanol would occur at lower GHSV (higher reactor residence time).

Table 3.1.7 shows results for the addition of a mixture of methanol, ethanol, and 1-propanol; an attempt to simulate total recycle of these three products. A fairly good match between the methanol, ethanol, and 1-propanol production rates and the rates of addition of these products was obtained, indicating a situation quite close to total recycle of these products. Addition of the mixture of these alcohols results in a much larger increase in isobutanol rate than that for methanol addition alone. The isobutanol rate increases by $60 \%$ upon addition of this alcohol mixture to the feed. The $C_{4+}$ 
liquid product obtained in this simulated total recycle of $C_{1}-C_{3}$ alcohols would contain an estimated $56 w t \%$ isobutanol, with the balance of the liquid products being esters and $C_{s_{+}}$alcohols.

TABLE 3.1.7

Addition of Mixture of Methanol, Ethanol, and 1-Propanol to Feed Reaction Conditions: Shell gas, $300^{\circ} \mathrm{C}, 850 \mathrm{psig}, 5000 \mathrm{GHSV}$

\begin{tabular}{||l|c|l|l|l|l|c||}
\hline & \multirow{2}{*}{\begin{tabular}{c} 
Time on \\
\cline { 3 - 7 }
\end{tabular}} & & \multicolumn{5}{|c|}{ Rate (g/kg-hr) } & $\begin{array}{c}\Sigma_{2}-\mathrm{C}_{6} \\
\text { alcohols }\end{array}$ \\
\hline Stream (hr) & $\mathrm{MeOH}$ & $\mathrm{EtOH}$ & $1-\mathrm{PrOH}$ & $\mathrm{i}-\mathrm{BuOH}$ & 70 \\
No alcohol addition & 118 & 243 & 12.4 & 13.7 & 26.1 & 122 \\
Alcohol addition & 122 & 359 & 25.8 & 33.2 & 41.7 & 57.8 \\
(Alcohol addition rate) & & 332 & 27.3 & 30.5 & -- & \\
\hline
\end{tabular}

The addition of a mixture of ethanol and 1-propanol, to simulate recycle of these products without methanol, was also investigated. The results of this experiment are shown in Table 3.1.8. For this experiment also, the rates of addition of ethanol and 1-propanol are quite close to the rates of production, indicating that this condition closely simulates total recycle of these products. The isobutanol rate increased from 24.1 , for syngas alone, to 34.1 upon addition of ethanol and 1-propanol, a $41 \%$ increase in rate. This is significantly lower than the $60 \%$ increase observed for the case of addition of methanol, ethanol, and 1-propanol (see Table 3.1.7). The reason why the isobutanol rate is higher for the case when methanol is also recycled is probably primarily that methanol recycle increases the ethanol and 1-propanol available for recycle. Recall that the results in Table 3.1.6, for the recycle of methanol alone, indicate that methanol addition substantially increases the ethanol and 1-propanol rates.

TABLE 3.1.8

Addition of Mixture of Ethanol and 1-Propanol to Feed

Reaction Conditions: Shell gas, $300^{\circ} \mathrm{C}, 850 \mathrm{psig}, 5000 \mathrm{GHSV}$

\begin{tabular}{||l|c|c|c|c|c|c||}
\hline & \multirow{2}{*}{\begin{tabular}{c} 
Time on \\
\cline { 3 - 7 }
\end{tabular}} & \multicolumn{6}{|c||}{ Stream (hr) } & $\mathrm{MeOH}$ & $\mathrm{EtOH}$ & $1-\mathrm{PrOH}$ & $\mathrm{i}-\mathrm{BuOH}$ & $\begin{array}{c}\Sigma \mathrm{C}_{2}-\mathrm{C}_{6} \\
\text { alcohols }\end{array}$ \\
\hline No alcohol addition & 165 & 241 & 12.4 & 13.4 & 24.1 & 66 \\
Alcohol addition & 169 & 239 & 17.0 & 22.7 & 34.1 & 92 \\
(Alcohol addition rate) & & 0 & 18.6 & 20.6 & -- & 39.2 \\
\hline
\end{tabular}

The results in the last column of Table 3.1.8 indicate that all of the added ethanol and 1-propanol was not incorporated into only $\mathrm{C}_{2}-\mathrm{C}_{6}$ alcohols. Specifically, the sum of the alcohol addition rate plus the rate of production of $\mathrm{C}_{2}-\mathrm{C}_{6}$ alcohols for syngas feed is larger than the production rate of $\mathrm{C}_{2}-\mathrm{C}_{6}$ alcohols during alcohol addition. A small portion of the added alcohols is incorporated into other products: alcohols greater than $C_{6}$ and hydrocarbons. The results in Table 3.1.8 indicate that recycle of ethanol and 1-propanol is a technically viable means of increasing isobutanol productivity. 
Literature Search on the Dehydration of 2-Methyl-1-Alkanols:

We completed the literature search on the dehydration of 2-methyl-1-alkanols, in particular isobutanol, to their corresponding olefins. A report was issued on 24 March and it is attached as Appendix 3.

From the literature search, several catalysts were identified for lab screening evaluations. These catalysts include gamma aluminas, calcium phosphate (hydroxyapatite) and zirconium sulfate. Alumina is the most widely used dehydration catalyst that has been implemented into at least two pilot plant evaluations for the dehydration of isoamyl alcohol.

The bulk of the work in the literature has been carried out in packed-bed reactors under reaction conditions of $300-400^{\circ} \mathrm{C}$ and atmospheric pressure. A limited amount of literature describes a process for the dehydration of tert-butyl alcohol using a slurry reactor.

\section{Liquid Phase Water-Gas Shift Lab Experiments:}

In support of the AFDU demonstration of the liquid phase shift process, two experiments were performed in the lab using a $300 \mathrm{cc}$ stirred autoclave. The first experiment (Run \#11782-58) used ground-up (-200 mesh) BASF K3-110 low temperature shift catalyst and the second experiment used the "LaPorte catalyst". The second experiment (Run \#11782-63) was actually a "quality control" test of the LaPorte catalyst batch, a powder K3-110 catalyst.

Dilute syngas was used to activate the catalyst in both experiments. The activation procedure was identical to that for a methanol catalyst as described in the finial report of a prior DOE contract, Contract \# DE-AC22-87PC90005. Figure 3.1.11 shows typical cumulative changes of $\mathrm{H}_{2}, \mathrm{CO}, \mathrm{H}_{2} \mathrm{O}$, and $\mathrm{CO}_{2}$ over the period of the catalyst activation. The total consumption of $\mathrm{H}_{2}$ and $\mathrm{CO}$ was around $1.6 \mathrm{scf} / \mathrm{b}$-catalyst. It should be pointed out that the water numbers are not quantitative because the analytical equipment (GC) was not calibrated for accurate water analysis.

The activity of these catalysts are comparable. Both catalysts were first tested for their methanol activity using Texaco gas. The powder catalyst (Run \#11782-63) seemed to have slightly higher activity and produce more by-products. After the initial methanol synthesis, steam was introduced to continue the water-gas shift reaction.

Several water-gas shift conditions were tested on the ground-up catalyst in Run \#11782-58. Run \#11782-58B through \#11782-58I include results using both Texaco gas and Shell gas as the feed. Detailed results and material balances are shown in Appendix 4.

Only one water-gas shift experiment was conducted on the powder K3-110 catalyst. Run 11782-63C summarizes the result using Texaco gas as the feed. The test suggested that the powder K3-110 has similar activity to its ground-up counterpart, and the data obtained from both catalysts can be used to predict the performance for the AFDU. 


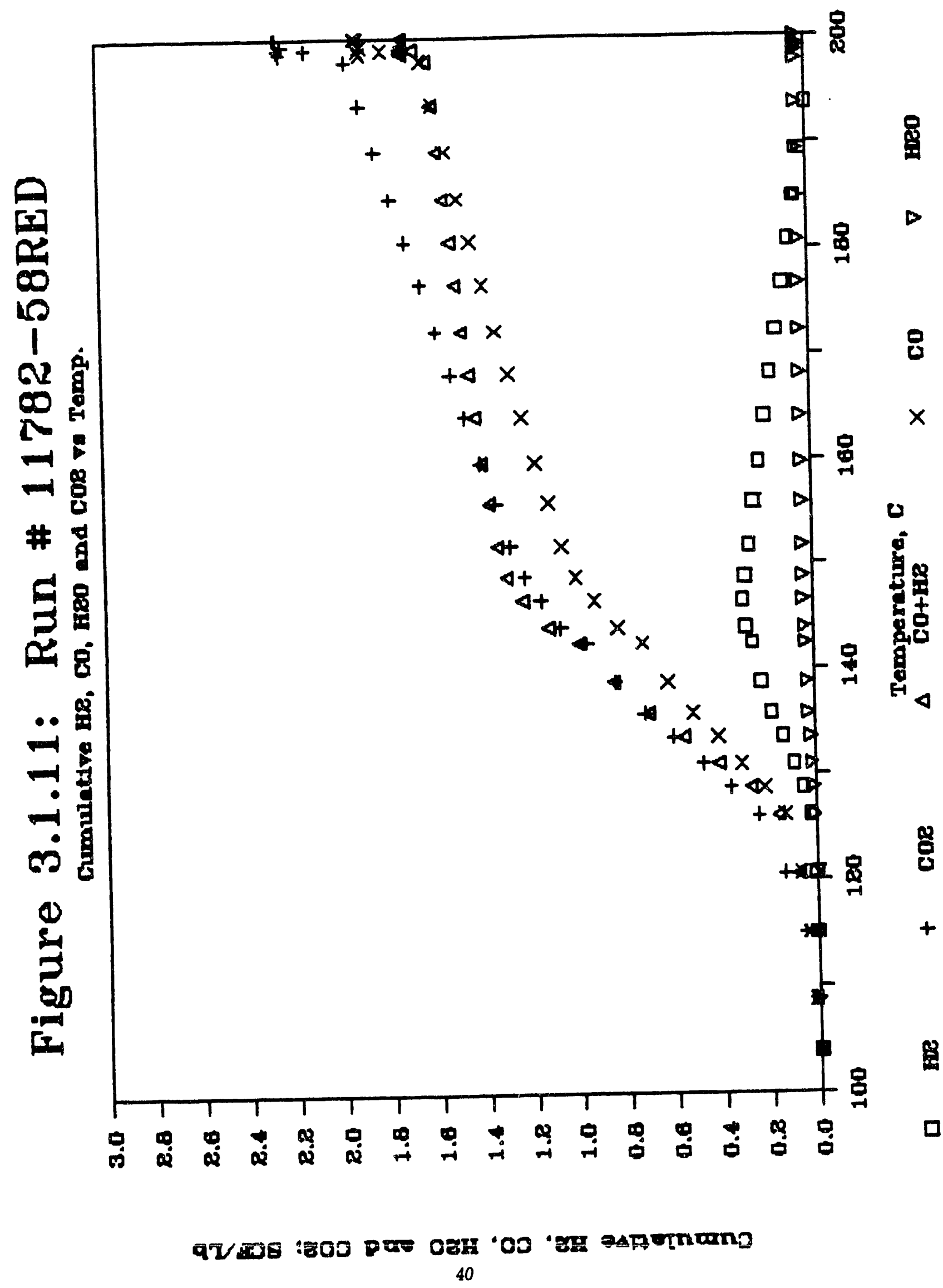




\section{Task 3.2 New Fuels From Dimethyl Ether (DME)}

\section{Overall 2QFY'92 Objectives}

The following set of objectives appeared in Quarterly Technical Progress Report No. 5.

- Continue modifying the mass balance $\left(\mathrm{C}\right.$ and $\left.\mathrm{H}_{2}\right)$ for the DME to isobutanol scheme.

- Define a series of catalyst compositions of one of the screened catalysts for a reactor parameter determination in the BTRS.

- Develop an octane number database for establishing a structure vs. octane number correlation.

\section{Laboratory Reactor Procurement}

- An existing Varian $6000 \mathrm{GC}$ was modified to act as a pulse/adsorption reactor to study the reaction of dimethyl ether, oxygen, and methanol with basic catalysts.

- A Management of Change was issued to change the original PHR for the dual atmospheric screening reactors to include the dehydration of isobutanol to butenes.

\section{Chemistry and Catalyst Development}

During this quarter, research activity has been split between 1) the conversion of dimethyl ether and oxygen to isobutanol, and 2) dehydration of isobutanol to isobutylene.

\section{Catalyst Screening for Isobutanol}

A series of lanthanide group oxides were screened for the conversion of DME and methanol to isobutanol. $\operatorname{Pr}_{6} \mathrm{O}_{11}, \mathrm{Nd}_{2} \mathrm{O}_{3}$, and $\mathrm{Eu}_{2} \mathrm{O}_{3}$ were active, while $\mathrm{Sm}_{2} \mathrm{O}_{3}$ was not. The chemistry is outlined in eqn. 1 or $1^{\prime}$.

$$
\begin{aligned}
& \mathrm{CH}_{3} \mathrm{OCH}_{3}+2 \mathrm{CH}_{3} \mathrm{OH} \rightarrow\left(\mathrm{CH}_{3}\right)_{2} \mathrm{CHCH}_{2} \mathrm{OH}+2 \mathrm{H}_{2} \mathrm{O} \\
& 2 \mathrm{CH}_{3} \mathrm{OCH}_{3} \rightarrow\left(\mathrm{CH}_{3}\right)_{2} \mathrm{CHCH}_{2} \mathrm{OH}+\mathrm{H}_{2} \mathrm{O}
\end{aligned}
$$

Atmospheric pressure gas phase reaction experiments were conducted at $300^{\circ}$ to $450^{\circ} \mathrm{C}$ with 2 or 20 grams of catalyst. The dimethyl ether to oxy gen ratio was varied between 5:1 and 50:1. Total flow rate was varied between 5 and $100 \mathrm{sccm}$. Contact times were on the order of $1-30$ seconds. $\operatorname{Pr}_{6} \mathrm{O}_{11}$ powder was pressed and sieved to $1 \mathrm{~mm}$ sized particles.

Reaction studies at $300 \mathrm{psig}$ were performed at $300^{\circ}$ to $450^{\circ} \mathrm{C}$ with 10 grams of catalyst. The oxygen was supplied from a $10 \%$ oxygen/nitrogen cylinder. Contact imes were on the order of 1 20 seconds. 
TABLE 3.2.1

Conversion of Dimethyl Ether and Oxygen over Basic Catalysts

\begin{tabular}{|l|c|c|c|c|c|c|c|c|c||}
\hline \multirow{2}{*}{ Catalyst } & Press & Contact & DME & \multicolumn{5}{|c|}{ Weight \% Selectivity } \\
atm & Time & Conv. & i-BuOH & DMET & $\mathrm{CH}_{3} \mathrm{OH}$ & $\mathrm{CO}$ & $\mathrm{CO}_{2}$ & $\mathrm{CH}_{4}$ \\
\hline $2 \mathrm{~g} \mathrm{Pr}_{6} \mathrm{O}_{11}$ & 1 & 1 & 8 & 0.3 & 0.0 & 30 & 22 & 28 & 1 \\
$20 \mathrm{~g} \mathrm{Pr}_{6} \mathrm{O}_{11}$ & 1 & 26 & 8 & 0.2 & 0.0 & 30 & 23 & 25 & 1 \\
& 1 & 5 & 8 & 0.4 & 0.1 & 34 & 21 & 25 & 2 \\
$10 \mathrm{~g} \mathrm{Pr}_{6} \mathrm{O}_{11}$ & 20 & 13 & 14 & 0.6 & 2.6 & 24 & 26 & 23 & 16 \\
$10 \mathrm{~g} 5 \% \mathrm{Li} / \mathrm{MgO}^{20}$ & 26 & 11 & 2.6 & 2.3 & 24 & 24 & 28 & 14 \\
$10 \mathrm{~g} \mathrm{3 \%} \mathrm{Sn/MgO}$ & 20 & 4 & 11 & 0.4 & 3.4 & 38 & 18 & 25 & 9 \\
& 20 & 26 & 12 & 0.6 & 2.5 & 14 & 23 & 36 & 18 \\
\hline
\end{tabular}

Temperature $400^{\circ} \mathrm{C}$

Feed Composition: $1 \mathrm{atm:} 8 \% \mathrm{O}_{2}, 92 \%$ DME

$20 \mathrm{~atm}: 5 \% \mathrm{O}_{2}, 50 \% \mathrm{DME}, 45 \% \mathrm{~N}_{2}$

Under these conditions both DME and $\mathrm{O}_{2}$ were required for the formation of isobutanol. Addition of methanol slightly increased the formation of isobutanol. The coupling product of two DME molecules, 1,2-dimethoxyethane, is dependent upon concentration. This product has been observed at pressures as low as 1.5 atmospheres.

Experiments with an empty reactor tube indicated that $100 \%$ of the $\mathrm{CO}_{2}$ and $50 \%$ of the $\mathrm{CO}$ formation was due to thermal oxidation of the DME, either in the gas phase or on the hot walls of the reactor. Passing a solution of $1 \%$ isobutanol/methanol through an empty reactor resulted in combustion on $75 \%$ of the isobutanol. The apparent independence of catalyst loading and flow rate on the isobutanol yield indicate that oxidation of DME on the walls or in the gas phase of the reactor is responsible for most of the conversion in the screening studies. Attempts to minimize these effects through reactor configuration have been unsuccessful to date.

Concentration of the reactor effluent revealed traces of acetaldehyde, ethanol, 1-propanol and 1,2-dimethoxyethane. The existence of trace amounts of acetaldehyde, ethanol, and propanol suggest that these are intermediates in the formation of isobutanol. A sequential reaction scheme utilizing aldol condensation/dehydration reactions as demonstrated in the literature could be formulated (Appl. Cat, 77 (1991), 123, and Wang and Lee, J. Chem. Soc., Chem. Comm, (1991), 1760).

$$
\begin{aligned}
& \mathrm{CH}_{3} \mathrm{CH}_{2} \mathrm{OH} \stackrel{-\mathrm{H}_{2}}{\rightarrow} \mathrm{CH}_{3} \mathrm{CHO} \stackrel{\mathrm{HCHO}}{\rightarrow} \mathrm{CH}_{2}=\mathrm{CHCHO} \stackrel{\mathrm{H}_{2}}{\rightarrow} \mathrm{CH}_{3} \mathrm{CH}_{2} \mathrm{CHO} \stackrel{\mathrm{HCHO}}{\rightarrow} \\
& \mathrm{CH}_{2}=\mathrm{C}\left(\mathrm{CH}_{3}\right) \mathrm{CHO} \stackrel{\mathrm{H}_{2}}{\rightarrow}\left(\mathrm{CH}_{3}\right)_{2} \mathrm{CHCHO} \stackrel{\mathrm{H}_{2}}{\rightarrow}\left(\mathrm{CH}_{3}\right)_{2} \mathrm{CHCH}_{2} \mathrm{OH}
\end{aligned}
$$


Ethanol was added to the feed so that the concentration was about $1 \%$. Ninety percent of the ethanol was converted at 7 second contact time; the amount of isobutanol in the product increased from $0.3 \%$ to $0.5 \%$ and the propanol content was measurable. At 2 second contact time $50 \%$ of the ethanol was converted and the isobutanol content was still $0.5 \%$, but the amount of propanol increased to $0.5 \%$. Most of the ethanol was converted to propanol and isobutanol, supporting the reaction scheme above. Increasing the concentration of ethanol in the feed to 5\% resulted in the formation of many products which were assumed to be the result of cross-condensation reactions occurring over the basic catalyst support.

Addition of acetaldehyde to the feed produced an identical response as ethanol addition. The acetaldehyde in the exit stream (estimated at $0.2 \%$ of the product) was the same whether the amount in the feed was $0 \%, 1 \%$ or $5 \%$. Ethanol, propanol and isobutanol yields increased with the addition of acetaldehyde to the feed. Trace amounts of isobutyraldehyde and propionaldehyde were also observed.

Addition of methanol to the feed also effected an increase in the amount of isobutanol formed. The isobutanol yield is a maximum when the methanol in the hydrocarbon feed is between 10 and $40 \%$. The addition of methanol provided a source for the formaldehyde.

TABLE 3.2.2

Effect of Methanol Cofeed on the Conversion of Dimethyl Ether and Oxygen

\begin{tabular}{|c|c|c|c|c|c|c|c|}
\hline \multirow{2}{*}{$\begin{array}{c}\text { MeOH: } \\
\text { DME }\end{array}$} & \multirow{2}{*}{$\begin{array}{l}\text { DME } \\
\text { Conv. }\end{array}$} & \multirow{2}{*}{$\begin{array}{l}\text { MeOH } \\
\text { Conv. }\end{array}$} & \multicolumn{5}{|c|}{ Weight \% Selectivity } \\
\hline & & & $\mathrm{i}-\mathrm{BuOH}$ & $\mathrm{CH}_{3} \mathrm{OH}$ & $\mathrm{CO}$ & $\mathrm{CO}_{2}$ & $\mathrm{CH}_{4}$ \\
\hline $0: 1$ & 7.7 & - & 0.28 & 30 & 23 & 28 & 1.0 \\
\hline $1: 8$ & 7.9 & 0.0 & 0.45 & 22 & 27 & 29 & 0.9 \\
\hline $1: 5$ & 7.5 & 0.0 & 0.54 & 14 & 29 & 30 & 0.8 \\
\hline $2: 3$ & 6.4 & 5.4 & 0.45 & - & 33 & 28 & 0.8 \\
\hline $1: 1$ & 7.9 & 7.5 & 0.38 & - & 25 & 32 & 0.9 \\
\hline
\end{tabular}

Temperature: $\quad 400^{\circ} \mathrm{C}, 1$ atmosphere

Feed Composition: $8 \% \mathrm{O}_{2}, 92 \% \mathrm{DME}, 18 \mathrm{sccm}$

$2 \mathrm{~g} \mathrm{Pr}_{6} \mathrm{O}_{11}$ : Contact time $\sim 1$ second

The overall conversion of DME was directly related to the amount of $\mathrm{O}_{2}$ in the feed. The yield of isobutanol was a maximum when the feed contained between 8 and $12 \% \mathrm{O}_{2}$. Dimethoxyethane formation decreased to zero when the $\mathrm{O}_{2}$ content was above $12 \%$. The formation of methanol decreased with increase in $\mathrm{O}_{2}$ content, while the $\mathrm{H}_{2} \mathrm{O}$ formation increased. 
TABLE 3.2.3

Effect of Oxygen Concentration on the Conversion of Dimethyl Ether over Basic Catalysts

\begin{tabular}{||c|c|c|c|c|c|c||}
\hline \multirow{2}{*}{$\begin{array}{l}\text { Oxygen } \\
\text { mol \% }\end{array}$} & \multirow{2}{*}{$\begin{array}{c}\text { DME } \\
\text { Conv. }\end{array}$} & \multicolumn{5}{|c||}{ Weight \% Selectivity } \\
\cline { 3 - 7 } & & $\mathrm{i}-\mathrm{BuOH}$ & $\mathrm{CH}_{3} \mathrm{OH}$ & $\mathrm{CO}$ & $\mathrm{CO}_{2}$ & $\mathrm{CH}_{4}$ \\
\hline 2 & 2.5 & 0.24 & 34 & 24 & 28 & 3.0 \\
4 & 4.3 & 0.29 & 33 & 23 & 29 & 1.9 \\
8 & 7.7 & 0.28 & 30 & 23 & 28 & 1.0 \\
16 & 14.5 & 0.14 & 24 & 26 & 25 & 0.4 \\
\hline
\end{tabular}

Temperature:

$400^{\circ} \mathrm{C}, 1$ atmosphere

Feed Composition: $\mathrm{O}_{2}$ varied, DME balance, $18 \mathrm{sccm}$

$2 \mathrm{~g} \mathrm{Pr}_{6} \mathrm{O}_{11}$ :

Contact time $\sim 1$ second

\section{a. Aldol Condensation/Dehydration Reactions to Isobutanol}

The cesium-promoted catalyst to be used in the LaPorte pilot plant for the higher alcohols campaign was used in the gas-phase atmospheric pressure reactor to screen aldol condensation/dehydration conditions and products. Two grams of the catalyst were reduced in a $2 \% \mathrm{H}_{2} / \mathrm{He}$ stream using standard conditions. Reactions were carried out with a $5 \mathrm{wt} \%$ ethanol in methanol feed diluted to 10 and $50 \%$ in $\mathrm{N}_{2}$. Total flow rates were either 20 or $100 \mathrm{ccm}$.

Because of the low pressure, methanol conversion was complete at $300^{\circ} \mathrm{C}$. At $250^{\circ} \mathrm{C}$ the methanol conversion ranged between 60 and $90 \%$ depending upon the flow rate. The total ethanol conversion was $100 \%$ at $300^{\circ} \mathrm{C}$ and $90 \%$ at $250^{\circ} \mathrm{C}$; however, the conversion to products positively identified as the result of the above reaction scheme was much less: $15 \%$ at $300^{\circ} \mathrm{C}$ and $40 \%$ at $250^{\circ} \mathrm{C}$.

The major hydrocarbon product at all conditions was isobutyl alcohol; however, significant amounts of isobutyraldehyde, propanol, and methyl acetate were also detected. Other unidentified products were also detected. The unidentified products had GC retention times around the isobutyl alcohol peak and were assumed to be the result of aldol condensation of the $C_{2}$ and $C_{3}$ aldehydes. Although analyses of the above results are complicated due to the activity of the catalyst, these experiments provide a basis for comparison with other potential catalysts.

Praseodymium oxide, which was shown to be active for the conversion of DME to isobutyl alcohol, was tested under similar conditions of ethanol in methanol. The conversion of ethanol to isobutyl alcohol and related alcohols and aldehydes was approximately $1 \%$ in the absence of $\mathrm{O}_{2}$. When $5 \%$ $\mathrm{O}_{2}$ was added to the reactor feed, the conversion of ethanol was $40 \%$, with about $30 \%$ selectivity to oxidative addition products. In the absence of $\mathrm{O}_{2}$ co-feed, reoxidized catalyst produced a similar amount of oxidative addition products showing that adsorbed or lattice $\mathrm{O}_{2}$ may participate in the reaction. 
b. $\mathrm{Eu}_{2} \mathrm{O}_{3}$ Catalyst

With $\mathrm{Eu}_{2} \mathrm{O}_{3}$ at $400^{\circ} \mathrm{C}, 8.2 \%$ of DME reacted with $1.1 \%$ DME going to isobutanol, $62 \%$ to $\mathrm{CO}, 35 \%$ to $\mathrm{CO}_{2}$ and balance methane. Carbon accountability was $90 \%$. Hydrogen accountability was $74 \%$.

Catalyst Screening for Dehydration of Isobutanol

Some of the preliminary findings on dehydration are summarized in Table 3.2.4. Gas phase conditions (flow and cat. amt.) have been adjusted to give $\sim 1$ second contact time in order to compare with the slurry phase reactor at Iron $\mathrm{Run} . \mathrm{Al}_{2} \mathrm{O}_{3}$ and $\mathrm{Ca}_{3}\left(\mathrm{PO}_{4}\right)_{2}$ are reasonable catalysts. To date, the GC capillary column does not separate isobutylene from 1-butene. The molar mass balances from experiment to experiment are very good with respect to $\mathrm{C}, \mathrm{H}$, and $\mathrm{O}$. At this time it appears that controlling Bronsted acidity will minimize skeletal rearrangement to linear olefins. The data in the table reflects screening and does not address lifetime performance. 
TABLE 3.2.4

Gas Phase Isobutanol Dehydration

\begin{tabular}{|c|c|c|c|c|c|c|c|c|c|}
\hline \multirow[b]{3}{*}{ Entry } & \multirow[b]{3}{*}{ Cat. } & \multirow{3}{*}{$\begin{array}{c}\text { Temp. } \\
\left({ }^{\circ} \mathrm{C}\right)\end{array}$} & \multirow{3}{*}{$\begin{array}{c}\text { Contact } \\
\text { Time } \\
(\mathrm{sec})\end{array}$} & \multirow[b]{3}{*}{$\begin{array}{l}\text { \% Conv. } \\
\text { i-BuOH }\end{array}$} & \multirow{3}{*}{$\begin{array}{l}\mathrm{i}-\mathrm{C}_{4}=+ \\
1 \cdot \mathrm{C}_{4}=\end{array}$} & \multirow{2}{*}{\multicolumn{2}{|c|}{$\%$ Selectivity }} & \multicolumn{2}{|c|}{ Molar Mass Balance } \\
\hline & & & & & & & & \multirow{2}{*}{$\begin{array}{l}\Sigma \mathrm{C}_{4} \\
\mathrm{i}-\mathrm{BuOH} \\
\text { at } 0 \% \\
\text { Conv. }\end{array}$} & \multirow{2}{*}{$\begin{array}{l}\Sigma \mathrm{C}_{4}= \\
\mathrm{H}_{2} \mathrm{O}\end{array}$} \\
\hline & & & & & & $t-2-C_{4}=$ & $c-2-C_{4}=$ & & \\
\hline 1 & $\mathrm{Al}_{2} \mathrm{O}_{3}$ & 250 & 13.7 & 99.2 & 97.5 & 0.5 & 2.0 & 0.94 & 1.0 \\
\hline 2 & $\mathrm{Al}_{2} \mathrm{O}_{3}$ & 300 & 13.1 & 100 & 95.5 & 1.9 & 2.5 & 0.81 & 0.88 \\
\hline 3 & $\mathrm{CaHPO}_{4}$ & 300 & 13.1 & 100 & 80.7 & 9.1 & 10.2 & 0.95 & 0.97 \\
\hline 4 & $\mathrm{CaHPO}_{4}$ & 290 & 13.3 & 96.5 & 85.1 & 5.7 & 9.2 & 0.97 & 0.99 \\
\hline 5 & $\mathrm{CaHPO}_{4}$ & 250 & 13.7 & 19.3 & 86.5 & 4.8 & 8.7 & 0.90 & 0.80 \\
\hline 6 & $\mathrm{ZrO}_{2}$ & 300 & 13.1 & 100 & 73.3 & 16.3 & 10.4 & 0.93 & 0.85 \\
\hline \multirow[t]{2}{*}{7} & $\mathrm{WO}_{3}$ & 250 & 13.7 & 100 & 66.2 & 20.2 & 12.9 & 0.83 & 0.86 \\
\hline & \multicolumn{9}{|c|}{$5 \mathrm{ml}$ cat.; $10.4 \mathrm{cc} / \mathrm{min} \mathrm{N}_{2} @ 298 \mathrm{~K} ; 1.54 \mathrm{cc} / \mathrm{min} . \mathrm{i}-\mathrm{BuOH} @ 298 \mathrm{~K}$} \\
\hline 8 & $\mathrm{CaHPO}_{4}$ & 325 & 6.2 & 100 & 81.5 & 8.7 & 9.8 & 0.94 & 0.93 \\
\hline \multirow[t]{2}{*}{9} & $\mathrm{CaHPO}_{4}$ & 300 & 6.5 & 78.9 & 85.7 & 5.7 & 8.6 & 0.91 & 1.0 \\
\hline & \multicolumn{9}{|c|}{$5 \mathrm{ml} \mathrm{cat.;} 20.8 \mathrm{cc} / \mathrm{min} \mathrm{N}_{2} @ 298 \mathrm{~K} ; 3.26 \mathrm{cc} / \mathrm{min} \mathrm{i}-\mathrm{BuOH} @ 298 \mathrm{~K}$} \\
\hline 10 & $\mathrm{CaHPO}_{4}$ & 325 & 1.2 & 79.5 & 85.9 & 5.1 & 9.0 & 0.98 & 0.94 \\
\hline 11 & $\mathrm{CaHPO}_{4}$ & 300 & 1.3 & 31.3 & 86.7 & 3.3 & 10.0 & 0.97 & 1.0 \\
\hline 12 & $\mathrm{Ca}\left(\mathrm{H}_{2} \mathrm{PO}_{4}\right)_{2}$ & 325 & 1.2 & 92.1 & 80.4 & 9.4 & 10.2 & 1.0 & 0.99 \\
\hline 13 & $\mathrm{Ca}\left(\mathrm{H}_{2} \mathrm{PO}_{4}\right)_{2}$ & 250 & 1.4 & 9.4 & 86.1 & 5.0 & 8.9 & 0.90 & 0.71 \\
\hline 14 & $\mathrm{Ca}_{3}\left(\mathrm{PO}_{4}\right)_{2}$ & 325 & 1.2 & 90.9 & 86.5 & 5.2 & 8.3 & 0.83 & 0.90 \\
\hline 15 & $\mathrm{Ca}_{3}\left(\mathrm{PO}_{4}\right)_{2}$ & 300 & 1.3 & 37.3 & 87.5 & 3.8 & 8.7 & 0.78 & 0.94 \\
\hline 16 & $\mathrm{Ca}_{2} \mathrm{P}_{2} \mathrm{O}_{4}$ & 325 & 1.2 & 20.6 & 86.7 & 4.4 & 8.9 & 1.0 & 1.0 \\
\hline 17 & $\mathrm{Ca}_{2} \mathrm{P}_{2} \mathrm{O}_{4}$ & 250 & 1.4 & 0 & - & 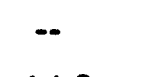 & $-\cdot$ & 1.0 & -- \\
\hline 18 & $\mathrm{Zn}_{2} \mathrm{P}_{2} \mathrm{O}_{7}$ & 325 & 1.2 & 100 & 73.2 & 14.9 & 11.9 & 0.98 & 0.98 \\
\hline 19 & $\mathrm{Zn}_{2} \mathrm{P}_{2} \mathrm{O}$ & 300 & 1.3 & 98.7 & 75.4 & 12.9 & 11.7 & 1.0 & 1.0 \\
\hline 20 & $\mathrm{Mg}_{2} \mathrm{P}_{2} \mathrm{O}_{7}$ & 300 & 1.3 & 10.7 & $\cdot-$ & -- & -- & 0.89 & - \\
\hline 21 & $\mathrm{Mg}_{2} \mathrm{P}_{2} \mathrm{O}_{7}$ & 250 & 1.4 & 7.8 & $\cdot-$ & $-\cdot$ & $\cdots$ & 0.95 & $-\cdot$ \\
\hline 22 & $\mathrm{~K}_{2} \mathrm{HPO}_{4}$ & 300 & 1.3 & 20.3 & $-\cdot$ & $-\cdot$ & -- & 0.84 & $\cdot-$ \\
\hline 23 & $\mathrm{~K}_{2} \mathrm{HPO}_{4}$ & 250 & 1.4 & 0 & $-\cdot$ & -- & -- & 0.94 & -- \\
\hline & $1 \mathrm{ml}$ cat., 20 & $0.8 \mathrm{cc} / \mathrm{mi}$ & in $N_{2} @ 2$ & $98 \mathrm{~K} ; 3.2$ & $\min \mathrm{i}$ & & & & \\
\hline
\end{tabular}




\section{QFY92 Objectives}

Future plans for Task 3.2 will focus on the following areas:

- Continue to examine the lanthanide series of oxides $\operatorname{Pr}_{6} \mathrm{O}_{11}$ and $\mathrm{Eu}_{2} \mathrm{O}_{3}$, in order to increase yield to isobutanol.

- Examine different reactor configuration to decrease the gas phase oxidation of DME and isobutanol to $\mathrm{CO}, \mathrm{CO}_{2}$.

- Determine the effect of calcination on Bronsted acidity of the phosphate catalyst for dehydration.

- Screen sulfate catalysts for isobutanol dehydration.

\section{Task 3.3: Catalyst Poisons Studies}

No activity in this period.

\section{Task 4: Program Support}

No activity to report. A comprehensive study of DME, isobutanol and MTBE economics is currently underway. A report in the June quarterly is expected.

Task 5: Program Management

\section{Task 5.1 Planning and Reports}

Monthly reports for January and February 1992 were prepared and issued to DOE. A draft Quarterly Report for October - December 1991 was also submitted. The Milestone Schedule Status Report and Milestone Log have been updated and are attached. In addition, monthly Cost Summaries continue to be issued to DOE.

During March, a meeting was held in Pittsburgh with DOE and a number of private organizations to organize the run plan for a July Fischer-Tropsch demonstration at LaPorte. The private partners include Exxon, UOP, Statoil, and Shell Oil. Criteria of run success, catalyst requirements, and analytical needs were addressed, as was the challenge of catalyst-wax separation. A run plan was approved, subject to Shell's input as they could not attend this particular meeting. Details of the meeting and the decisions made can be found in a report by Dr. B. L. Bhatt (see Appendix 5). 


\section{Task 5.2 Management Activities}

DOE PETC has accepted a proposal to demonstrate Liquid Phase Shift (LPS) chemistry at LaPorte as an altemative to isobutanol. There are two principal reasons for carrying out this run. First, following the extensive modifications at the site, operation on a relatively "benign" system is needed before we start on Fischer-Tropsch technology in July. Second, use of shift catalyst in a slurry reactor will enable DOE's program on coal-based Fischer-Tropsch to encompass commercially available cobalt catalysts-up to now they have been limited to iron-based catalysts which have varying degrees of shift activity. DOE is also supportive of continued fuel testing of LaPorte methanol-tests of M100 at Detroit Diesel have been going particularly well-and are favorably disposed to a run where methanol can be made to supplement the dwindling pool. LPS offers the opportunity to produce methanol as the catalyst, in the absence of steam, is active for methanol synthesis.

The proposed contract between M. W. Kellogg and Air Products to assist in the design of a PETC generic unit is still under negotiation. Nevertheless, technical assistance was provided at meetings in Pittsburgh and Houston. DOE has decided to go with 6" diameter reactors for more authentic hydrodynarnic studies providing the funding for gas supplies is available. A fallback to 2" (or 4") reactors is also recommended which will, at a minimum, provide information on catalyst activity.

Methanol from LaPorte was used in a 100 hour engine test at Detroit Diesel Corporation (DDC). The goal was to assess what compositional changes, if any, would need to be made in the crude methanol product anticipated in the CCT III CoolWater project, for it to be used in M100 applications. A particular concern was the water content $(-0.5 \mathrm{wt} \%$ on average in CoolWater product) as the preferred specification (based on chemical grade methanol) in 0.3 wt\% maximum. The LaPorte material passed the test, in DDC's new 6V-92TA $276 \mathrm{hp}$ methanol engine, with flying colors. An understanding of why, and the potential for running with even higher water levels, is being developed with DDC.

\section{OPEN ITEMS:}

None

\section{ATTACHMENTS:}

Milestone Schedule Status Repor

Milestone Log

Appendix 1: Design Hazards Review Report; March 1992 IBOH Run Appendix 2: Design Hazards Review Repor; April 1992 Liquid Phase Shift (LPS) Run Appendix 3: Literature Search on Dehydration of Isobutanol to Isobutylene

Appendix 4: Material Balance Sheets for A. Run \#11782-58 (Ground-up K3-110) and B. Run \#11782-63 (Powder K3-110, LaPorte Batch)

Appendix 5: Meeting Notes from Partners' Meeting in Pittsburgh, March 19 - 20. 1992. 


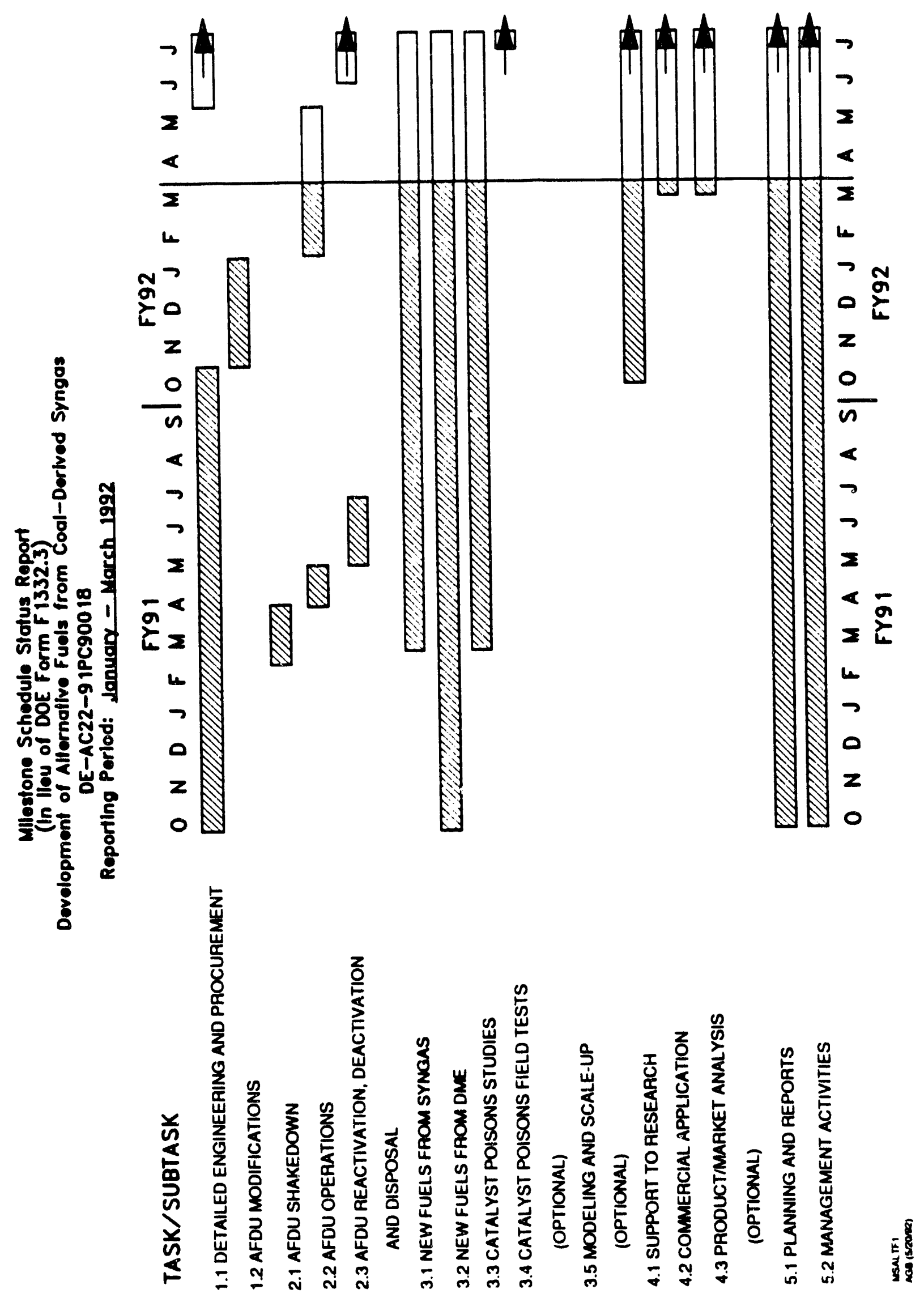




\section{MILESTONE LOG}

Report Date: 31 January 1992

Contract No. DE-AC22-91PC90018

Ident.

No.

Description

1.1 Detailed Engineering and Procurement

1.2 AFDU Modification

2.1 AFDU Shakedown

2.2 AFDU Operations

2.3 AFDU Reactivation, Deactivation, and Disposal

3.1 New Fuels from Syngas

3.2 New Fuels from DME

3.3 Catalyst Poisons Studies

3.4 Catalyst Poisons Field Tests (Optional)

3.5 Modeling and Scale-up (Optional)

4.1 Support to Research

4.2 Commercial Application (Optional)

4.3 Product/Market Analysis (Optional)

5.1 Planning and Reports

5.2 Management Activities
Pianned Actual

Completion Completion

Date

Date

Comments

Apr 92

Oct 92

Apr 91

Completed for DME Operation

Jul 93

Sep 93

Started 5/91

Oct 92

Started 3/91

May 93

On Schedule

Oct 92

Started 4/91

$\operatorname{Jan} 93$

Jul 93

Oct 93

Oct 93

Oct!3

Oct 93

Oct 93 


\section{APPENDIX 1}

\section{DESIGN HAZARDS REVIEW REPORT MARCH 1992 IBOH RUN}




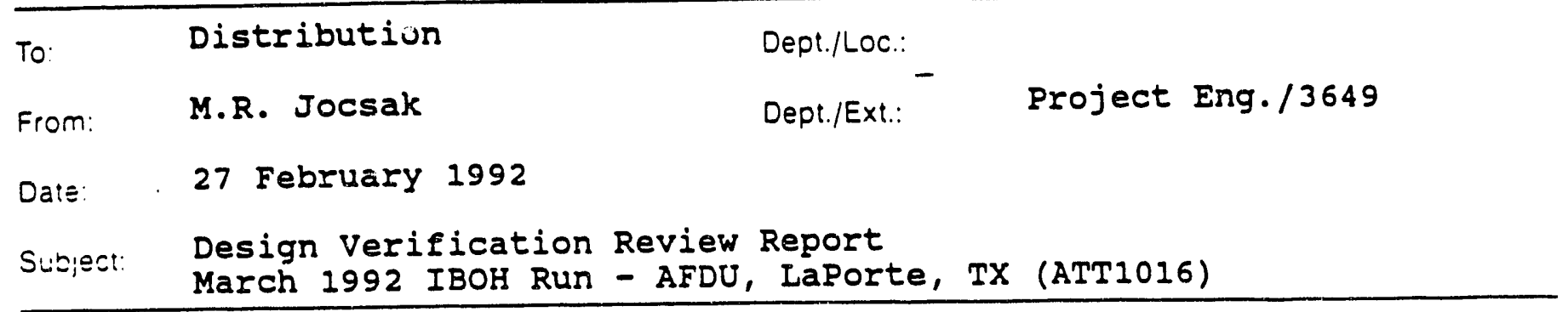

Distribution:

w.C. Allen (MC\$83)

A.G. Barbieri

D.M. Brown

T.E. Conway

D.A. Kosciusko

S. Dewire (LAPOrte AFDU)

E.C. Heydorn (Laporte AFDU)

T. Hsiung/R.P. Underwood

G.A. Peters

-D.H. Herron "

E. Schaub/B. Bhatt/D. Studer

R.I. Williams

Attached is a copy of the Design Verification Review report for the isobutanol demonstration at the Alternative Fuels Development Unit (AFDU) in Laporte, TX.

The schedule for performing the isobutanol run has been delayed due to problems in manufacturing the required catalyst. It is uncertain as to when the run will be performed, but most likely it will be within the next two years. This document serves to finalize the hazard review process for the isobutanol demonstration.

Efforts are currently underway in preparation for an alternative run this spring at the AFDU: water gas shift (WGS) demonstration. A separate Hazards Review will be performed and documented for the WGS run, but since this run will utilize all of the recently installed equipment, many of the same hazards addressed for the isobutanol run will apply to the wGS run.

Please contact me if you have any questions or comments.

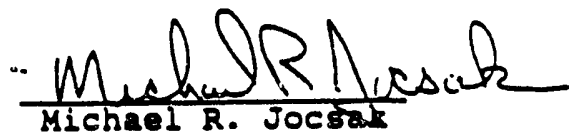

MRJ/026

RECEIVEE

MAR O 21996 


\section{DESIGN VERIFICATION REVIEW (DVR)}

Alternative Fuels Development Unit (AFDU)

March 1992 Iso-Butanol Run

LaPorte, Texas

21 February 1992

\section{Review Team}

T. E. Conway

D. M. Herron

M. R. Jocsak

G. A. Peters

E. S. Schaub
Start-Up Engineering

Process Engineering

Project Engineering

PSG Engineering Safety

Process Engineering 


\author{
Design Verification Review (DVR) \\ Alternative Fuels Development Unit (AFDU) \\ March 1992 Iso-Butanol Run \\ LaPorte, Texas \\ 21 February 1992
}

Table of Contents

Page No.

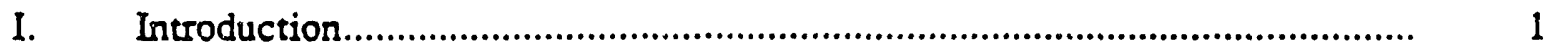

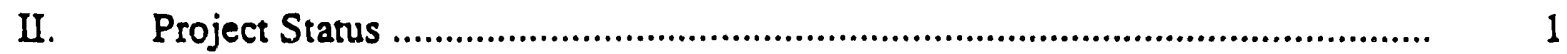

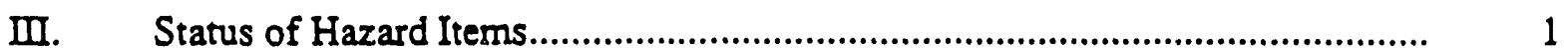

\title{
Appendices
}
A. Process Flow Diagram
B. Justification for Changing the High Temperature Shutdown SD-2 Setpoints
C. MSDS - Isobutanol Catalyst
D. LaPorte AFDU Operations in the Spring of 92 - Materials Review
E. $\mathrm{CO}_{2}$ Vent Stack Review for the Spring '92 Demo at the AFDU
F. $\quad \mathrm{CO}_{2}$ Vent Stack for Spring '92 Run

\section{References}

1. Preliminary Process Hazards Review Report - 12 September 1991

2. Design Hazard Review (DHR) Report - 4 November 1991

3. Engineering Flowsheet (P\&ID) for the Spring '92 ISOBL " "OL DEMONSTRATION - ATT 1016B, revision 2, January 3, $\$ 92$

4. Engineering Flowsheet (P\&ID) 87-7-1533, Liquid Phase Methanol, revision 15, 19 September, 1991.

5. FCN (to F/S 87-7-1533) \#'s: $2,3,4,5,6,7,8,9,10,11,12,14,15,18,19,20, \& 30$. 


\section{INTRODUCTION}

A Design Verification Review (DVR) meeting was conducted on 21 February 1992 for the isobutanol demonstration at the LaPorte, TX Alternative Fuels Development Unit (AFDU). The run objectives are to investigate mixed alcohol synthesis in a bubble column reactor and to study the influence of light alcohol recycle on isobutanol selectivity.

The purpose of the DVR was to review the status of each hazard item addressed during the Design Hazards Review (DHR) and to ensure these items have been satisfactorily considered during the design phase.

\section{PROJECT STATUS}

The schedule for performing the isobutanol demonstration has been delayed due to problems associated with manufacturing a suitable catalyst. In an effort to shake down the newly installed DCS system and GC laboratory equipment, an alternate operating campaign is being planned for the spring of 1992. This run will demonstrate a water-gas shift (WGS) reaction in our liquid phase reactor train and will utilize the recently installed methanol circulation equipment.

It is likely that the isobutanol demonstration will be performed during FY'93, assuming a suitable catalyst is available.

A separate Hazards Review will be performed and documented for the WGS demonstration.

III. STATUS OE HAZARD ITEMS

The following lists the staus of each hazard item as discussed during the DVR meeting. 


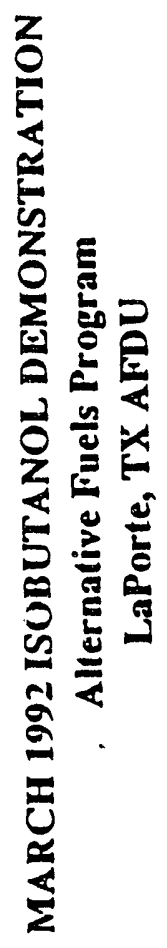

\begin{tabular}{|c|c|c|c|}
\hline 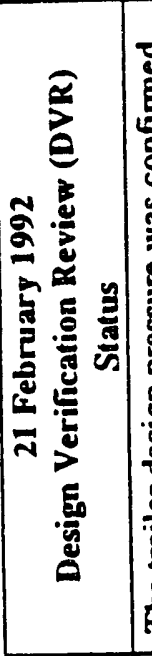 & 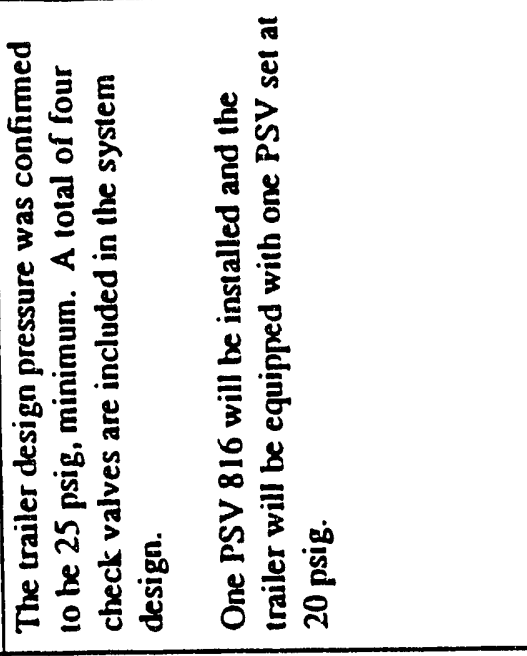 & - & 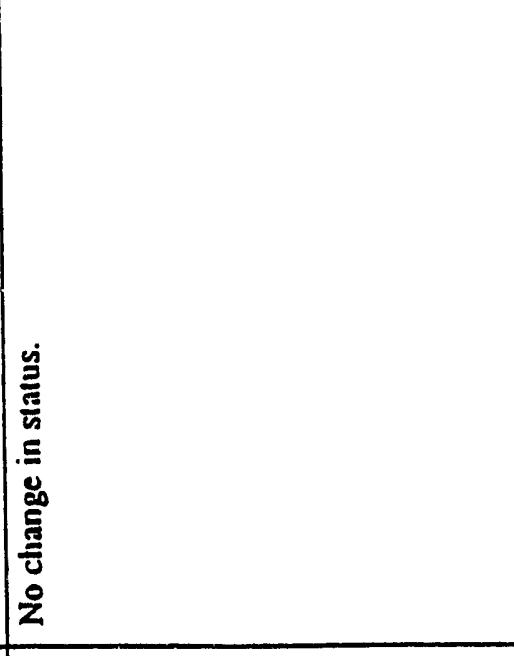 \\
\hline 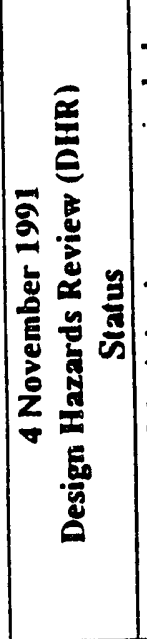 & 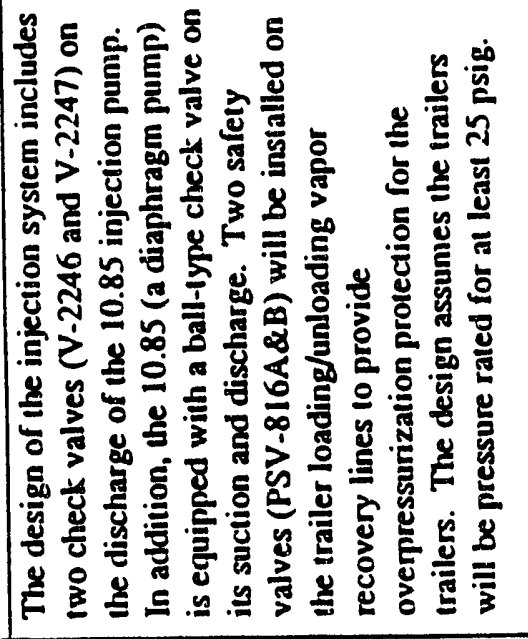 & 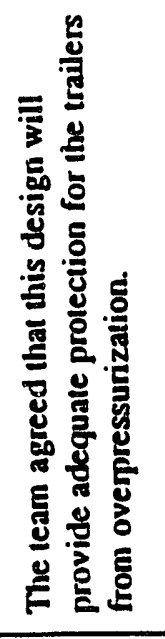 & 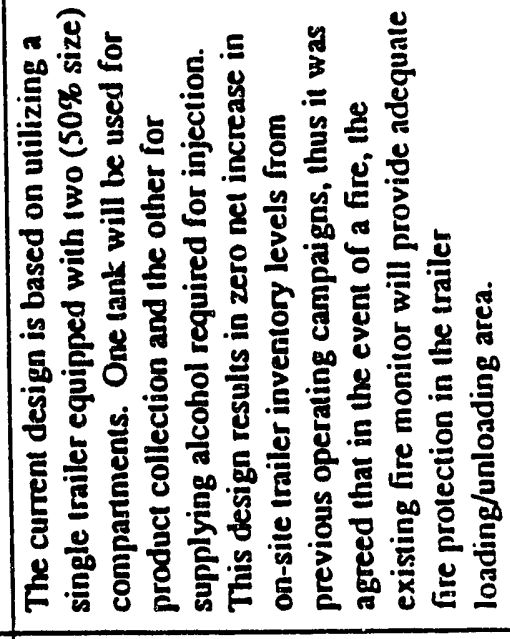 \\
\hline 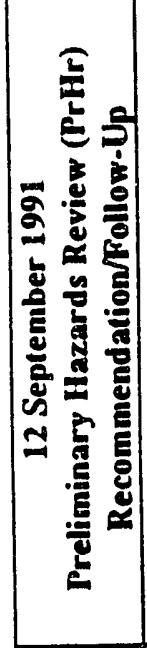 & 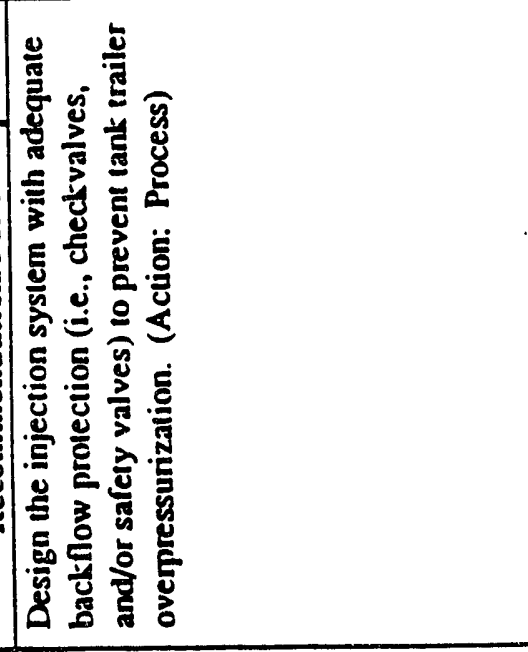 & & 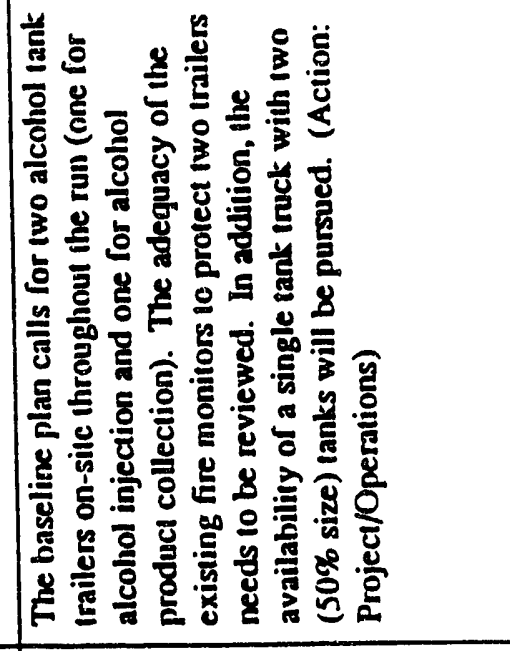 \\
\hline & 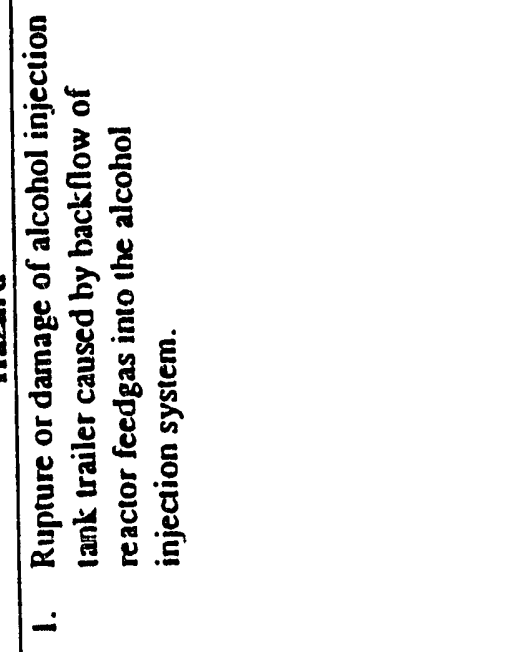 & & 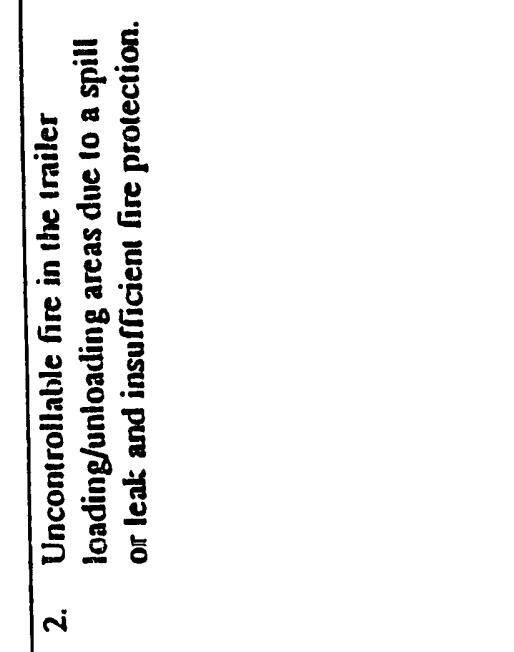 \\
\hline
\end{tabular}




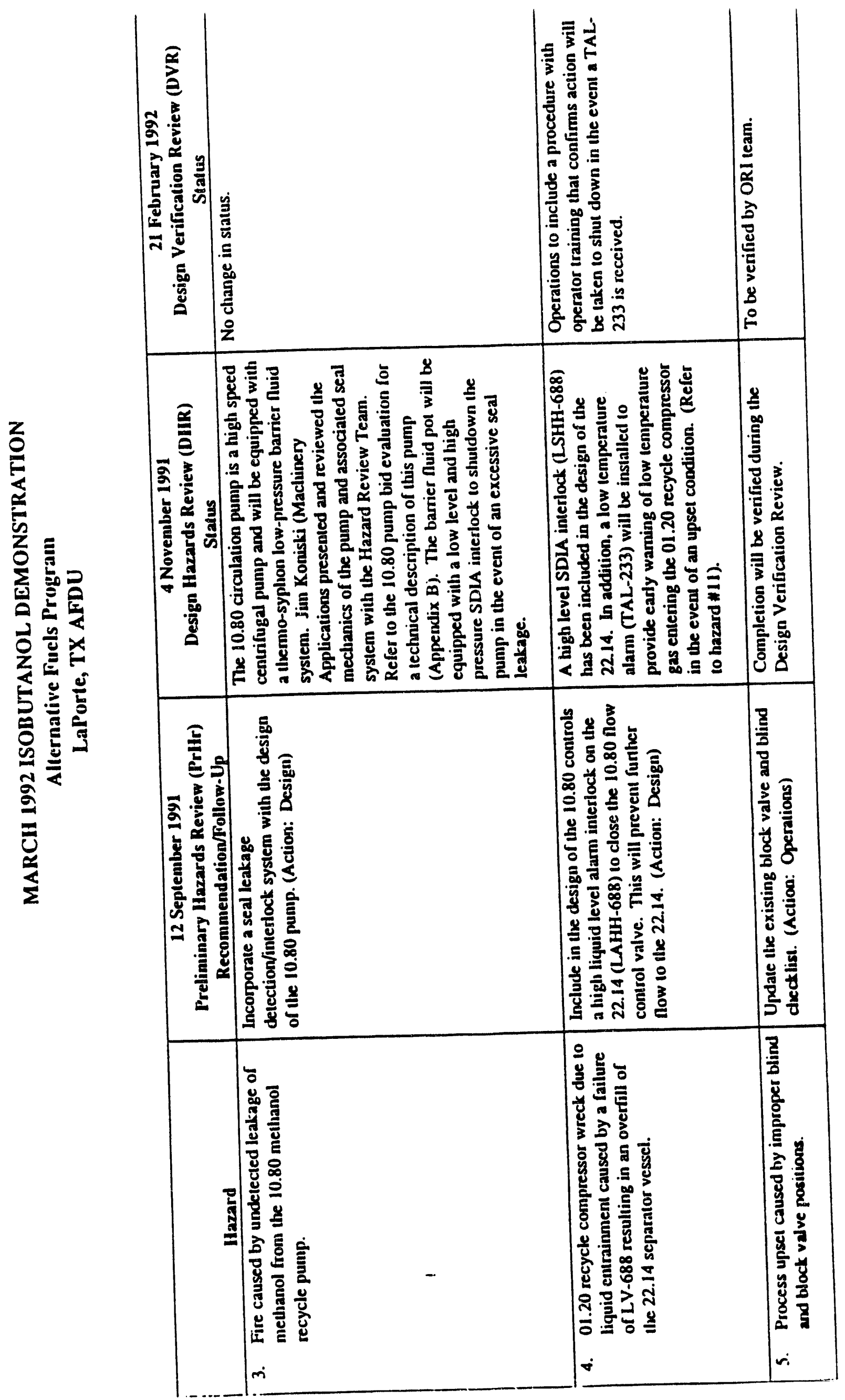




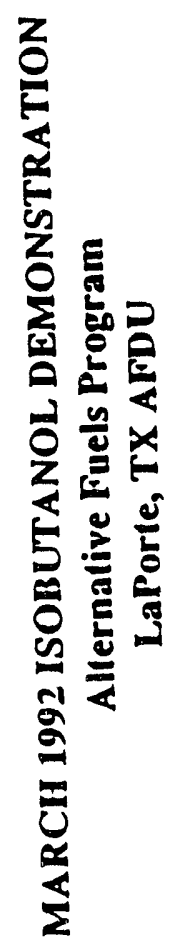

\begin{tabular}{|c|c|c|c|}
\hline 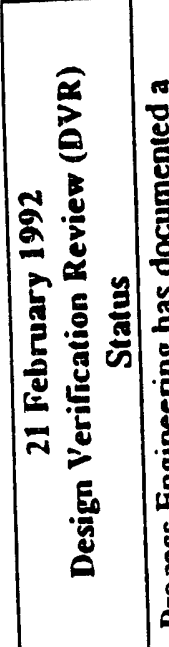 & 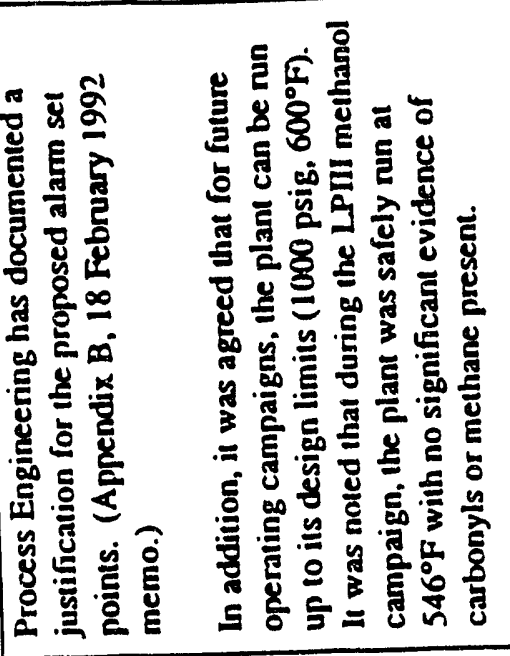 & 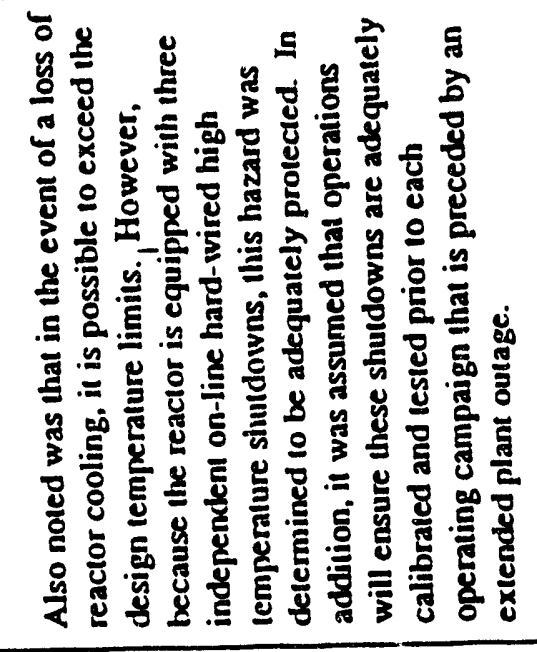 & 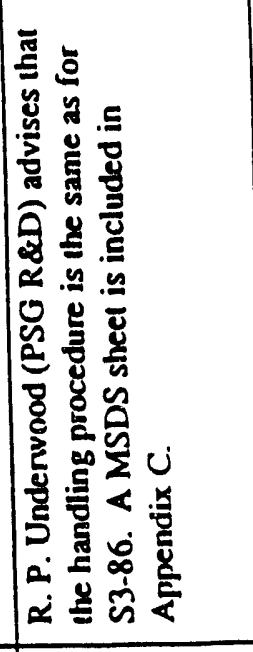 \\
\hline 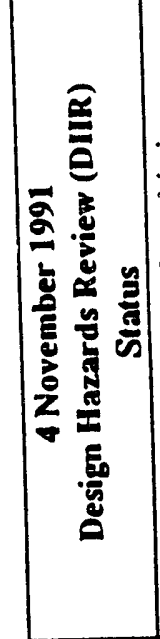 & 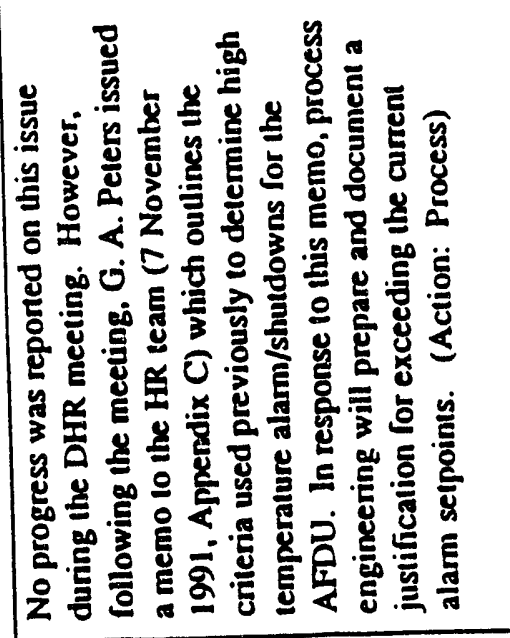 & & 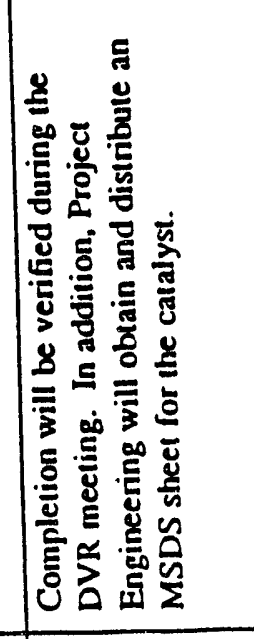 \\
\hline 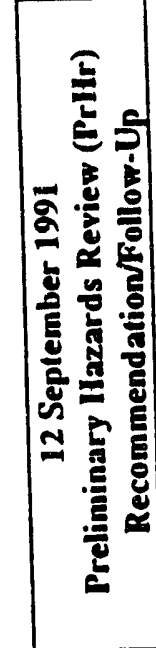 & 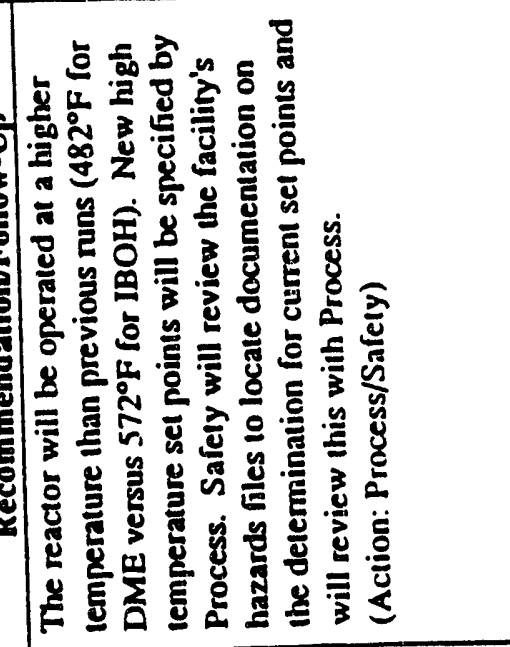 & & 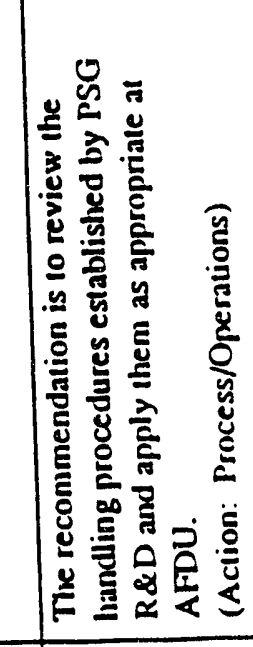 \\
\hline & 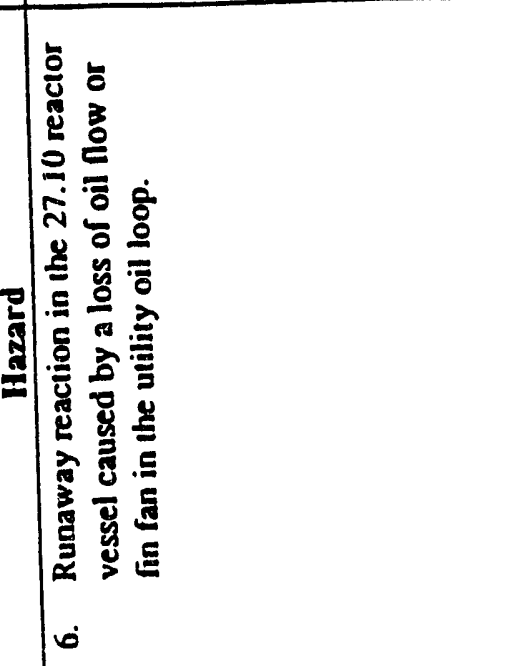 & & 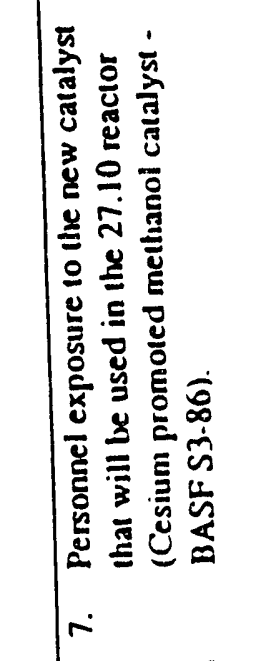 \\
\hline
\end{tabular}



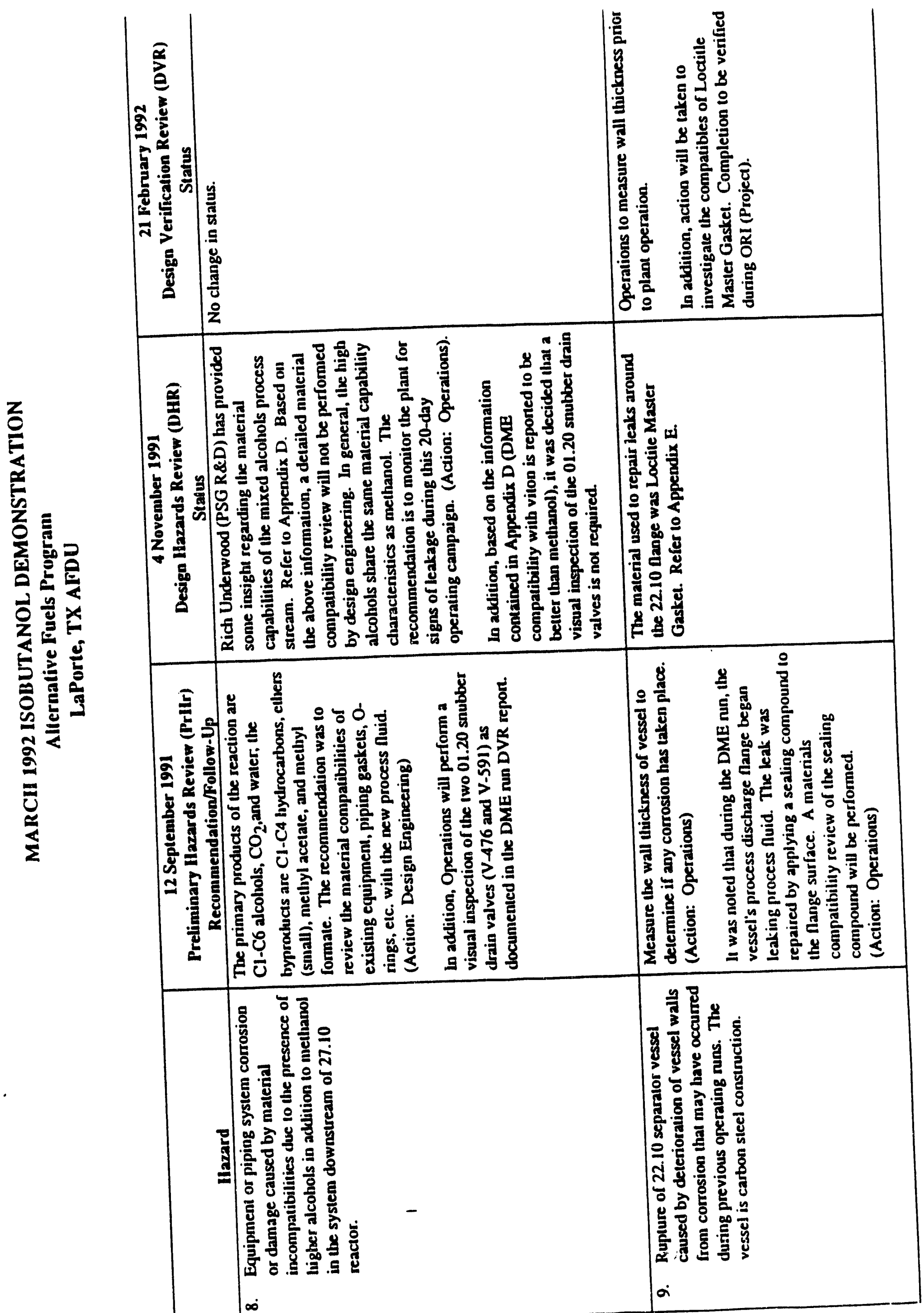


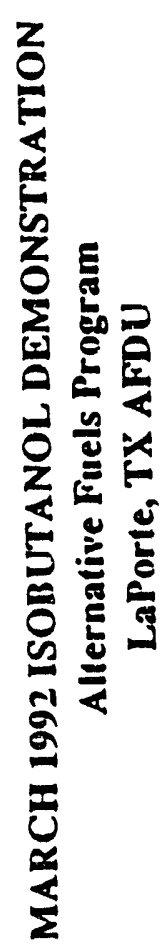

\begin{tabular}{|c|c|c|c|c|}
\hline 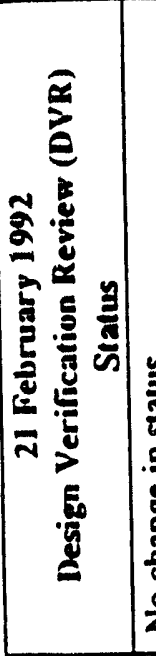 & 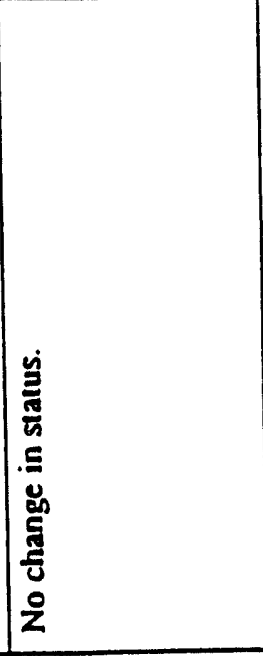 & & 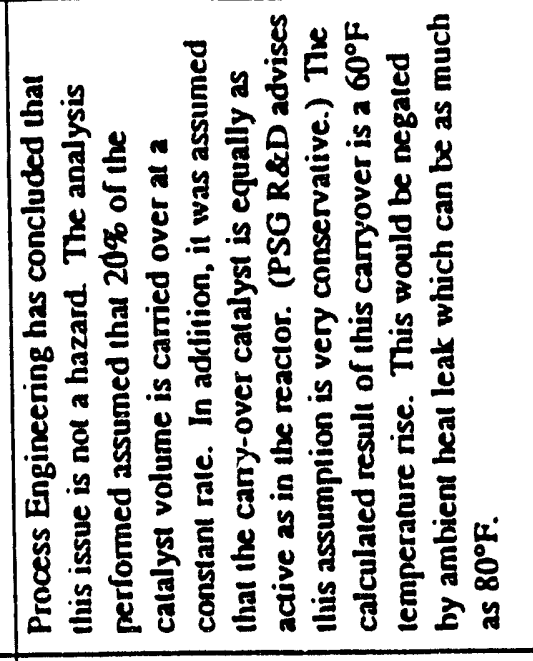 & 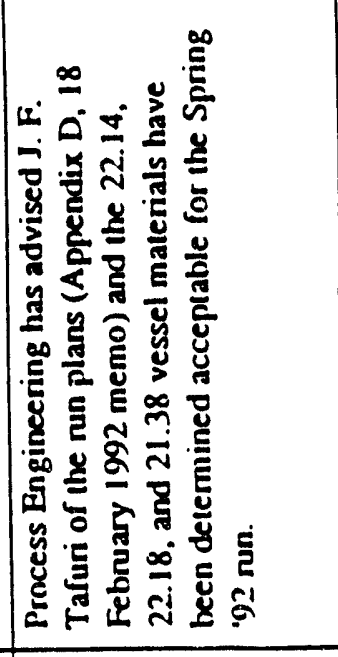 \\
\hline 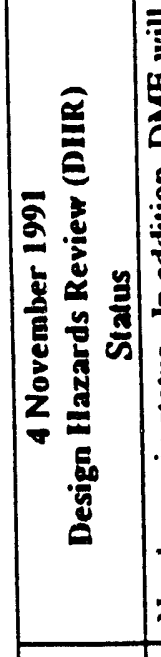 & 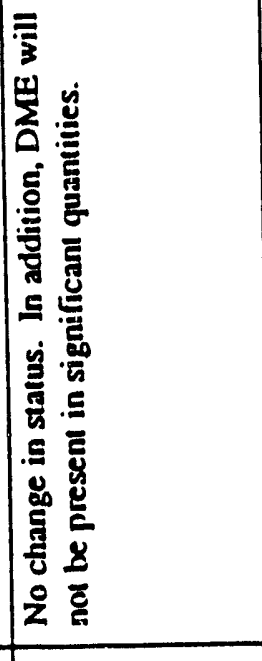 & 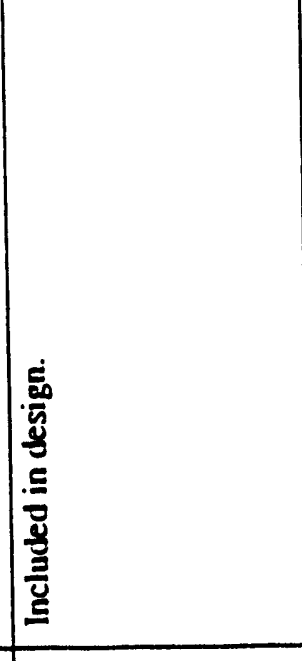 & 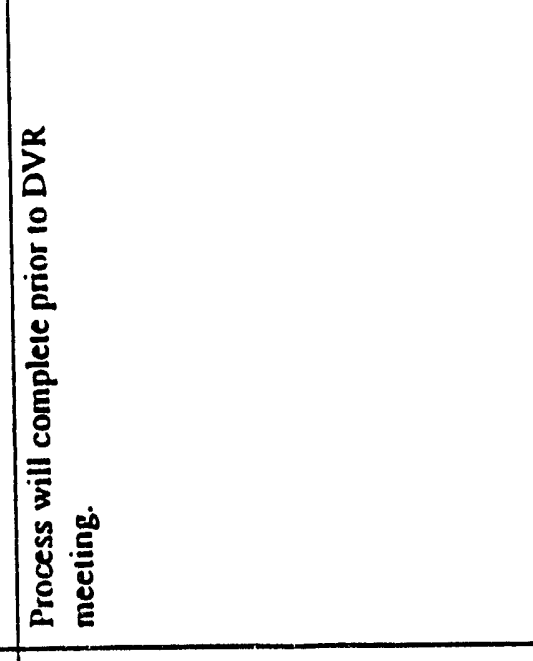 & 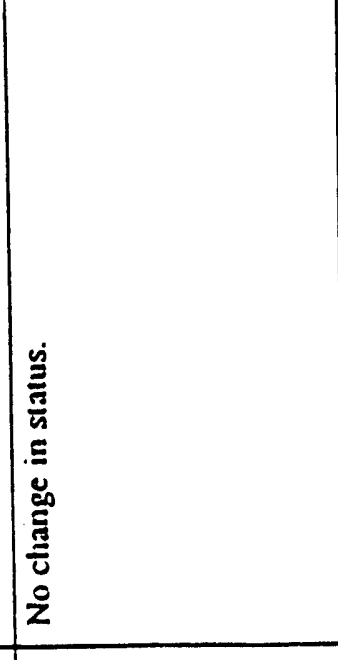 \\
\hline 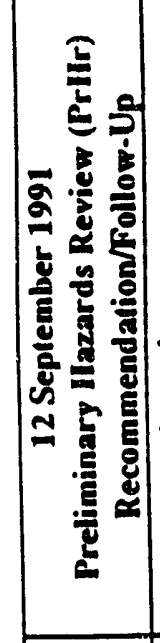 & 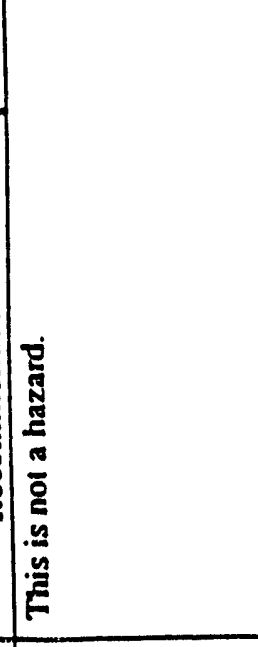 & 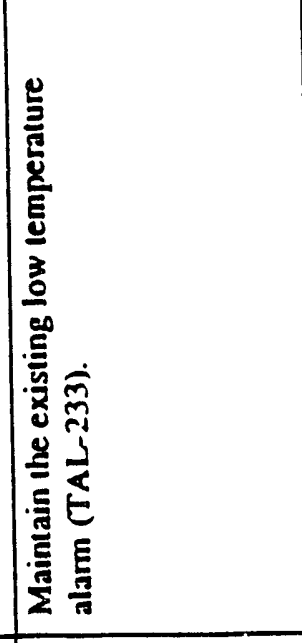 & 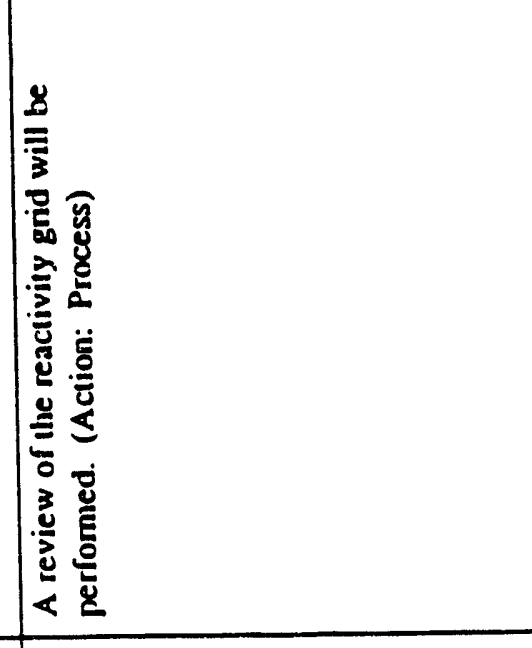 & 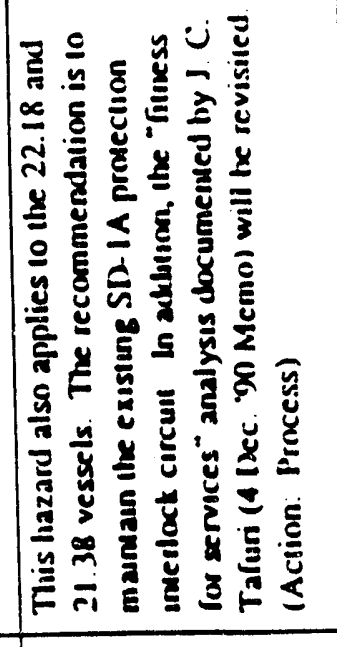 \\
\hline & 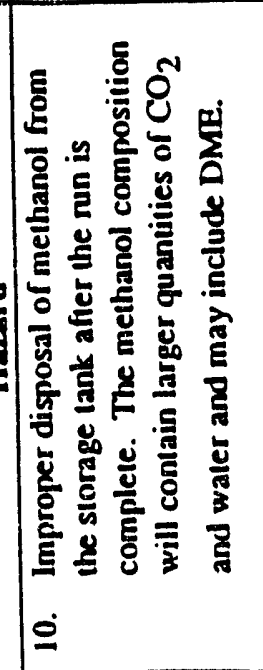 & 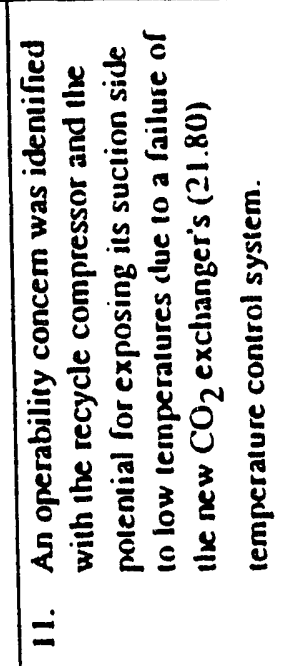 & 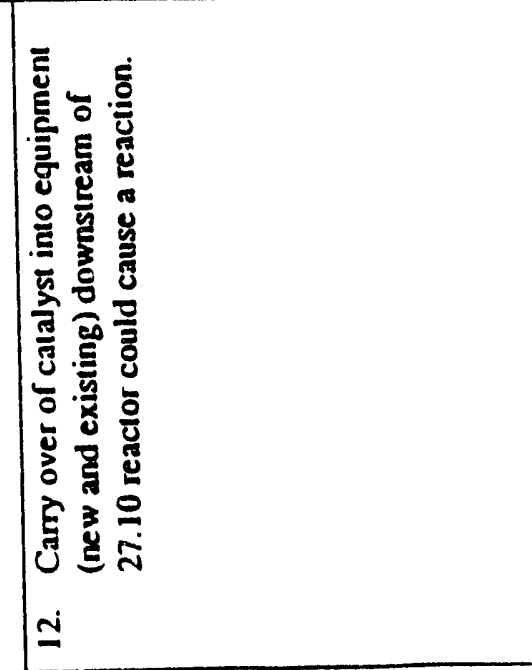 & 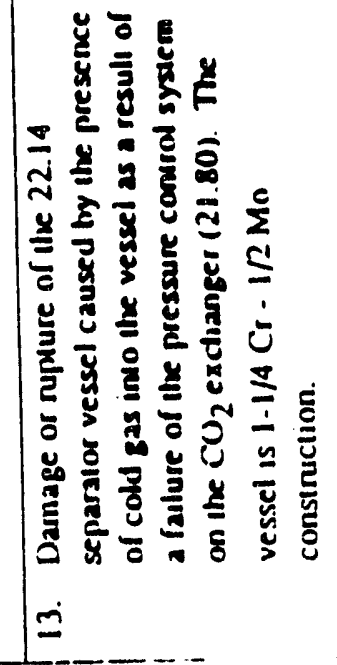 \\
\hline
\end{tabular}




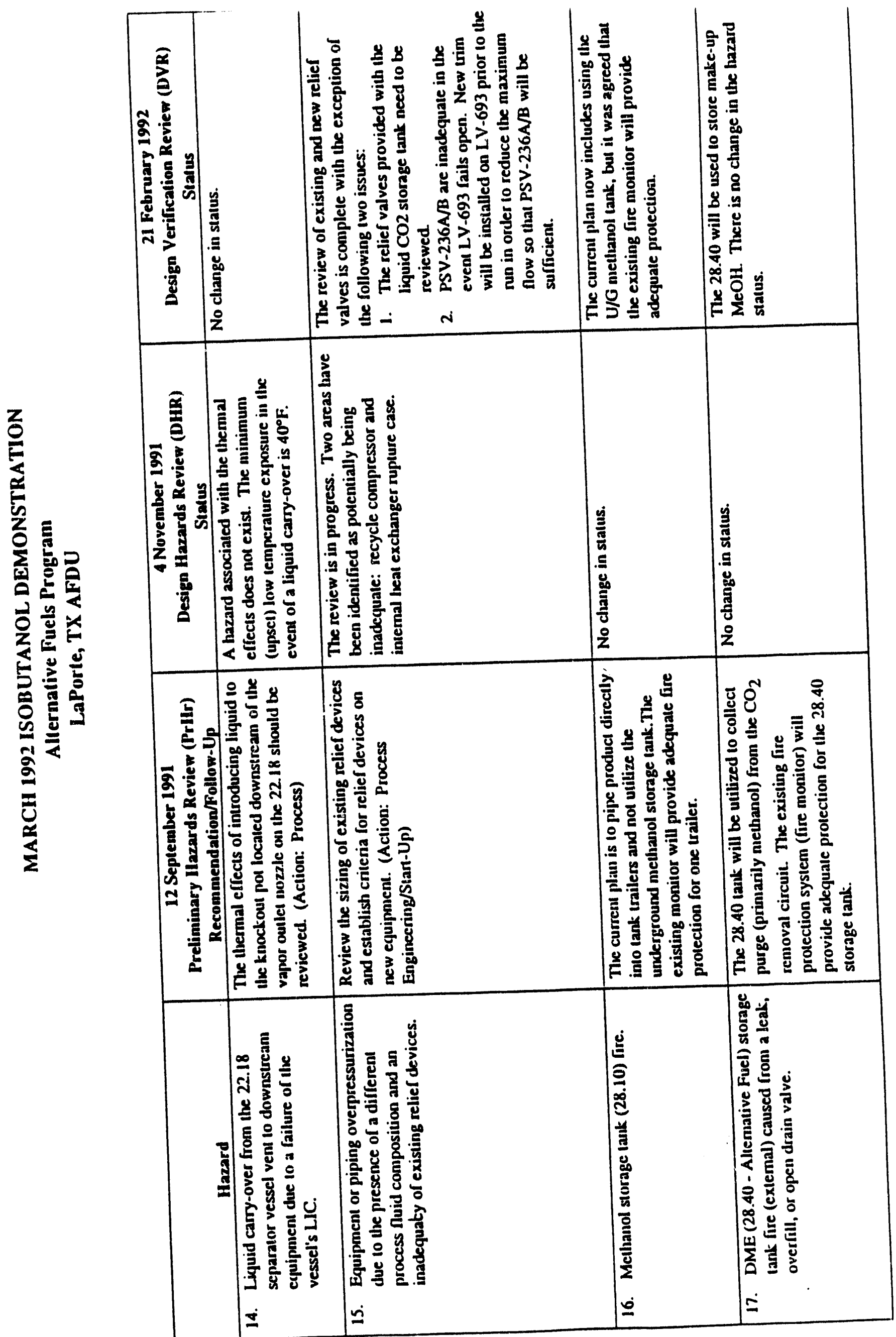



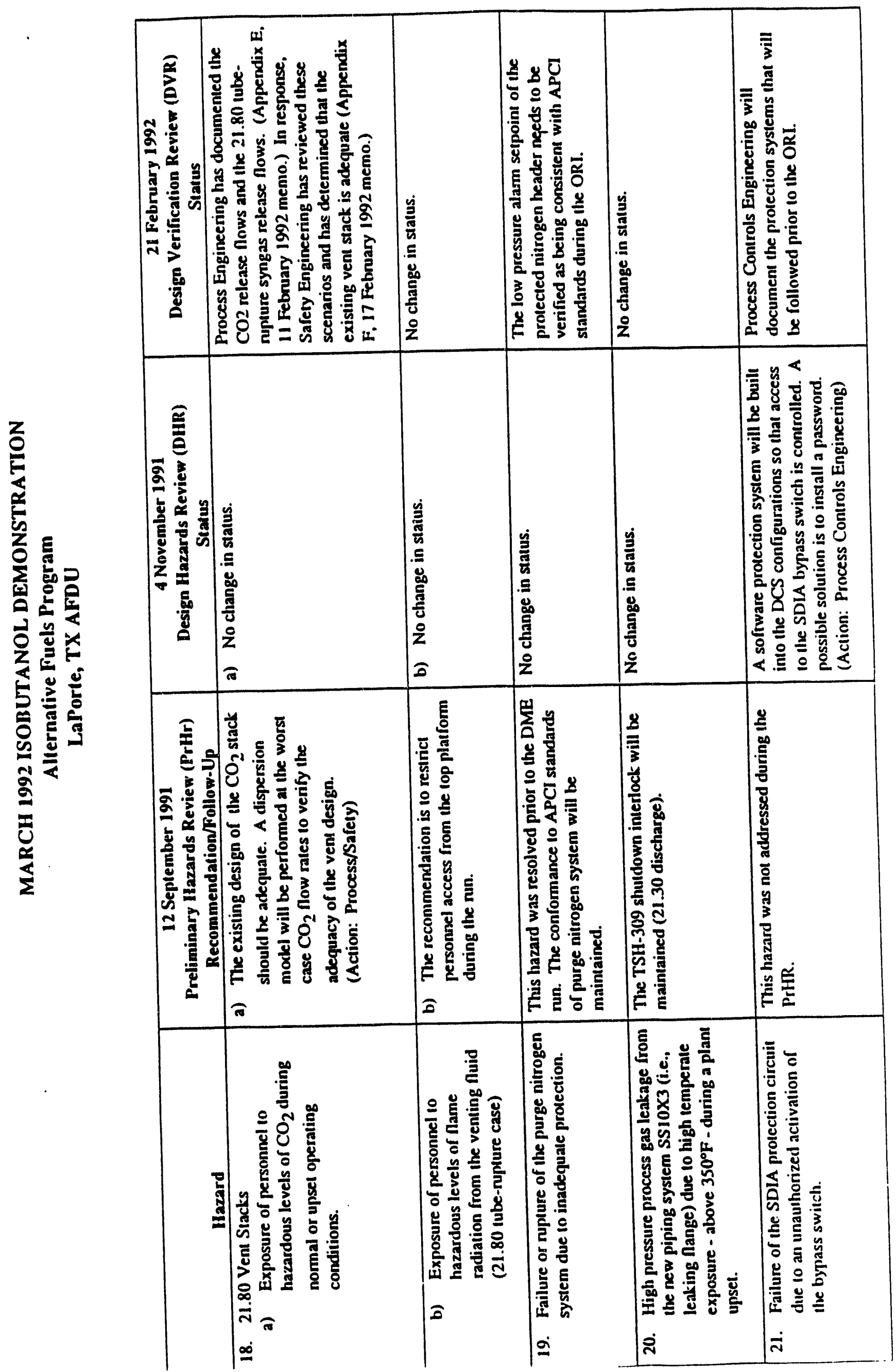


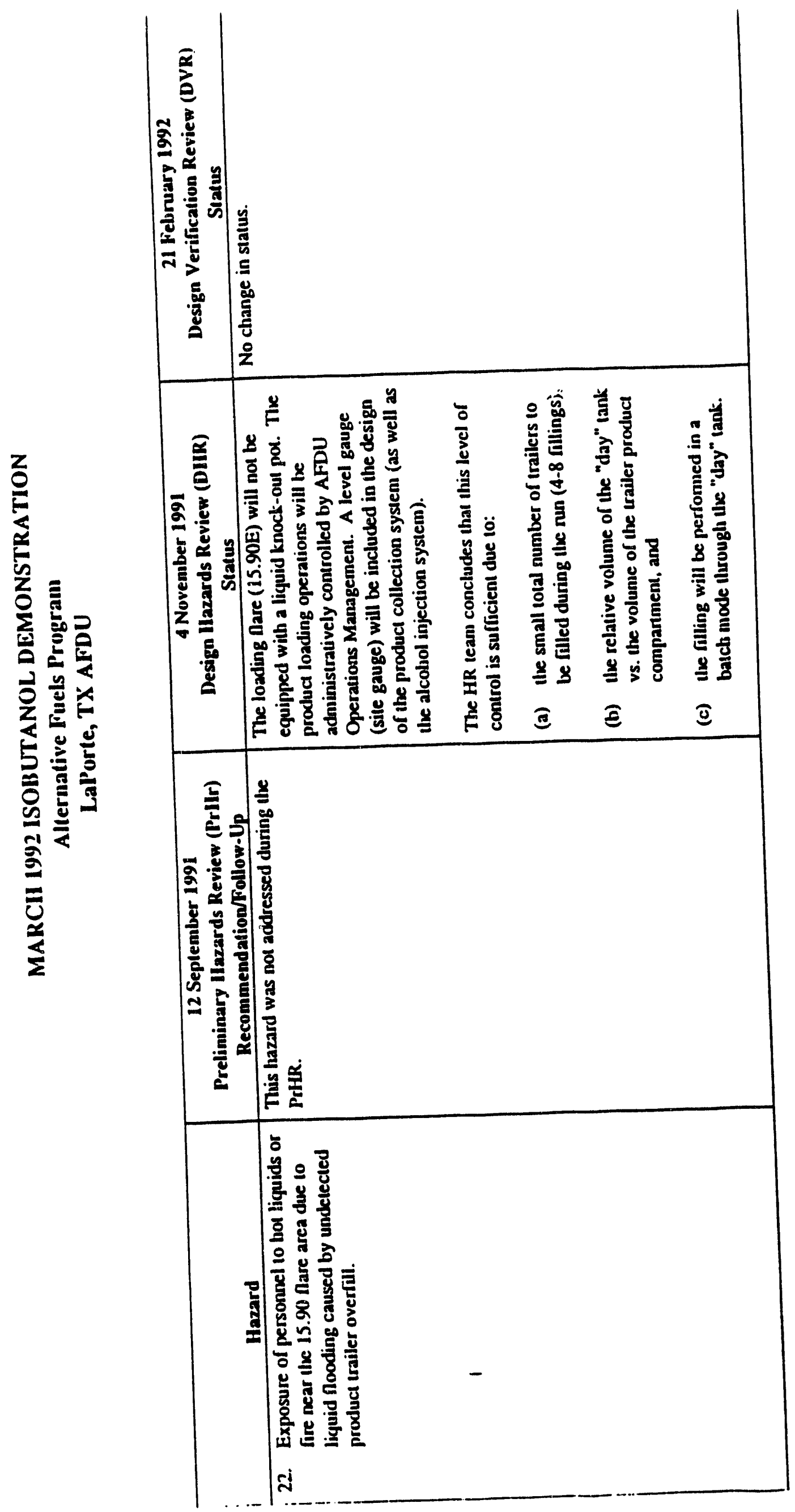




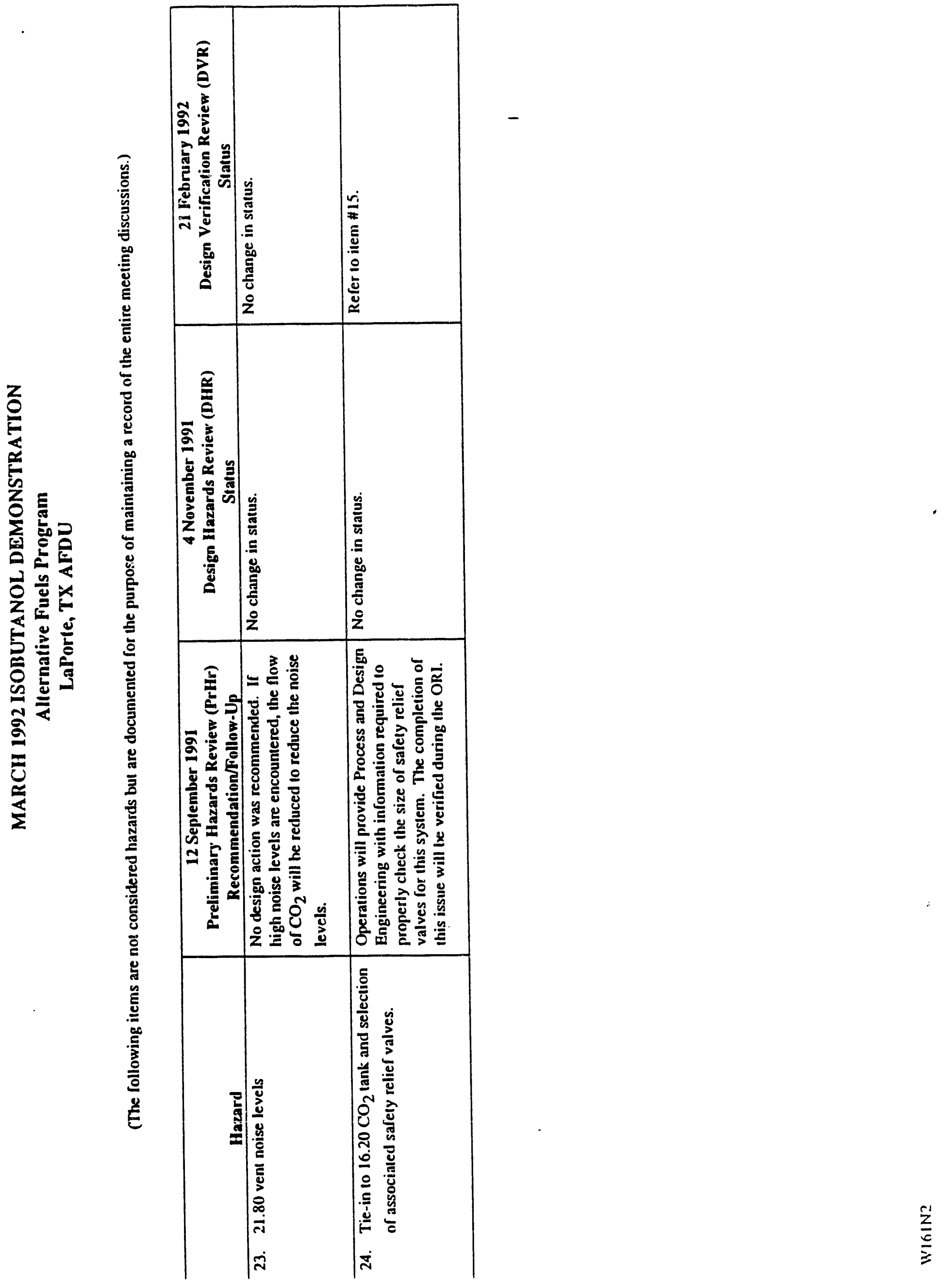




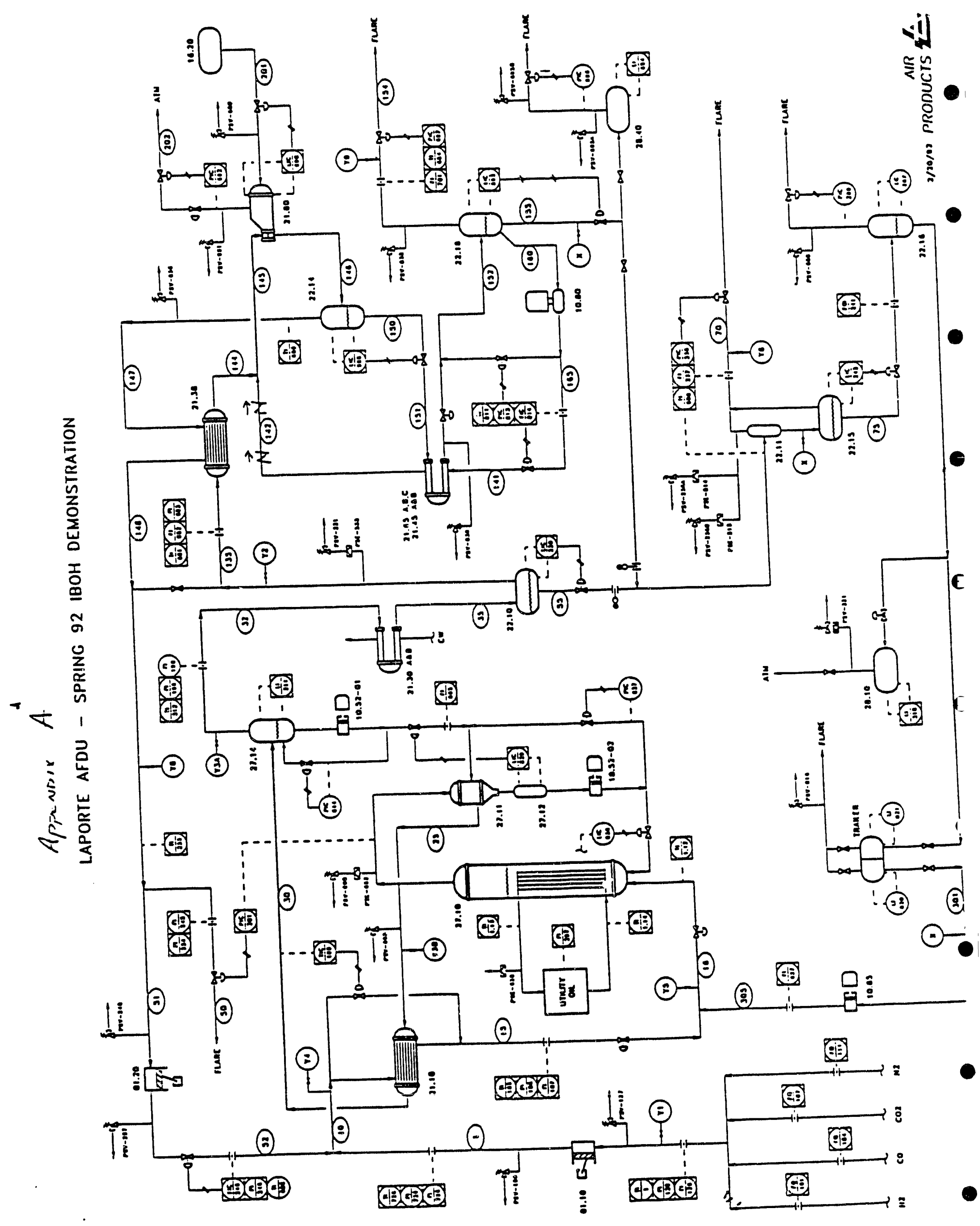


To: $\quad$ Distribution

From:

D. M. Herron

Date:

18 February 1992
Dept /oc.:

Dept/Ext: PSG-Process

Subject: Justification for Changing the High Temperature Shutdown (SD02) Set-Points - Spring ' 92 IBOH Demo at the AFDU

Distribution:
T. E. Conway
E. C. Heydom
M. R. Jocsak
G. A. Peters

ISSUE:

Process and R\&D would like to operate the reactor at $572 \mathrm{~F}$ and increase the high temperature shutdown set-points for the following devices:

$\begin{array}{lll}\text { TISH-182 } & 21.10 \text { Tubeside Inlet } & 590 \mathrm{~F} \\ \text { TSHH-190 } & 27.10 \text { Reactor } & 590 \mathrm{~F}\end{array}$

\section{POTENTIAL HAZARD WHICH IS BEING PROTECTED AGAINST:}

1. Unexpected, violently exothermic side reactions being triggered at elevated temperature ( primarily the methanation reaction).

2. Loss of coolant resulting in exceeding the design temperature of materials.

\section{HISTORY:}

G. A. Peters has determined that the installation of the existing high temperature shutdowns resulted from a hazards review following an exotherm in late 1983 (1). As explained by D. J. Silkworth (2)...

-A significant inventory of an old nickel catalyst was subsequently found to have remained in the product cooler, which had been a component of used equipment from a methanation pilot plant. Nickel catalyst particles had been able to recirculate through the original feed gas preheat system, and undoubtedly had provided a superior catalytic surface for the promotion of the methanation reaction during the December 1983 trials."

Following the ' 83 exotherm, the plant was thoroughly cleaned and according to Peters (1), the high temperature shutdowns were installed. The piant was subsequently operated over a two year period without incident. The normal reactor temperature was $482 \mathrm{~F}$ and the maximum was $507 \mathrm{~F}$. 
According to Heydorn, the normal high temperature shutdowns set-points used during the LP III contract and during the '91 DME Demo, were:

$\begin{array}{lll}\text { TISH-182 } & 21.10 \text { Tubeside Inlet } & 550 \mathrm{~F} \\ \text { TISH-183 } & 21.10 \text { Shellside Outlet } & 550 \mathrm{~F} \\ \text { TSHH-190 } & 27.10 \text { Reactor } & 515 \mathrm{~F} \\ \text { TSHH-312 } & 27.14 \text { Separator } & 550 \mathrm{~F} \\ \text { TSHH-550 } & \text { 02.62 Red. Gas Heater Outlet } & 550 \mathrm{~F}\end{array}$

Extended operations under the LP III contract were completed without any exothermic incident. The normal operating temperature of the reactor was $482 \mathrm{~F}$. On at least one occasion, the reactor was operated at $545 \mathrm{~F}$.

During the start-up for the DME Demonstration in 1991, testing for poisons was performed which revealed extremely low levels of iron and nickel carbonyls. This result indicates that the internals of the plant remain clean and devoid of loose nickel catalyst. Furthermore, continuous GC analysis of the gas streams during normal operations rarely picked-up methane.

\section{EVALUATION:}

It is my opinion that the lack of subsequent exotherms, low nickel carbonyl concentrations during carbonyl bum-out operations, and low to nil methane concentrations during normal operations support the supposition that the loose nickel catalyst has been successfully purged from the plant.

In addition, the risk of reintroducing nickel to the plant is minimal for the following reasons:

1. New stainless steel materials used in syngas service are passivated in nitric acid.

2. No electric heating elements are in direct contact with the syngas (excepting the reduction heaters which have been used previously, which process $96 \%$ N2 4\% syngas, and which retain the existing high temperature shutdown temperature).

Finally, nickel carbonyls tend to decompose on, and poison the catalyst within the reactor. The presence of small amounts of nickel in the reactor, though not desirable, does not seam to be a major safety issue since the heat of methanation is absorbed by the slurry oil along with the heat release associated with the major reaction.

\section{RECOMMENDATIONS:}

1. We should continue to use the high temperature shutdowns for the purpose of guarding against plant upsets such as loss of utility oil coolant flow. If this is the case, the sel-points should be based on intended operating temperature.

2. Implied in 1) is that high temperature shutdowns are being retained to protect oquipment and materials from being subjected to temperatures exceeding their design values, which is currently $600 \mathrm{~F}$ at 1000 psig for some pieces in and around the reactor. 
3. Concern for the presence of loose nickel in the existing plant should not be the basis for establishing shut-down set points. Rather, it should be demonstrated that the addition of new materials and equipment does not inadvertently introduce catalytic materials.

4. An exception to 3) is the high temperature shutdown on the electric reduction gas heaters. The current set point for TISH-550 (based on LP III) should be retained unless the exchanger is subjected to a controlled temperature-ramping demonstration. It may be useful to perform this work following the upcoming run.

5. Whenever we bring a piece of equipment to a new elevated temperature, the temperature should be ramped in a cautious and controlled manner.

6. Specific to the upcoming run, the set-points for TISH 182, and TSHH 190 should be increased to accommodate the new normal operating temperature of the reactor. The alarm and shut-down temperatures should be as near $572 \mathrm{~F}$ as possible and defined by operations to allow for small transients.

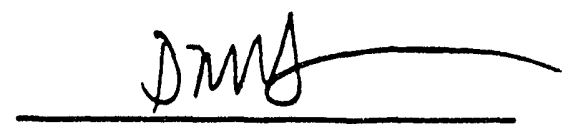

D. M. Herron

1) G.A. Peters to AFDU Hazards Review Team Members, "Criteria for High Temperature Alams/Shutdowns on the LaPorte Alternative Fuels Development Unit", 7 November 1991.

2) D.J. Silkworth to D.W. Studer, "LPMEOH - Part III, 87-7-1565, Hazards Review", 28 March 1988. 
PP.ODUCT NUMBER: 828931

DASF Catalyst S3-a6 Modified W/CS

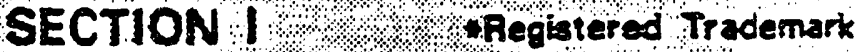

TRADE NAME: BASF Catalyst 53-86

CHEMICAL NAME: coppor oxide catalyst

\begin{tabular}{l|l|l|}
\hline SYNONYMS: & Low Pressura mathanol & FORMULA N/A
\end{tabular}

CHEMICAL FAMILY: Wetegeneus Catalysts

MOL. WGT.: N/A

\section{SECTION II - INGREDIENTS}

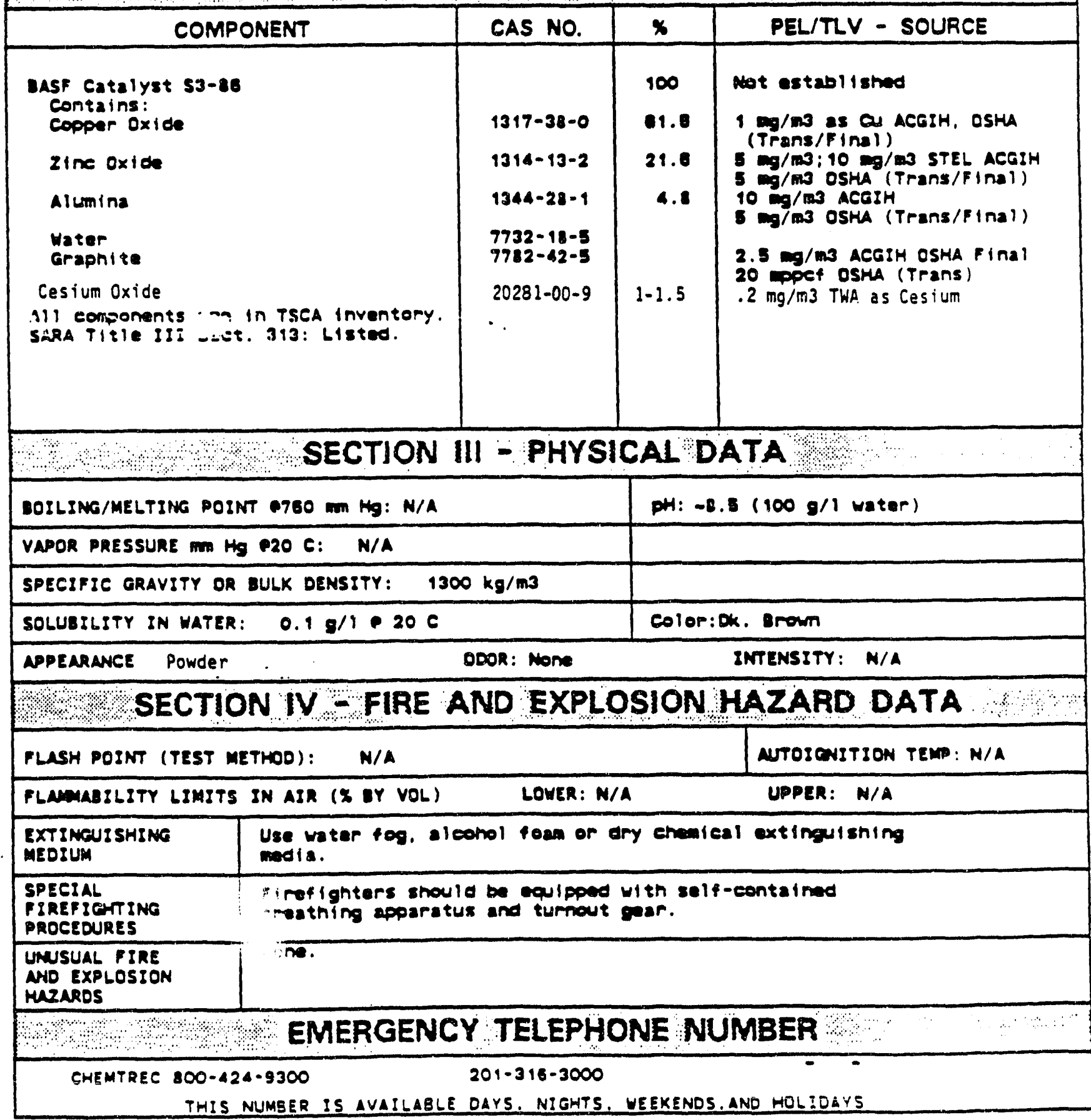


TOXICOLOGICAL TEST DATA:

BASF Catalyst 53-86

Rat, OPal LDSO

Rabolt, Skin Irrltation

Raboit. Eye Irritation
RESULT:

$4650 \mathrm{~m} / \mathrm{kg}$

Non-1rritating

Moderately irritating

EFFECTS OF OVEREXPOSURE:

contact with the powder or 1ts dusts ay nesult in modarate Irritation of the eyes and mochanical Irpitation of the skin. Inhalation of dusts causes respiratory Irritation. Chronic overexposure to copper compounds can lead to anemia, and damage to the liver, kldneys, lungs, and spleen. Gamm-alumina, a form of alumirum oxide, was florogenie then injected into the lungs of animais; however, aluminum oxide has not bean implleated as a cause of lung disease in humans. Inhalation of zine fumes may cause "metal fume fever". symetoms of wetal fume fever include metallie taste. Arymess, and irritation of the throat, difficult breathing, wakness, fatlgue, and fever. Thirtcen of nimeteen workers in a zine powder factory were reported to exhtbit inflammation of the upper nespiratory traet after 2-3 years of caployment. ingestion of zinc extoe powder may cause gastrie disturbances.

Existing madical conditions aggravated by exposure to this material:

No information found for this mixture.

FIRST AID PROCEDURES:

Eyes-Imnadiately wash oyes with ruming water for is mimutes. If irritation develoos, consult a physician.

Skin-Wash affected areas with soap and water. Renove and launder contaminated elothing before reuse. If Irritation davelops, consult a physleir.n.

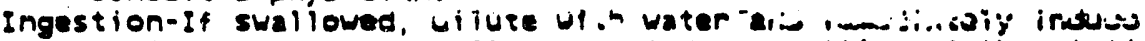
vomiting. Never give fluids or induce vomiting if the victim is unconseious or having convulsions: Cat immediate codical attention.

Inhalation-Move to fresh alr. Aid in breathing, if nocessary. and get lamadiate madical attantion.

\section{SECTION VI - REACTIVITY DATA}

STABILITY: Stable.

CONDITIONS TO AVOID: N/A

CHEMICAL INCOMPATIBILITY: N/A

HAZARDOUS DECOMPOSITION PRODUCTS: N/A

HAZARDOUS POLYMERIZATION: Does not coour CONDITIONS TO AVOID:

CORROSIVE TO METAL: NO

SECTION VII - SPECIAL PROTECTION

RESPIRATORY PROTECTION:

If eusts are ganirated, war a NIOSM/msm approved dust mask.

EYE PROTECTION: Chemieal goggles or side-shield safety glasses.

PROTECTIVE CLOTHING: Gloves and protective clothing as necessapy to prevent skin contact.

VENTILATION: Leeal exhaust roquITad to control to P.E.L.

OTHER: ciean clothing shoula be born dally.

snower after handiting. 
PRODUCT NUMBER: 828931 BASF Cataiyst 53-88 Modified W/CS

W. SECTION WII -ENUIRONIENTAL DATA
ENVIRONMENTAL TOXICITY DATA
Non aValiable.

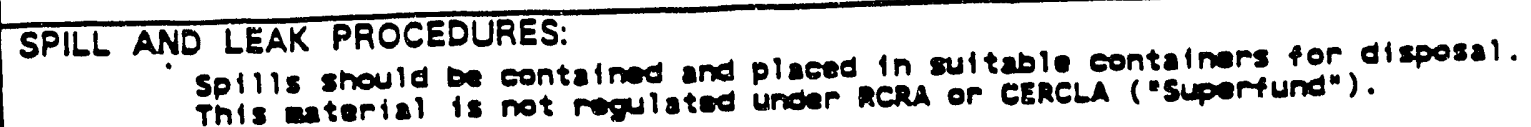

HAZARDOUS SUBSTANCE SUPERFUND: No RQ (lbst:

WASTE DISPOSAL METHOD:

Landf 111 in a licensed faellity.
Do not diseharge into waterways or sower systems without proper authorlty.

HAZARDOUS WASTE 4OCFR261: No MAZARDOUS WASTE NUMBER:

CONTAINER DISPOSAL:

Dispose of in licensed facility.

Recommend erushing or other mans to provent unauthorlzed rouse.

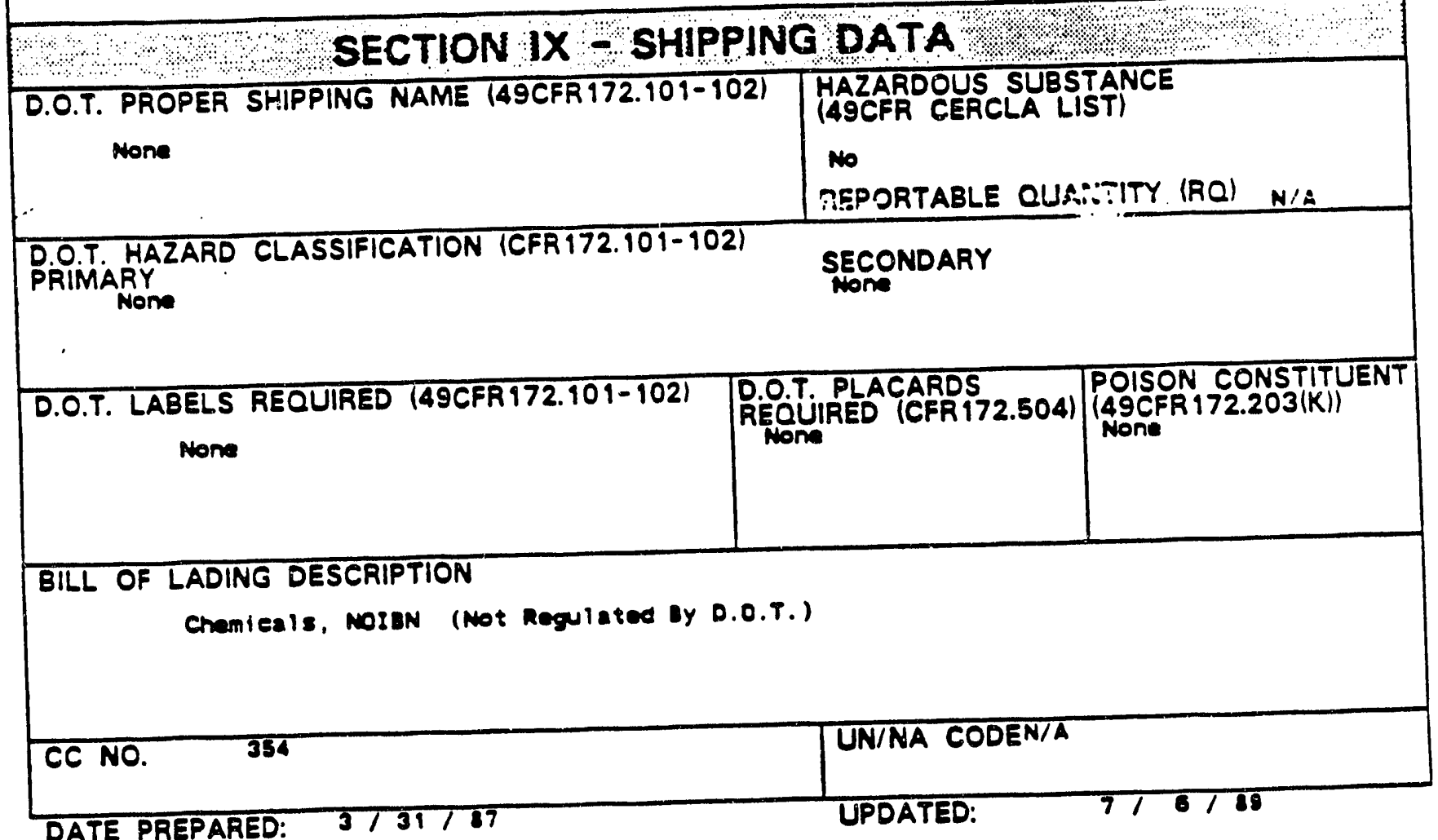

WHILE BASF CORPORATION BELIEVES THE DATA SET FORTH HEREIN ARE ACCURATE WHILE BASF CORPORATION BELIEVES THE DATA METES NO WARRANTY WITH RESPECT AS OF THE DATE HEREOF. BASF CORPORATION MAKES NO WARRANTY WTTHRESPEC THERETO AND EXPRESSLY DISELAIMS ALL LIABILITY FOR RELIANCE THEREON. SUCH DATA ARE OFF 
Dasf Catalyst 53-88 Modified W/CS

MARNING:

CONTAINS COPPER OXIDE (CAS NO.: 1317-38-0); NUMINA (CAS NO.: 1344-28-1);

ZINC OXIDE (CAS NO.: 1314-13-2).

CONTACT WITH EYES OR SKIN MAY RESULT IN IRRITATION.

INGESTION MAY RESULT IN GASTRIC DISTUREANCES.

INHALATION OF DUSTS MAY IRRITATE THE RESPIRATORY TRACT.

GAMMA ALUMINA, A FORM OF ALUMINUM OXIDE, WAS FIBROGENIC WHEN INJECTED INOT

THE LUNGS OF ANIMALS.

CARONIC OVEREXPOSURE TO COPPER COMPOUNDS CN LEAD TO ANEMIA ND DAMAGE TO THE LIVER, KIDNEYS. LUNGS NO SPLEEN.

INHALATSON OF ZINC OXIOE FUMES MAY CAUSE METAL FUME FEVER, SYMPTOMS OF MHICH

IMELUDE METALLIC TASTE, ORYNESS ANO IRRITATION OF THE THROAT, OIFFICULTY

IN GREATHING, WEAKNESS, FATIGUE AND FEVER.

Avold contact with eyes, skin or elothing. Avold brathing dusts.

Use with loesl exhaust. Hear a NIOSH/MSHA-approved dust respirator, chemical goggles, gloves, covaralls, epron, boots and othar protective clothing as mecessary to prevent contact. Shower after handing. Claan clothing should be worn dally.

FIRST AIO:

Eyes-Immediately wash eyes with running water for 15 minutes. If irritation cavelops, consult a physiclan.

Skin-Wash affected areas With soap and water. Remove and launder contaminated elothing before ruse. If irritation davelops, consult a physieian.

Ingestion-If swallowed, allute with water and lmadately induce vomiting. Never give flutds or induee vomiting if the vietim is unconselous of having convulsions. Cat immedate medieal attention.

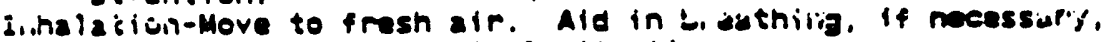
and get immediate madical attention.

IN CASE OF FIRE: Use water fog, aleohol foam or dry chemical extingulshing madia. Firefighters should be caipped with self-contained breathing apparatus and turnout gear.

EMPTY CONTAINERS: All labeled precautlons must be coserved then handiling. storing and transporting empty containars tue to produet residues. Do not reuse this container uniess it is professionally cleanad and reconditioned.

DISPOSAL: Spllied material, unused contents and empty containars must bo disposed of in aceordance with local. state and federal regulations. Refer to our Material Safety Data Sheat for specific disposal instruetions.

IN CASE OF CHEMICAL EMERGENCY: Call CHEMTREC day or night for assistance and information concerning spilied material, fire, oiposure and other chemical aceidents. $800-424-9300$

ATTENTION: This product is sold solely for use by industrial institutions.

Refer to our Technieal bulletin and Material Safety Data Sheet ragarding safety, usage applications, hazards. proceduras and disposal of this product. Consult your supervisor for additional information.

Cas Nos.: Graphlte: 7782-42-5

Made in West Gormany

intermodiates and fine chemicals

0489 


\section{Memorandum}

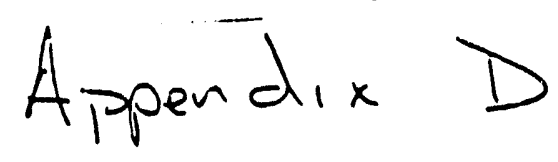

Dept $/ 0 c . \overline{1} \quad$ PSG Engineering Technology

To: J. C. Tafuri

Dept/Ext: PSG Process Engineering (4765)

From:

D. M. Herron

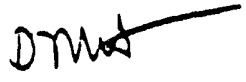

Date: 18 February 1992

Subject: LaPore AFDU Operation in the Spring of 92 - Materials Review

c: T. E. Conway

E. C. Heydom

M. R. Jocsak

G. A. Peters

Last year I had asked you to review two phase separators and one heat exchanger for fimess of service. We had intended to use the 22.14, 22.18 and 21.38 in service where the normal and/or upset temperatures were below that which was originally intended. To review:

$\begin{array}{lcc}\text { Item } & \text { Normal Temperature } & \text { Upset Temperature } \\ 22.14 & 0^{\circ} \mathrm{F} & -70^{\circ} \mathrm{F} \\ 22.18 & 80^{\circ} \mathrm{F} & -20^{\circ} \mathrm{F} \\ 21.38 & 0^{\circ} \mathrm{F} & -70^{\circ} \mathrm{F}\end{array}$

You had previously determined that these items were fit for use under these conditions for two, nominal two week runs. Low temperanure shut-downs were incorporated in the design and operation of the plant.

The first use of these items in "low" temperature service was completed in May 1991. The temperature control of the 22.14 was very stable and neither the 22.14 nor the 21.38 were subjected to temperatures below $0^{\circ} \mathrm{F}$. On one occasion the 22.18 was manually depressurized to near-amospheric pressure; details of the event are not documented but it is possible that the temperature in the heal of the 22.18 may have reached $-20^{\circ} \mathrm{F}$ (at amospheric pressure) for a short period of time.

As part of the Hazards Review for an upcoming ran (scheduled to begin early April this year) I have been asked to let you know that we intend to use these items again in similar service. Normal conditions are the same while the potential upset conditions result in less cool temperanures than previous. In addition, the probability for a repeat of the 22.18 depressurization event is much lower since this vessel will always be operated at nearatmospheric pressure. Following this run, these pieces of equipment will be permanently reconfigured and place back into high temperanure service (for another run scheduled in July of this year). 
I will stop up to discuss the use of these items in the upcoming run. A written response is not required unless you wish us not to proceed as indicated. 
Appendix E.

Memorandum

PROOUCARS

To:

G. A. Peters

From:

D. M. Hermon

Date: 11 February 1992
Dept/Le:: PSG-Engr Safety

Dept/Ext: $\quad$ PSG-Process

Subject: CO2 Vent Stack Review for the Spring '92 Demo at the AFDU

ce:

T.E. Conway

E.C. Heydorn

M.R. Jocsak

For the purpose of completing the hazards review, we need to review the $\mathrm{CO} 2$ vent stack. To summarize, two cases need consideration:

1. Release of $\mathrm{CO} 2$ during normal operations, and

2. Release of syngas during the 21.80 tube-rupture event.

Case 1:

Currently, the design max $\mathrm{CO} 2$ vent flow is $833 \mathrm{lb} / \mathrm{hr}$; the design minimum is $685 \mathrm{lb} / \mathrm{hr}$. Both these flows fall between the minimum and maximum flows which we examined last time (299 to $1128 \mathrm{lb} / \mathrm{hr})$.

Case 2:

I've looked at 8 different subcases for the tube rupture event. The results are tabulated in Tables $1,2 \& 3$.

Table 1 shows the assumptions made to arrive at each of the subcases. The maximum vent flow occurs when syngas blows into the 21.80 shell and vaporizes $\mathrm{CO} 2$. The two cases you may want to focus on are 1 and 3.

Table 2 shows the flows and composition for the release through the 3" vent; Table 3 shows the flows

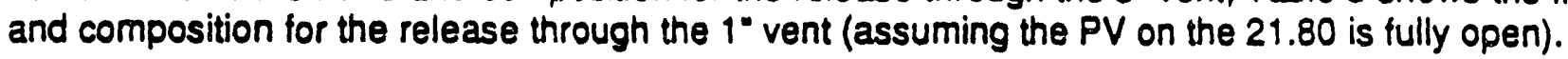

Please take a look these flows and make an operating recommendation.

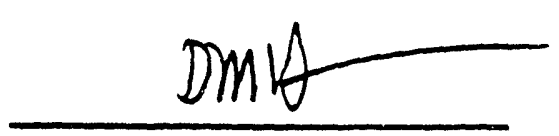

C

D. M. Hermon

PIS.

Tables 4', 5 Sinew the releagerates and riant pressures during de events (case 1-8) as a fiction of tine 
TABLE 1: KEY TO THE DIFFERENT CASES

\begin{tabular}{|c|c|c|c|c|c|c|c|c|}
\hline CASE & 1 & 2 & 3 & 4 & 5 & 6 & 7 & 8 \\
\hline $\begin{array}{l}\text { Synges through Tube? } \\
\text { Mothand through Tube? } \\
\text { Syngas mixes with } \mathrm{CO} 2 \text { Lquid? } \\
\text { Matiand mixes with } \mathrm{CO} 2 \text { \& Syngas? } \\
\text { PV-692 (evaporator vent) wide Open? }\end{array}$ & $Y$ & $Y$ & $Y$ & $Y$ & $\begin{array}{l}Y \\
Y\end{array}$ & $\begin{array}{l}Y \\
Y\end{array}$ & $\begin{array}{l}Y \\
Y \\
Y \\
Y \\
Y\end{array}$ & $\begin{array}{l}Y \\
Y \\
Y \\
Y\end{array}$ \\
\hline
\end{tabular}

TABLE 2: AELEASE TO THE 3 VENT

\begin{tabular}{|c|c|c|c|c|c|c|c|c|c|}
\hline CASE & & 1 & 2 & 3 & 4 & 5 & 6 & 7 & 8 \\
\hline Flow & $\begin{array}{l}\text { Ibshr } \\
\text { lo molahr }\end{array}$ & $\begin{array}{c}8132 \\
370\end{array}$ & $\begin{array}{l}8480 \\
385\end{array}$ & $\begin{array}{c}10780 \\
300\end{array}$ & $\begin{array}{c}10560 \\
375\end{array}$ & $\begin{array}{l}8070 \\
367\end{array}$ & $\begin{array}{l}8420 \\
383\end{array}$ & $\begin{array}{c}10401 \\
373\end{array}$ & $\begin{array}{c}10700 \\
381\end{array}$ \\
\hline Temperaure & $\boldsymbol{F}$ & 170 & 170 & .20 & .20 & 170 & 170 & -15 & .15 \\
\hline Pressure & pain & 17.5 & 18 & 17 & 17 & 17 & 18 & 17.5 & 17.5 \\
\hline Nob Wt & • & 22 & 22 & 292 & 292 & 22 & 22 & 28.1 & 28.1 \\
\hline Densiny & Ibris & 0.057 & 0.050 & 0.108 & 0.105 & 0.055 & 0.059 & 0.103 & 0.103 \\
\hline$C_{p}$ & BTUAB-F & 0.35 & 0.35 & 0.35 & 0.35 & 0.35 & 0.35 & 0.35 & 0.35 \\
\hline $\begin{array}{c}\text { Composition } \\
\mathrm{H} 2\end{array}$ & molo \% & & & & & & & & \\
\hline $\begin{array}{l}\mathrm{H} 2 \\
\mathrm{CO}\end{array}$ & & $\begin{array}{l}26 \\
67\end{array}$ & 26 & $\begin{array}{l}18 \\
4\end{array}$ & $\begin{array}{l}18 \\
44\end{array}$ & $\begin{array}{l}20 \\
67\end{array}$ & $\begin{array}{l}25 \\
67\end{array}$ & 22 & 22 \\
\hline $\mathrm{CO2}$ & & 7 & 7 & 38 & 39 & 7 & 7 & 37 & 37 \\
\hline HHV & BTUnb mols (TTF) & 113529 & 113520 & 75604 & 75004 & 113520 & 113529 & 76961 & 76951 \\
\hline Pipo 10 & in & 3 & 3 & 3 & 3 & 3 & 3 & 3 & 3 \\
\hline Tis Velocin & trsec & 800 & 817 & 580 & 500 & 825 & 813 & 576 & 588 \\
\hline
\end{tabular}

TABLE 3: RELEASE TO THE 1" VENT

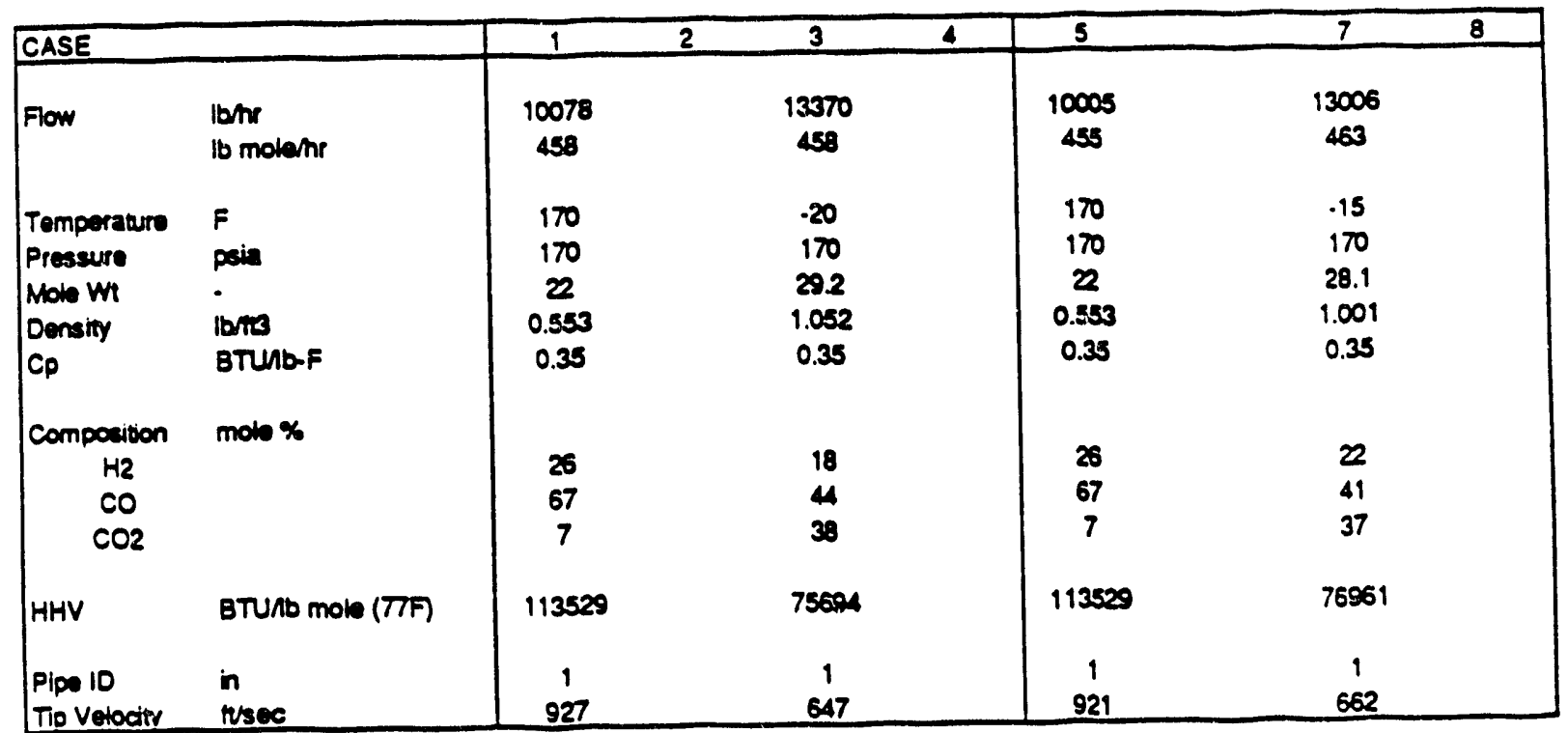


TABLE 4: RELEASE PREDICT̃ONS WTHOUT METHANOL FLOW

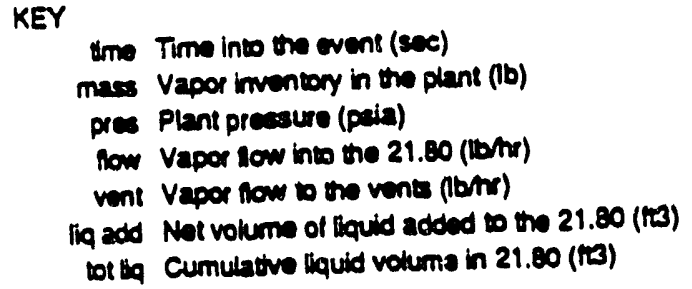

case I

$\begin{array}{rrrrr}\text { ime } & \text { mass } & \text { pres } & \text { now } & \text { vent } \\ 0 & 905.3 & 1015 & 18210 & 18210 \\ 53 & 702.8 & 780 & 14150 & 14150 \\ 76 & 631.5 & 708 & 12585 & 12560 \\ 87 & 606.5 & 680 & 7760 & 7780 \\ 191 & 454.9 & 510 & 5720 & 5720 \\ 318 & 330.9 & 371 & 3830 & 3930\end{array}$

$\begin{array}{ll}\text { liq add } & \text { itid } \\ 0.00 & 18.53 \\ 0.00 & 18.53 \\ 0.00 & 1853 \\ 0.00 & 18.53 \\ 0.00 & 18.53 \\ 0.00 & 18.53\end{array}$

CASE 2

$\begin{array}{rrrrr}\text { inm } & \text { mass } & \text { pres } & \text { now } & \text { vent } \\ 0 & 905.3 & 1015 & 8400 & 8400 \\ 79 & 767.9 & 861 & 7160 & 7180 \\ 201 & 601.2 & 674 & 5600 & 5600 \\ 212 & 594.9 & 657 & 836 & 836 \\ 384 & 594.9 & 657 & 836 & 836\end{array}$

liq add

oxio

$0.00 \quad 10.53$

$0 . \infty$

10.59

$0 . \infty$

:0s

$0 . \infty$

1053

$0.00 \quad 1859$

CASE 3

$\begin{array}{rrrrr}\text { ims } & \text { mass } & \text { pres } & \text { now } & \text { vent } \\ 0 & 869.8 & 975 & 11670 & 24150 \\ 63 & 718.9 & 806 & 9210 & 20230 \\ 122 & 607.4 & 681 & 7770 & 17100 \\ 128 & 599.4 & 672 & 4825 & 10520 \\ 308 & 449.5 & 501 & 3555 & 7820 \\ 522 & 328.2 & 368 & 2710 & 5310\end{array}$

liq ad ax

$0.00 \quad 1850$

$-3.19 \quad 1859$

$-5.75 \quad 1531$

$.5 .94 \quad: 2 \pi$

$.9 .82 \quad 125$

$.12 .94 \quad 71$

CASE 4

$\begin{array}{rrrrr}\text { und } & \text { mass } & \text { pres } & \text { now } & \text { vent } \\ 0 & 869.8 & 975 & 5290 & 10950 \\ 148 & 726.0 & 814 & 4210 & 9270 \\ 321 & 597.6 & 670 & 3480 & 7650 \\ 320 & 594.9 & 657 & 836 & 1700 \\ 384 & 594.0 & 657 & 836 & 1709\end{array}$

$\begin{array}{cc}\text { lif } 2000 & \text { bra } \\ 0.00 & 1859 \\ -3.40 & 1050 \\ -6.80 & 1913 \\ 6.89 & 1173 \\ .7 .00 & 114\end{array}$




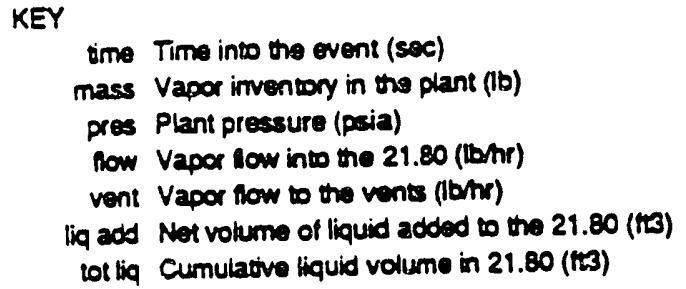

CASE 5

$\begin{array}{rrrrr}\text { time } & \text { mass } & \text { pres } & \text { how } & \text { vent } \\ 0 & 905.3 & 1015 & 18075 & 18075 \\ 52 & 709.1 & 795 & 14175 & 14175 \\ 77 & 630.6 & 707 & 12575 & 12570 \\ 86 & 611.0 & 685 & 7760 & 7760 \\ 190 & 457.6 & 513 & 5720 & 5720 \\ 317 & 333.6 & 374 & 3830 & 3830\end{array}$

$\begin{array}{rr}\text { liq add } & \text { tot liq } \\ & \\ 0.00 & 18.53 \\ 1.73 & 20.26 \\ 2.58 & 21.11 \\ 2.86 & 21.39 \\ 6.36 & 24.89 \\ 10.61 & 29.14\end{array}$

CASE 3

time mass pres how vent

$\begin{array}{lllll}0 & 905.3 & 1015 & 8420 & 8420\end{array}$

$\begin{array}{lllll}79 & 769.7 & 853 & 7180 & 7180\end{array}$

$\begin{array}{lllll}198 & 604.7 & 670 & 5600 & 5600\end{array}$

$\begin{array}{lllll}214 & 595.8 & 688 & 836 & 836\end{array}$

$\begin{array}{lllll}475 & 595.8 & 668 & 836 & 836\end{array}$

liq add bot tiq

$0.00 \quad 18.53$

$2.63 \quad 21.16$

$6.63 \quad 25.16$

$7.14 \quad 25.67$

$15.88 \quad 34.41$

CASE 7

$\begin{array}{rrrrr}\text { ime } & \text { mass } & \text { pres } & \text { flow } & \text { vent } \\ 0 & 869.8 & 975 & 11350 & 23495 \\ 60 & 725.1 & 813 & 9660 & 20000 \\ 117 & 611.9 & 686 & 8155 & 16880 \\ 122 & 604.7 & 670 & 4940 & 10680 \\ 300 & 452.2 & 507 & 3640 & 7820 \\ 522 & 330.0 & 370 & 2480 & 5340\end{array}$

liq add tot liq

$0.00 \quad 18.53$

$-1.35 \quad 17.18$

$-2.20 \quad 16.33$

$-2.23 \quad 16.30$

$-1.40 \quad 17.13$
0.97

$0.97 \quad 19.50$

CASE 8

$\begin{array}{rrrrrrrr}\text { time } & \text { mass } & \text { pres } & \text { How } & \text { vent } & \text { liq add } & \text { tot liq } \\ & & & & & & & \\ 0 & 869.8 & 975 & 5170 & 10700 & 0.00 & 18.53 \\ 155 & 718.9 & 805 & 4470 & 9040 & 0.61 & 19.14 \\ 305 & 600.3 & 673 & 3650 & 7550 & 1.72 & 20.25 \\ 3 i 6 & 555.8 & 658 & 836 & 1700 & 1.92 & 20.45 \\ 475 & 595.8 & 668 & 336 & 1700 & 5.37 & 23.90\end{array}$


'O: D. M. Herron

rom: G. A. Peters

late: 17 Pebruary 1992
Dept: - PSG Process

Dept/Ext: PSG Engineering Safety/8127

jubject: $\mathrm{CO}_{2}$ Vent stack for spring '92 Run - LaPorte APDU

s: T. E. Conway

E. C. Heydorn

M. R. Jocsak

I have reviewed the $\mathrm{CO}_{2}$ vent stack at the LaPorte APDU for the release cases sent to me in your memo dated 11 February 1992 per your request. Using the release information provided, I have determined that the existing stack will nct require any modifications for the Spring 1992 runs. The calculations have been performed for a stack that is 10 feet above the top operator platform.

Attached is some documentation supporting ny conclusion. Attachment 1 includes the dispersion runs performed on the $\mathrm{CO}_{2}$ releases from the I" $^{\prime \prime}$ stack. The diagrams indicate that the $\mathrm{CO}_{2}$ should not slump onto operating platforms at the release rates you provided. Attachment 2 is a. graph of the radiation that can result from ignition of the releases as defined in cases 1 and 3 of your memo. The acceptable radiation

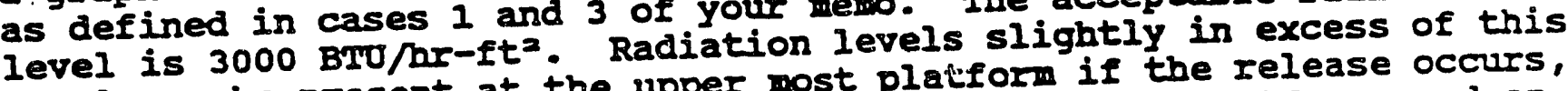
level may be present at the upper most platform if the release occurs, the material ignites, the wind is blowing toward the plate limit operator is present. As I recall, we mad operation of the APDO. This operator access to the tonforced during the spring 1992 runs.

I will be glad to provide any additional information on this issue. 
Buoyant Jet ModeI - JETX LAPORTE AFDU CO2 VENT ( 1 in)

MAX. CO2 RELEASE CASE FOR SPRING ' 92 RUN (833 lb/hr)

MDOT, $1 \mathrm{~b} / \mathrm{s}$

$0.23000 E+00$

UW, ft/s

$1.00000 \mathrm{E}+00$

DS

$0.50000 E+00$

MOLE FRACT

$0.12404 \mathrm{E}+00$

MOLE FRAC

4. $96478 E-03$

GAMMA, deg

$-1.78162 E+01$
$D$, in

1. $00000 \mathrm{E}+00$

TO, deg $F$

$-6.50000 E+01$

$1 /$ F N NO.

3.51087E-05

TUEI, sec

2.09859E-02

TLEL, sec

$9.66173 \mathrm{E}+00$

S, ft

$48.06250 \mathrm{E}+00$

ft2 =

MW

$44.00000 E+00$

GAMMA (0)

89.99900E+00

$\mathrm{Ta}, \operatorname{deg} F$

$70.00000 \mathrm{E}+00$

$z, f t$

$51.72908 \mathrm{E}+00$

$z, f t$

$85.72976 E+00$

$\mathrm{U}, \mathrm{ft} / \mathrm{s}$

1.11327E+00

$0.00000 E+00$
LEL

5.00000E-03

RHOO, 1b/ft3

$0.15261 E+00$

Uo, ft/s

$27.63295 \mathrm{E}+01$

$x, f t$

$1.45380 \mathrm{E}-02$

$\mathrm{x}, \mathrm{ft}$

$20.95962 E+00$

B, ft

$13.29287 \mathrm{E}+00$

at $\mathrm{Z}=$
UEI

$0.12500 E+00$

STABILITY

6.00000E+00

ALPHA 3

$1.00000 E+00$

MEX, I bs

$0.00000 E+00$

MEX, I DS

2. $21737 E+00$

Ho, ft

$50.00000 E+00$

$0.00000 E+00$

The Program Date is: 24 April, 1991 - Version 6.7

100

Buoyant Jet Mode1 - JETX .00496ב

$Z, f t$

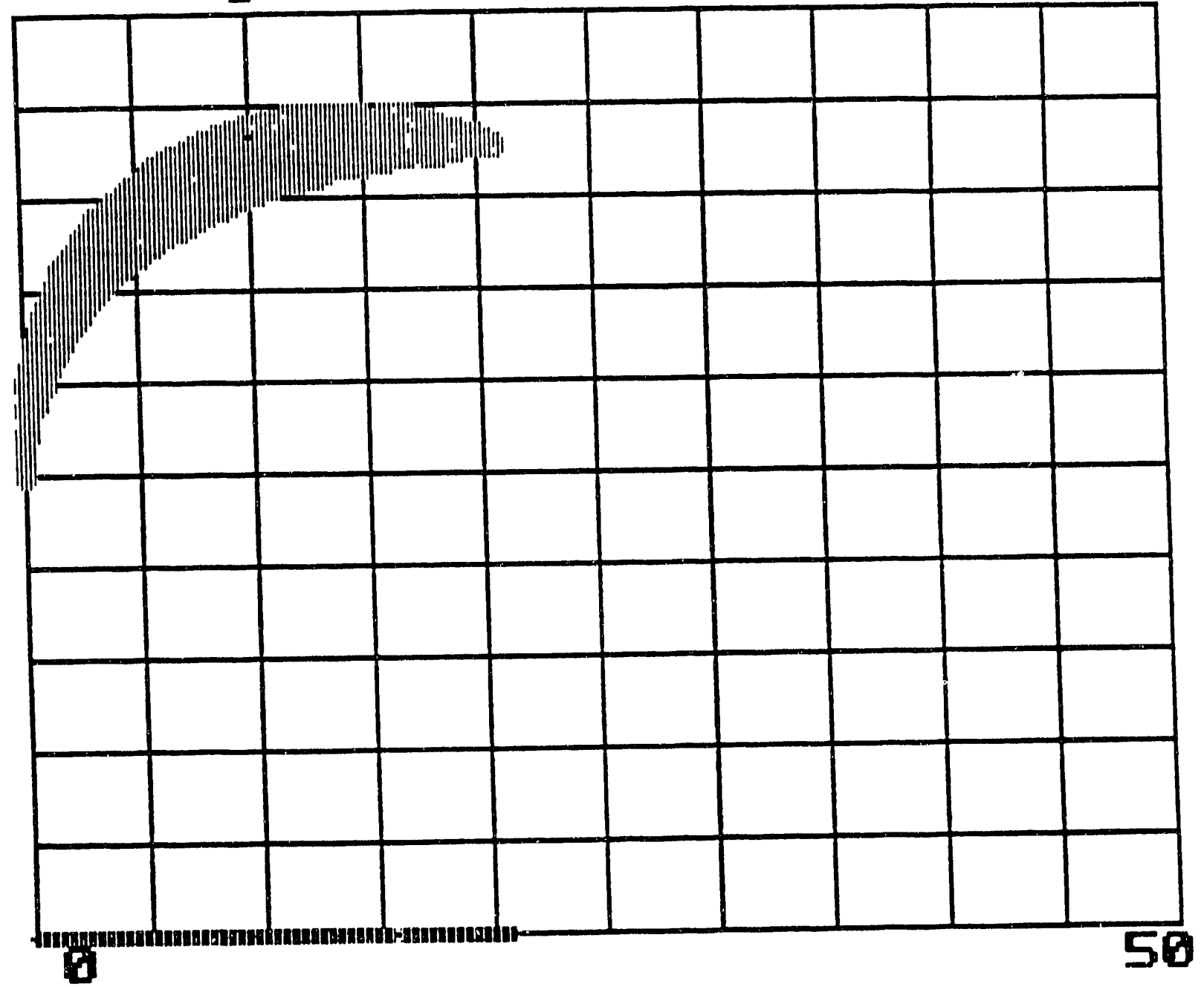


Buoyart Jet Model - JETX

LAPORTE AFDU CO2 VENT (1in)

MIN. CO2 REIEASE FOR SPRING '92 RUN (685 lb/hr)

MDOT, Ib/s

$0.19000 E+00$

Uw, ft/s

$1.00000 E+00$

DS

$0.50000 E+00$

MOLE FRACT

$0.12403 E+00$

MOLE FRAC

4. $95460 E-03$

GAMMA, deg

$-3.08401 E+01$

Isopleth Ar
$D$, in

$1.00000 \mathrm{E}+00$

To, deg $F$

$-6.50000 E+01$

$1 / F r$ NO.

5.14474E-05

TUEL, sec

2.54115E-02

TLEL, Sec

$10.93143 \mathrm{E}+00$

S,ft

$44.54167 \mathrm{E}+00$

ea, $f t 2=0.00000 E+00$
MW

$44.00000 E+00$ GAMMA (0)

$89.99900 E+00$

$\mathrm{Ta}, \operatorname{deg} \mathrm{F}$

$70.00000 E+00$

$\mathrm{Z}, \mathrm{ft}$

$51.72905 E+00$

$\mathrm{Z}, \mathrm{ft}$

$77.40084 E+00$

$U, f t / s$

$1.22100 E+00$
100

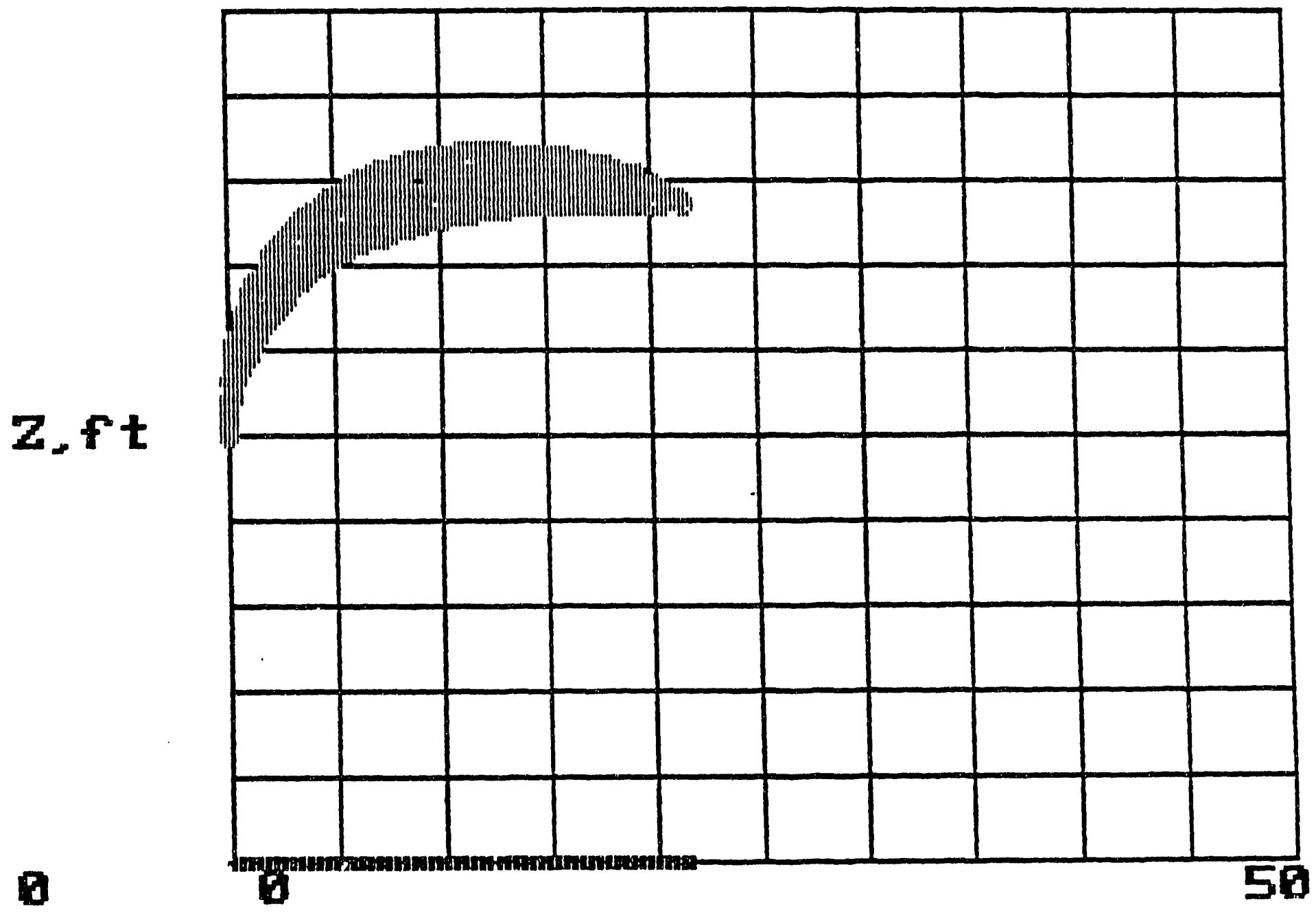

Buqyant Jet Mode1 - JETX.004959

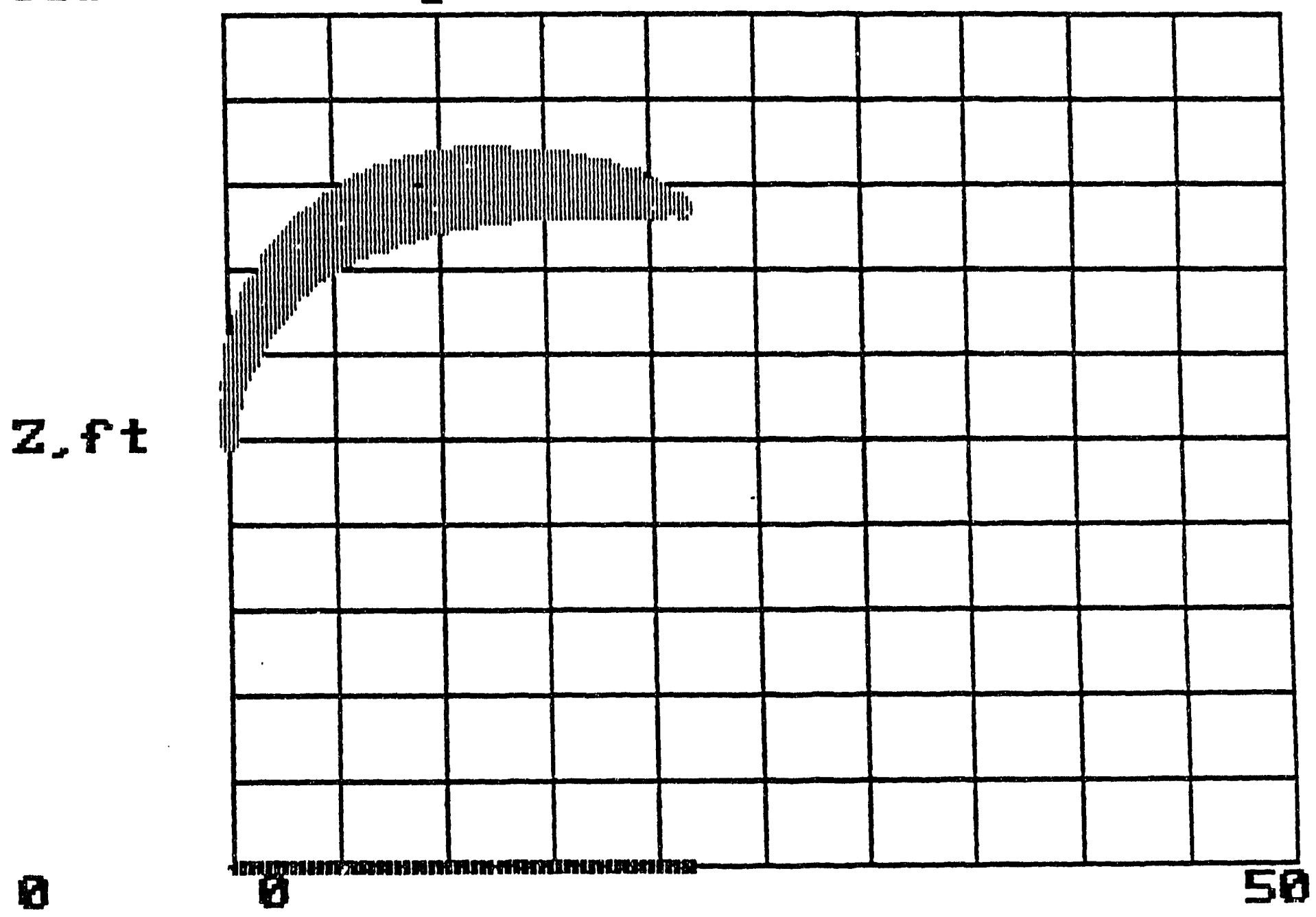

UEL

$0.12500 E+00$

STABILITY

$6.00000 E+00$

ALPHA 3

$1.00000 E+00$

MEX, Ibs

$0.00000 E+00$

MEX, Ibs

$2.07214 E+00$

Ho, ft

$B, f t$

$50.00000 E+00$ at $z=0.00000 E+00$ 


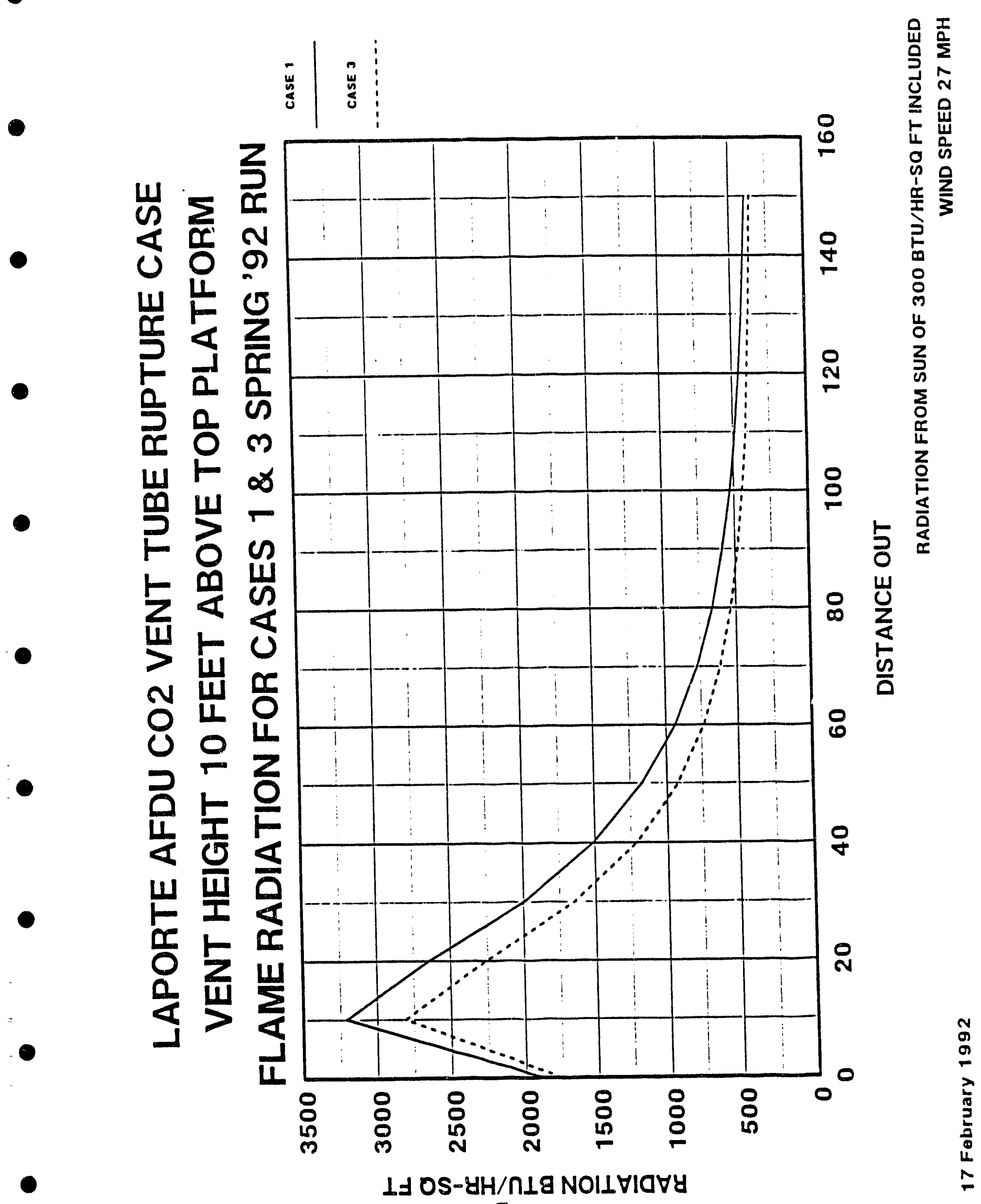




\section{APPENDIX 2}

\section{DESIGN HAZARDS REVIEW REPORT APRIL 1992 LIQUID PHASE SHIFT (LPS) RUN}




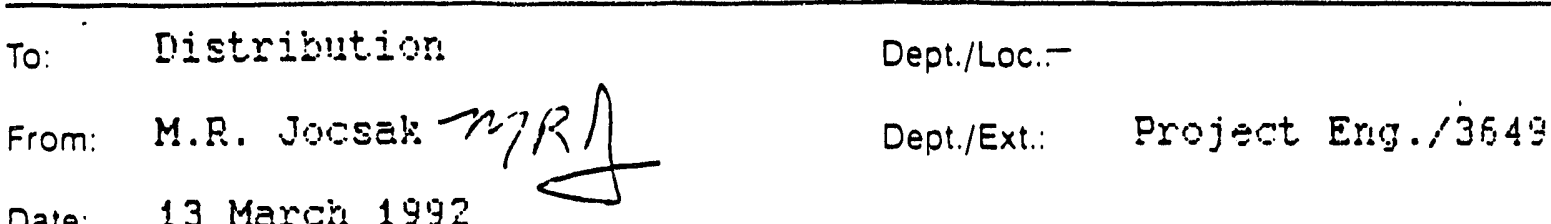

Date: 13 Marcin 1992

Subject: Design Verification Reviow Report April 1922 Liguid phase Shift. (LPS) Rut

Distribution:

W.C. Allen (MC\#83)

A.G. Barbieri

D.M. Erown

T.E. Conway

E.C. Heydorn (Laporte AFDU)

T. Hsiung, R.F. Underwood

G.A. Peters -Proe Exg.

E. Schaub/E. Bhatt/D. Studer

R.I. Williams

Attached is a copy of the Design Verification keview report for the Liquid Phase Shift (LPS) demonstration at the Alternative Fuels Development Unit (AFDU) in LaForte, TX.

Most of the hazard items have been satisfactolily addressed and included in the plant design and/or operating procedures. The status of all action itens will be reviewed during the ORI-Safety Audit.

Please contact me if you have any questions of comments.

MEJ $/ 029$

RECEIVED

MAR 181992

FROCESS ENGINEERING 


\section{DESIGN VERIFICATION REVIEW (DVR)}

Alternative Fuels Development Unit (AFDU)

April 1992 Liquid-Phase Shift (LPS) Run

LaPorte, Texas

11 March 1992

Review Team

T. E. Conway

D. M. Herron

E. C. Hcydom

M. R. Jocsak

G. A. Peters
Start-Up Engineering Process Engineering Operations Project Engineering PSG Safety Engineering 


\author{
Design Verification Review (DVR) \\ Altemative Fuels Development Unit (AFDU) \\ April 1992 Liquid Phase Shirt (LPS) \\ LaPorte, Texas \\ 11 March 1992
}

\title{
Table of Contents
}

\section{Page No.}

I. Introduction

II. Status of Hazard Items...

\section{Appendices}
A. E.S. Schaub, 13 March 1992 memo, Review of tube ruphure anlysis.
B. G.A.Peters, 10 March 1992 memo, $\mathrm{CO}_{2}$ Vent Stack safety review.

\section{References}

1. Design Hazards Review Report (DHR) - 3 March 1992 (LPS)

2. Engineering Flowsheet (P\&ID) for the Spring ' 92 Liquid Phase Shift DEMONSTRATION - ATT1016C, revision 1, March 10, 1992

3. Engineering Flowsheet (P\&ID) 87-7-1533, Liquid Phase Methanol, revision 15, 19 September, 1991.

4. FCN (to F/S 87-7-1533) \#'s: $31,32, \& 33$. 


\section{NTRODUCTION}

A Design Verification Review (DVR) meeting was conducted on 11 March 1992 for the April 1992 Liquid Phase Shift (LPS) run.

The meeting was conducted by first reviewing the Rev. 1 P\&ID and preliminary FCN's and then addressing hazard items. All of the hazard items identified for the iso-butanol demonstration were addressed and a determination was made as to their relevance to the LPS run. In addition, several new hazard items were discussed.

\section{STATUSOFHAZARD ITEMS}

The following lists the status of each hazard item as discussed during the DHR meeting. 


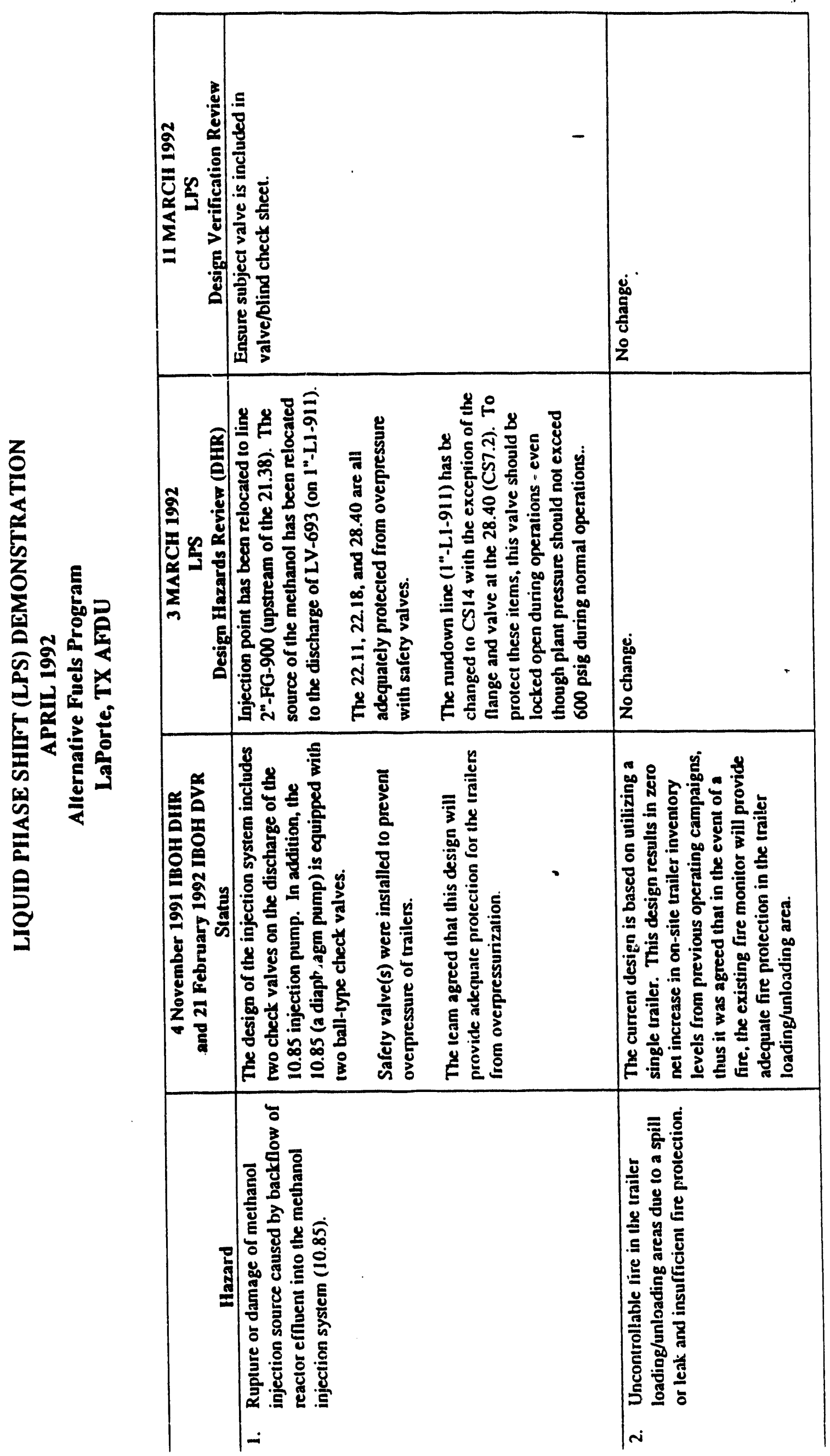



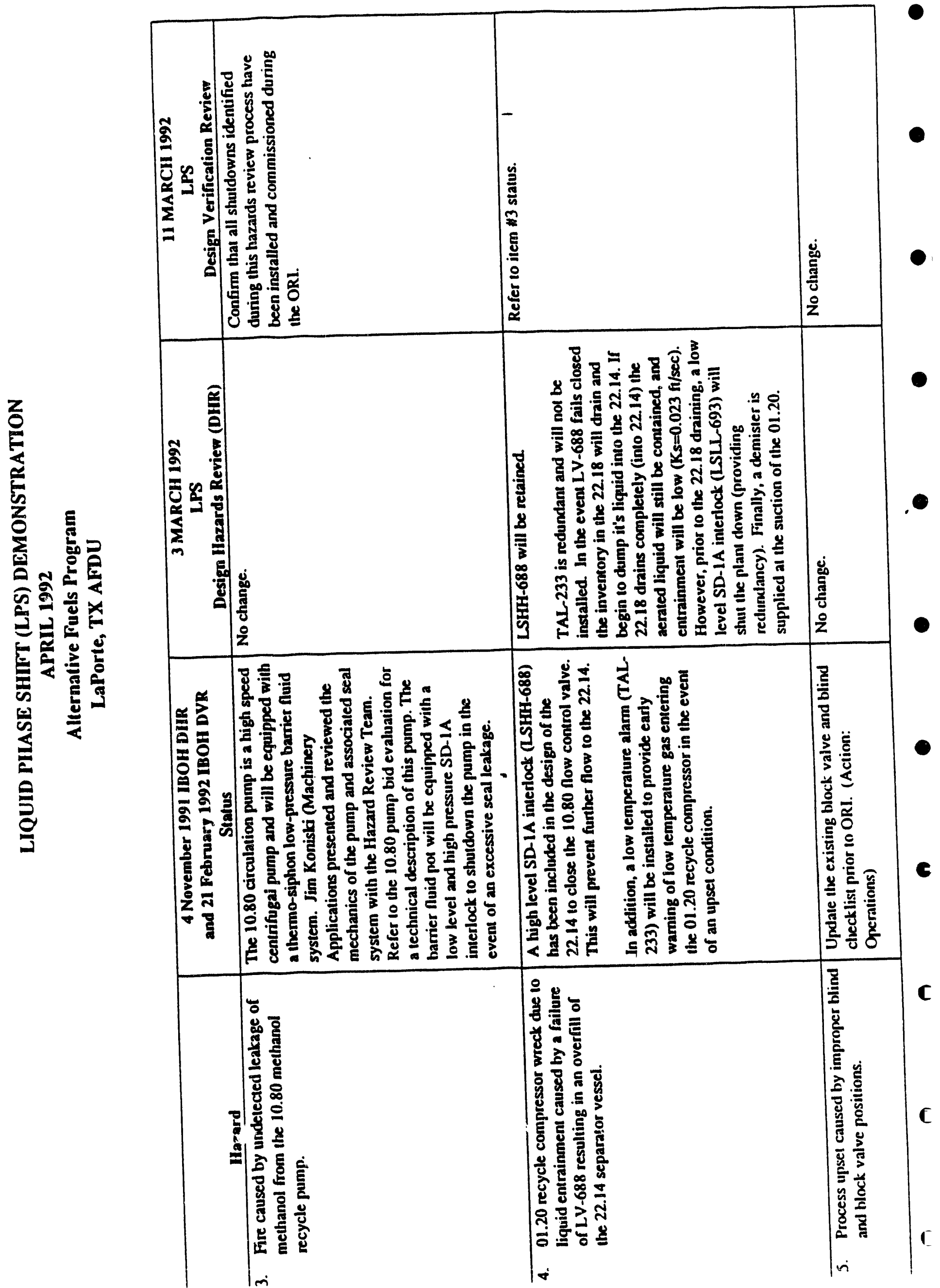


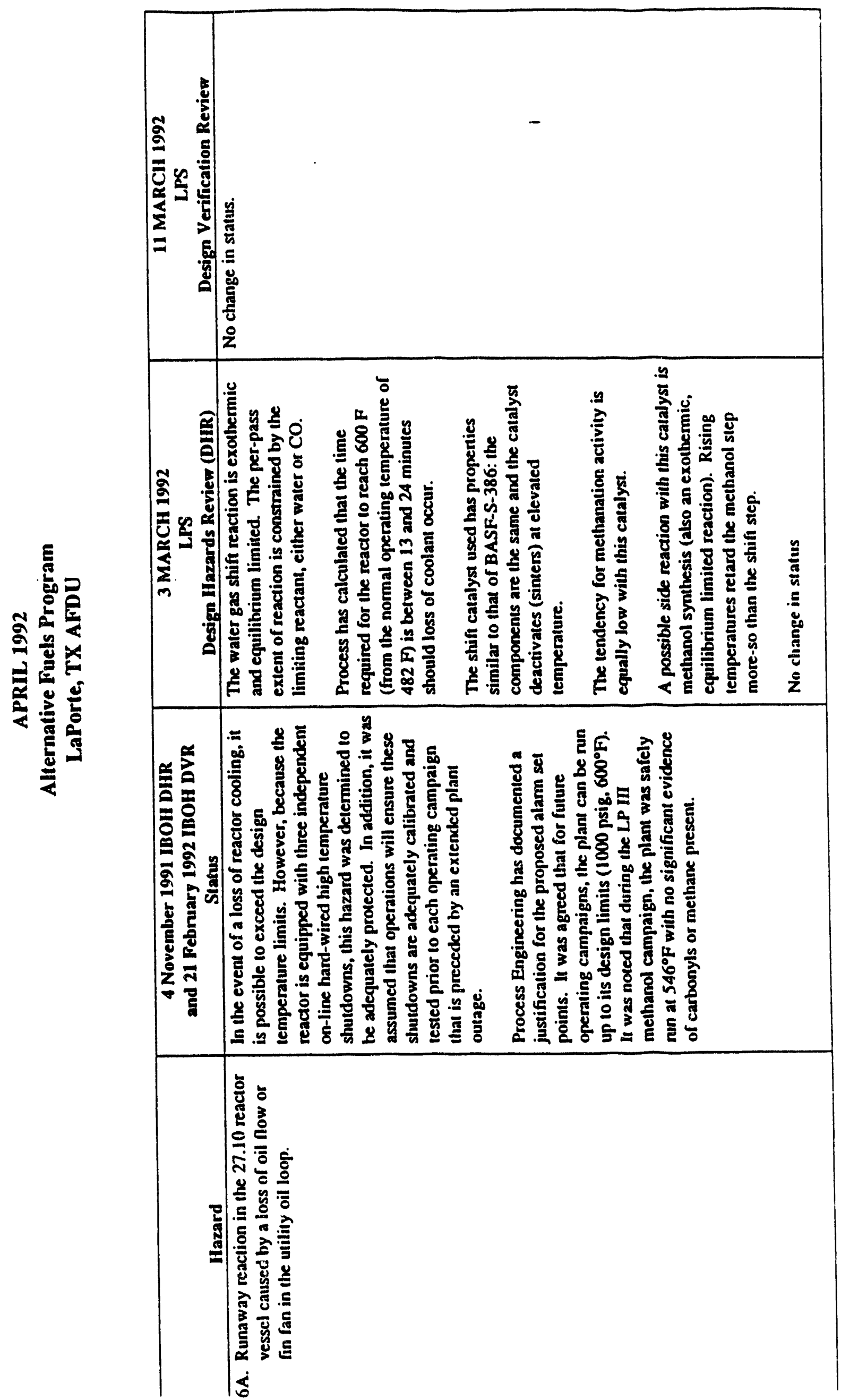




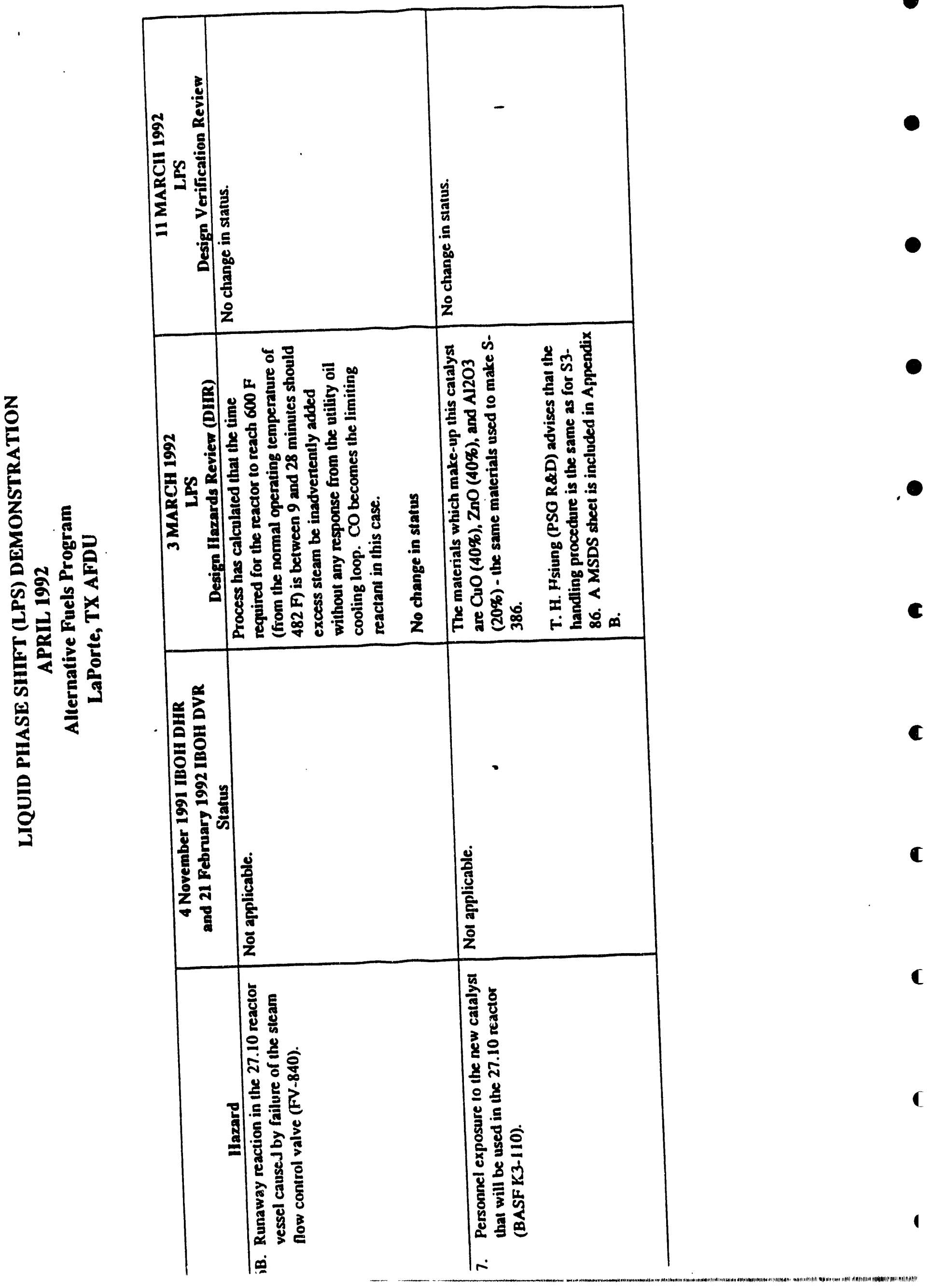



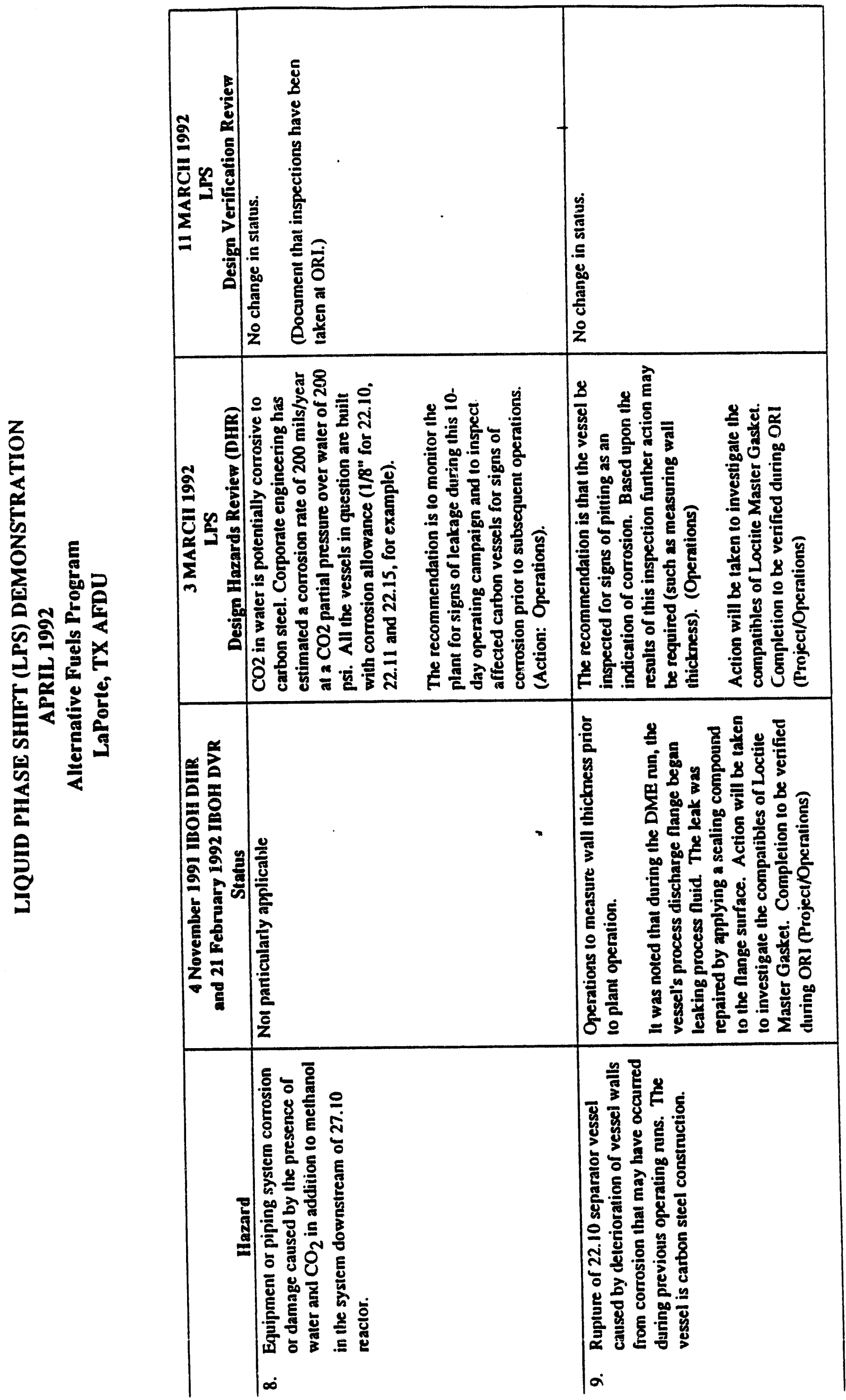


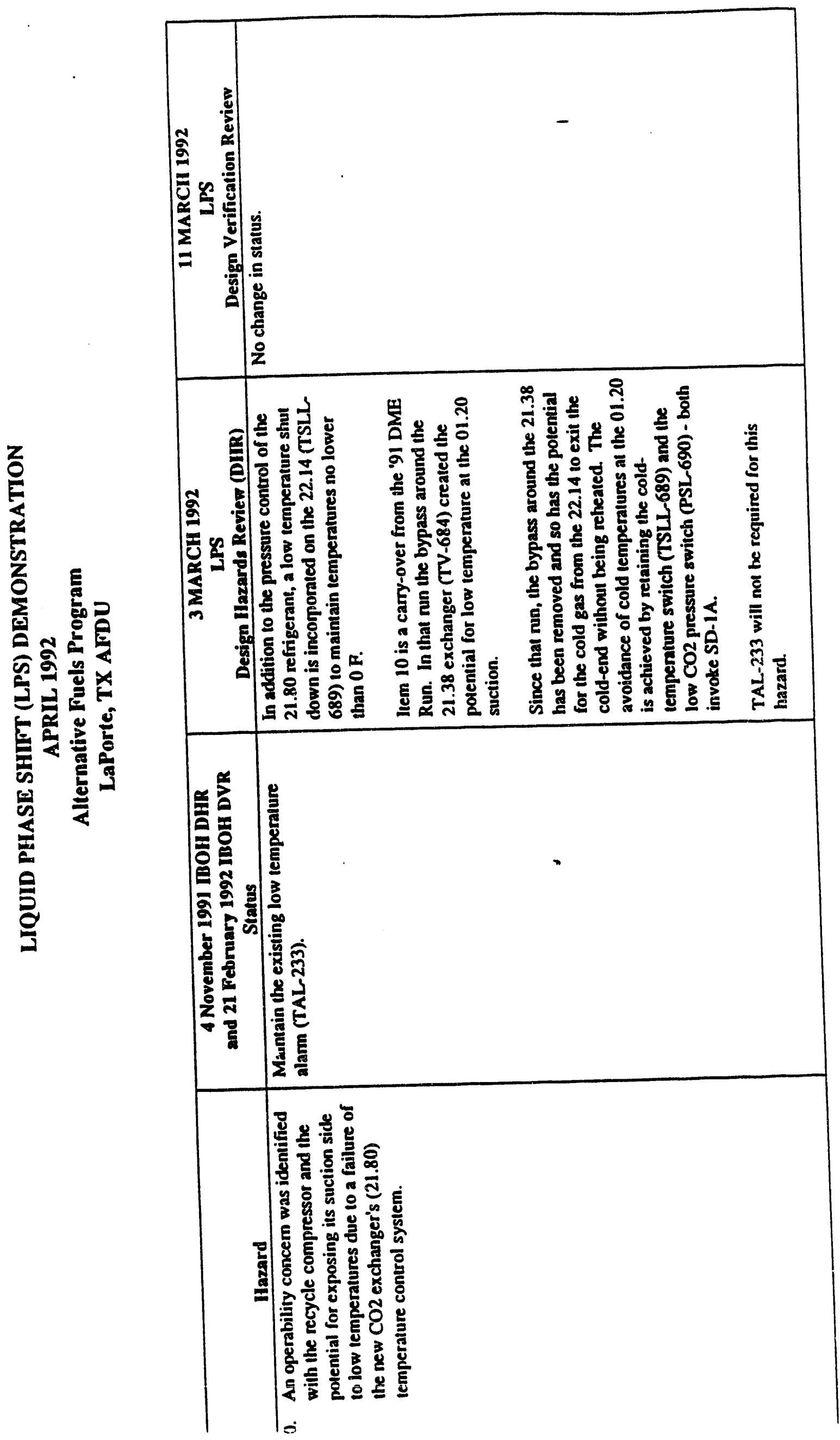



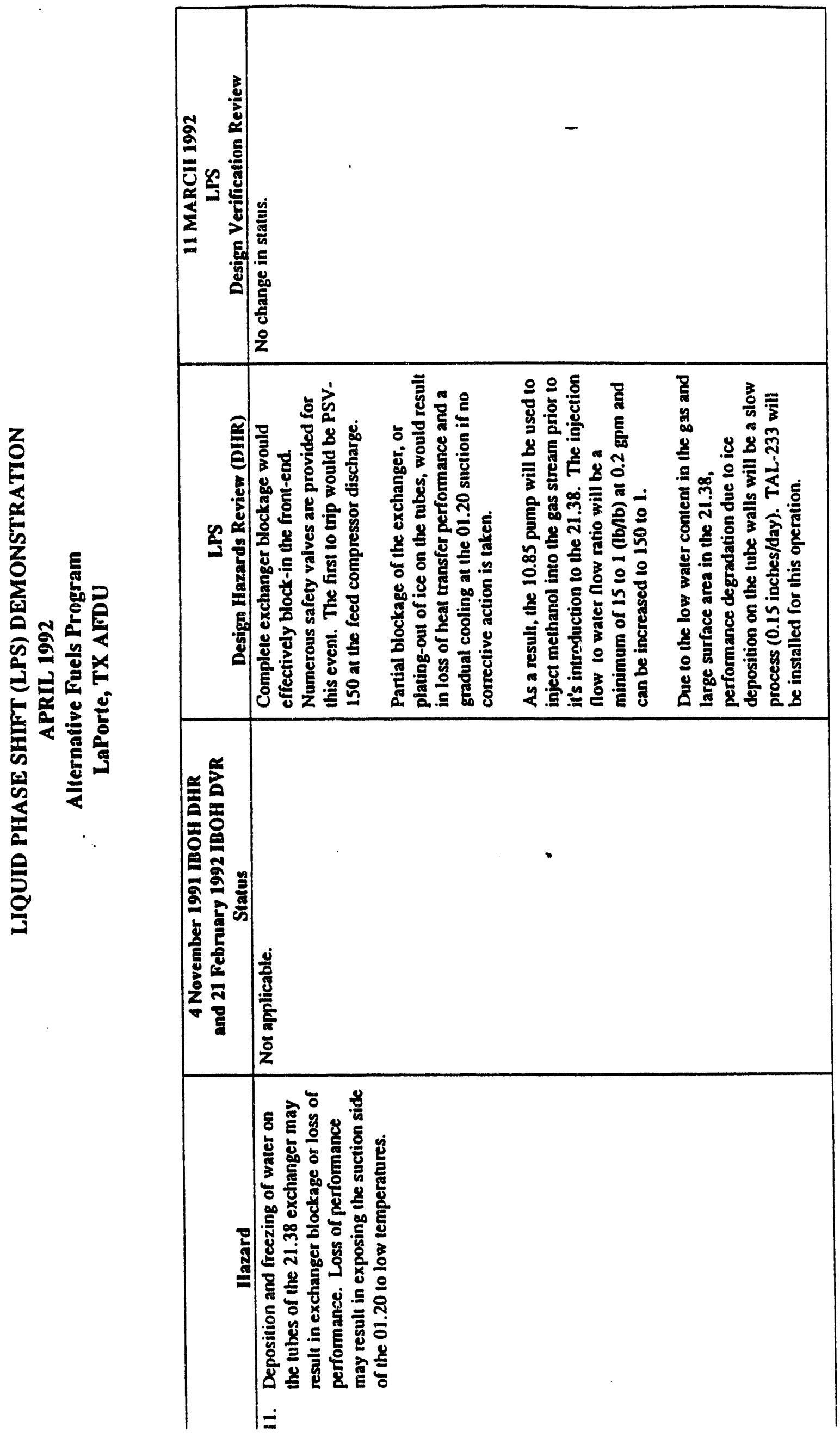

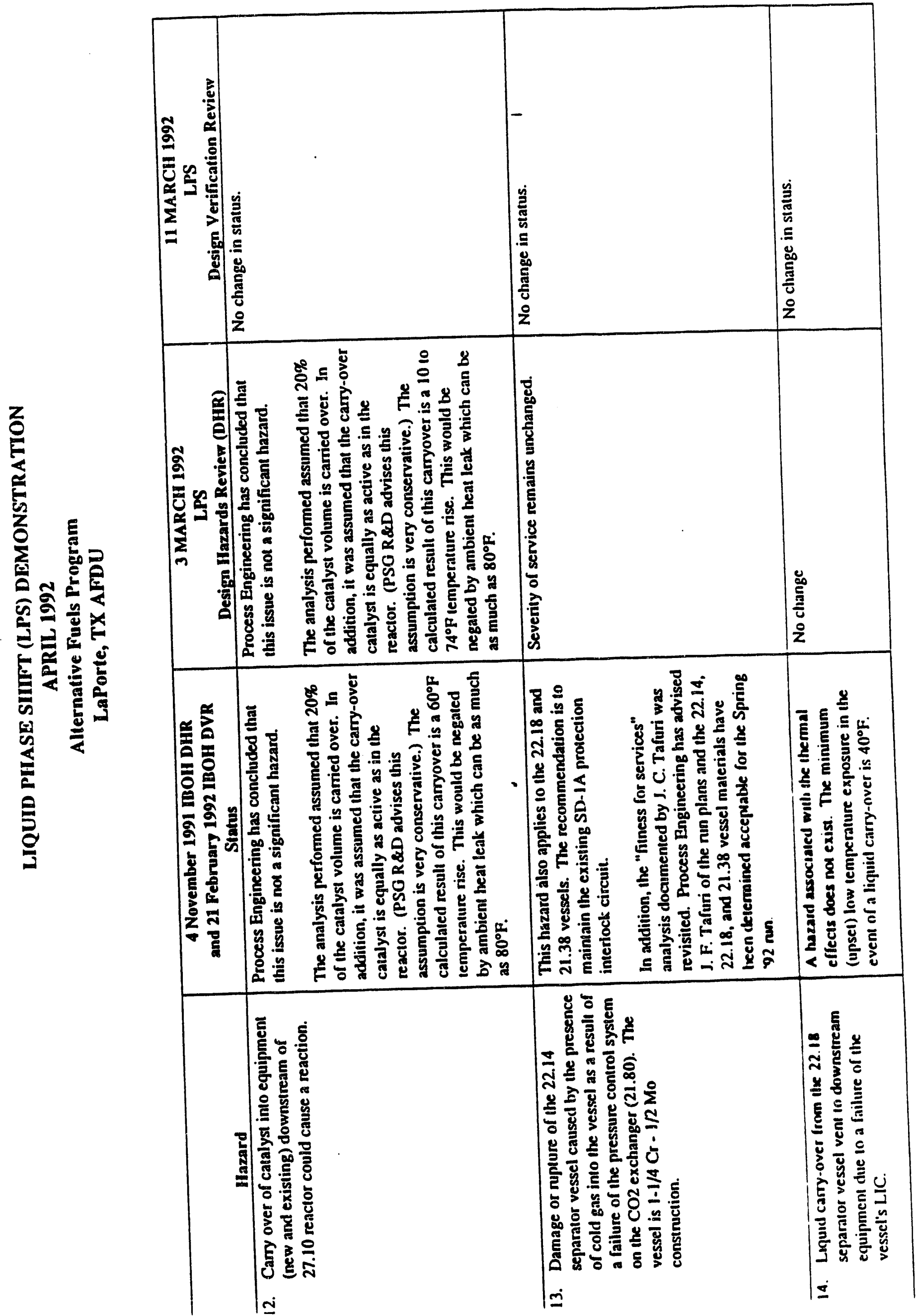


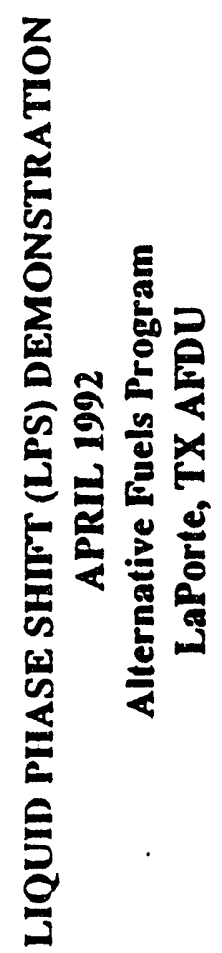

\begin{tabular}{|c|c|c|c|c|c|}
\hline 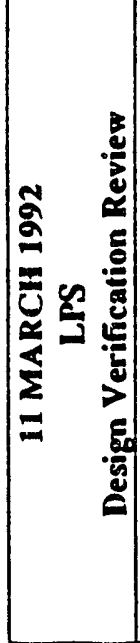 & 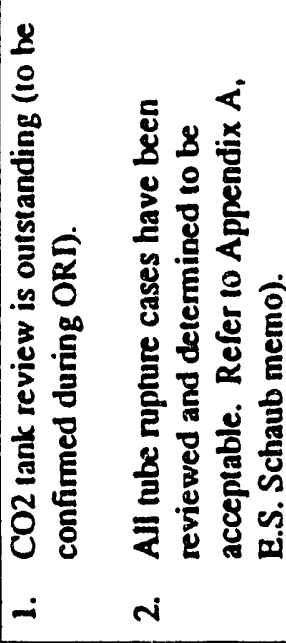 & 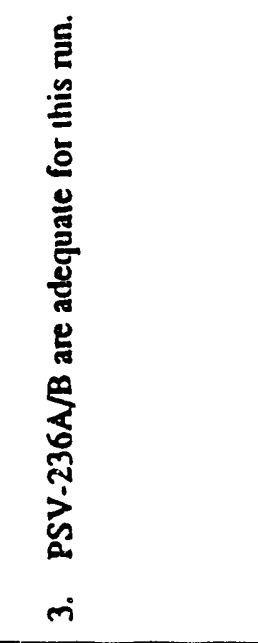 & 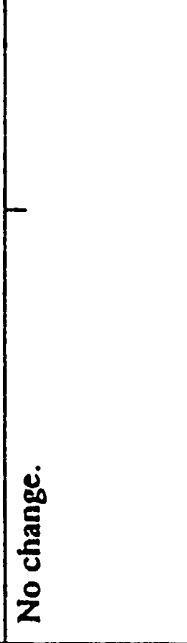 & 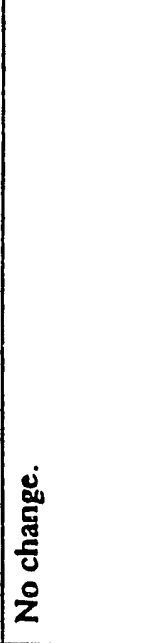 & 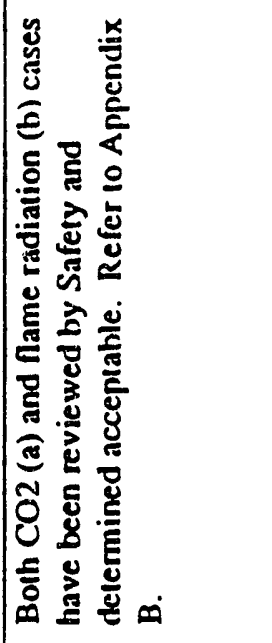 \\
\hline 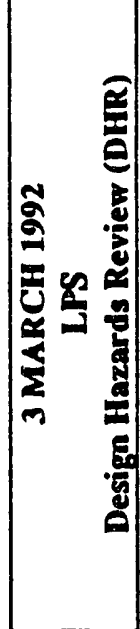 & 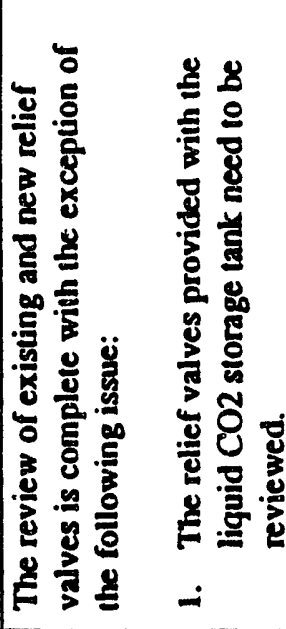 & 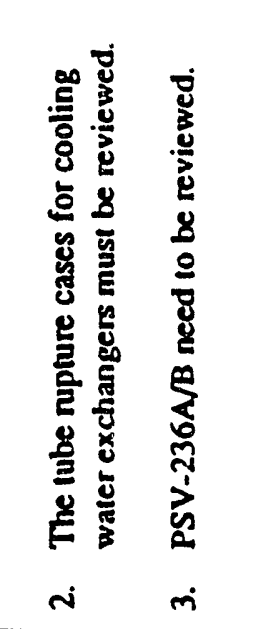 & 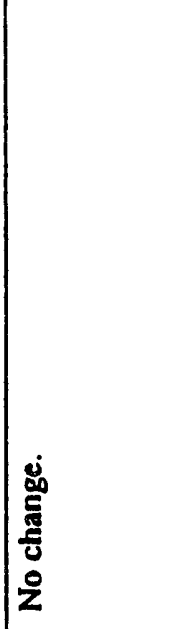 & 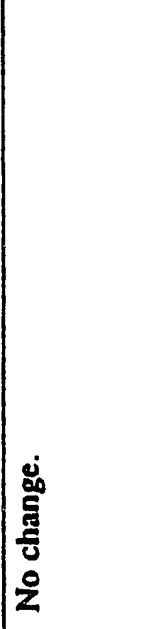 & 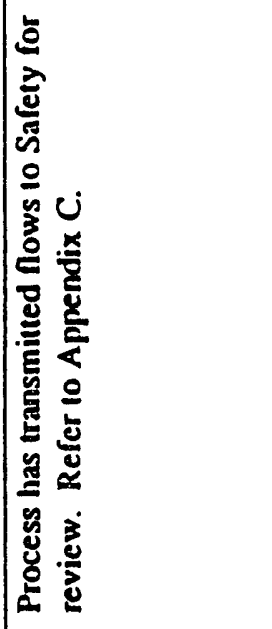 \\
\hline 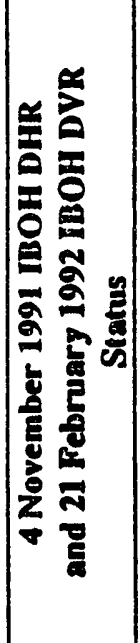 & 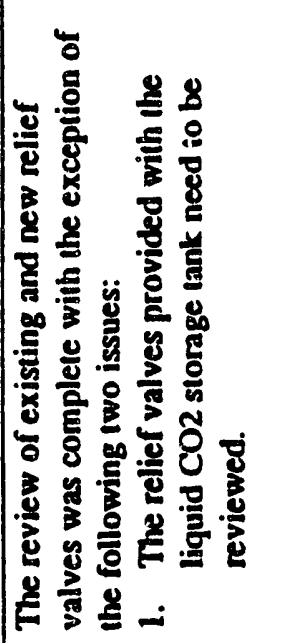 & 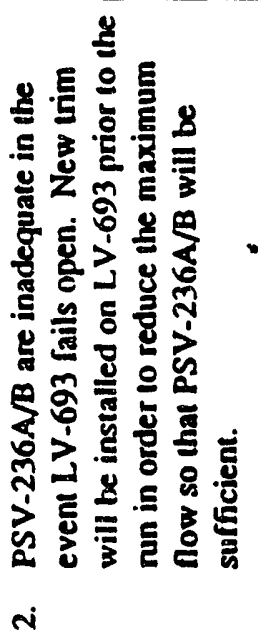 & 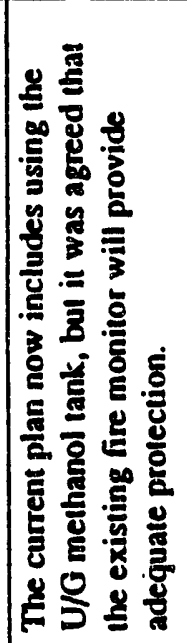 & 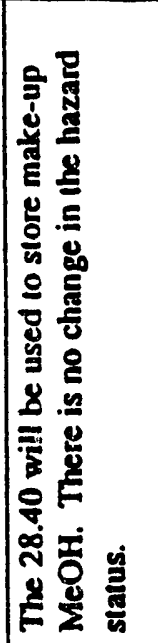 & 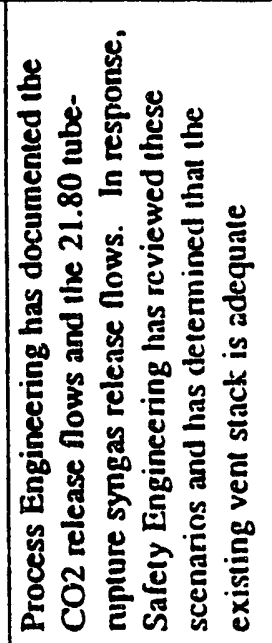 \\
\hline & 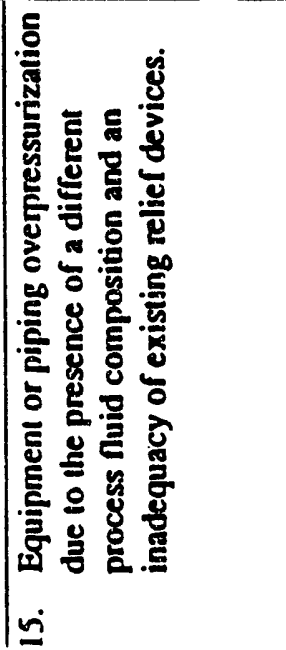 & & 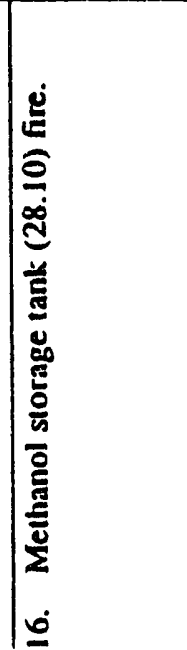 & 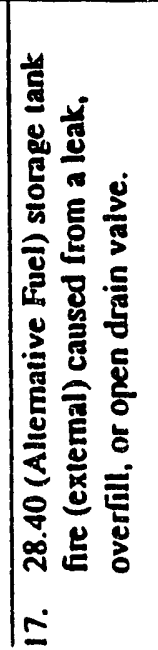 & 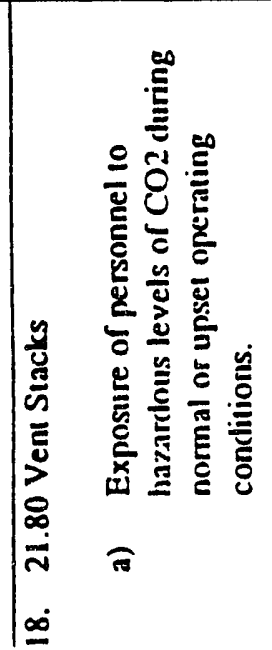 \\
\hline
\end{tabular}




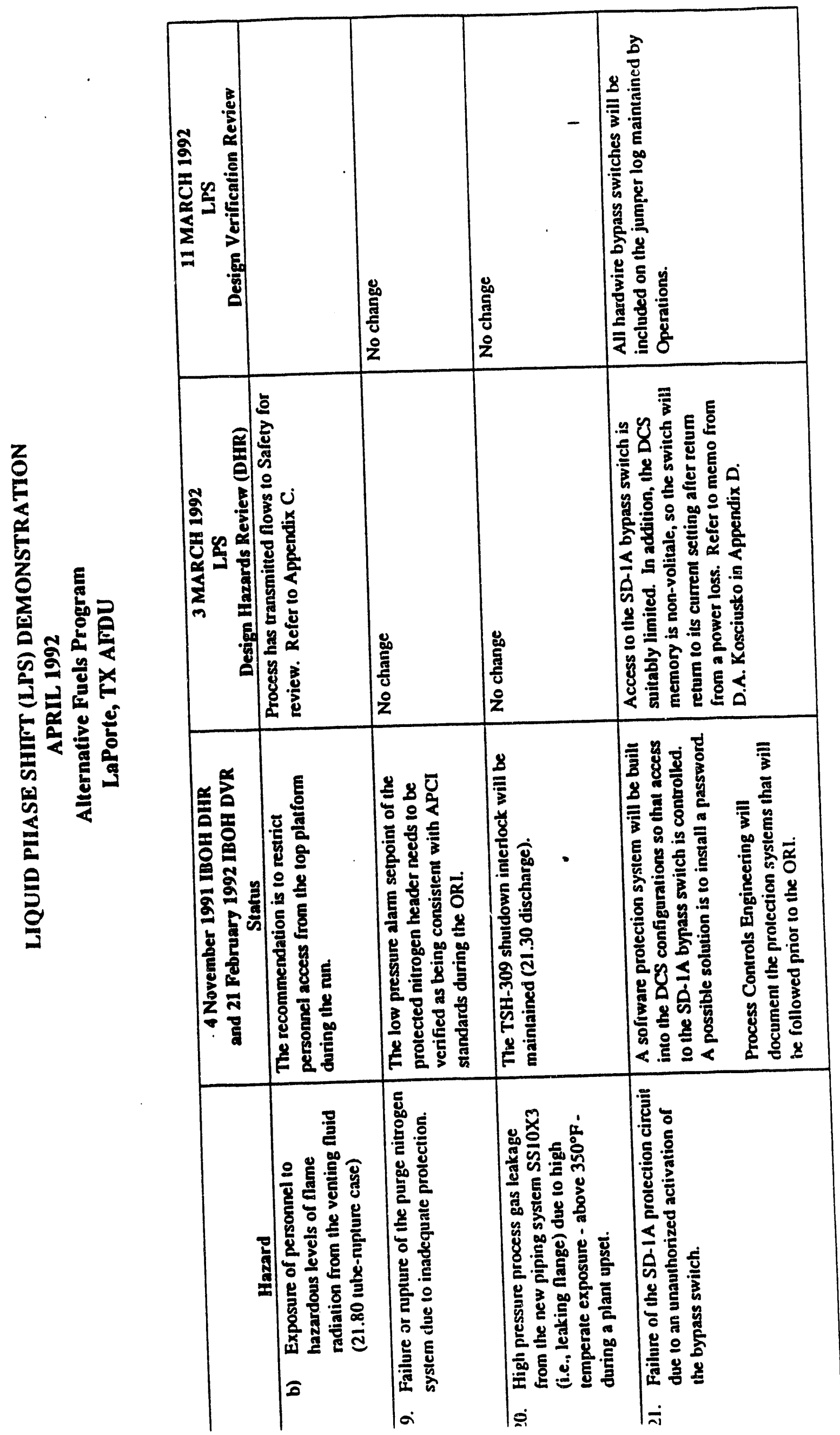




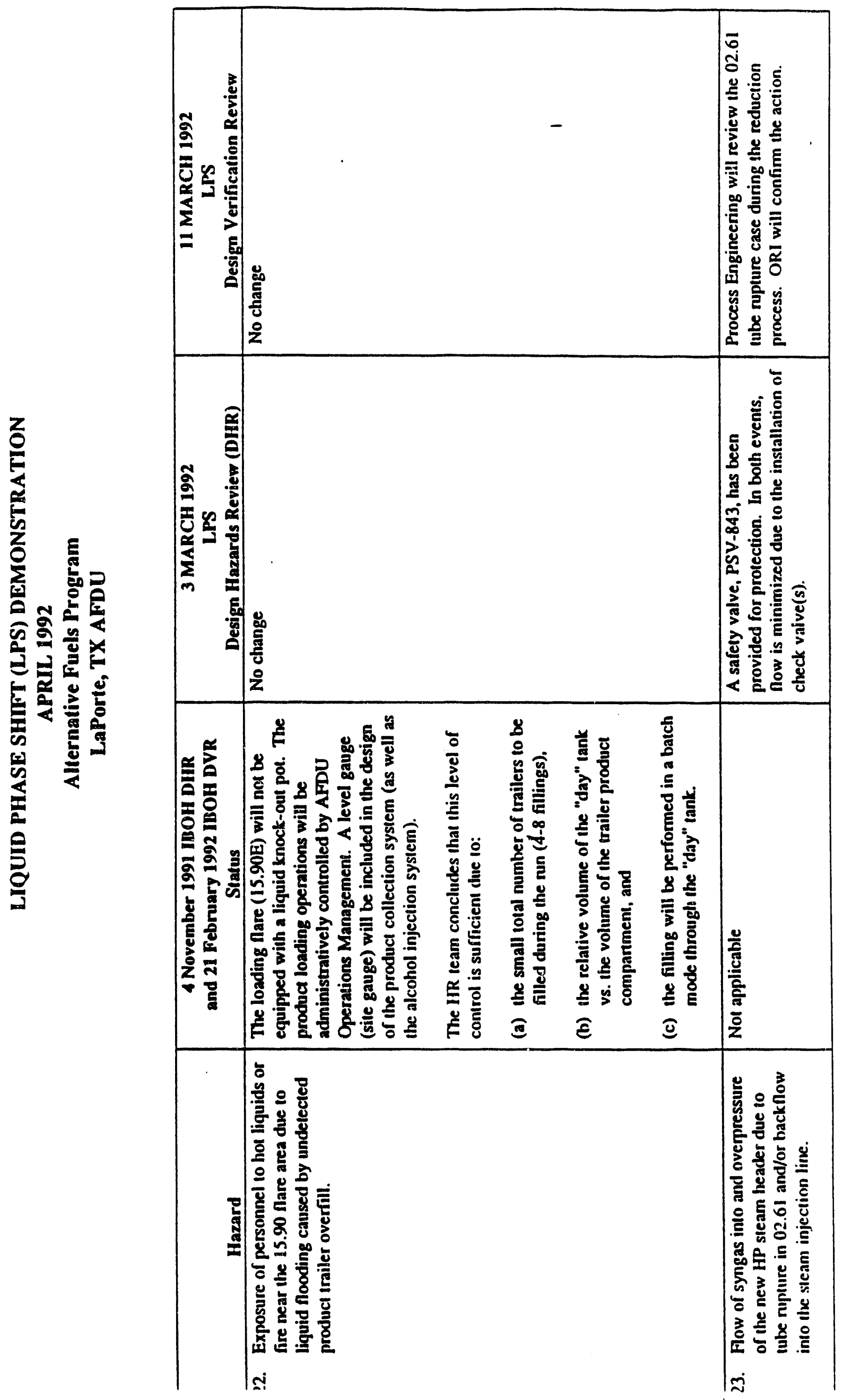




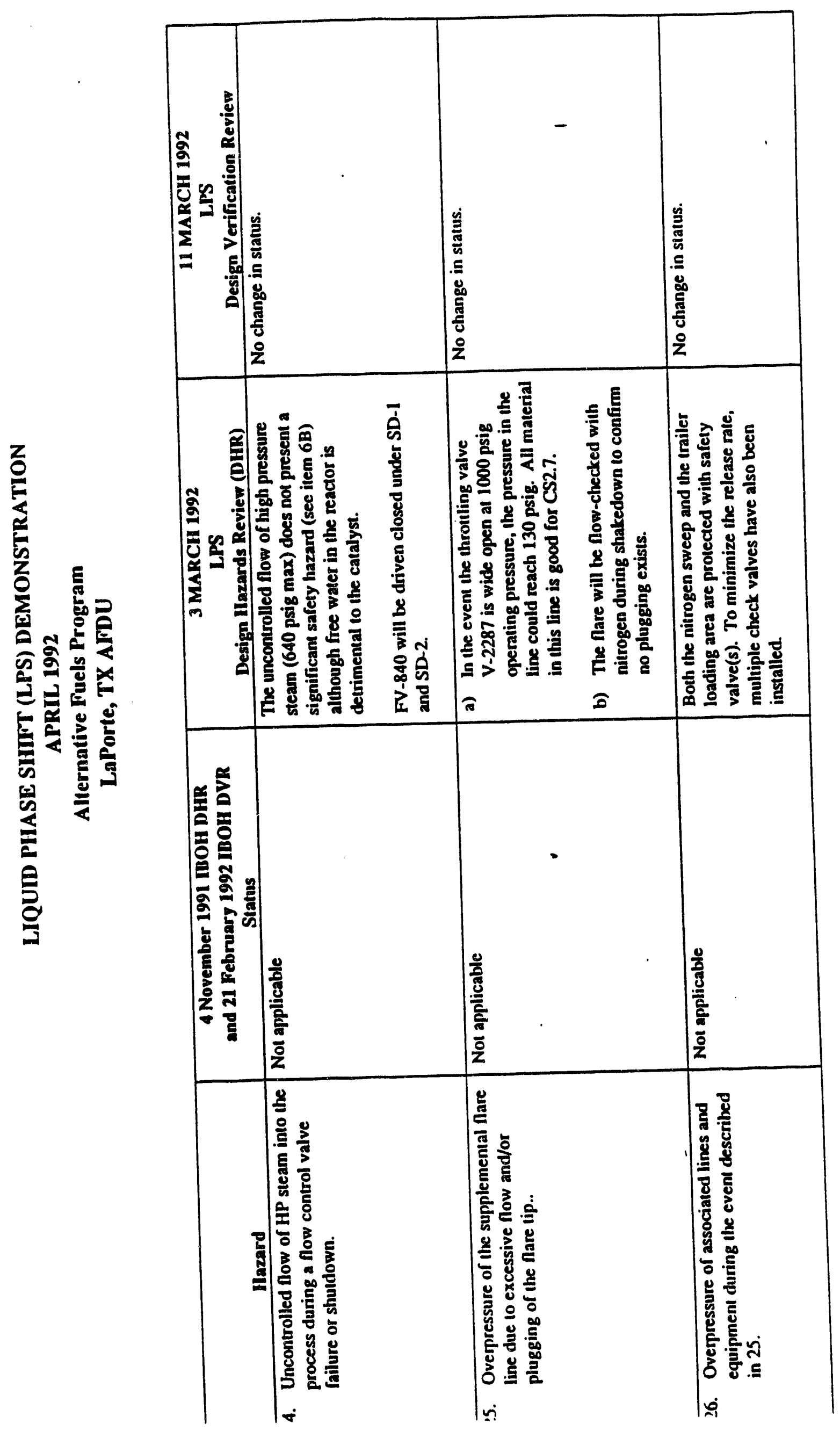




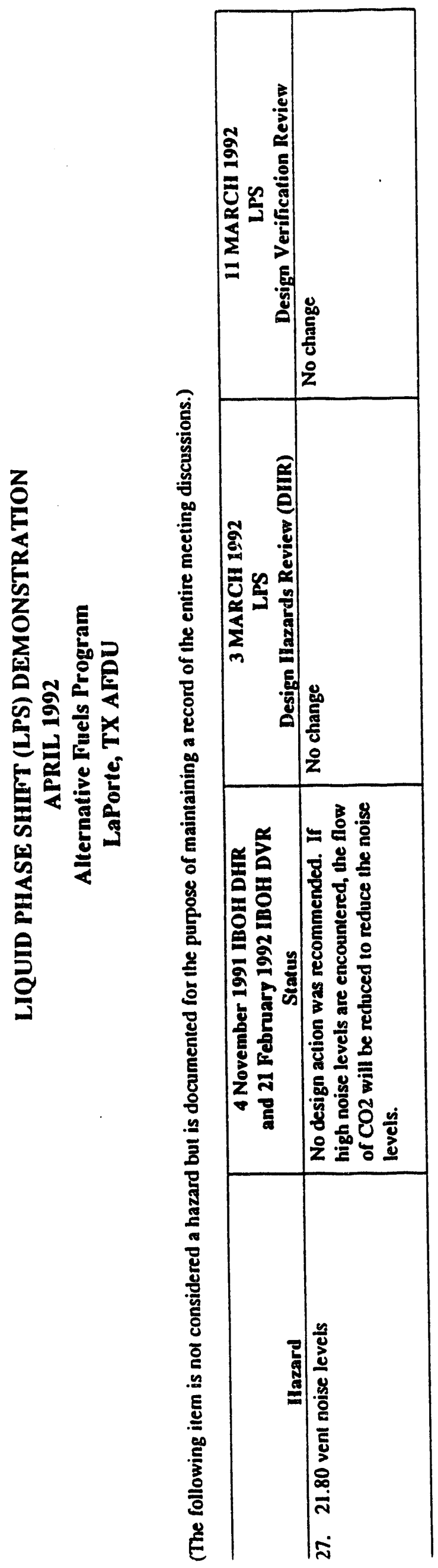




\section{APPENDIX 3}

\section{LITERATURE SEARCH ON DEHYDRATION OF ISOBUTANOL TO ISOBUTYLENE}


Memorandum

$\begin{array}{llll}\text { To: } & \text { T.H. Hsiung } & \text { Dept./Loc.: } & \text { PG\&E Research/Iron Run } \\ \text { From: } & \text { B.E. Latshaw } & \text { Dept./Ext.: } & \text { PG\&E Research/3995 }\end{array}$

Date: 24 March 1992

Subject: Literature Report and Related Information - Dehydration of Isobutanol to Isobutylene
cc: D. M. Brown
T. W. Copeman
R. P. Underwood
D. M. Herron
F. J. Waller

\section{SUMMARY:}

A thorough literature search was performed to obtain information on the dehydration of isobutanol to isobutylene. Because of the limited information available on this particular reaction, the search strategy was broadened to the dehydration of alcohols to alkenes with special interest in obtaining information on the catalyst, reactor type, and reaction conditions used in the work. Work on the dehydration of ethanol was not included because of the lack of correlation between the mechanisms followed for the dehydration of ethanol and isobutanol, i.e. isomerization is an important factor for isobutanol.

A number of catalysts have been used in the literature to study the dehydration of alcohols to alkenes. These catalysts can be divided into four groups: aluminas and modified aluminas, zeolites, metal phosphates and sulfates, and oxides. Alumina has been the most widely used dehydration catalyst and has been implemented into at least two pilot plant operations for the dehydration of isoamyl alcohol. From this information, it appears that the catalysts best suited for the dehydration of isobutanol would be a treated alumina or possibly just a less pure gamma-alumina, a phosphate or sulfate modified zirconia, or a calcium phosphate. These catalysts were specified because of their inactivity for producing the butanol isomers during the course of the reaction. The reaction conditions obtained from the literature indicate temperatures ranging from about 300 to $400 \mathrm{C}$ and pressures around atmospheric. The thermodynamic calculations for the dehydration of isobutanol show that the reaction is endothermic and therefore, requires the higher temperatures in order to obtain a reasonable conversion. According to the literature, the majority of the work has been performed in packed bed reactors; however, a limited amount of literature has been found which describes a process for the dehydration of tertiary-butyl alcohol utilizing a slurry phase reactor. Attempts are being made to obtain more information on this matter. It was difficult to make any reasonable conclusions in regard to the catalyst life expectancy. It appears that the occurrence of side reactions which lead to carbon formation on the catalyst surface should be inhibited by the absence of strong acid sites. 


\section{INTRODUCTION:}

The dehydration of isobutyl alcohol to isobutene is an important reaction because of the use of isobutene as a feed stock for the production of methyl tertiary butyl ether (MTBE). Since it has been shown that isobutyl alcohol can be successfully produced from coal derived syngas, the next step to the production of MTBE is to develop the dehydration process of isobutanol. A literature review of the dehydration of isobutyl alcohol has been conducted; however, there does not appear to be a large amount of information on this specific reaction. In regard to this fact, an expanded view of the literature was undertaken to obtain any available information on the dehydration of alcohols with a similar carbon structure, i.e. 2 methyl-1-alkanols. The desired product of the dehydration reaction is isobutene (2-methyl-1olefin), but it is quite possible to obtain all of the butene isomers. Thus, a catalyst and reaction conditions need to be determined which will give isobutene as the primary product and inhibit to a large extent any isomerization from occurring.

\section{DEHYDRATION REACTION:}

Since the dehydration mechanism is undoubtedly a function of both the structure of the catalyst as well as the structure of the alcohol, a single reaction mechanism cannot be established. According to the literature though, alumina appears to have been the most widely used dehydration catalyst and therefore, the most widely studied. In order to obtain some insight into the reaction mechanism, information will be presented on the dehydration of alcohols over alumina with specific reference to isobutanol when applicable.

In general, dehydration of alcohols occurs over an acid catalyst. On alumina, two different acid sites are present, namely Lewis and Bronsted. The Bronsted acid sites result from the surface hydroxyl groups and are considered on average to be weakly acidic. ${ }^{1}$ The Lewis acid sites result from the incomplete coordination of surface aluminum atoms by surrounding oxygen atoms. ${ }^{2}$ These incompletely coordinated aluminum atoms arise due to removal of the surface hydroxyl groups through condensation with adjacent hydroxyl groups and evolution of water. This removal of surface water also creates Lewis base sites which are oxygea ions. ${ }^{2}$

The adsorption of the alcohol to the surface occurs through hydrogen bonds between the alcohol hydroxyl group and the surface hydroxyl group and oxide ion. ${ }^{3}$ At this point it is believed that the reaction scheme is slightly different depending on the structure of the alcohol. 3 The schemes proposed are based on the fact that the alumina contains only weak to moderate acidic sites and thus the reaction can be compared to dehydration in dilute aqueous acids. Taft et al. 4 found that tertiary alcohols abstract the hydrogen from the acid forming a carbonium ion basically free of covalently bonded water. Less stable secondary carbonium ions were found to be stabilized by specific interaction with two water molecules indicatiog a more concerted mechanistic character. 5 Dostrovsky and KJein 6 determined that oxyg exchange with primary alcohols in dilute acid solution occurred through a concerted mechanism and not by way of a carbonium ion.

The mechanism of dehydration for a primary alcohol such as isobutanol occurs through abstraction of the $\beta$-hydrogen of the alcohol by the surface oxide ion with subsequeat cleavage of the alcohol hydroxyl group forming water and a surface oxide ion. 7 This

$\mathbf{c}$


mechanism has been concluded through a number of experimental observations. Knozinger 8 found that if aluminum hydroxide (which exposes solely hydroxyl groups at the surface) is used as the catalyst, there is complete inactivity for the dehydration of tertiary butanol. However, if the catalyst is heated such that the trihydroxide losses water to form the monohydroxide resulting as well in the formation of oxygen and aluminum ions, the dehydration reaction is observed. This indicates that other surface sites must take part in the formation of olefins. It has also been shown that selective poisoning of the Lewis acid sites by pyridine does not significantly alter the dehydration of alcohols. ${ }^{8}$ Roca et al. ${ }^{9}$ on the other hand have verified the participation of basic sites by poisoning experiments with tetracyanoethylene.

The rate limiting step during the dehydration reaction has been studied by Knozinger and Scheglila.10 By examining primary kinetic isotope effects for the dehydration of tertiary, secondary, and iso-butanol in the gas phase, they determined that deuteration of the hydroxyl group does not cause an isotope effect and thus excludes the hydroxyl proton from any rate determining participation. This result also excludes the desorption of water as being rate determining at least in the case where the water is adsorbed by hydrogen bonds to hydroxyl or deuteroxyl surface groups. The kinetic isotope effect for $\beta$-carbon deuteration was greatest for the primary isobutanol and least for tertiary butanol. At temperatures below $200 \mathrm{C}$, they believe that all three alcohols exhibit $\mathrm{E} 2$-like behavior, but as the temperature is raised the mechanism for tertiary alcohol shifts to E 1-like. An E2 reaction mechanism involves a single transition state in which the base pulls a proton away from the carbon while the hydroxide ion simultaneously departs allowing the double bond to form. The E1 reaction mechanism however, involves two steps whereby the alcohol undergoes cleavage of the hydroxyl ion with formation of a carbonium ion. This carbonium ion then loses a proton to the base to form the alkene. The results presented by Knozinger and Scheglila10 reaffirm the mechanisms postulated earlier by Pines and Manassen 3 for the dehydration of tertiary, secondary, and primary alcohols on weak acid sites.

The mechanism for dehydration is not the same for all alcohols. Arai et al. ${ }^{11}$ found while studying the dehydration of ethanol that at low temperatures $(T<135 \mathrm{C})$ the major product desorbed from the alumina catalyst was diethyl ether. At higher temperatures they found a decrease in ether formation and an increase in ethylene formation. They postulated that the ether was formed by reaction of two nearby surface ethoxides. The presence of the surface ethoxides was verfied through IR studies. Knozinger and Kohne ${ }^{12}$ however, found ethylene to be produced only above $250 \mathrm{C}$ during ethanol dehydration. They believed that the ethylene was formed directly from dehydration as well as through decomposition of the ether. As the temperature was increased, the ether composition decreased significantly. The difference between the two findings is most likely a result of slight variations in the catalyst as well as the fact that Knozinger and Kohne performed continuous operation while Arai et al. performed batch experiments. Knozinger and Kohne proposed that the ether formed by reaction of an adsorbed alcohol with a surface ethoxide. They found a similar behavior for straight-chained alcohols up to a-hexanol; however, the temperature range in which ether could be isolated as the only product decreased with increasing chain length. They were also unable to detect any ether as a dehydration product of the branched butanols. This appears to be due to the instability of the alkoxide of the branched butanols. Surface alkoxides were 
detected by IR spectroscopy for the ether-forming alcohols wheceas no surface alkoxide could be detected for the olefin-forming alcohols. ${ }^{2}$ Thus it appears that the dehydration of isobutanol over alumina occurs through the concerted mechanism proposed by Pines and Haag. 7

The E 2-like mechanism for dehydration of primary and secondary alcohols has been fairly well accepted. It is the transition state during the dehydration of the alcohol which appears to still be in question. Pillai and Pines ${ }^{13}$ as well as Kibby et al. ${ }^{14}$ had determined that alcohol dehydration on $\gamma$-alumina occurs as the trans-elimination of the elements of water. It has also been found that when formation of the cis- and trans-isomers is possible, the cis-olefin forms preferentially. 2,3,7 From the results of selectivity studies, Schwab and Schwab-Agallidis 15 proposed that the dehydration proceeded in pores and crevices of the catalyst. This view was also taken by Pines and Manassen 3 and Pines and Pillai ${ }^{16}$ on the assumption that acidic and basic sites would be located on opposite sides of the pore. This scheme would indicate a reaction controlled by diffusion which has never been observed for alumina. Knozinger et al. 17 proposed that the alcohol molecule adsorbed onto the surface exercises as a whole vibrational motions, such that the $\mathrm{O}-\mathrm{C}_{\alpha}-\mathrm{C}_{\beta}-\mathrm{H}$ plane inclines to the surface. This would lead to the sterically more favorable conformation where bulky substituents are farthest away from the surface leading to preferential cis formation. Sedlacek and Kraus ${ }^{18}$ have deternined from quantum chemical modelling using the adsorbed state proposed by Knozinger et al. 17 that anti-elimination is the more energetically favorable path on the alumina surface.

Sedlacek ${ }^{19}$ was also able to explain the significant preference for cis-olefin formation by taking into account geometric and electronic factors.

It appears that an E2 reaction mechanism is followed for the dehydration of isobutanol on alumina. According to Pines and Haag ${ }^{7}$ as well as Knozinger and Scheglila 10 , it appears that pure $\beta-\mathrm{H}$ elimination occurs to form the primary dehydration product. This olefin product may then readsorb onto the strong acid sites where it may undergo isomerization. It is also assumed that oligermization occurs on these strong acid sites when the olefin is readsorbed. This most likely can be avoided by either running at lower conversions so as to avoid the olefin concentration from building up to a point where the probability of readsorption becomes high or by selectively poisoning the strong acid sites. Running at lower conversions was proposed due to the observed increase in isomer composition with increased contact time. It is also possible that at higher temperatures ( $\mathrm{T}>300 \mathrm{C}$ ) $\mathrm{y}-\mathrm{H}$ elimination may occur with sebsequent migration of the hydrogen or methyl group forming a number of isomers. 20

\section{DEHYDRATION CATALYSTS AND REACTION CONDITIONS:}

The information presented in this section has been divided into subsections according to the type of catalyst used for the dehydration reaction, namely: aluminas, zeolites, metal phosphates and sulfates, and oxides. According to the literature, alumina is a widely used catalyst for the dehydration of alcohols. Because of this, the information regarding alumina has been organized according to the structure of the alcohol (mixed alcohols, 2-methyl-1alkanols, and isoamyl alcohol) used in the reaction so as to provide only that information which is most relavent in regard to the dehydration of isobutanol. The type of reactor and reaction conditions used by the various authors is also discussed as well as any perinent information with respect to catalyst fouling and competitive side reactions. 


\section{A. ALUMinA:}

The surface of alumina contains both acidic and basic sites. These acidic sites range in strength from strong to weak. Pines and Pillai 21 found that by modifying alumina with ammonia it was possible to produce relatively pure primary $\beta-H$ dehydration products from a number of alcohols such as 3,3-dinethyl-1-butanol without significant quantities of their isomers. Pines and $\mathrm{Haag}^{7}$ found that by incorporating small amounts of sodium $(0.001 \%$ $1.5 \%$ weight) into the alumina, the activity for dehydration decreased as the sodium content increased, however the more significant finding was that the activity for isomerization decreased substantially. According to the findings of Pines and Haag, 22 aluminas without alkali contain a substantial number of strong acid sites; aluminas prepared from alkali aluminates contain a large number of weak acid sites; and aluminas impregnated with alkalibase contain a reduced number of acidic sites without an appreciable change in the strength distribution. When the alumina is impregnated with alkali base, it is quite possible that if the base concentration is low and the solute is nonselectively adsorbed, the solution may be depleted of solute before the pores are filled. This would lead to the nonpreferential decrease in acid sites. The fact that both isomerization and dehydration decrease on impregnation of an alkali-base could result from adsorption of the base on the aluminum ions as well as sodium exchange with the surface hydroxyl protons.

\section{MIXED ALCOHOLS:}

Several patents have been issued which describe the use of an alumina catalyst for dehydration of alcohols. Hofstadt et al. ${ }^{23}$ suggested using an alumina catalyst impregnated with $\mathrm{LiOH}, \mathrm{KOH}$, or $\mathrm{NaOH}$ with alkali metal concentrations of 0.1 to $1.5 \mathrm{wt} . \%$. for the dehydration of $\mathrm{C}_{4}-\mathrm{C}_{6}$ alcohols produced from a synthesis gas. An undisclosed alumina catalyst was proposed by Reichi 24 for the dehydration of a mixed alcohol stream produced from synthesis gas. Reichle 25 used a high-purity (alkoxide derived) $y$-alumina with low impurity levels impregnated with metal nitrates for the dehydration of normal alcohols to high-purity $\alpha$-olefins. The metal ion consisted of $\mathrm{Ba}, \mathrm{K}, \mathbf{R b}$, or $\mathrm{Cs}$ with a concentration on the doped catalyst of $0.05-2.0 \mathrm{wt} . \%$. Reichle suggests a low impurity alumina most likely so that the poisoning can be controlled solely through impregnation with the metal nitrates. Alvila et al. ${ }^{26}$ proposed the use of a commercially available (Harshaw) aluminum oxide catalyst for the dehydration of a stream of mixed butanols. The proportion of straightchained: branched alcohols was 1.3:1. The preparation of a-olefins in high selectivity from fatty alcohols was described by Voeste and Buchold. 27 in their process, they used a $\gamma$ alumina doped with $\mathrm{NH}_{3}$ to dehydrate the alcohols while inhibiting any isomerization. Min'ko and Timofeev 28 described a pilot facility which uses an aluminum oxide catalyst treated with $0.25 \% \mathrm{KOH}$ for the dehydration of several normal alcohols and isoamyl alcohol. They found that using this catalyst they could produce 1-hexene with $90-95 \%$ selectivity.

The above mentioned dehydration reactions were carried out in packed bed reactors. The reaction conditions used were temperatures ranging from $300-500 \mathrm{C}$ and pressures ranging from 0.5 to 1 atmosphere. The LHSV (liquid hourly space velocity) were on the order of 1-4 liters of alcohol feed per liter of catalyst per hour. These conditions were utilized to obtain a product stream which consisted of a high selectivity for the primary olefin. 


\section{ISOBUTANOL OR 2-METHYL-1-ALKANOLS:}

The dehydration of isobutanol was performed by Kim et al. ${ }^{29}$ using an aluminum oxide catalyst doped with $1.5-2 \% \mathrm{Ca}\left(\mathrm{H}_{2} \mathrm{PO}_{4}\right)_{2}$ to inhibit skeletal isomerization. The reaction was carried out at temperatures of 300-400 C and GHSV of 300-2500 providing contact times of 5 seconds or less. They found that the yield of isobutylene could be raised from $80 \%$ to $96 \%$ by modifying the alumina catalyst. It was determined by $\mathrm{Kim}$ et al. ${ }^{30}$ that by carrying out the reaction in a fluidized bed reactor they were able to obtain results which were similar to those obtained in a fixed bed reactor.

Several patents were issued on the use of modified alumina as a dehydration catalyst for 2methyl-1-alkanols whereby the modified alumina produces a higher yield of the 2-methyl-1olefin. Specific increases in the product selectivity or yield were not always stated. Shioyama ${ }^{31}$ proposed using a zinc aluminate catalyst which is prepared by mixing equimolar portions of $y$-alumina and zinc oxide in a ball mixer and then processed to produce the final physicai form. Results were obtained which were similar to those using a sodium modified alumina, but the zinc aluminate had a wider temperature range over which the maximum olefin yield was produced. He also determined that the zinc aluminate was more effective than simple mixtures of zinc oxide and alumina. Resofszkj et al. 32 studied the dehydration reaction using a solid solution of iron oxide and aluminum oxide prepared by spraydecomposing the aqueous solution of the nitrates at $500 \mathrm{C}$. They found that the addition of 110 mole\% of iron oxide caused a sharp decrease in the acidity of the catalyst as well as total inactivity for skeletal isomerization. A zinc aluminate catalyst was also suggested by John 33 . However, John used a $\gamma$-alumina which was impregnated with an aqueous zinc salt solution producing an alumina carrier with zinc aluminate on its surface. With this zinc aluminate he was able to obtain 1-pentene with better than $90 \%$ selectivity. Drake ${ }^{34}$ proposed the use of an alumina treated by soaking it in a solution of an organic carboxylic acid and a diluent to produce 2-methyl-1-butene with a selectivity of $85-95 \%$. The amount of carboxylic acid used in the treatment of the silica can range from about 0 01-0.1 $\mathrm{g}$ per gram of alumina. An alumina catalyst which was modified simply by heat treatment was utilized by Drake ${ }^{35}$ for the dehydration of branched alcohols. According to his process, a mixed bochmite (aluminum oxide-hydroxide)/chi-alumina catalyst is heated to about $550 \mathrm{C}$ for several hours under a stream of nitrogen. The result is a relatively pure chi-alumina which shows high selectivities for the primary dehydration products without subsequent isomerization.

The above discussed catalysts were utilized for the dehydration reaction of branched alcohols to their corresponding olefins. The reactions were carried out in fixed bed reactors over a temperature range of $250-450 \mathrm{C}$ and pressures of $1-7$ atmospheres. The alcohol was introduced to the reactor at a WHSV ranging from 0.1 to 20 grams of alcohol feed per gram of catalyst per hour along with an inert carrier gas flow of 40-50 liters per hour.

\section{ISOAMYL ALCOHOL:}

Two studies have been performed on the dehydration of 3-methyl-1-butanol to provide information for optimal pilot plant operation. The studies were concerned with determination of a catalyst and reaction conditions which would produce a product stream with a high yield of 3-methyl-1-butene and low concentrations of product isomers. Drake et al. ${ }^{36}$ of the Phillips Petroleum Co. found that a base treated gamma alumina inhibited the formation of 
product isomers. The pilot plant utilized a packed bed reactor operating at about $300 \mathrm{C}$ core temperature and a pressure of approximately 3 atmospheres. The alcohol feed was varied from 1.0-1.5 LHSV resulting in a product yield of greater than 85\% 3-methyl-1-butene. It should be noted that the product yield dropped to about $70-75 \%$ when the unit was run on a lower purity feed. Nitrogen was used as a carrier gas for the alcohol feed. Early tests on the catalyst life revealed that approximately 1000 pounds of 3-methyl-1-butene were produced per pound of catalyst. The second pilot plant operation was described by Timofeev et al. 37 Their process relied on a $\gamma$-alumina impregnated with 0.25 wt.\% KOH. The dehydration was carried out at approximately $380 \mathrm{C}$ with an alcohol feed of 4 liters per liter of catalyst per hour. Under these corditions, they were able to obtain a product selectivity of about $70 \%$.

\section{B. ZEOLITES AND AMORPHOUS ALUMINOSILICA:}

Several experimental studies have been carried out in which silica-alumina catalysts of various compositions have been used for the dehydration of isobutyl alcohol. Weisz and coworkers 38 looked at the molecular shape selective dehydration of the isomeric butanols on Ca-zeolites 5A and 10X. They found that approximately $100 \%$ conversion of the isobutanol could be obtained at $300 \mathrm{C}$ on the $10 \mathrm{X}$ catalyst, but that negligible conversion occurred for the dehydration on the 5A. This implies that the isobutanol is excluded from the crystal interior of the zeolite 5A. Normal butanol was dehydrated to about the same extent on both. No analysis of the butene products was presented. Amorphous aluminosilica gels and zeolites having chemical compositions corresponding to that of type $\mathrm{X}$ zeolite were used for the dehydration of isobutanol by Levchuk and Dzis'ko. 39 Running the reaction at $310 \mathrm{C}$ they determined that the conversion could be increased by lowering the space velocity; however, they also found a corresponding increase in the concentration of polymeric products. Over the range of space velocities used, normal butene isomers constituted approximately $20-30 \%$ of the product stream. Samples with low sodium content were found to decrease in activity quite rapidly with time. This could result from oligomer formation within the pores and their inability to diffuse out. Their results showed that at low conversions the rate of dehydration as well as isomerization were independent of the alcohol conversion, but both became dependent with increasing conversion. They also found a linear decay of both rates with increasing sodium content.

Makarova et al. 40,41 performed limited experiments on the dehydration of isobutanol on $H$ ZSM-5. Their reaction conditions were 100-150 C, 1 atmosphere pressure, and low conversions ( $<10 \%$ ) such that the reaction was zero order with respect to isobutanol. They did not provide an analysis of the product stream butene isomer composition. IR studies were performed to determine a possible reaction scheme. They believe that the reaction occurs through formation of a surface alkoxide which reacts with the alcohol to form a hydrogen bonded ether. This ether, restricted from diffusing out of the channel intersection, decomposes to form a butene and an alcohol molecule. Under conditions of higher conversion or interupted alcohol flow, they found a significant increase in oligomer formation. They postulate this to arise from interaction of the butene with the highly reactive alkoxide as the butene is diffusing through the pore. 


\section{METAL PHOSPHATES AND SULFATES:}

Hofstadt et al. 23 suggested using either an aluminum phosphate or a calcium phosphate as the dehydration catalyst for a mixed alcohol stream. However, they stated that they preferred using an aluminum oxide or calcium phosphate, $\mathrm{Ca}_{3}\left(\mathrm{PO}_{4}\right)_{2}$, as the dehydration catalyst so that secondary reactions (condensation and polymerization) could be suppressed. A phosphorous rich hydroxyapatite catalyst $\mathrm{Cag}_{2}\left(\mathrm{HPO}_{4}\right)\left(\mathrm{PO}_{4}\right)_{5} \mathrm{OH}$ was investigated by Kibby et al. 14,42 for the dehydration reaction of several alcohols. They found that upon dehydration of isobutanol they were able to obtain abour $90 \%$ isobutene with $10 \%$ normal butenes. The reaction was carried out at $300-400 \mathrm{C}$ and low conversions such that the reaction was zero order with respect to the alcohol concentration. The calcium rich form of this catalyst, $\mathrm{Ca}_{10}\left(\mathrm{PO}_{4}\right)_{6}(\mathrm{OH})_{2}$ makes it a suitable catalyst for alcohol dehydrogenation. Brett et al. 43 states that the dehydration reaction is catalyzed by the acidic phosphate hydrogen. Clearfield and Thakur ${ }^{44}$ studied the dehydration of cyclohexanol using a zirconium phosphate catalyst. They found the catalyst to be very selective toward the dehydration reaction with little activity for isomerization or dehydrogenation. The reaction was performed over a temperature range of 300-400 C and they determined that the dehydration data fit a first order rate equation. Clearfield and Thakur also proposed that the primary active sites are the monohydrogen phosphate protons with a possible secondary active site being of the Lewis acid type.

A sulfate modified zirconia catalyst was proposed by Klier et al. 45 as a possible catalyst for the dehydration of isobutanol. They found that when a mixture of isobutanol and methanol were charged to the reactor, the catalyst proved to be efficient and highly selective for the production of isobutene with methanol dehydration suppressed. However, no work has been done to study solely the dehydration reaction of isobutanol with this catalyst. Thorton and Gates 46 studied the dehydration of isobutyl alcohol using a poly(styrene-divinylbenzene) matrix containing sulfate groups as the catalyst. The reaction was performed at approximately $100 \mathrm{C}$ giving a mixture of butene isomers and isobutane formation at low substrate partial pressures. The reaction was accompanied by about a $20 \%$ decrease in rate over tens of hours of operation resulting from a catalyst which became covered in a dark, sticky tar. The catalyst deactivation was not observed with either isopropyl or sec-butyl alcohols. According to Knozinger, ${ }^{20}$ it is believed that the dehydration of alcohols on ion exchange resins occurs through oxonium or carbonium ion intermediates.

\section{OXIDE CATALYSTS:}

Schwab and Schwab-Agallidis ${ }^{15}$ studied the dehydration of ethanol to ethylene on a number of oxide catalysts $\left(\mathrm{ZnO}, \mathrm{TiO}_{2}, \mathrm{Cr}_{2} \mathrm{O}_{3}, y-\mathrm{Al}_{2} \mathrm{O}_{3}, \mathrm{CeO}_{3}\right.$, and $\left.\mathrm{ThO}_{2}\right)$ and found that the product stream from the alumina and thoria catalysts consisted of better than $90 \%$ ethylene. Canesson and Blanchard 47 found that on dehydration of secondary alcohols over thoria a high selectivity was shown for the formation of the 1-alkene. They proposed that the reaction proceeds as a syn-elimination occurring by an E1cB pathway. A reaction occurring by an E1cB mechanism involves the loss of a proton from the alcohol to the base with formation of a negatively charged carbanion which then losses the hydroxide ion in a separate step to yield the alkene. Studying the possibility of $\gamma-\mathrm{H}$ eliminations from certain alcohols during the course of dehydration at 300-350 C, Siddhan and Narayanan 48 found that thoria showed very little propensity for $y$-eliminations whereas the products obtained from alumina doped 
with sodium exhibited a significant contribution from $\gamma$-eliminations. It should also be noted that alumina exhibited a much higher activity for the dehydration of alcohols such as 3 methyl-1-pentanol than did thoria.

The dehydration of isobutanol was observed by Kotsarenko and Malysheva 49 using binary compounds of the type $a \mathrm{M}_{\mathrm{m}} \mathrm{O}_{\mathrm{n}}(1-a) \mathrm{SiO}_{2}$, where $\mathrm{M}=\mathrm{Al}, \mathrm{Ga}, \mathrm{Zr}, \mathrm{Be}$, and $\mathrm{Y}$ as catalysts. The reactions were carried out over the temperature range of 275-350 $\mathrm{C}$ using a circulation-flow method with a circulation rate of 800 liters per hour. They found that with increasing alcohol concentration, the order of the reaction changed from first to zero on all of the catalysts. The results of their experiments showed that isobutylene made up about $60-70$ mole\% of all the butylenes formed for all of the binary compounds. They also found that a gamma-alumina sample produced about $95 \%$ isobutylene. No indication as to the chemical composition of the alumina was given. Results for the isomerization of an isobutylene feed showed that alumina and the binary compounds of $\mathrm{Be}$ and $\mathrm{Y}$ were inactive for this reaction. From their results they concluded that the dehydration reaction of isobutanol on the binary oxides occurs through a carbonium ion mechanism leading to a high rate of normal olefins. Davis 50 looked at the dehydration of branched secondary and tertiary alcohols over aluminum and molybdenum oxide at temperatures of 180-275 C. For certain alcohols (i.e. 2,2-dimethyl-3pentanol) it was found that molybdena produced a significant quantity of products which resulted from skeletal isomerization whereas the alumina did not. Davis postulated that the skeletal isomerization resulted from the dehydration step and not from a secondary reaction. The acidity and basicity of a number of metal oxides were investigated by Gervasini and Auroux. 51 The catalysts were tested for the decomposition of isopropanol to propene and acetone. While it is difficult to make any conclusions about the use of these catalysts for the dehydration of isobutanol, there are a few points that should be mentioned. They found that the oxides of $\mathrm{Mo}$ and $\mathrm{W}$ gave propene in the temperature range of $400-430 \mathrm{~K}$ while those of $\mathrm{Al}, \mathrm{Nb}, \mathrm{Ta}, \mathrm{Ti}$, and $\mathrm{Zr}$ were active in the temperature range of $430-490 \mathrm{~K}$. This would indicate that $\mathrm{MOO}_{3}$ and $\mathrm{WO}_{3}$ possess stronger acid sites than the other oxides. However, it should be noted that $\mathrm{MoO}_{3}$ and $\mathrm{WO}_{3}$ also gave acetone, an undesired product in the dehydration reaction, at lower temperatures.

\section{DEHYDRATION IN A SLURRY REACTOR:}

Some work has been undertaken in the use of liquid phase reaction technology for the dehydration of tertiary butyl alcohol (TBA). A patent issued to Dockner and Krug 52 describes a process in which a feed of TBA and nitrogen are passed into a packed quartz tube filled with vacuum gas oil (boiling point $400 \mathrm{C}$ ) containing about $5 \%$ resin catalyst. The reaction is carried out at $205 \mathrm{C}$ giving $97 \%$ yield isobutene. Abraham and Prescott 53 discuss the processes utilized by several companies for the dehydration of tertiary butanol to isobutene. According to the authors, Cities Service dissolves the TBA and a p-toluene sulfonic acid catalyst in a reaction medium of xylene. The isobutylene is removed as a gas and the water separates out and is removed continuously. Nippon, Asashi, and Maruzen use powdered resin catalysts in a stirred reactor for their processes. It must be noted that the patents referenced by Abraham and Prescott could not be located as cited in their article. 


\section{THERMODYNAMICS:}

Calculations were made to determine the heat of reaction as well as the change in the Gibbs free energy upon dehydration of isobutanol to form isobutene and water. The heat of reaction at $298 \mathrm{C}$ and 1 atmosphere is $8.16 \mathrm{kcal} / \mathrm{mole}$ and the Gibbs free energy change is -0.64 $\mathrm{kcal} / \mathrm{mole}$. The entropy change was determined to be $24.1 \mathrm{cal} / \mathrm{mole} \mathrm{K}$ The heat of reaction was also calculated at $300 \mathrm{C}$ with its value being $8.75 \mathrm{kcal} / \mathrm{mole}$. Thus, the reaction is endothermic and will require the process to be run at elevated temperatures in order to obtain good conversions. Klotz 54 performed some equilibrium calculations for the dehydration reaction and found that the equilibrium favors almost $100 \%$ conversion in the temperature range of 100-300 C and that it was only slightly shifted toward isobutanol at elevated pressures up to 52 atmospheres. The adiabatic temperature drop for the reaction was also determined by $\mathrm{KJotz}^{55}$. He found that at inlet conditions of 1 atmosphere and $200 \mathrm{C}$ the temperature dropped to $77 \mathrm{C}$ for $100 \%$ conversion while for an inlet temperature of $300 \mathrm{C}$ the temperature dropped to $130 \mathrm{C}$. The temperature drop for the low inlet condition is controlled by the condensation of water in the reactor.

\section{CONCLUSIONS:}

From the information that has been gathered on the dehydration of alcohols, and in particular 2-methyl-1-alkanols, it appears that the catalysts best suited for the dehydration of isobutanol would be a treated alumina or possibly just a less pure gamma-alumina, a phosphate or sulfate modified zirconia, or a calcium phosphate. The literature indicates that the reaction should be run at temperatures ranging from about 300 to $400 \mathrm{C}$ and at pressures around atmospheric. From the thermodynamies it is seen that the reaction is endothermic and requires the higher temperatures in order to obtain reasonable conversion of the isobutanol. According to the literature, the majority of the work has been performed in packed bed reactors; however, some of the TBA dehydration processes indicate that a slurry phase reactor should provide the proper conditions for an efficient and economic isobutanol dehydration process. It was difficult to make any reasonable conclusions in regard to the catalyst life expectancy. It appears that a catalyst which does not possess strong acid sites such that isomerizations do not occur should also inhibit other side reactions from occurring which lead to carbon formation on the catalyst surface.

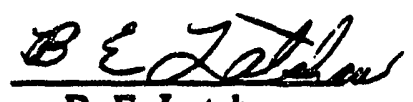

B. E. Latshaw

\section{REFERENCES:}

1. E. P. Parry, J. Catal., 2. 371 (1963).

2. H. Knozinger, Angew. Chem. Intern. Ed., 7791 (1968).

3. H. Pines and J. Manassen, Advan. Catsl., 16, 49 (1966).

4. R. W. Taft Jr., E. L. Purles, P. Riesz, and C. A. De Fazio, J. Am. Chem. Sos., 771584 (1955).

5. Manassen, J., and F. S. Klien, Chem. Soc. (London) Spec. Publ., 144203 (1960).

6. I. Dostrovsky and F. S. Klien, J. Chem. Soc., 4401 (1955).

7. H. Pines and W. O. Haag, J. Am. Chem. Soc., 83,2847 (1961). 
8. H. Knozinger, Angew. Chem., 80778 (1968).

9. F. Fiqueras Roca, L. de Mourges, and Y. Tranbouze, J. Catal., 14 107 (1969).

10. H. Knozinger and A. Scheglila, J. Catal., 17252 (1970).

11. H. Arai, J. Take, Y. Saito, and Y Yoneda, J. Catal., 9, 146 (1967).

12. H. Knozinger and R. Kohne, J. Catal., 5, 264 (1966).

13. C. N. Pillai and H. Pines, J. Am. Chem. Soc., 83, 3274 (1961).

14. C. Kibby, S. Lande, and W. Hall, J. Am. Chem. Soc., 94,214 (1972).

15. G. Schwab and E. Schwab-Agallidis, J. Am. Chem. Soc., 71, 1806 (1949).

16. H. Pines and C. N. Pillai, J. Am. Chem. Soc., 83, 3270 (1961).

17. H. KInozinger, H. Buhl, and K. Kochloefl, J. Catal., 24. 57 (1972).

18. J. Sedlacek and M. Kraus, React. Kinet. Catal. Lett., 2,57 (1975).

19. J. Sedlacek, J. Catal., 57, 208 (1979).

20. H. Knozinger, "The Dehydration of Alcohols" in "The Chemistry of the Hydroxyl Group," S. Patai, ed., Interscience Publishers, 1971.

21. H. Pines and C. Pillai, J. Am. Chem. Soc., 82, 2401 (1960).

22. H. Pines and W. Haag, J. Am. Chem. Soc., 82, 2471 (1960).

23. C. E. Hofstadt, M. Schneider, and K. Kochloefl, U.S. Pat. 4,398,050 (1983).

24. E. Reichl, U.S. Pat. 4,534,772 (1985).

25. W. Reichle, Res. Discl., 283, 717, Union Carbide Corp. (1987).

26. L. Avila, T. Pakkanen, O. Krause, and M. Joutsimo, U.S. Pat. 4,777,320 (1988).

27. T. Voeste and H. Buchold, DE Pat. 3,915,493 (1990).

28. T. Min'ko and A. Timofeev, Khim. Prom-st. (Moscow), (10), 595 (1986).

29. S. Kim, H. Chang, J. Che, and J. Rim, Choson Minjujuui Inmin Konghwaguk Kwahagwon Tongbo, 26 (6), 303 (1978).

30. S. Kim, H. Chang, J. Je, C. Lin, Choson Minjujuui Inmin Konghwaguk Kwahagwon Tongbo, (6), 47 (1979).

31. T. Shioyama, U.S. Pat. 4,260, 845 (1981).

32. G. Resofszki, J. Juhasz, T. Kovacs, and B. Jover, Geterog. Katal., 5th, Pt.1, 273 (1983).

33. C. S. John, GB Pat. 2,181,070 (1987).

34. C. Drake, U.S. Pat. 4,602,119 (1986).

35. C. Drake, U.S. Pat. 4,529,827 (1985).

36. C. Drake, M. Martinovich, and S. Marwil, Chem. Eng. Prog., 81,52 (1985).

37. A. Timofeev, L. Romanchenko, I. Pis'man, and T. Min'ko, Prom-st. Kauch., (6), 6 (1982).

38. P. B. Weisz, V. J. Frillette, R. W. Maatman, and E. B. Mower, J. Catal., 1, 307 (1962).

39. V. S. Levchuk and V. A. Dzis'ko, Kinet. Katal., 10 (6), 1289 (1969).

40. M. Makarova, C. Williams, V. Romannikov, K. I. Zamaraev, and J. M. Thomas, J. Chem. Soc. Faraday Trans., 86 (3), 581 (1990).

41. C. Williams, M. Makarova, L. Malysheva, E. Paukshtis, K. Zamaraev, and J. M. Thomas, J. Chem. Soc. Faraday trans., 86 (20), 3473 (1990).

42. C. L. Kibby and W. K. Hall, J. Catal., 29, 144 (1973).

43. J. A. S. Brett, L. G. Christner, and W. K. Hall, J. Am. Chem. Soc., 89, 5535 (1967).

44. A. Clearfield and D. S. Thakur, J. Catal., 65, 185 (1980).

45. K. Klier, R. G. Herman, M. A. Johansson, and O. C. Feeley, Div. Fuel Chem., ACS Spring Meeting, April, 1992.

46. P. Thornton and B. C. Gates, J. Catal., 34, 275 (1974).

47. P. Canesson and M. Blanchard, J. Catal. 42,205 (1976). 
48. S. Siddhan and K. Marayanan, J. Catal., 59, 405 (1979).

49. N. S. Kotsarenko and L. V. Malysheva, Kinet. Katal., 24877 (1983).

50. B. H. Davis, J. Catal., 79, 58 (1983).

51. A. Gervasini and A. Auroux, J. Catal., 131,190 (1991).

52. T. Docker and H. Krug, DE Pat. 3,317,165 (1983).

53. O. C. Abraham and G. F. Prescott, Hydrocarbon Proc., Feb., 51 (1992).

54. H. Klotz, APCI memo, "Equilibrium Conversions for Isobutylene/Alcohol Reactions," 6 November (1991).

55. H. Klotz, APCI memo, "Isobutanol Heats of Reaction," 30 January (1992). 


\title{
APPENDIX 4
}

\section{MATERIAL BALANCE SHEETS}

FOR

\author{
A. RUN \#11782-58 (GROUND.UP K3-110) \\ \&
}

B. RUN \#11782-63 (POWDER K3-110, LAPORTE BATCH) 
A. Run \#11782-58 (Ground-up K3-110) 


$$
\begin{aligned}
& \text { Texaco Gas } \\
& \text { Methanol syutherin }
\end{aligned}
$$

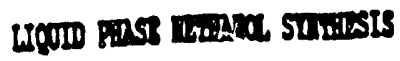

\begin{tabular}{|c|c|c|c|}
\hline 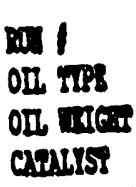 & 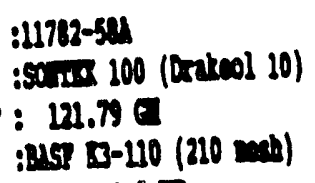 & 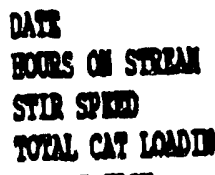 & $\begin{array}{l}: 02 / 21 / 32 \\
: \quad 25.00 \mathrm{ES} \\
: \quad 1200.00 \mathrm{ET} \\
6: \quad 30.31 \mathrm{E}\end{array}$ \\
\hline & 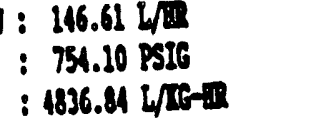 & & $\begin{array}{l}121.51 \mathrm{~W} / 10 \\
250.00 \mathrm{C}\end{array}$ \\
\hline
\end{tabular}

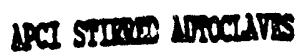

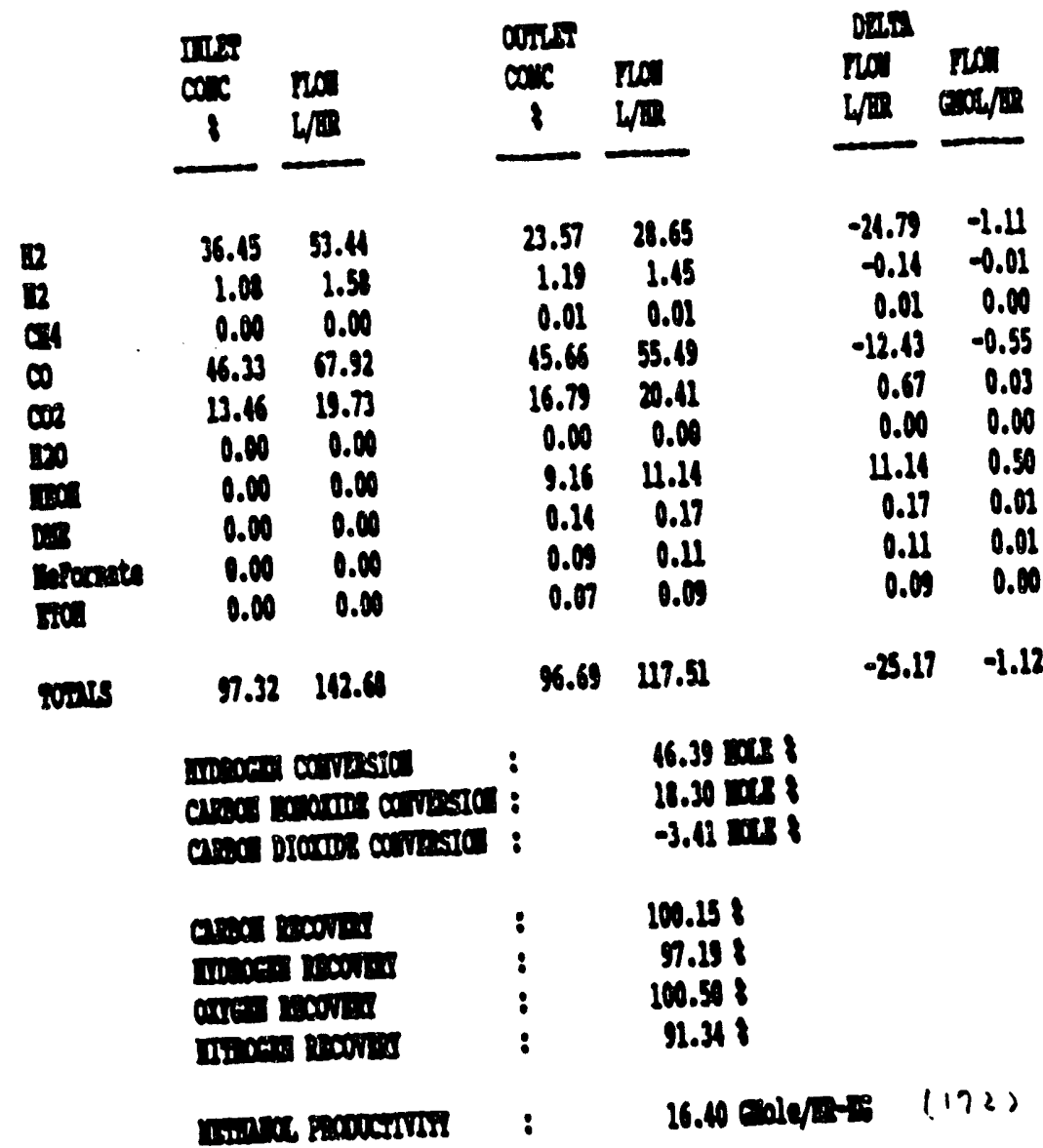

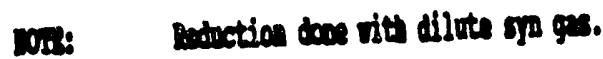


of tware Version: 3.2 COEOL.

Sample Name: $3000 c-1$

Sample Number: $300 \mathrm{cc}$ H

Operator: : seg

Instrument : 950-1 ALCOHOLS GC Channel : A A/D mV Range : 1000

Autosampler : NONE

Rack/Vial: $0 / 0$

Interface Serial \#:9212551066 Data Acquisition Time: $2 / 28 / 92$ 5:27 PM

Jelay Time : $0.00 \mathrm{~min}$.

End Time : $15.00 \mathrm{~min}$.

Sampling Rate : $5.0000 \mathrm{pts} / \mathrm{sec}$

Raw Data File : $c: \backslash 2700 \backslash$ datal $\backslash 059 a 004$.raw

Result File: $c: \backslash 2700 \backslash$ datal 1059 a004.rst

Instrument file: c: $\backslash 2700 \backslash$ methods $\backslash$ alcohols.ins

Process file : c: $\backslash 2700 \backslash$ methods $\backslash$ alcohols.prc

Sample file : c:\2700\methods $\backslash$ alcohols.smp

sequence file: $C: \backslash 2700 \backslash S E Q U E N C E \backslash A L C O H O L S . s e q$

Inj. Volume : 1 MOL\% Area Reject $: 0.00$

Sample Amount : $1.0000 \quad$ Dilution Factor $: 1.00$

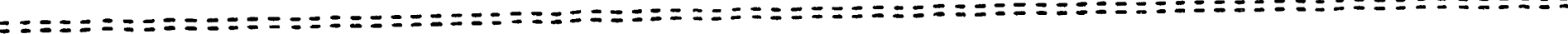

ALCOHOLS

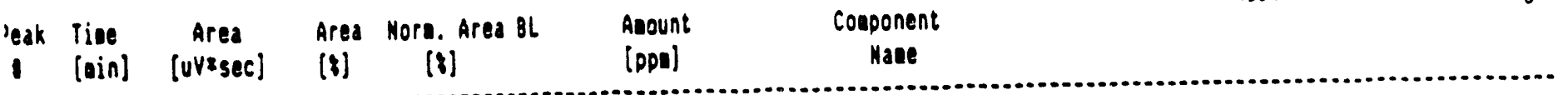

\begin{tabular}{|c|c|c|c|c|c|}
\hline 0.723 & 1528.71 & 0.21 & $0.21 \mathrm{BV}$ & 0.0000 & \\
\hline 0.774 & 633.29 & 0.09 & $0.09 \mathrm{VB}$ & 60.8212 & METHANE \\
\hline 0.991 & 17085.81 & 2.36 & $2.36 \mathrm{BB}$ & 1470.7085 & OIMETHYL ETHER \\
\hline 1.109 & 668060.69 & 92.36 & $92.36 \mathrm{BV}$ & 91190.3750 & METHANOL \\
\hline 1.318 & 8128.98 & 1.12 & $1.12 \mathrm{VB}$ & 937.1200 & METHYLFORMATE \\
\hline 1.539 & 12418.00 & 1.12 & 1.7288 & 797.0054 & ETHANOL \\
\hline 2.454 & 2927.99 & 0.41 & $0.418 B$ & 179.8903 & METHYL ACETATE \\
\hline 3.144 & 5192.41 & 0.72 & $0.72 \mathrm{BB}$ & 200.6799 & 1-PROPANOL \\
\hline 4.660 & 3353.78 & 0.16 & 0.4688 & 89.1717 & ISOBUTANOL \\
\hline 5.407 & 1852.24 & 0.26 & 0.2688 & 50.7410 & 1-BUTAMOL \\
\hline 6.376 & 747.10 & 0.10 & 0.1088 & 0.0000 & \\
\hline 6.745 & 662.04 & 0.09 & 0.0988 & 14.2106 & 2- METHYL-1-BUTANOL \\
\hline 7.253 & 719.20 & 0.10 & $0.10 \mathrm{BB}$ & 15.8368 & 1-PENTANOL \\
\hline
\end{tabular}

$723310.31 \quad 100.00 \quad 100.00$

95006.5625 


\section{RUN * \\ OIL TYPE OIL WEIGKT CATALYST INRET FLOW PRESSURE} GHSV (DRY) $5067.96 \mathrm{SL} / \mathrm{KG}-\mathrm{HR}$ (6176.5)
H2O INTJECTION RATE: $27.00 \mathrm{ML} / \mathrm{HR}$

11782-588 SONTEX 100 (Drakeol 10) 121.78 Get BASF K3-110 (210 mesh) $153.61 \mathrm{SL} / \mathrm{HR}$

467.30 PSIG H2O/CO RATIO IN FETO 0.44

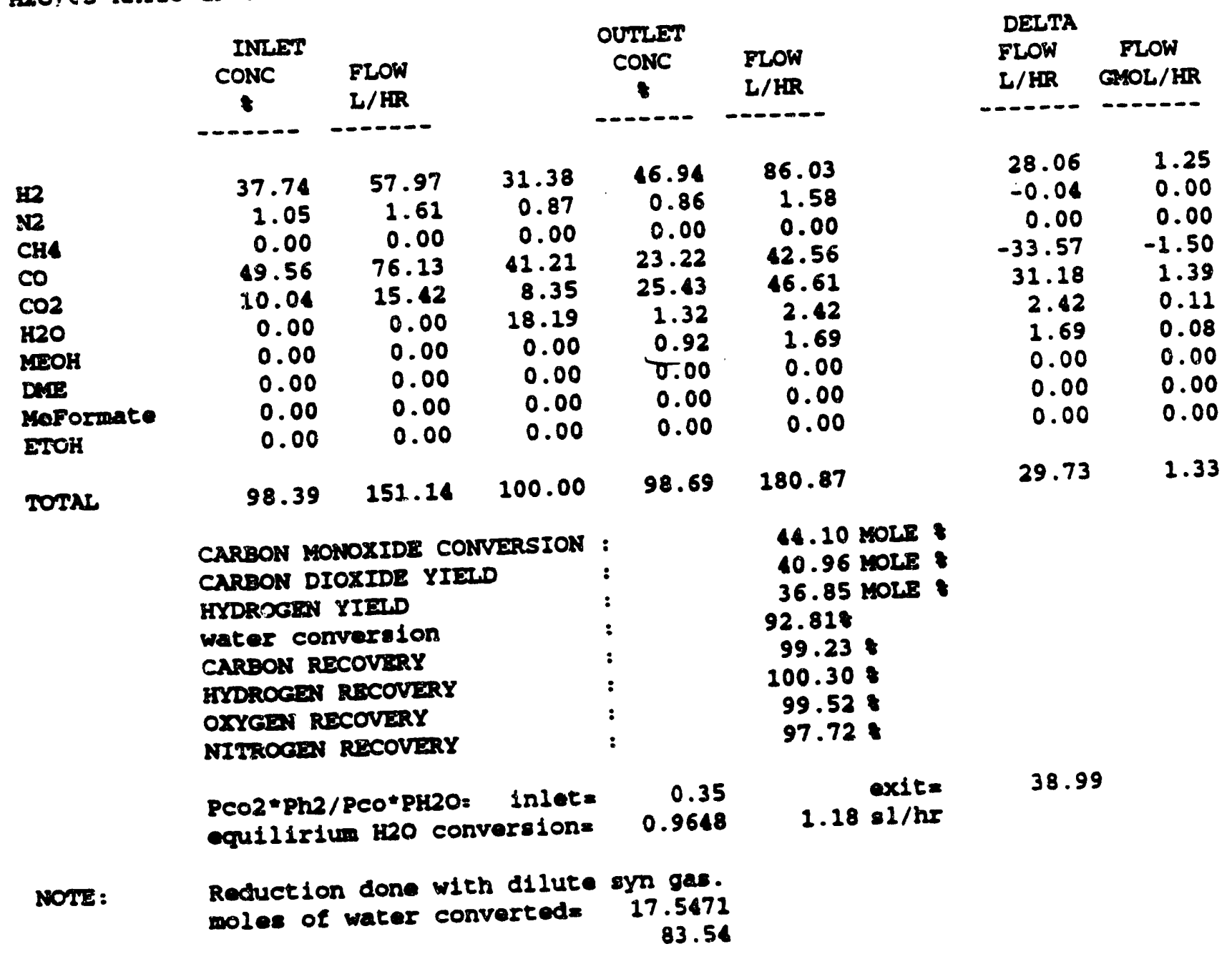

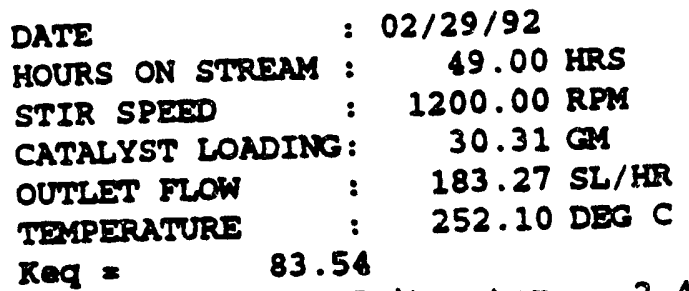


LIQUID PHASE SHIFT

APCI STIRRED AUTOCLAVES

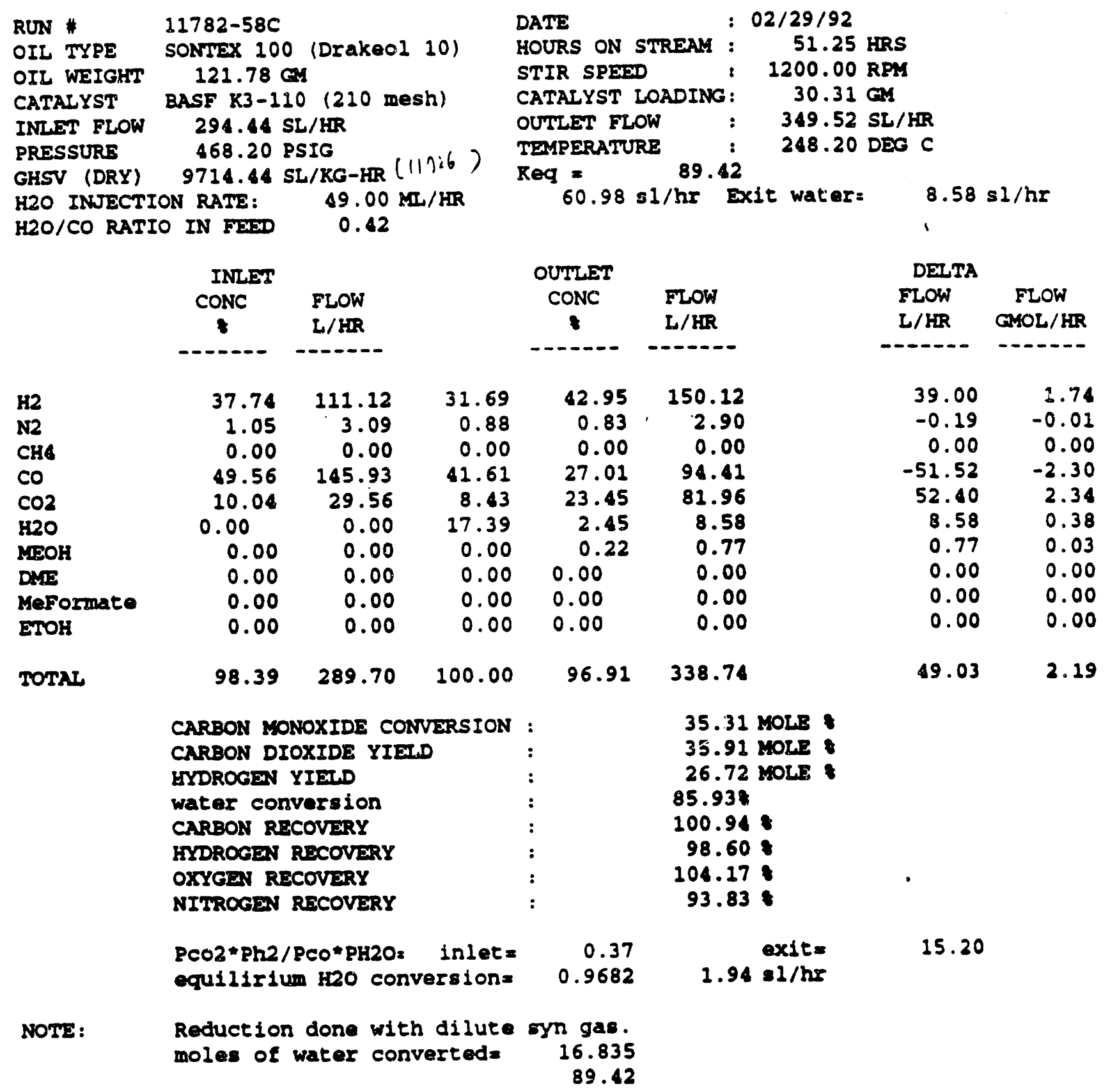


LIQUID PHASE SHIFT

APCI STIRRED AUTOCLAVES

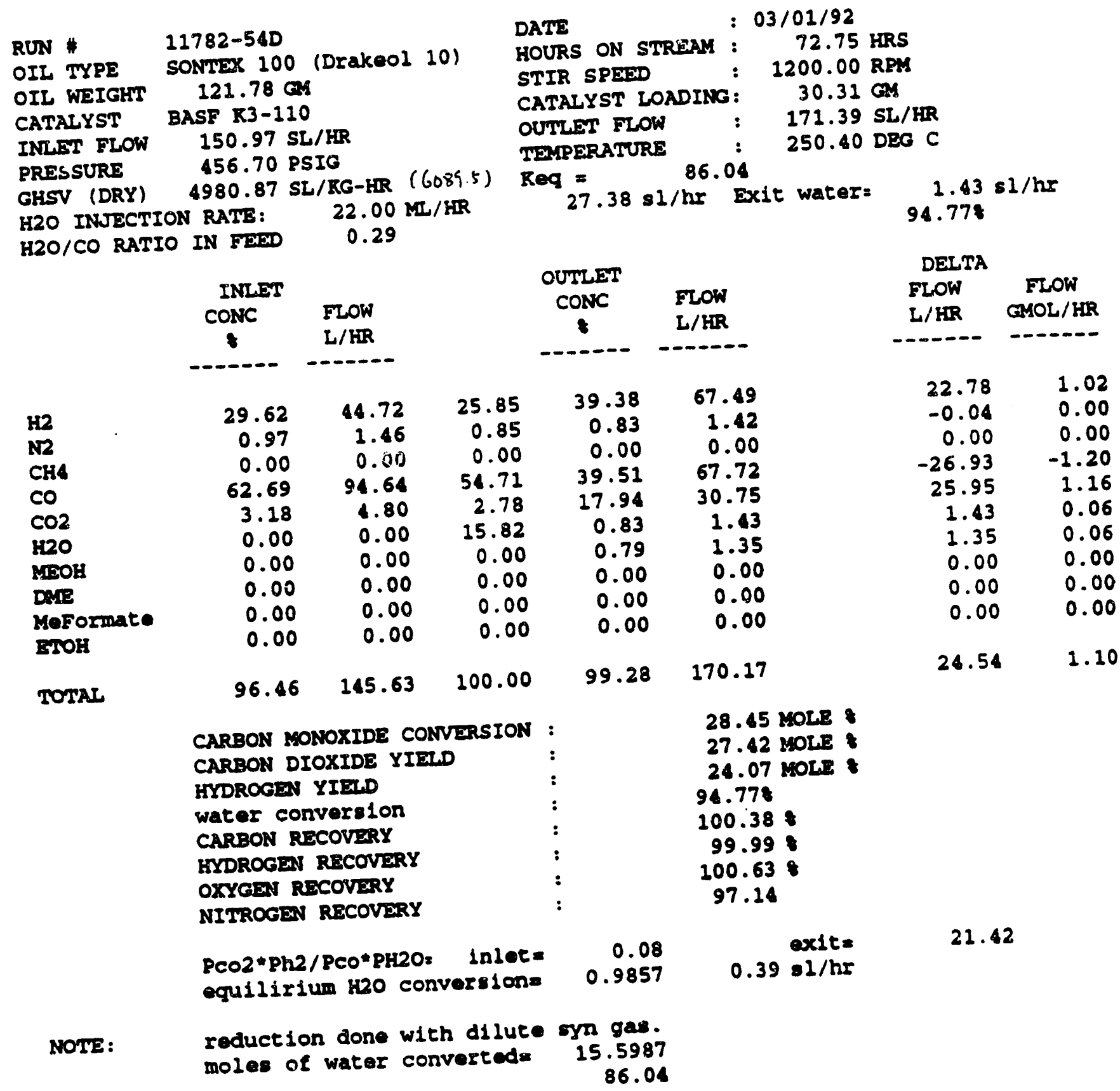




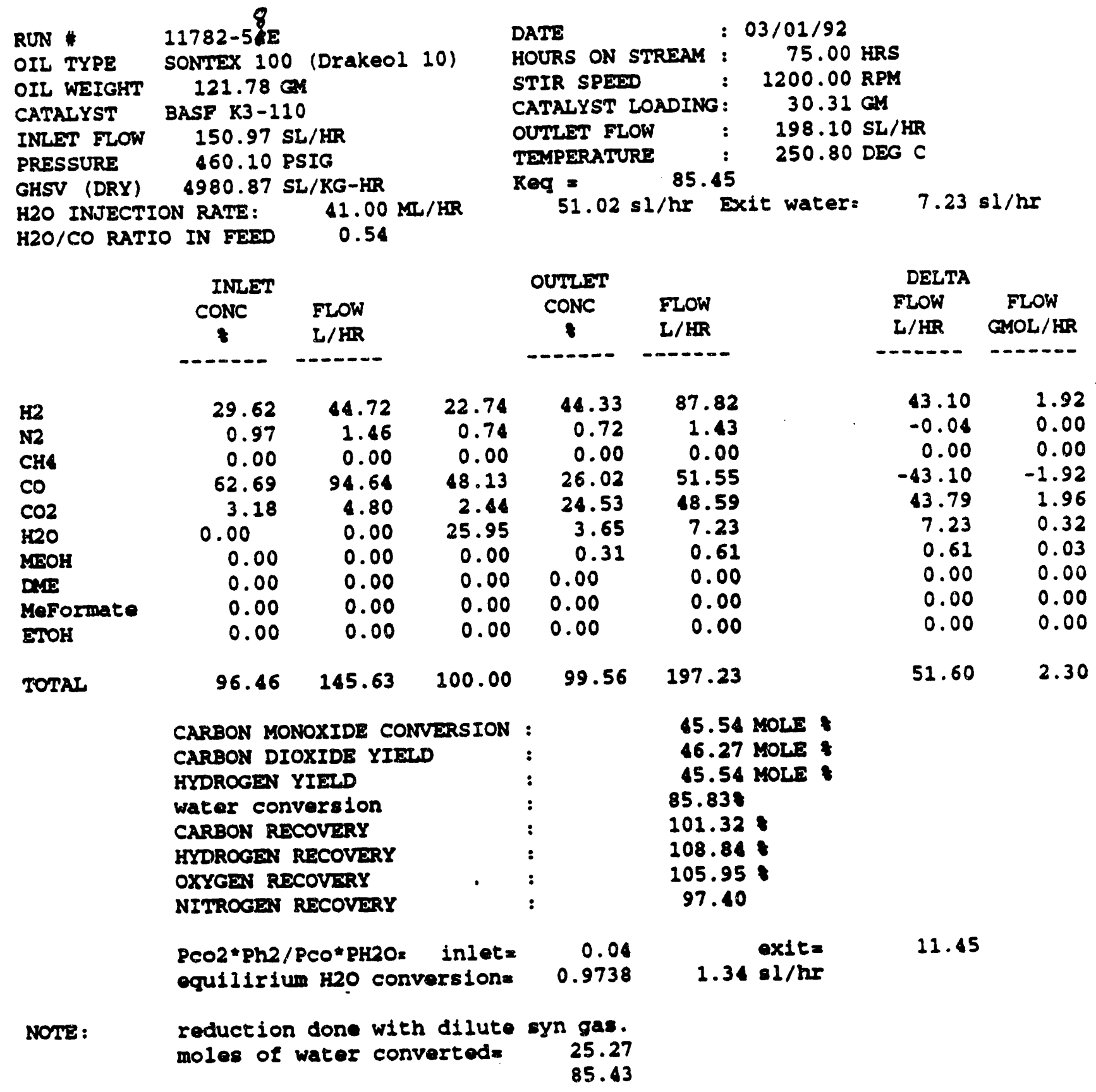




\section{LIQUID PHASE SHIFT}

APCI STIRRWD AUTOCLAVES

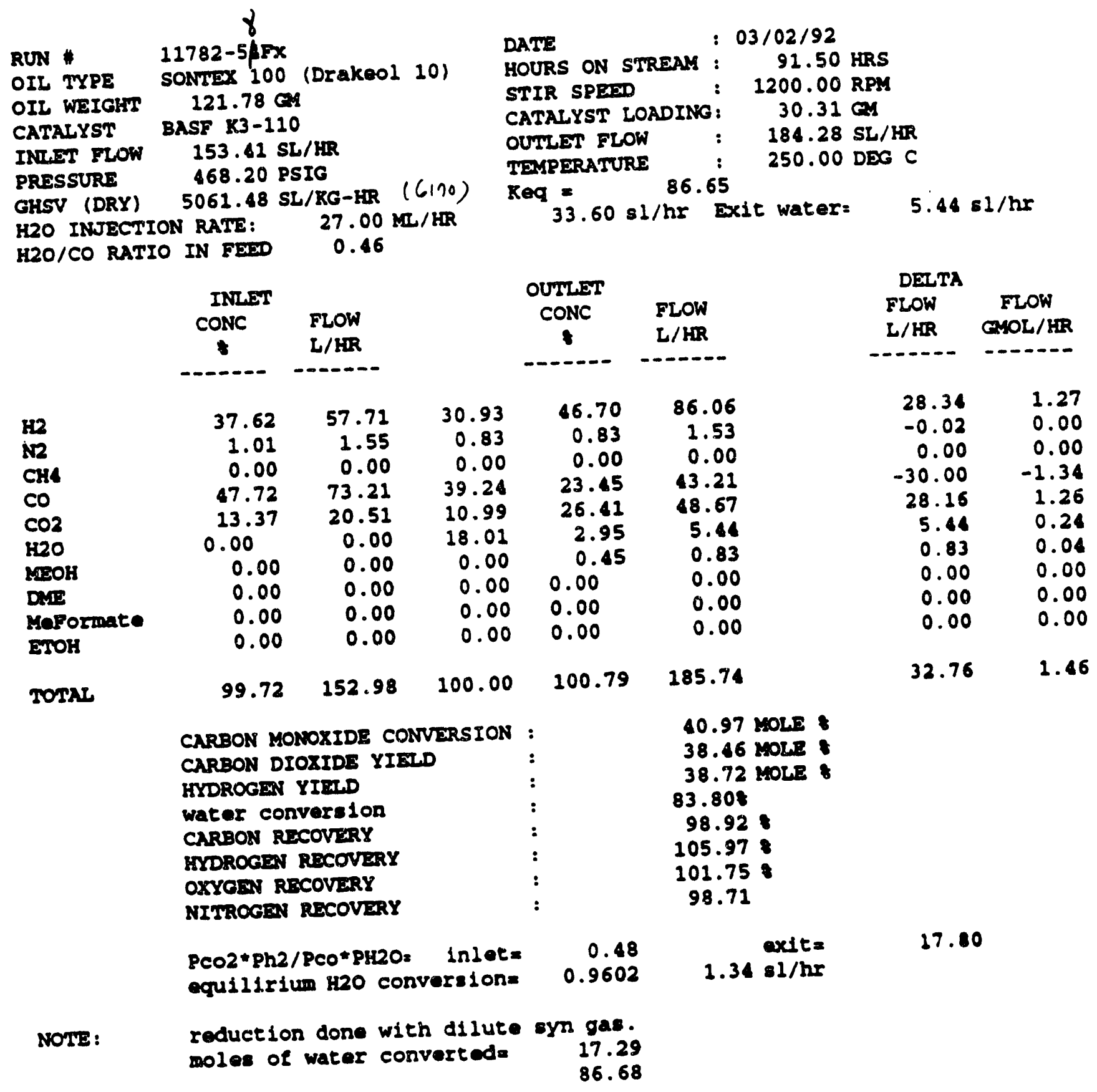


LIQUID PHASE SHIFT

APCI STIRRED AUTOCLAVES

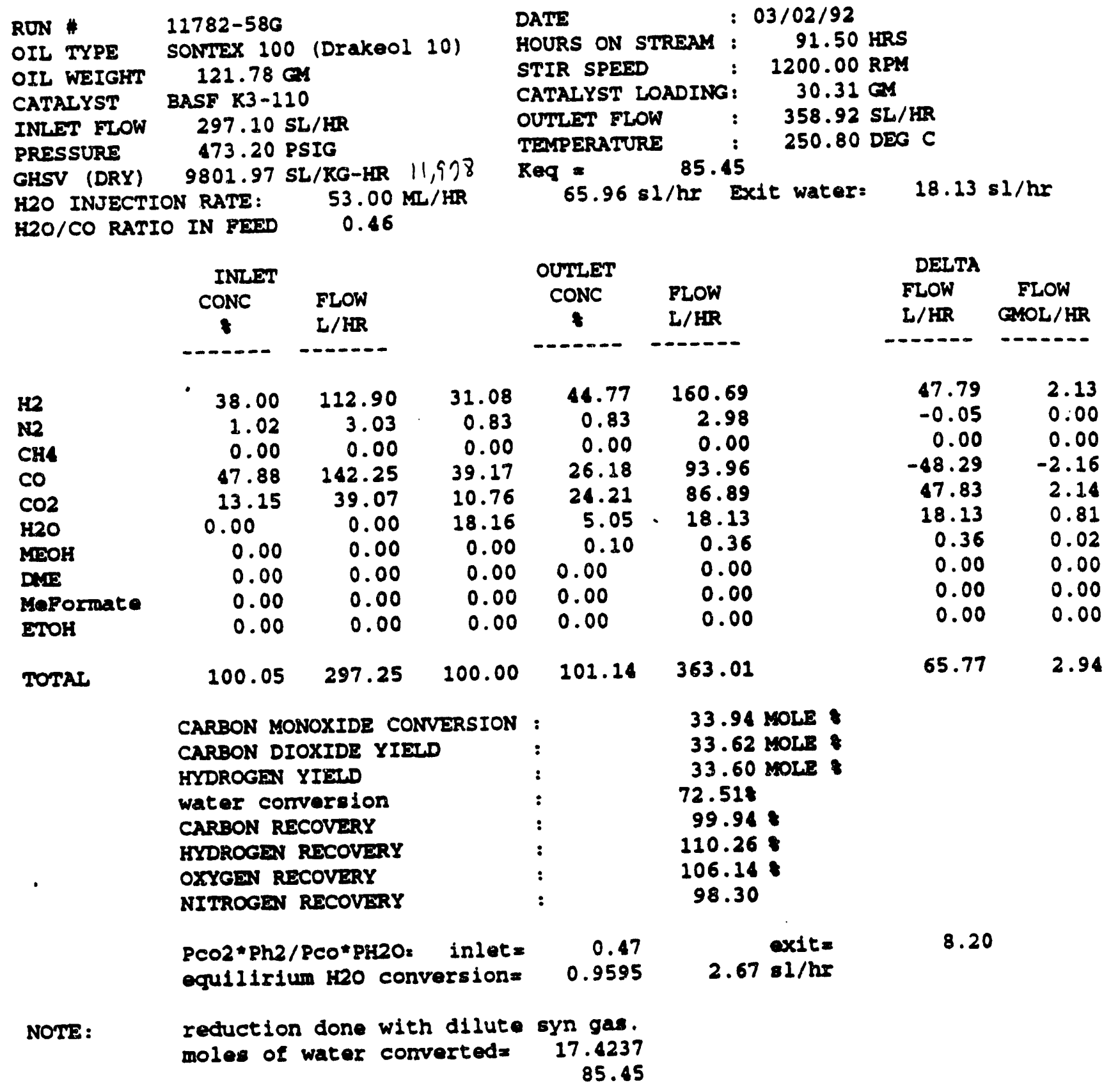


LIQUID PHASE SHIFT

APCI STIRRED AUTOCLAVES

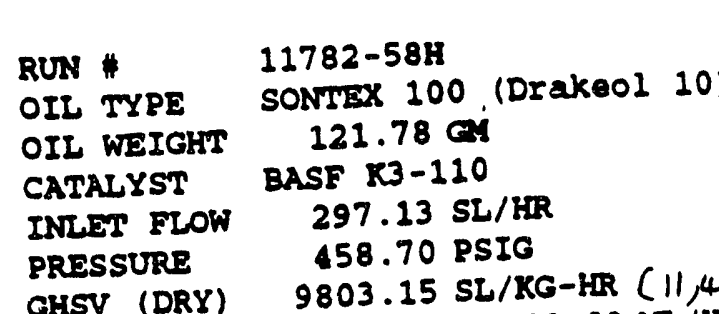

GHSV (DRY) $9803.15 \mathrm{SL} / \mathrm{KG}-\mathrm{HR}(11,445.5)$ H2O INJECTION RATE: $\quad 40.00 \mathrm{ML} / \mathrm{HR}$ H2O/CO RATIO IN FEINO 0.26

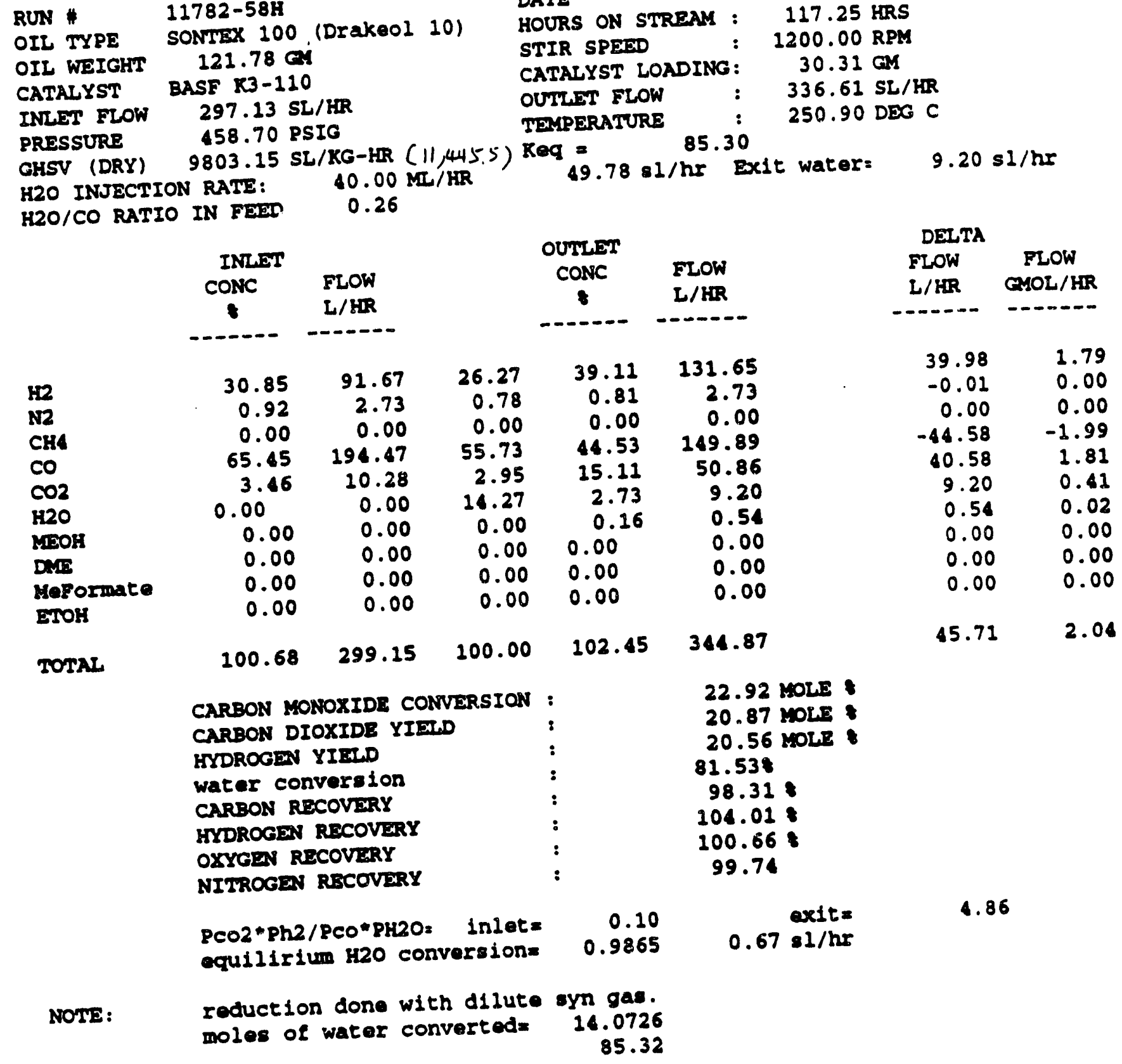

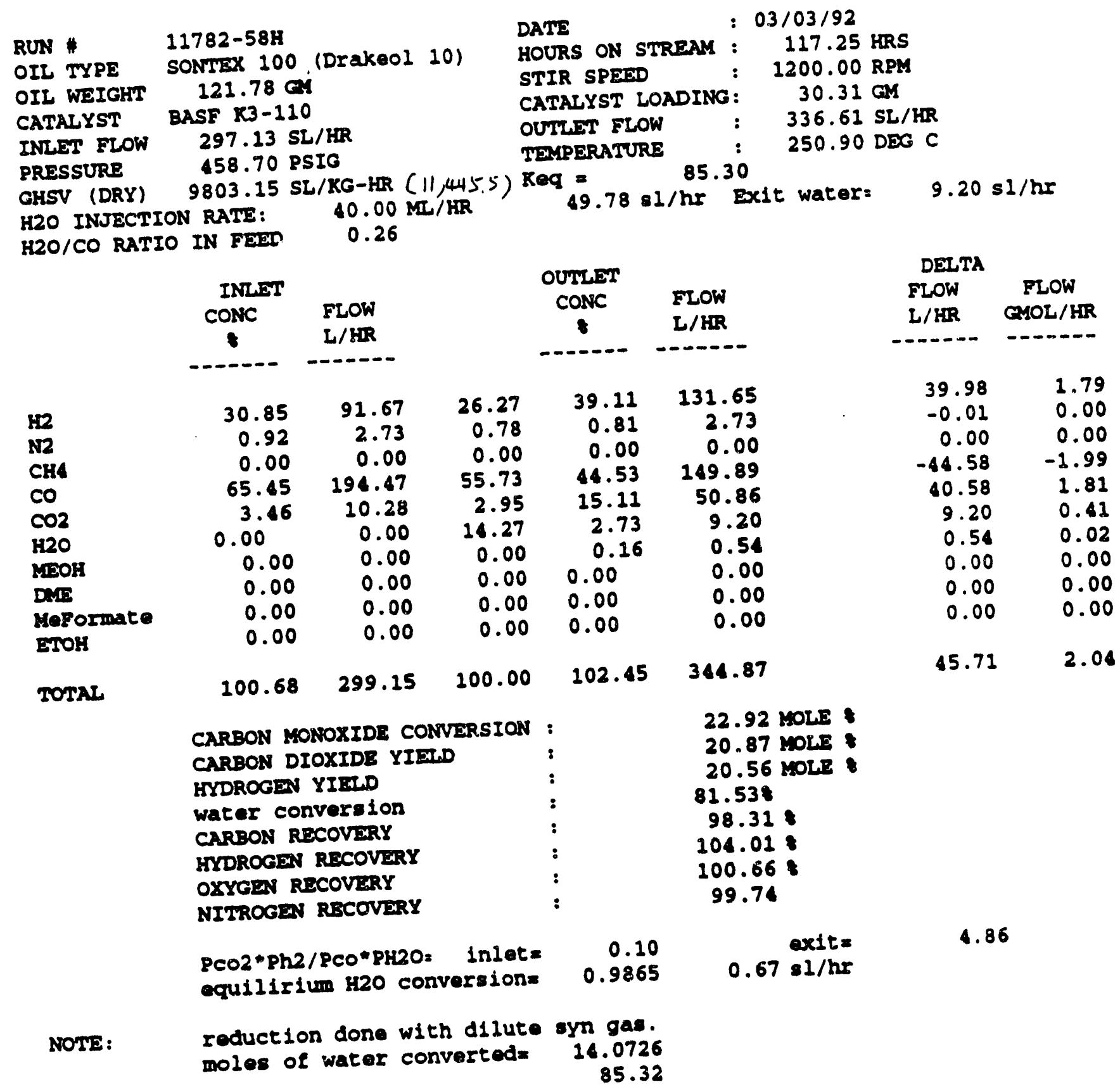

Req $=78 \mathrm{sl} / \mathrm{hr}$ Exit water $=9.20 \mathrm{sl} / \mathrm{hr}$
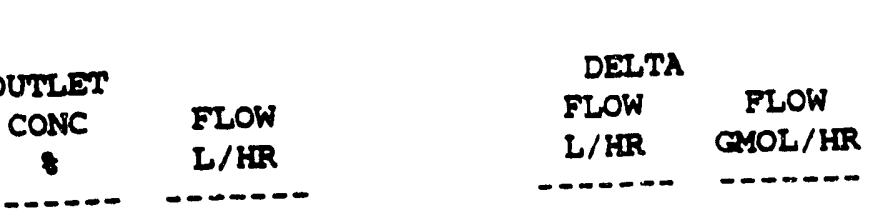

$$
\begin{array}{rr}
39.98 & 1.79 \\
-0.01 & 0.00 \\
0.00 & 0.00 \\
44.58 & -1.99 \\
40.58 & 1.81 \\
9.20 & 0.41 \\
0.54 & 0.02 \\
0.00 & 0.00 \\
0.00 & 0.00 \\
0.00 & 0.00
\end{array}
$$

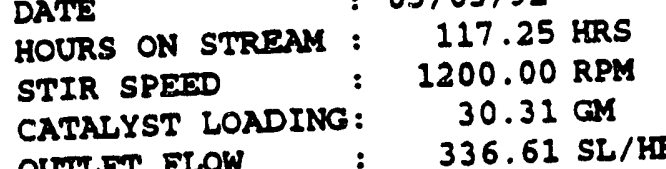




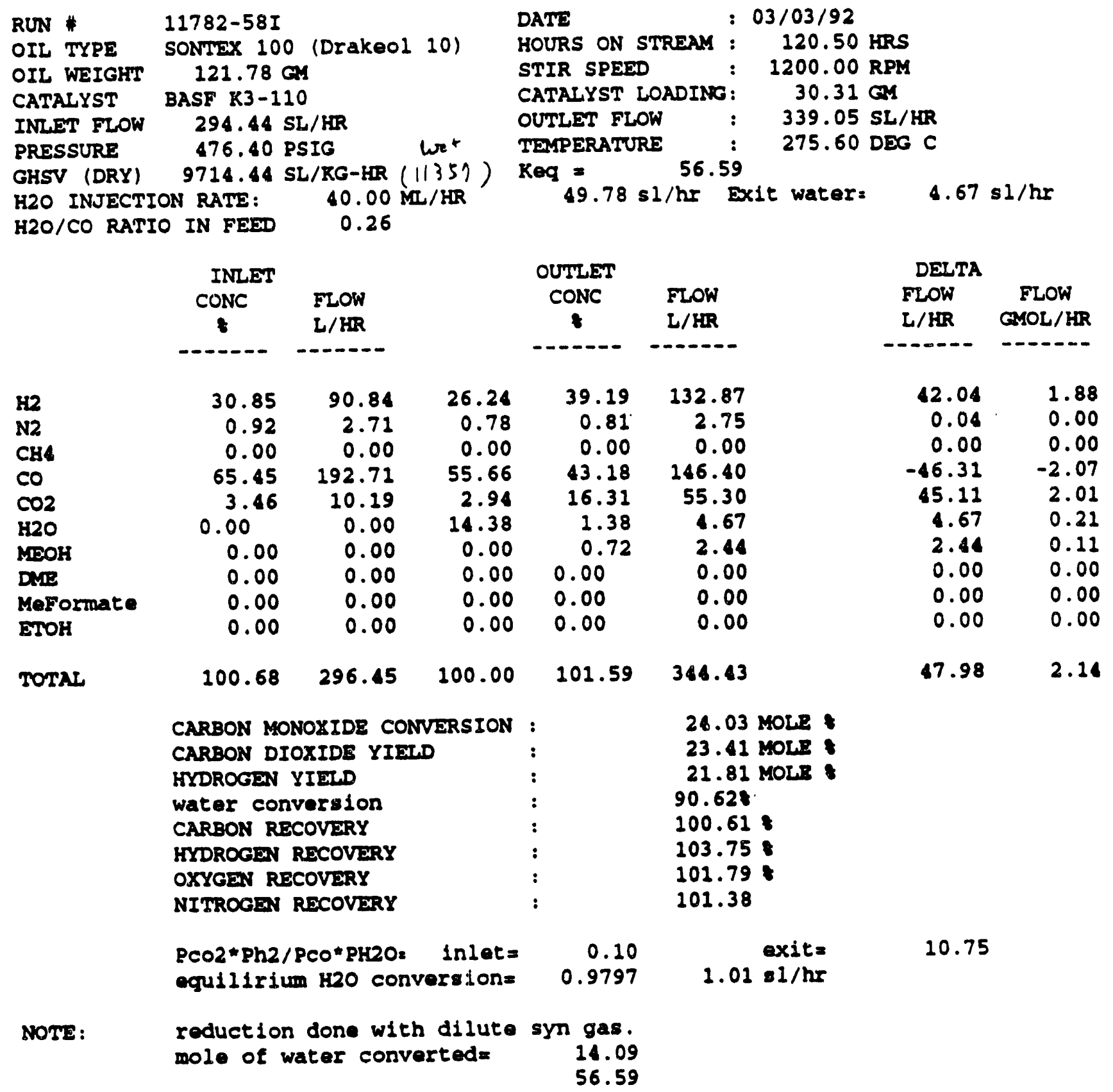


B. Run \#11782-63 (Powder K3-110, LaPorte Batch)

-

B. Run :11782-63 (Powder K3-110, LaPorte Batch)

-

c

C

1.

$=$ 


$$
\begin{aligned}
& \text { LPPoute Catalyst k3-110 } \\
& \text { (Shipped from Germany) }
\end{aligned}
$$

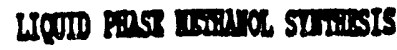

\section{IPCI Sation Inochats}

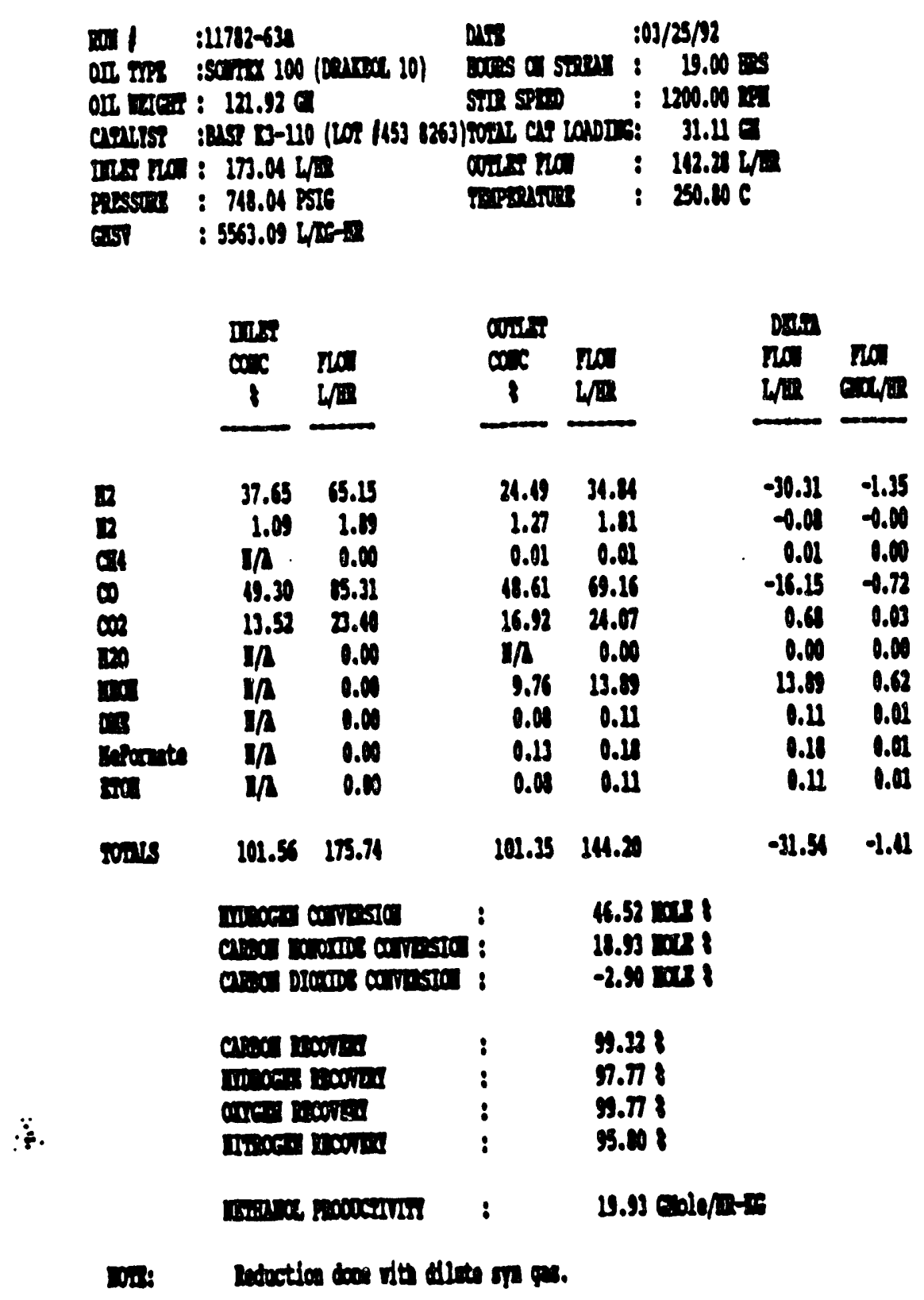




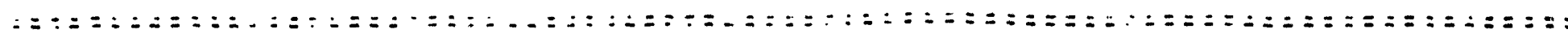

Sof tivale Ve-siori: $3.2<$ C.ES 1 .
Simple Name: jo0cc-1
Time
sampie Number: $3000 \mathrm{c} \# 1$
Etudy
OERITtor
: seg

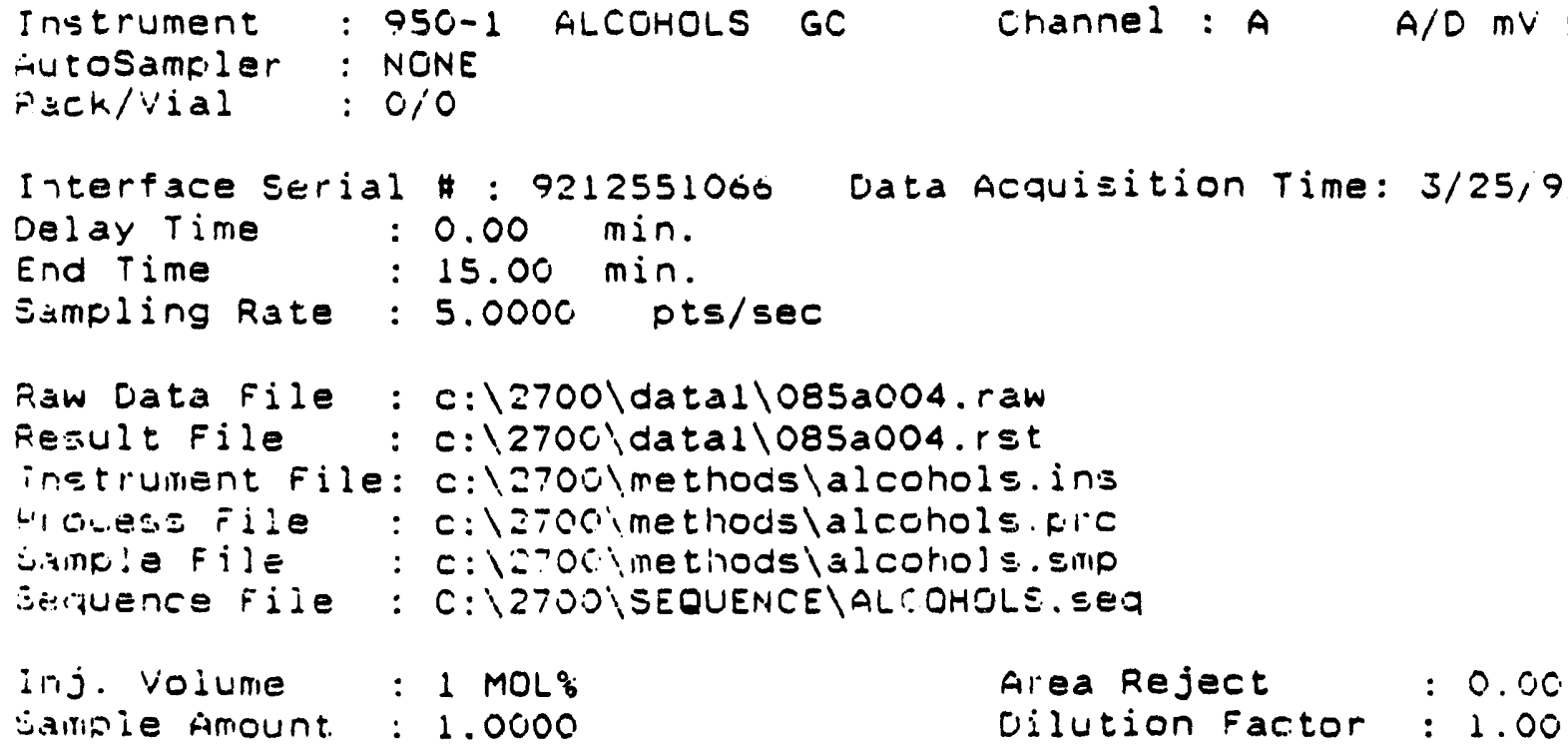

$3 / 25 / 9211: 29$ AM

: alconois research

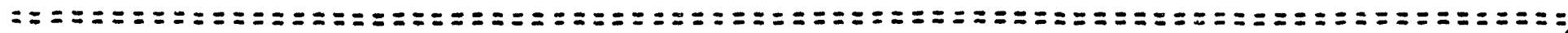

ALCOHOLS

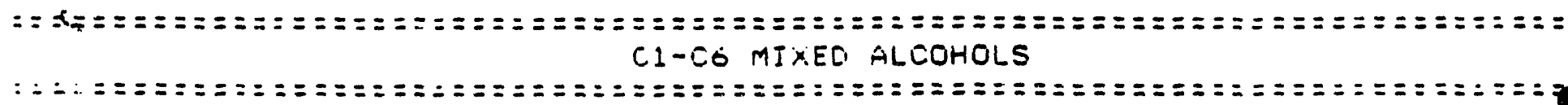

inak liae ared Area Morn. Arez Bi Alount Conponent

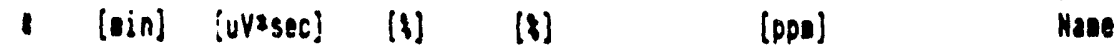

\begin{tabular}{|c|c|c|c|c|c|c|c|}
\hline 1 & 0.725 & 1164.64 & 0.18 & $0.188 \mathrm{~V}$ & 140.6647 & MEFHANE & \\
\hline 2 & 0.776 & 018.96 & 0.08 & $0.08 \mathrm{VB}$ & 27.5824 & ETHAME & \\
\hline 3 & 0.996 & 8534.80 & 1.04 & 1.0688 & 891.6980 & DIMETHYL ETHER & \\
\hline 4 & 1.107 & 739286.06 & 90.08 & $90.08 \mathrm{BV}$ & 97394.9453 & METHANOL & \\
\hline 5 & 1.324 & 10206.25 & 1.24 & $1.24 \mathrm{~V} 8$ & 1293.2148 & METHYLFORMATE & \\
\hline 6 & 1.532 & 14601.78 & 1.78 & 1.7888 & 893.6423 & ETHAKOL & \\
\hline ; & 2.162 & 3520.77 & 0.43 & 0.4388 & 209.4092 & METHYL ACETATE & $\# 11782-639$ \\
\hline 8 & 3.101 & 7573.34 & 0.92 & 0.9288 & 277.8900 & 1-PROPANOL & \\
\hline 9 & 4.043 & 1165.58 & 0.14 & 0.1488 & 0.0000 & & $9 \mathrm{hr} 3$ on - strreare \\
\hline 10 & 4.638 & 3414.21 & 0.12 & 0.1288 & 85.6162 & ISOBUTAMOL & 7 nrs on - smeam \\
\hline il & 5.325 & 1538.05 & 0.55 & 0.5588 & 123.5396 & 1-BUTANOL & \\
\hline 12 & 5.986 & 1467.64 & 0.18 & $0.18 B 8$ & 36.5261 & METHYL ISOBUTYRATE & \\
\hline 13 & 6.374 & 1270.50 & 0.16 & 0.1688 & 0.0000 & & \\
\hline 14 & 6.676 & 1753.13 & 0.21 & 0.2188 & 35.7360 & 2-HETHYL-I-BUTAMOL & \\
\hline 15 & 7.134 & 2566.10 & 0.31 & 0.3188 & 51.7179 & I-PENTANOL & \\
\hline 16 & 7.602 & 1133.76 & 0.14 & 0.1488 & 0.0000 & & \\
\hline 17 & 7.997 & 756.80 & 0.09 & 0.0988 & 0.0000 & & \\
\hline 18 & 8.168 & 1083.43 & 0.13 & 0.1388 & 21.0583 & 2-METHYL-1-PENTANOL & \\
\hline$: 9$ & 8.056 & 2198.12 & 0.27 & 0.2788 & 50.6085 & 1-HEXANOL & \\
\hline 20 & 9.534 & 1101.59 & 0.13 & 0.1388 & 0.0000 & & \\
\hline $2 !$ & 9.997 & 1616.80 & 0.17 & 0.1780 & 0.0000 & & \\
\hline $9 \hat{\imath}$ & 10.373 & 632.33 & 0.08 & 0.0888 & 0.0000 & & \\
\hline
\end{tabular}


Loun ping berne subists

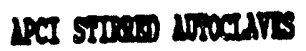

\begin{tabular}{|c|c|c|c|}
\hline 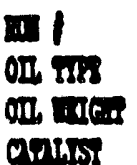 & 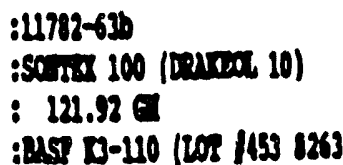 & 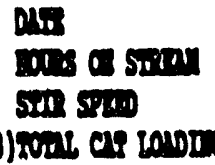 & 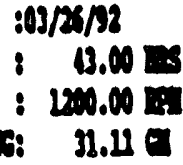 \\
\hline man & $\begin{array}{l}\text { : } 179.04 \text { La } \\
: 799.50 \text { P3Is }\end{array}$ & 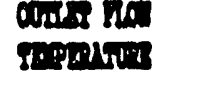 & \\
\hline
\end{tabular}

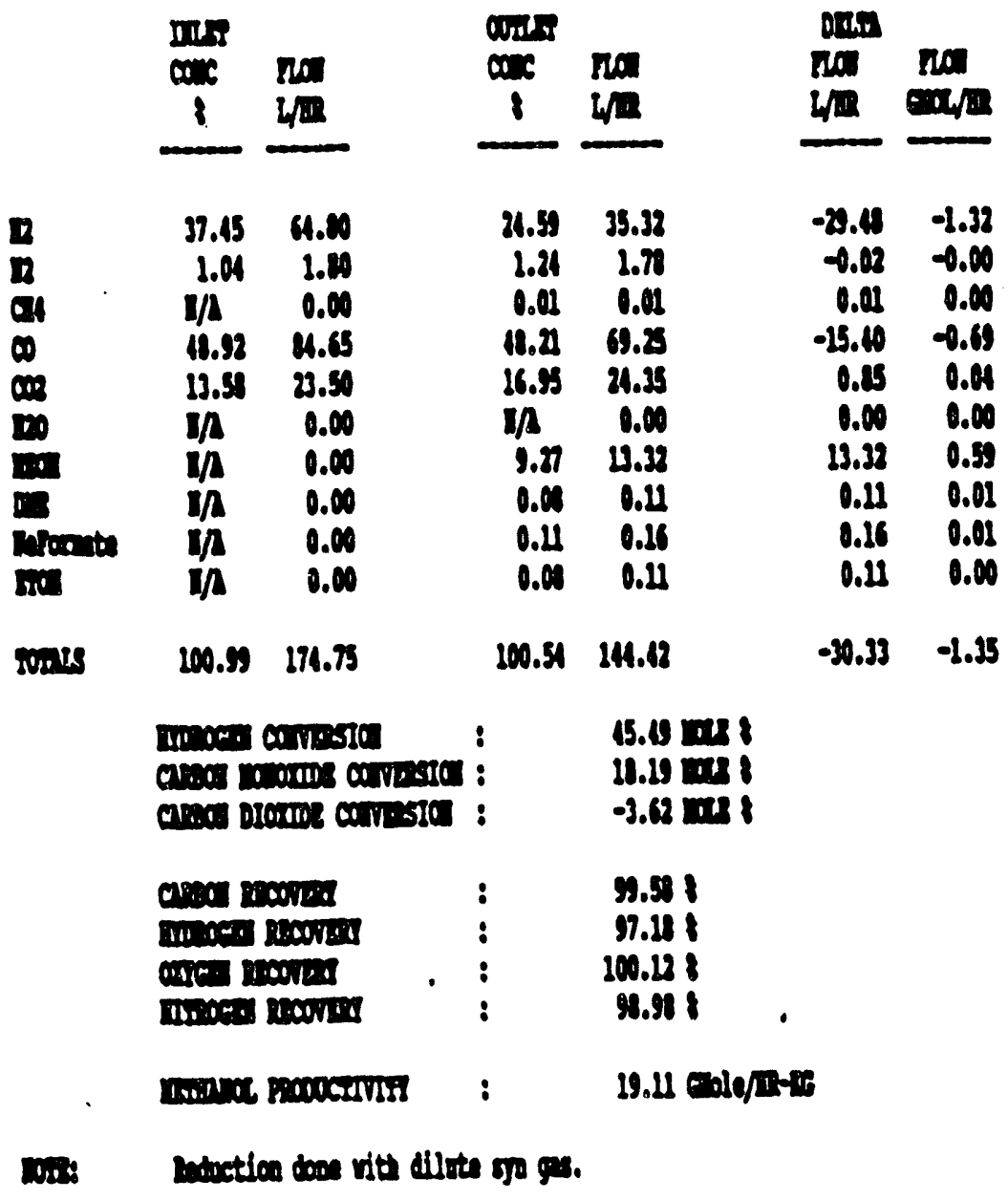


Autosiampler : NUNE

Rack/Vial: : $0 / 0$

Rack/Vial : $0 / 0$
Interface Serial : 9212551000 Data Acquisition Time: $3 / 26 / 92$ 11:40 AM
Delay Time : $0.00 \mathrm{~min}$.

End Time : $15.00 \mathrm{~min}$.

Eampling Rate: 5.0000 pts/sec

Raw Data File: $c: \backslash 2700 \backslash$ datal 10803004 .raw

Result file: $c: \backslash 2700 \backslash$ datal $c 0800004 . r s t$

Instrument File: $c: \backslash 2700 \backslash$ methods $\backslash$ alcohols. ins

Process File: $c: \backslash 2700 \backslash$ methods $\backslash$ alcohols.pre

Sequence file : $:: \backslash 2700 \backslash$ SEQUENCE\ALCOHOLS.Sea

$\begin{array}{lll} & \text { Area Reject } & : 0.00 \\ \text { Inj. Volume } & : 1 \text { MOL\% } & \text { Dilution Factor }: 1.00 \\ \text { Sample Amount } & : 1.0000 & \end{array}$

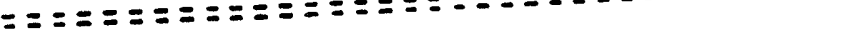

1

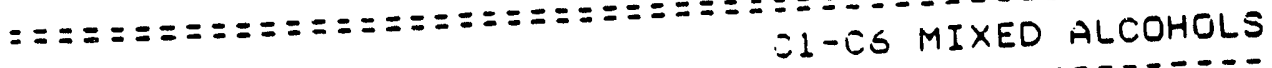

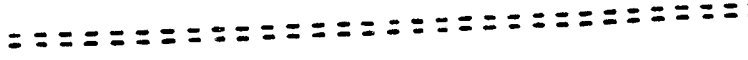

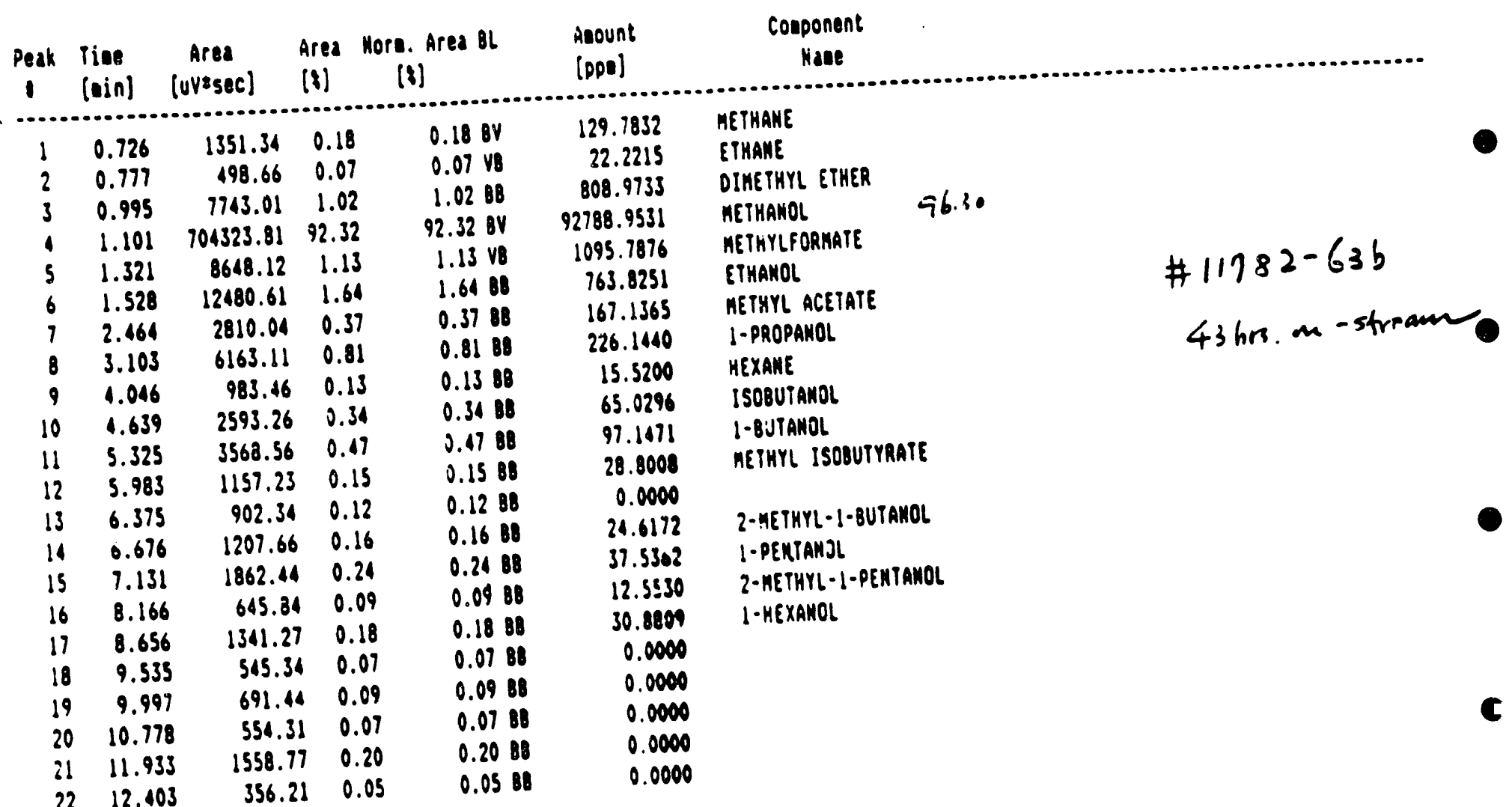

$\begin{array}{llllll}23 & 13.017 & 929.47 & 0.12 & 0.1288 & 0.9000\end{array}$

$762916.25 \quad 100.00 \quad 100.00 \quad 96314.9141$ 


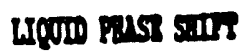

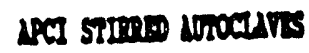

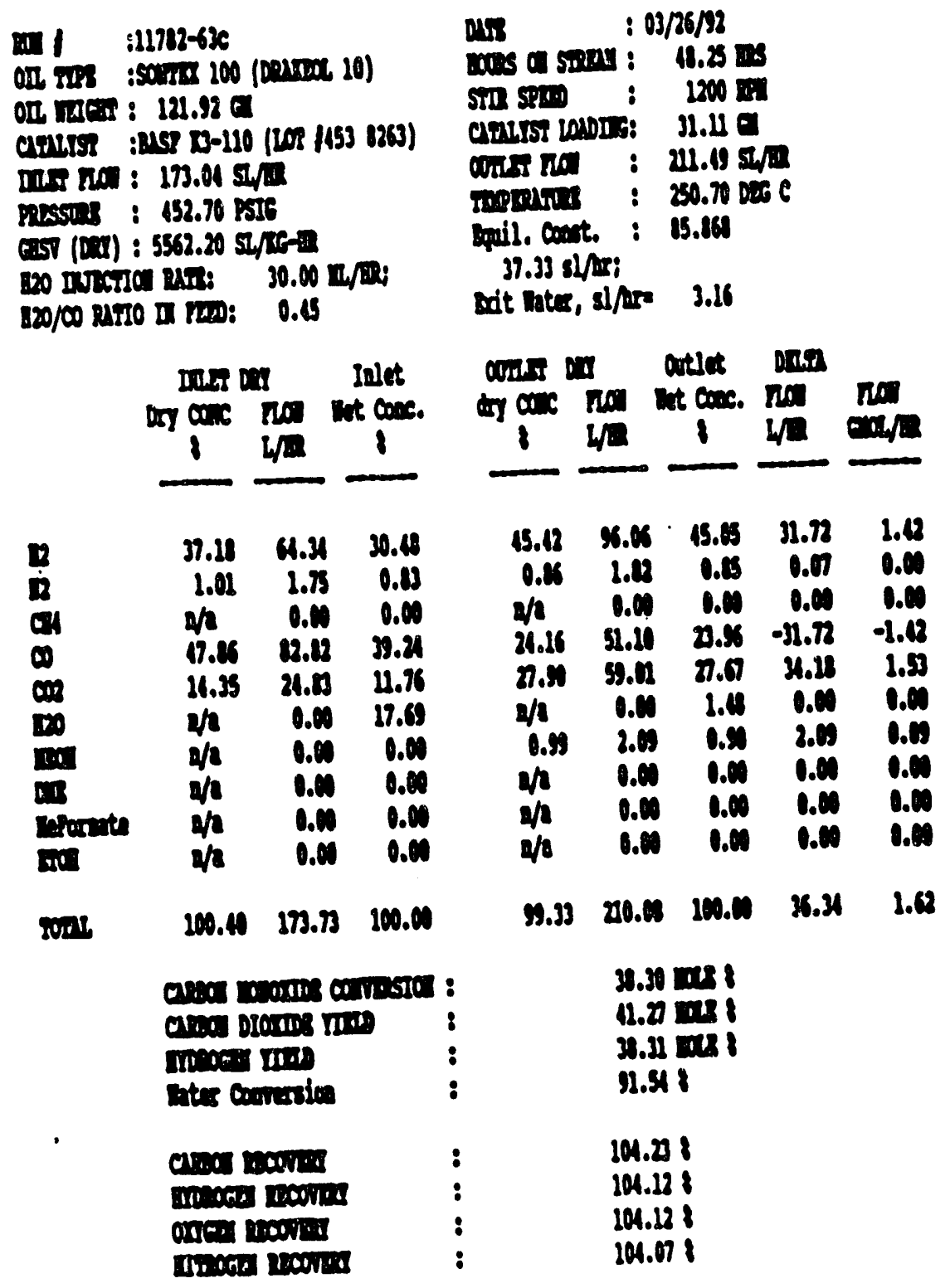

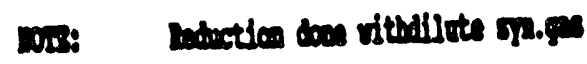


RUN \# OPERATION

DURATION

CATALYST ACTIVATION

AF-A2 Activation of 550\# of K3-110 catalyst 2.0 days

\section{LPMDEMONSTBATION}

AF-R4

Methanol synthesis w/K3-110

Drain reactor to $275 \#$ of catalyst (oxide basis)

6.5

0.5

\section{LPS DEMONSTRATION}

\begin{tabular}{|c|c|}
\hline $\begin{array}{r}\text { AF-R5 } .1 \\
.2 \\
.3 \\
.4\end{array}$ & $\begin{array}{l}\text { Texaco Gas, } S V=10000, \mathrm{H2}: C O=1: 1 \\
\text { Texaco Gas, } S V=10000, \mathrm{H2}: \mathrm{CO}=2: 1 \\
\text { Texaco Gas, } S V=6000, \mathrm{H2}: \mathrm{CO}=2: 1 \\
\text { Texaco G2s, } S V=6000, \mathrm{H2}: \mathrm{CO}=1: 1 \\
\text { Change-out methanol in } \mathrm{CO} 2 \text { removal section }\end{array}$ \\
\hline $\begin{array}{r}\text { AF-R5 .5 } \\
.6 \\
.7 \\
.8\end{array}$ & $\begin{array}{l}\text { Shell Gas, } S V=7000, H 2: C O=2: 1 \\
\text { Shell Gas, } S V=7000, H 2: C O=1: 1 \\
\text { Shell Gas, } S V=4000, H 2: C O=1: 1 \\
\text { Shell Gas, } S V=4000, H 2: C O=2: 1 \\
\text { Prepare for once-through operation }\end{array}$ \\
\hline $\begin{array}{r}\text { AF-R5 } .9 \\
.10 a \\
10 b\end{array}$ & $\begin{array}{l}\text { H2 Lean Gas, SV=6000, H2:CO=2:1 } \\
\text { POX Gas, SV=6000, H2:CO=20:1 } \\
\text { POX Gas, SV=6000, H2:CO=40:1 }\end{array}$ \\
\hline
\end{tabular}

TOTAL $\quad 22.0$

SV is space velocity expressed as sLkg-hr. Runs R5.6, R5.7, and R5.10b are optional and will be carried-out if the schedule can be maintained. The feed gas compositions to be used are presented in Table 2.

TABLE 2: Feed Gas Compositions for Spring '92 LPS Demonstration

$\begin{array}{lrrrr}\text { Component: } & \mathrm{H} 2 & \mathrm{CO} & \mathrm{CO} 2 & \mathrm{~N} 2 \\ & & & & \\ \text { Shell Gas } & 31.0 & 65.0 & 3.0 & 1.0 \\ \text { Texaco Gas } & 35.0 & 51.0 & 13.0 & 1.0 \\ \text { H2 Lean Gas } & 1.5 & 72.0 & 13.4 & 13.1 \\ \text { POX Gas } & 60.7 & 37.7 & 1.6 & 0.0\end{array}$

\section{Process Development}




\section{APPENDIX 5}

\section{MEETING NOTES OF PARTNERS' MEETING IN PITTSBURGH; MARCH 19-20, 1992}


Mr. Gary J. Stiegel

Project Manager

Liquid Fuels Division

Pittsburgh Energy Technology Center

US Department of Energy

PO Box 10940

- ins 922-H

Pittsburgh, PA 15236

Dear Gary:

Attached please find:

- Our notes on the Partners' Meeting at Pittsburgh on March 19-20.

- A summary of follow-up discussion with Dr. Fred Tungate, UCI regarding catalyst preparation for F-T demonstration at LaPorte.

- A summary of follow-up discussion with Dr. Rocco Fiato, Exxon regarding starting wax at LaPorte.

- Information on Drakeol-10.

- A Proposed Run Plan for the F-T demonstration in July 92.

Timely comments from everyone on the distribution list are welcome.

Yours truly,

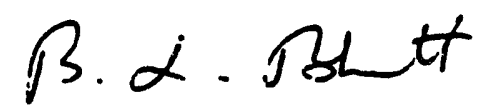

Dr. Bharat L Bhatt

Senior Principal Process Engineer

PSG Process Engineering

(215) 481-5995 
cc: Dr. Udaya Rao

Project Manager

Liquid Fuels Division

Pittsburgh Energy Technology Center

US Department of Energy

PO Box 10940

MS 922-H

Pittsburgh, PA 15236

Dr. Hemant B. Gala

Project Coordinator

Project Development Department

UOP Inc

25 E Algonquin Rd

Des Plains, IL 60017-5017

Dr. Dennis M. Brown

Technology Manager

Methanol and Alternative Fuels

Air Products and Chemicals, Inc

7201 Hamilton Blvd.

Allentown, PA 18195-1501
Mr. Keijo Kinnari

Staff Engineer

Research and Development

Statoil

PO Box 300

$\mathrm{N}-4001$ Stavanger

Nonway

Dr. Rocco Fiato, Exxon

Research Manager

Exxon Research \& Engineering Co.

180 Park avenue

Florham Park, NJ 07932 
NOTES FROM MEETING

Page One of One

\begin{tabular}{|c|c|c|c|c|}
\hline DATE OF MEETING & WEEKDAY & & & LOCATION \\
\hline $3 / 19 / 92-3 / 20 / 92$ & $\begin{array}{l}\text { Thursday \& } \\
\text { Friday }\end{array}$ & $\begin{array}{l}\text { STARTED } \\
8: 30 \text { AM } \\
8: 30 \text { AM }\end{array}$ & $\begin{array}{l}\text { ENDED } \\
\text { 5:00 PM } \\
\text { 12:00 Noon }\end{array}$ & $\begin{array}{l}\text { Holiday Inn Airport, } \\
\text { Pittsburgh }\end{array}$ \\
\hline
\end{tabular}

SUBJECT ANDOR PUAPOSE

Fischer-Tropsch Partners Meeting

\begin{tabular}{c|c|c|c}
\hline ITEM & RESPONSIBLE & TARGET \\
NO. & PERSON (INMALS) & DATE \\
\hline
\end{tabular}

1.

2.

APCI

Statoil
The partners agreed to include the following individuals at any future meetings or discussions as non-financial contributing attendees. Each will bring different areas of expertise to the group. They are:

- Dr. Norman Carr-Statoil Consultant- hydrodynamics expert

- Dr. Fred Tungate- UCI catalyst developer

- Prof. Drago Bukur- Texas A\&M research scientist- catalyst testing capability, DOE FT advisor

UOP noted that they may need to sign a secrecy agreement with Dr. Fred Tungate/UCI. Dr. Carr joined the meetings after lunch on Thursday. Dr. David Gray from Mitre was attending as DOE's FT advisor.

The possibility of including Rentech in the LaPorte planning was discussed at several points during the meeting. Since Rentech is in a partnership with Fuelco and Houser Chemical, this complicates the matter. They are also busy trying to solve problems in their own unit at this time. It was suggested that Bob Senn or Dennis Brown of APCI contact Rentech and determine if they are available to provide insight into possible startup problems, with limited legal problems.

In place of possibly using Rentech's 1.6" bubble column reactor, Statoil offered to run a few tests in a 2 " bubble column reactor once we have decided LaPorte operating conditions, the catalyst, and the wax starting material. This will provide an intermediate data point between the autoclaves and the LaPorte reactor. However, this test will not be in the decision scheme for LaPorte; it will be a parallel effort.

The partners agreed that they would prefer to run low alpha (0.700.78 ) cases at LaPorte this year. However, this was a change from our original objectives to make as much wax as possible. The reasons for preferring low $\alpha$ operations include:

- higher chance of success for our first run

- minimize our dependence on the catalyst/wax separation equipment to achieve maximum days on stream 


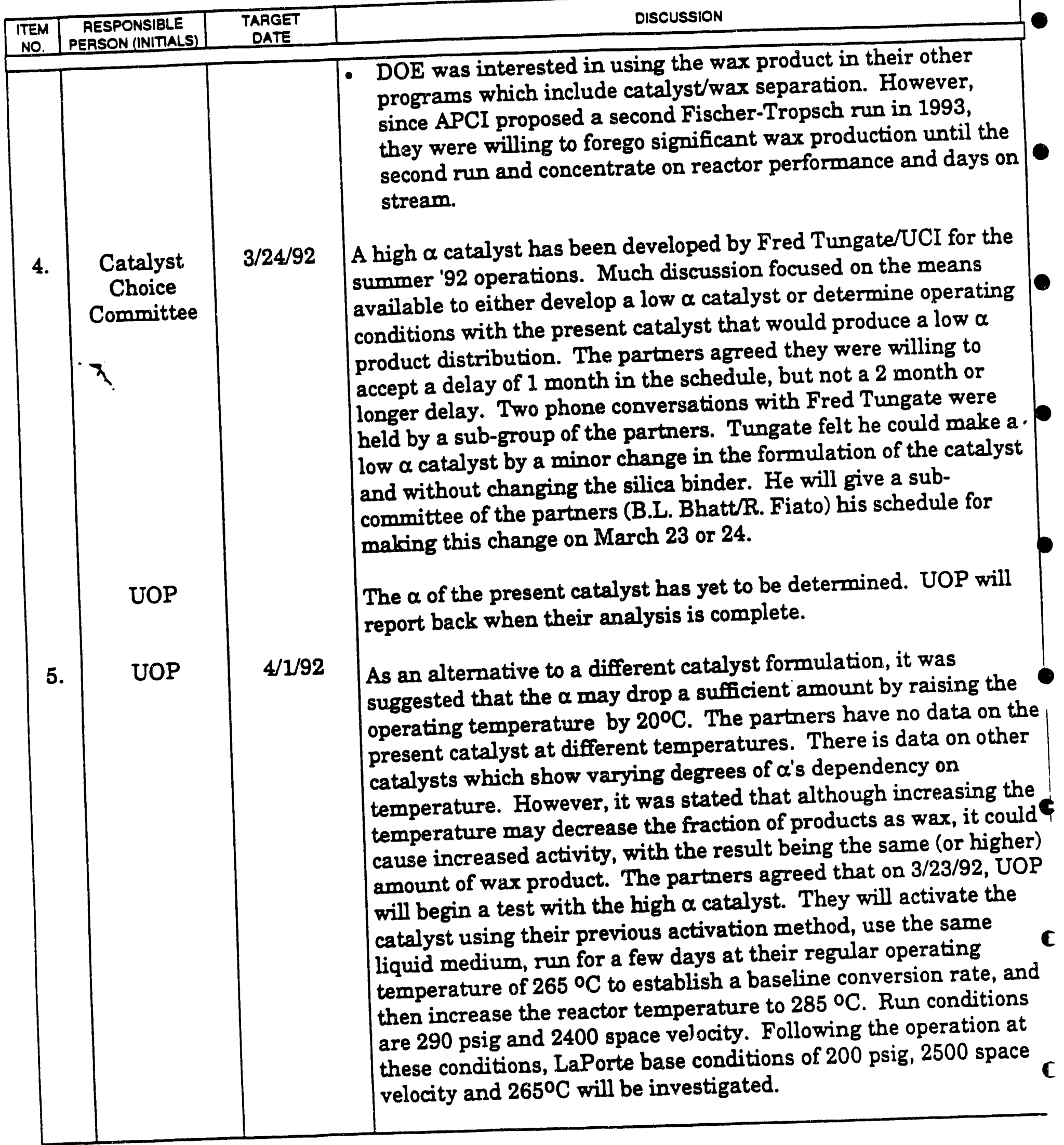




\begin{tabular}{|c|c|c|c|}
\hline $\begin{array}{l}\text { ITEM } \\
\text { NO. }\end{array}$ & $\begin{array}{c}\text { AESPONSIBLE } \\
\text { PERSON (INITALS) }\end{array}$ & $\begin{array}{l}\text { TARGET } \\
\text { DATE }\end{array}$ & DISCUSSION \\
\hline 6. & & & $\begin{array}{l}\text { Another method discussed for lowering the catalyst } \alpha \text { was de- } \\
\text { surfacing the present catalyst by pretreating it with steam. De- } \\
\text { surfacing the catalyst will reduce the sites available for the longer } \\
\text { chain hydrocarbons to grow. However, Rocco Fiato stated that by } \\
\text { pretreating the catalyst in a } \mathrm{H}_{2}, \mathrm{~N}_{2}, \text { steam mixture would } \\
\text { deactivate the catalyst by roughly } 50 \% \text {. The partners agreed that } \\
\text { such a reduction in catalyst activity would not be acceptable. }\end{array}$ \\
\hline 7. & Exan & & $\begin{array}{l}\text { Since low } \alpha \text { conditions will result in a longer turnover period for } \\
\text { the LaPorte reactor, the partners felt that the starting slurry } \\
\text { medium was more important than in a high } \alpha \text { run, where reactor } \\
\text { turnover would occur rapidly. Rocco Fiato will investigate what } \\
\text { wax starting material Exxon could provide for the operations. The } \\
\text { closer the starting wax is to an FT product, the more legal work } \\
\text { will be required by Exxon to allow its use. Therefore, legal matters } \\
\text { may require us to use Drakeol as our starting medium. }\end{array}$ \\
\hline & $\begin{array}{c}\text { Wax } \\
\text { Starting } \\
\text { Medium } \\
\text { Committee }\end{array}$ & & $\begin{array}{l}\text { A sub-committee of Bharat Bhatt, Rocco Fiato, Udaya Rao and } \\
\text { Hemant Gala was identified to chose the starting medium. They } \\
\text { will inform the other partners of their choice and their reasons. } \\
\text { If a solid Exxon wax is provided, a partial charge of Drakeol would } \\
\text { be used to preheat the equipment while the wax was being melted } \\
\text { externally with steam coils. The liquid would then be added to the } \\
\text { Drakeol. }\end{array}$ \\
\hline 8. & DOE & & $\begin{array}{l}\text { A discussion of the CAER's test results using Drakeol with the UCI } \\
\text { catalyst indicated that most participants felt that the poor CO } \\
\text { conversions seen by CAER may have been the result of the unit } \\
\text { (for example, no gas sparger) or the conditions, rather than the } \\
\text { Drakeol (no controls were run). Udaya Rao will have an X-ray } \\
\text { analysis done on both the spent CAER catalyst and some spent } \\
\text { catalyst tested by UOP. }\end{array}$ \\
\hline 9. & APCI & & $\begin{array}{l}\text { Bharat Bhatt presented the gas analysis points we are planning to } \\
\text { use and the use of DOE methods to do the gas analysis. Since } \\
\text { operating decisions will be made based on the on line gas analysis, } \\
\text { duplicate analysis will be done on the gas samples. This will } \\
\text { involve altering the new FID analyzer and one of the new TCD gas } \\
\text { analyzers. }\end{array}$ \\
\hline
\end{tabular}


NOTES FROM MEETING CONTINUATION

Page Four of Six

\begin{tabular}{|c|c|c|c|}
\hline $\begin{array}{l}\text { TTEM } \\
\text { NO. }\end{array}$ & $\begin{array}{c}\text { AESPONSIBLE } \\
\text { PERSON (INITALS) } \\
\end{array}$ & $\begin{array}{c}\text { TARGET } \\
\text { DATE }\end{array}$ & DISCUSSION \\
\hline 10. & $\begin{array}{l}\text { UOP/DOE/ } \\
\text { Exxon/APCI }\end{array}$ & & $\begin{array}{l}\text { It was further agreed that Joe Hackett of DOE/PETC would spend } \\
\text { one week at LaPorte, during the startup, training the APCI } \\
\text { analytical technician in the DOE gas sampling methods. After the } \\
\text { frst week, APCI will provide two analytical technicians. } \\
\text { On line hydrocarbon analysis cannot be done for this run since the } \\
\text { LaPorte lab is too remote from the sample points and it is likely } \\
\text { that the hydrocarbons will condense in the sample lines. DOE } \\
\text { suggested that to install their hydrocarbon analysis methods at the } \\
\text { LaPorte facility in time for the run would be extremely difficult, } \\
\text { due to the different analytical computer setup. The partners } \\
\text { agreed that batch hydrocarbon liquid, aqueous, and wax samples } \\
\text { will be priority shipped to PETC for analysis and they will fax the } \\
\text { results back to LaPorte. This should allow for a } 48 \text { hour } \\
\text { turnaround time on liquid and wax analysis. Two samples per day } \\
\text { each of the liquid hydrocarbon, wax, and aqueous cuts will be } \\
\text { analyzed. This plan may be modified when Shell joins the } \\
\text { discussions, since they have previously offered analytical } \\
\text { capabilities. PETC has the capabilities to analyze C }{ }_{15} \text {-C } \\
\text { hydrocarbons and intends to archive all samples received from } \\
\text { LaPorte for future re-analysis. } \\
\text { Exxon offered to analyze a limited number of representative wax } \\
\text { samples from the run. Their analytical capabilities include C } \\
\text { C } 10.0 \\
\text { An }\end{array}$ \\
\hline
\end{tabular}


Some areas of operations which will require further action from the partners include:

- Due to the expected exotherm, it is desirable that the LaPorte reactor only be preheated to $240^{\circ} \mathrm{C}$ during catalyst activation. Heat of reaction will then increase the temperature further. UOP currently does catalyst activation at $280^{\circ} \mathrm{C}$. Any effects on catalyst activity of introducing syngas at the lower temperature will need to be quantified before the run.

- The amount of aromatics which the present catalyst makes must be quantified before the LaPorte run so that the appropriate safety precautions may be taken.

- Ed Heydorn (APCI) will investigate how the analytical samples can be shipped to PETC for analysis. The equivalent of MSDS's will be required, as may special packaging or ground transportation, instead of air.

- Each partner must let APCI know what quantity of each product cut they want at the end of the run. This will affect APCI storage and therefore, APCI safety/hazard analysis.

- The concept of lowering the operating pressure to increase the superficial velocity through the reactor was discussed. Currently, APCI intends to run LaPorte at 200 psig and 400 psig.

13.

Bharat Bhatt presented the results from the cross flow filter tests. The results were disappointing, but APCI has incorporated a gravity settling method into the system so that the filters will see a less concentrated slurry than was tested. No additional tests are planned with the filters since it would require an additional 10 to $12 \mathrm{lbs}$ of reduced catalyst, which is not available. The first set of tests were done with the catalyst oxide. It is lnown that the reduced catalyst properties are much different than that of the oxide.

The reactor feed gas will have a $\mathrm{H}_{2} / \mathrm{CO}$ ratio of 0.7 and will contain no $\mathrm{CO}_{2}$. 


\begin{tabular}{|c|c|c|c|}
\hline $\begin{array}{l}\text { TEM } \\
\text { NO. }\end{array}$ & $\begin{array}{l}\text { AESPONSIBLE } \\
\text { PERSON (INITALS) }\end{array}$ & $\begin{array}{c}\text { TAAGET } \\
\text { DATE }\end{array}$ & DISCUSSION \\
\hline 15. & & & $\begin{array}{l}\text { The partners identified their criteria of success: } \\
\text { - high number of days on stream } \\
\text { - good catalyst activity- CO conversion at least } 50 \% \\
\text { - stable bubble column reactor performance } \\
\text { - good correlation of catalyst performance between the autoclaves } \\
\text { and the LaPorte reactor } \\
\text { Criterion identified as not being required for a successful run } \\
\text { included: } \\
\text { clean wax product } \\
\text { \% filtration catalyst recovery }\end{array}$ \\
\hline
\end{tabular}


Eollow-up Discussion with Dr. Fred Tungate (UCU) regardina Catalyst Preparation

After the partners' meeting on March 19-20, follow-up discussions were held by Dr. Bharat Bhatt (APCI) and Dr. Rocco Fiato (Exxon) with Dr. Fred Tungate (UCI) regarding the catalyst preparation for the F.T run at LaPorte. UCI has agreed to prepare two different low alpha catalysts on a small scale by end April. One batch will made with about $1 \% \mathrm{~K}_{2} \mathrm{O}$ and $1.6 \% \mathrm{SiO}_{2}$, starting with potassium silicate. This requires a minimum change from the current method of producing high alpha catalyst which also uses potassium silicate as starting material $\left(5.9 \% \mathrm{~K}_{2} \mathrm{O}\right.$ and $\left.9.7 \% \mathrm{SiO}_{2}\right)$. The $\mathrm{K}_{2} \mathrm{O}$ to $\mathrm{SiO}_{2}$ ratio would remain the same. The second batch would involve adding extra $\mathrm{SiO}_{2}$ from another source making up $105 \% \mathrm{SiO}_{2}$. The second batch will be a back-up catalyst, in case the first batch has less than acceptable physical properties due to lower silica content. Both the samples would be tested for physical properties such as attrition resistance by UCl. UOP will quickly activity test the catalyst selected from the two in early May. By mid-May, a decision will be made on whether to proceed with a high or a low alpha catalyst. UCI has blocked out pilot plant Yime to prepare 2000 lbs of the selected catalyst between mid-May and mid-June. Thus, the catalyst would be prepared in time for the July run as scheduled. Dr. Udaya Rao (DOE) and Dr. Hemant Gala (UOP) were consulted during the discussions and they are in agreement with the above plans.

\section{Eollow-uo Discussion with Dr. Bocco Fiate (Exxon) regardino Stanting Wax}

Follow-up discussions were held by Dr. Bharat Bhatt (APCI) with Dr. Rocco Fiato (Exxon) regarding the supply of the starting wax for the LaPorte F-T run. For Exxon to supply their process wax, they would need to restrict access to their wax and would require those with the access to sign a non-disclosure agreement with them. However, since starting wax would end up with the product wax, it would be very difficult to limit access to the starting wax. Also, with the run coming up in about three months, there is not enough time to get legal agreements in place. Exxon offered isopar, which is a $C_{20}-C_{30}$ saturated isoparaffin liquid. In absence of availability of wax, APCI would rather use Drakeol-10, which has been extensively successfully used at LaPorte for LPMEOH and LPDME. Drakeol-10 is a $\mathrm{C}_{16}-\mathrm{C}_{38}$ saturated hydrocarbon liquid which includes straight chain and branched paraffins as well as naphthenic compounds. Dr. Rocco Fiato agrees with the plan of using Drakeol-10. The catalyst performance would be independent of starting medium so long as it does not contain any contaminants. Dr. Udaya Rao (DOE) and Dr. Hemant Gala (UOP) were consulted during the discussions and they are in agreement with our plans of using Drakeol-10. Drakeol-10 will be used by UOP in future tests after a catalyst decision has been made. Information on Drakeol-10 is given below.

\section{Information on Drakeol-10}

Drakeol-10 is a white mineral oil, manufactured by Penreco. It contains $C_{16}-C_{38}$ saturated straight chain and branched paraffins as well as naphthenic hydrocarbons. Some relevant physical properties of Drakeol-10 are given in Table 1. Results of a simulated distillation (ASTM D2887-73) to check for the oil's stability are shown in Figure 1. A calibration curve 
using $n$-alkanes as a standard to identify carbon numbers quantitatively is given in Figure 2. $\mathrm{C}_{25}$ is the maximum ingredient of the oil. The autoclave spent sample shows only a slight decrease in the light ends $\left(<\mathrm{C}_{20}\right)$. Density, viscosity, themal conductivity and heat capacity of Drakeol-10 as function of temperature are given in Figures 3-6.

\section{Proposed Bun Plan}

The proposed run plan as discussed at the partners' meeting is summarized in Table 2. The plan was accepted by the partners. About $780 \mathrm{lbs}$ of catalyst and 210 gallons of Drakeol-10 will be loaded in the reactor to make about 35 wt\% slurry. The catalyst will be activated using $0.7 \mathrm{H} / \mathrm{CO}$ syngas at $2000 \mathrm{n} / \mathrm{hr}-\mathrm{kg} \mathrm{Fe}, 150 \mathrm{psig}$ and $280^{\circ} \mathrm{C}$ for about 12 16 hours. About $1 \% \mathrm{~N}_{2}$ will be added to the syngas as an internal standard. The inlet gas velocity of about $0.23 \mathrm{ft} / \mathrm{sec}$ will be sufficient for adequate mixing. Expanded slurry height of $20 \mathrm{ft}$, which is maximum, will be maintained throughout the run. The decline in $\mathrm{CO}_{2}$ and

Tise in $\mathrm{CH}_{4}$ content of the product gas will be monitored and when they level off, the operating conditions will be changed to Run No. 1.

\section{BunNo.1}

The baseline run will be conducted with $0.7 \mathrm{H}_{2} / \mathrm{CO}$ syngas ( $1 \% \mathrm{~N}_{2}$ ) at $2500 \mathrm{nl} / \mathrm{hr}-\mathrm{kg} \mathrm{Fe}$, $200 \mathrm{psig}$ and $265^{\circ} \mathrm{C}$. It is estimated that the reactor will contain about $490-500 \mathrm{lbs}$ of catalyst during the run; the remaining catalyst will be in the slurry holding tank and the cross-flow filter system. The slumy concentration in the reactor will be about 26 wt\%. The inlet gas velocity will be about $0.14 \mathrm{ft} / \mathrm{sec}$, which is the minimum velocity required for adequate mixing. Run No. 1 will be continued for 10 days to check for stabilization of the catalyst performance. The conditions of Run No. 1 will be repeated for 4 days after Run No. 3 to check for any catalyst deactivation.

\section{BunNo.2}

Following Run No. 1, the space velocity will be doubled to $5000 \mathrm{n} / \mathrm{hr}-\mathrm{kg} \mathrm{Fe}$ at $200 \mathrm{psig}$ and $265^{\circ} \mathrm{C}$ to study the effect of space velocity. The inlet gas velocity will be about $0.27 \mathrm{H} / \mathrm{sec}$. These conditions will be maintained for 3 days.

\section{Bun No.3}

The reactor pressure will then be doubled to $400 \mathrm{psig}$ at $5000 \mathrm{n} / \mathrm{hr}-\mathrm{kg} \mathrm{Fe}$ and $265^{\circ} \mathrm{C}$ to study the effect of reactor pressure. The inlet gas velocity will be back to about $0.14 \mathrm{ft} / \mathrm{sec}$. Run at these conditions will be continued for 3 days.

\section{Catalyst Loading}

The catalyst loading in the above plan is based on the use of high alpha catalyst, requiring significant catalyst-wax separation. The initial loading may be reduced if our efforts to prepare a low alpha catalyst are successful. Lower wax production will mean lower catalyst inventory outside the reactor. The reactor slurry concentration will remain the same. 


\section{Table 1}

\section{Drakeol-10 Physical Propenties}

Average Molecular Weight 366

Distillation (ASTM D1160), ${ }^{\circ} \mathrm{C}$

IBP

283

$10 \%$

$50 \%$

353

$90 \%$

407

481

Specific Gravity, $\mathrm{g} / \mathrm{ml}$

$25^{\circ} \mathrm{C}$

0.849

Hydrocarbon Type (PONA)

$\%$ Paratfinic/Naphthenic

$65 / 35$

Surface Tension, DYNE/CM $25^{\circ} \mathrm{C}$

30

Viscosity, CP

$25^{\circ} \mathrm{C}$

31.2

Pour Point, ${ }^{\circ} \mathrm{C}$

$-7$

Flash Point, ${ }^{\circ} \mathrm{C}$

185 


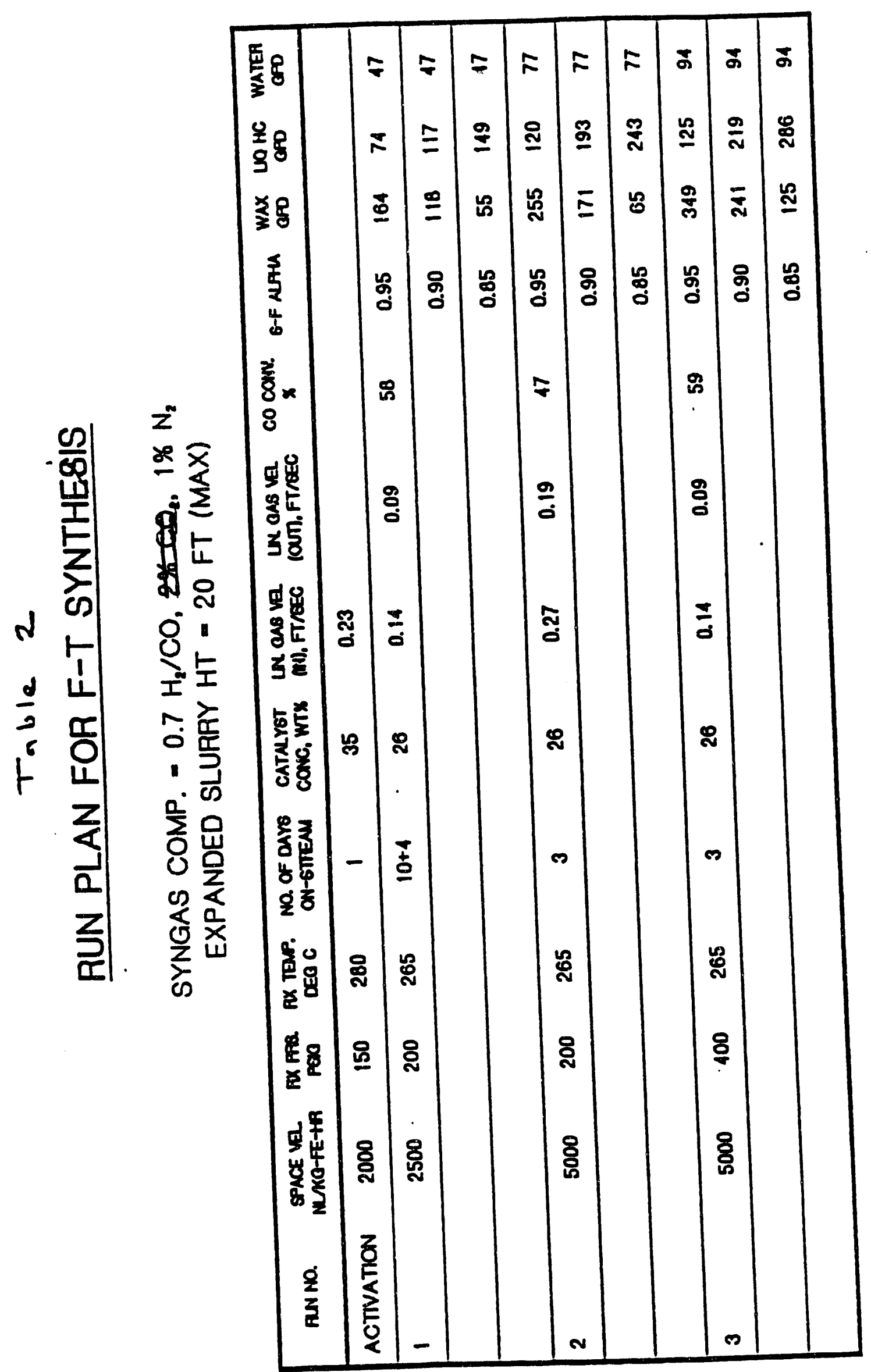


FIGURE 1 - Simulated Distillation of Drakeol $100 i l$
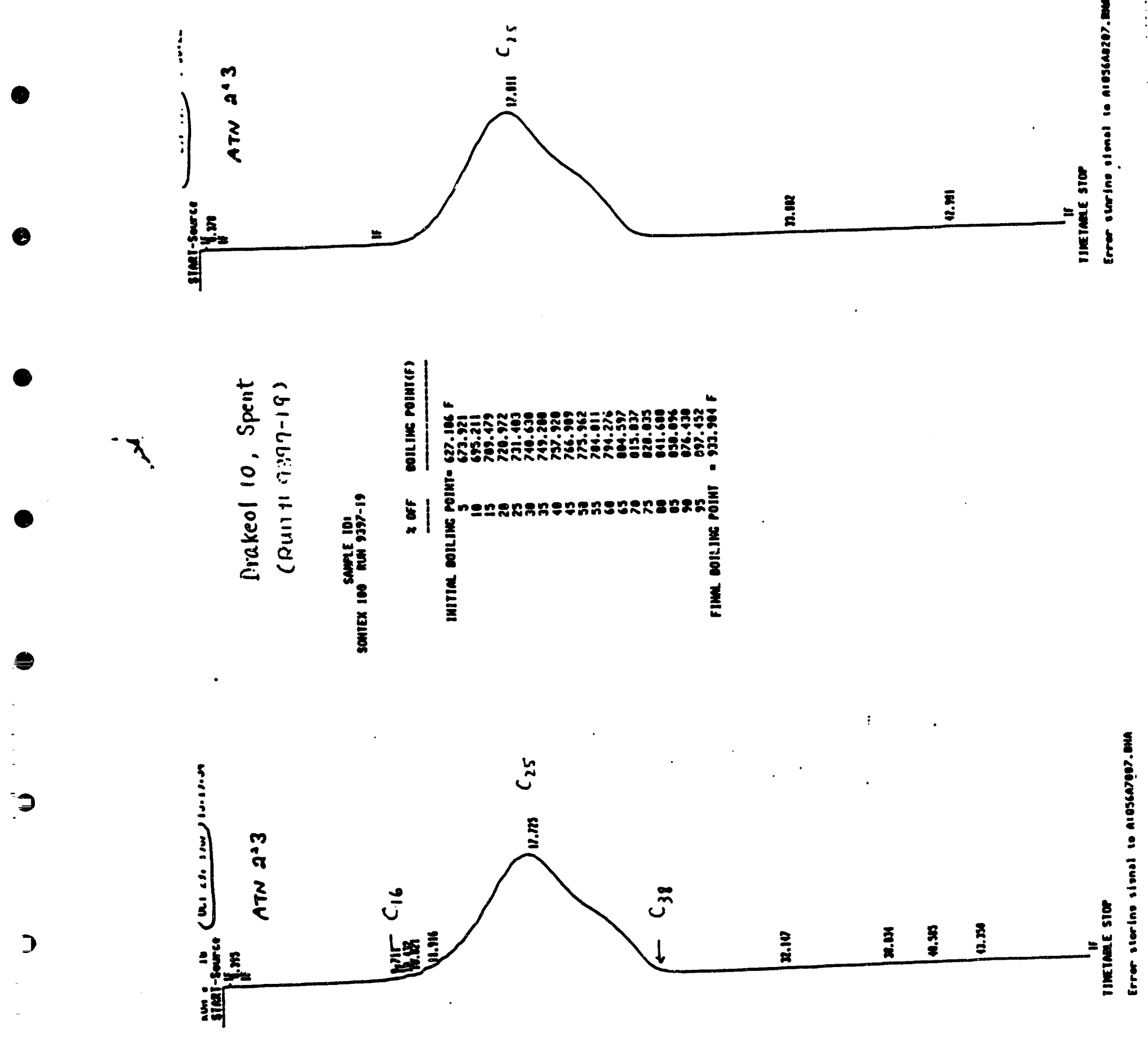

3

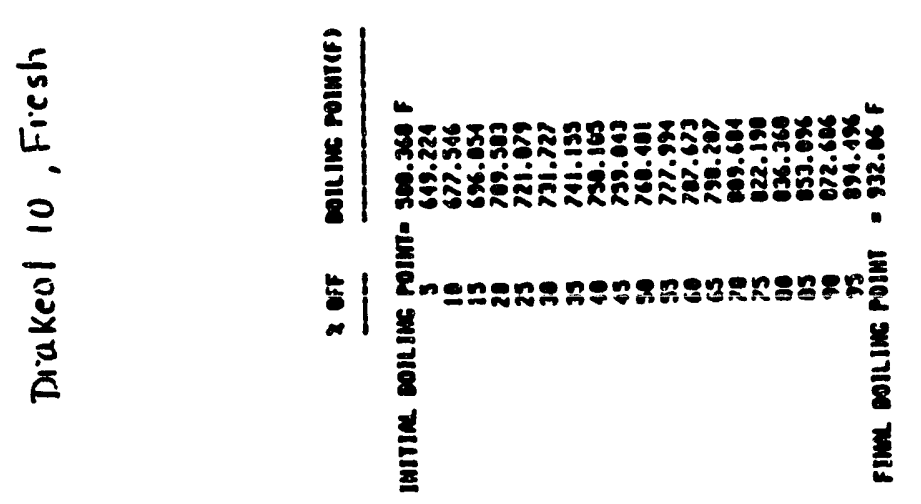


* RUN 38 HOY 2ิ, 1987 18:27:51

START-SOURCE

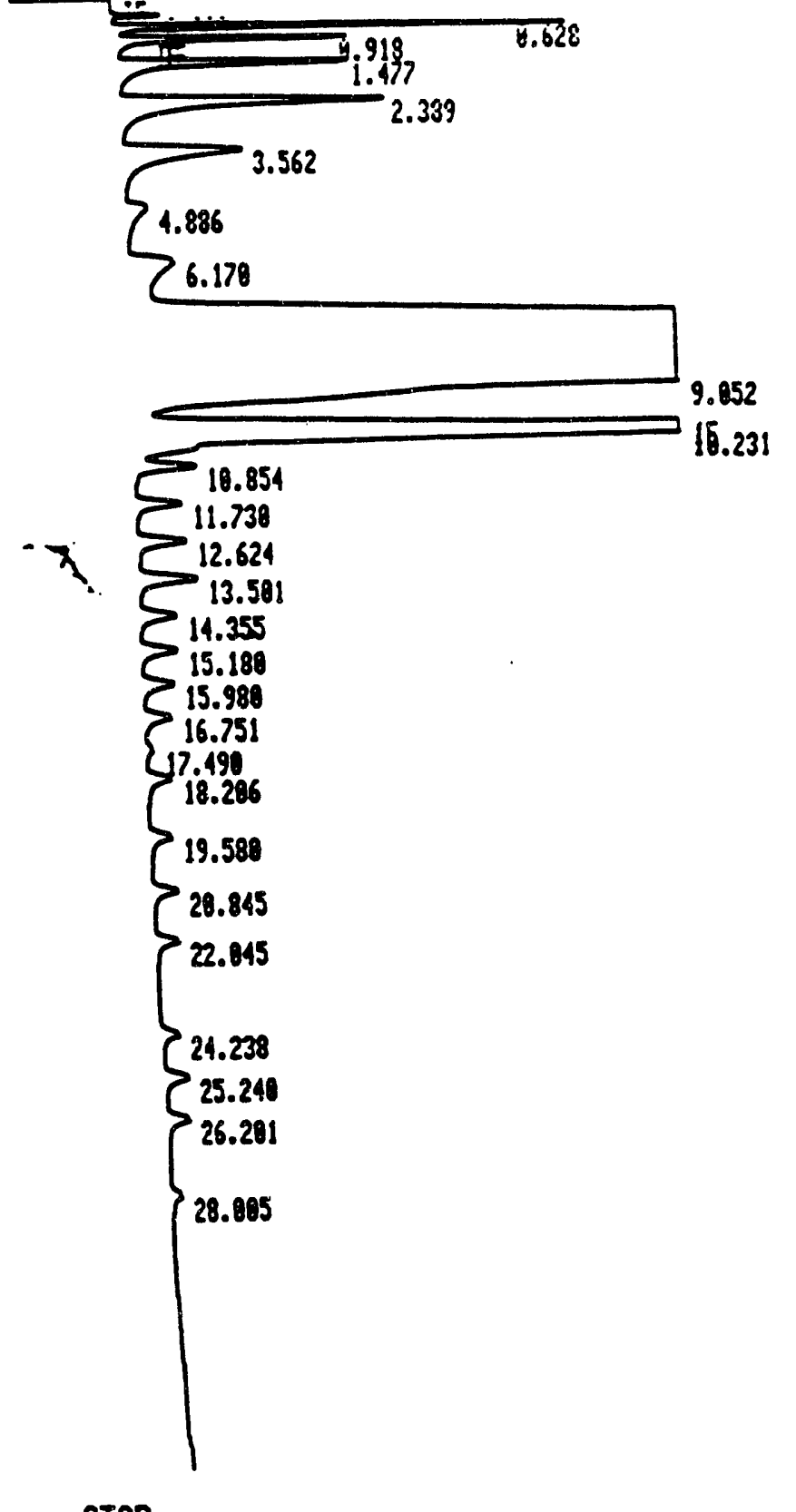

STOP

Closing sisnal file B:056F71A7.BMC

RUN 38 NOY 2,1987 10:27:51

SIGMAL FILE: B: Q56F71A7.BNC

\begin{tabular}{|c|c|c|c|}
\hline $\begin{array}{c}\text { CAL } \\
1 \\
2 \\
3 \\
4 \\
5 \\
6 \\
7 \\
8 \\
9 \\
18 \\
11 \\
12 \\
13 \\
14 \\
15 \\
16 \\
17 \\
18 \\
19 \\
28 \\
21 \\
22 \\
23 \\
24 \\
25 \\
26\end{array}$ & $\begin{array}{l}R T \\
8.636 \\
9.948 \\
1.524 \\
2.464 \\
3.653 \\
4.984 \\
6.284 \\
7.598 \\
9.830 \\
19.968 \\
11.844 \\
12.739 \\
13.615 \\
14.468 \\
15.296 \\
16.895 \\
16.868 \\
17.624 \\
18.327 \\
19.691 \\
28.964 \\
22.162 \\
24.366 \\
25.365 \\
26.331 \\
27.388\end{array}$ & 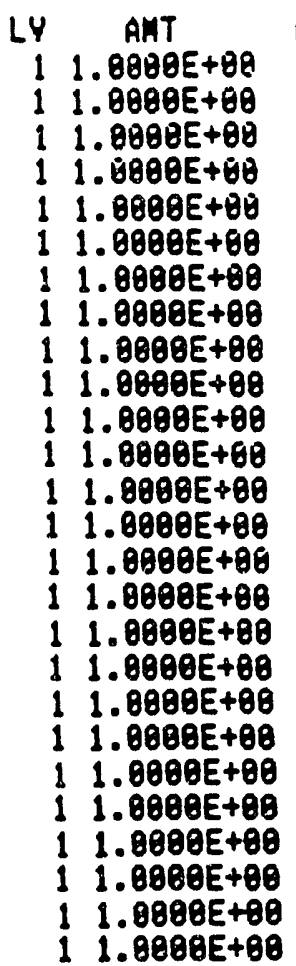 & 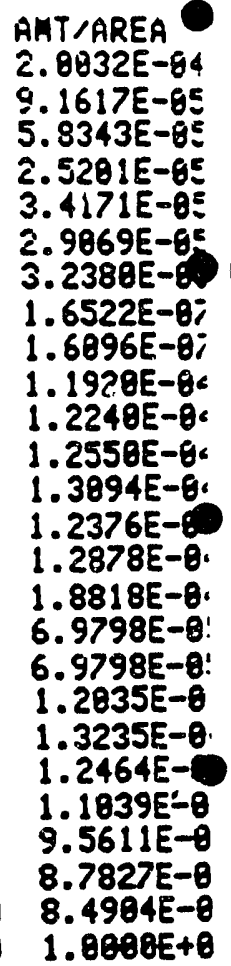 \\
\hline & & & \\
\hline
\end{tabular}

$1 \mathrm{CP}$

$2 \mathrm{C8}$

$4 \mathrm{ClO}$

$5 \mathrm{Cl1}$

$6 \mathrm{C12}$

$7 \mathrm{Cl3}$

$8 \mathrm{C14}$

$9 \mathrm{Cl6}$

$10 \quad \mathrm{CI7}$

$11 \mathrm{C18}$

$12 \quad 19$

13 C28

14 C21

$15 \quad C 22$

$16 \quad \mathrm{C23}$

$17 \quad 024$

18 C25

$19 \quad 226$

$28 \quad C 28$

21 $\quad 38$

$22 \quad 032$

$23 \quad \mathrm{C36}$

$24 \quad C 38$

$25 \quad C 48$

$26 \quad \mathrm{C4}$ 


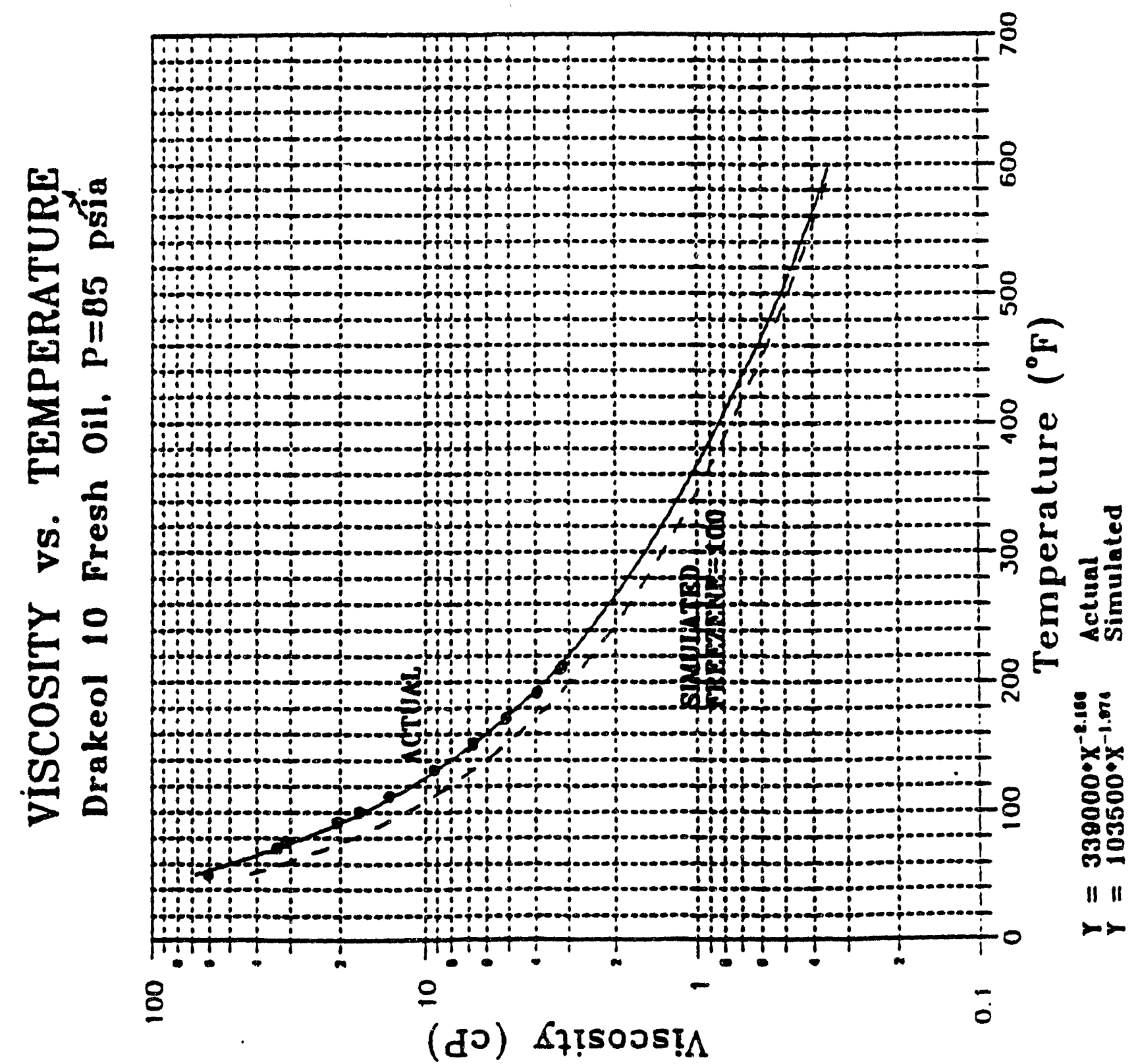




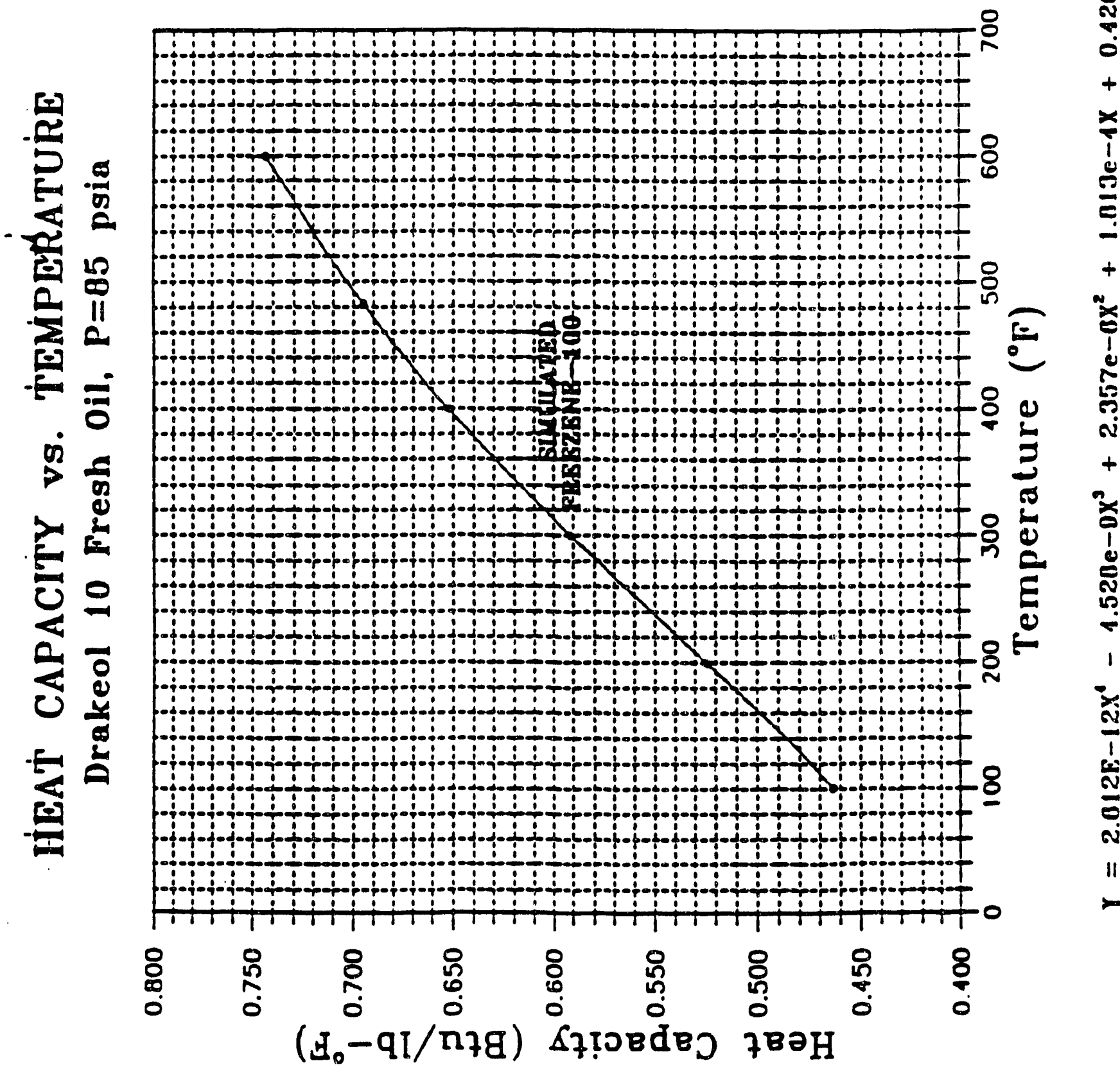

9 3ะกอIป 


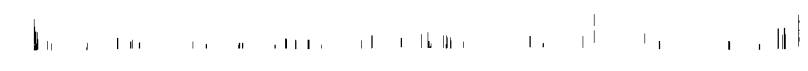
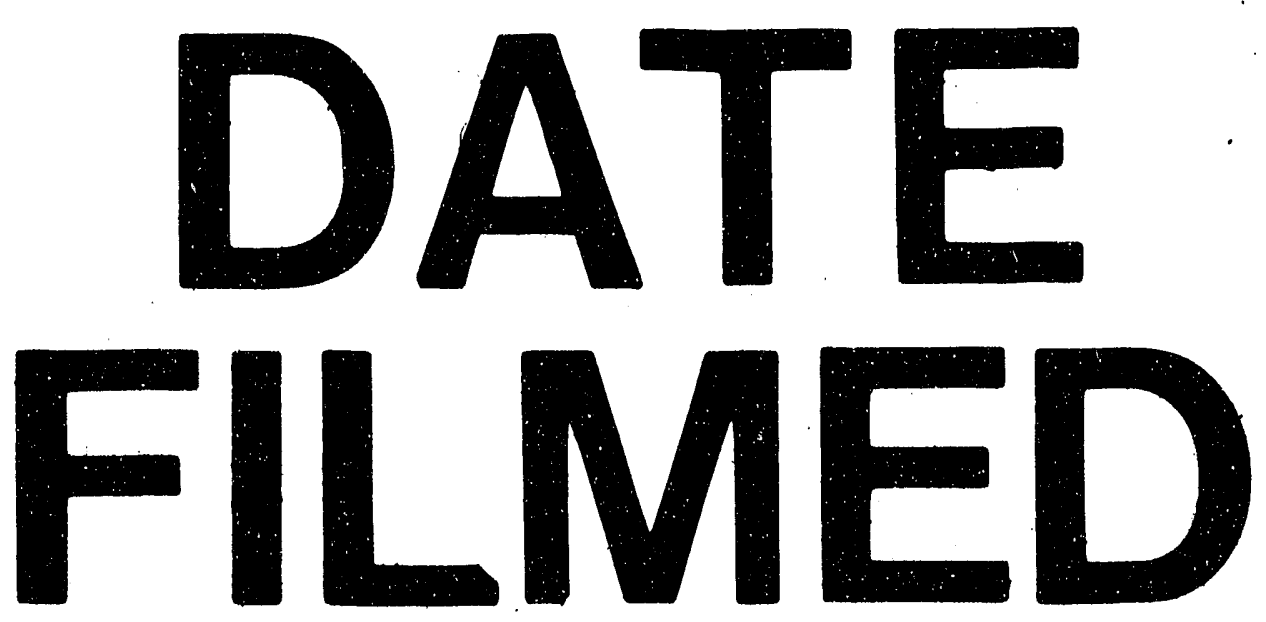

|

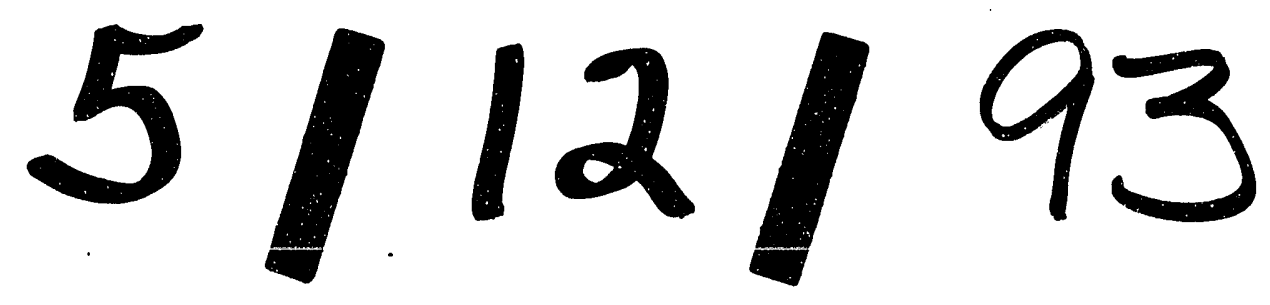


